\title{
Storying place A tok stori about relationalities in Oceanic education and development
}

\author{
Lorena de la Torre Parra
}

A thesis submitted to the Victoria University of Wellington in fulfilment of the requirements for the degree of Doctor of Philosophy

Victoria University of Wellington

2020 


\section{Table of Contents}

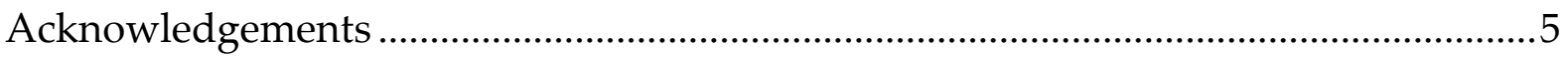

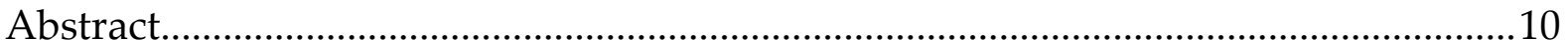

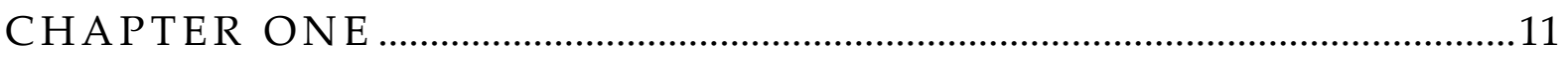

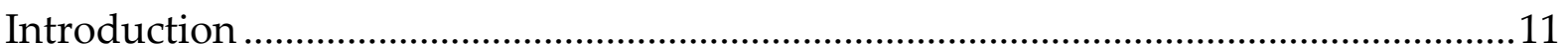

1.1. A relational approach to development and education in Oceania ............................. 14

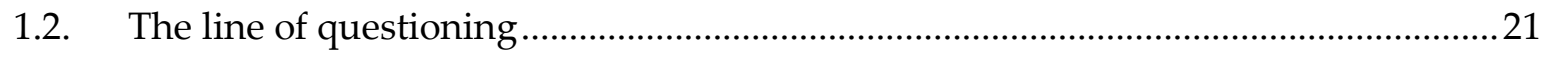

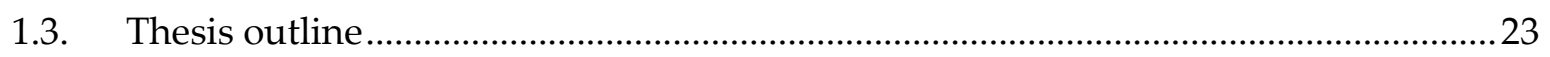

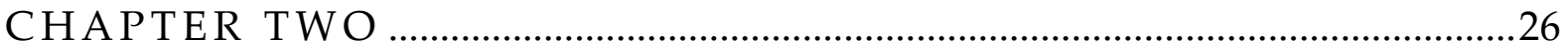

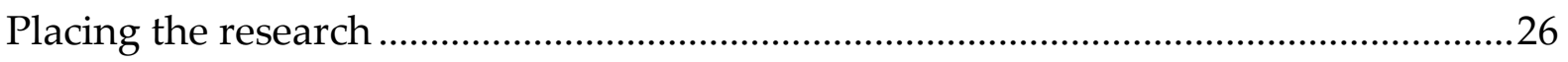

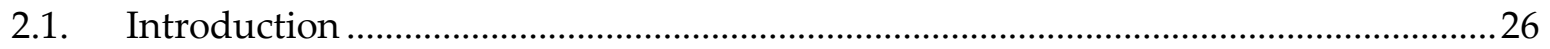

2.2. Weaving ples: stories, relationality and place.............................................................. 28

2.3. Indigenous epistemology and Indigenous knowledge ................................................ 41

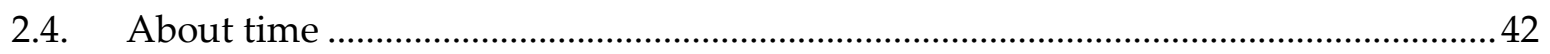

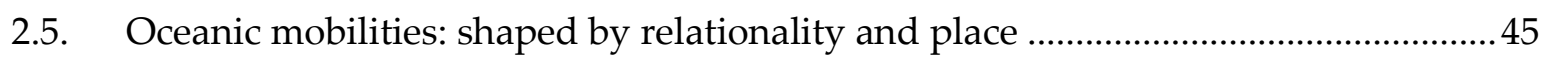

2.6. Decolonisation: 'A language of possibility' ................................................................... 50

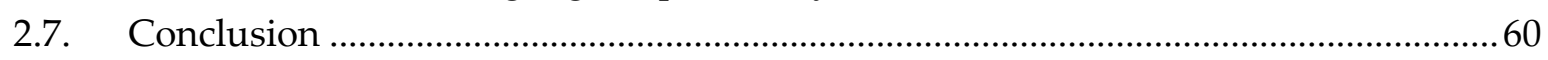

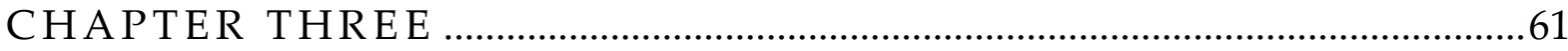

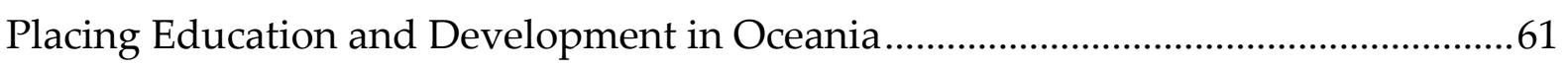

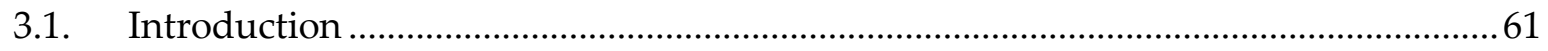

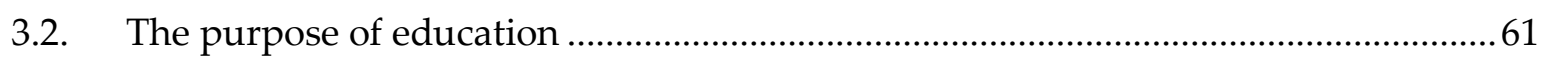

3.3. What types of education, for what types of development in Oceania?.......................65

3.4. Rethinking and reshaping education and development in Oceania ...........................68

3.5. Regional context: Responses to education-for-development trends .........................69

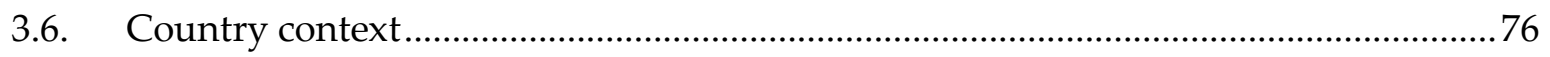

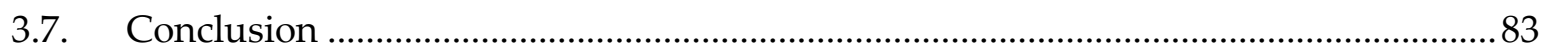

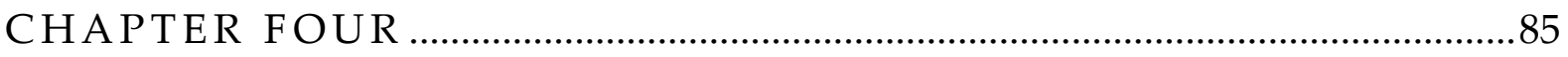

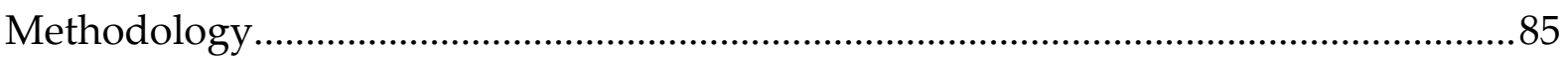

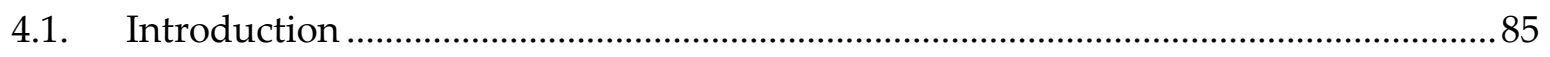

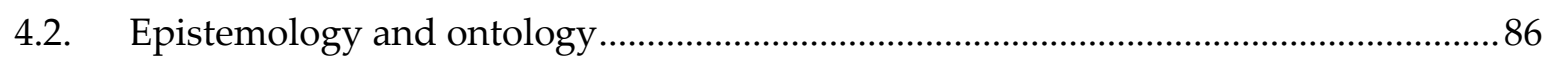

4.3. Indigenous knowledge: values, domains, and knowing your place .......................... 89

4.4. Methodology: Qualitative Research ......................................................................... 91

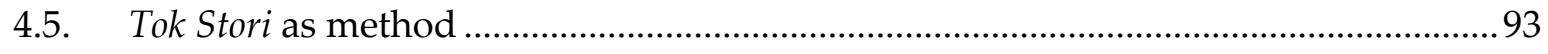

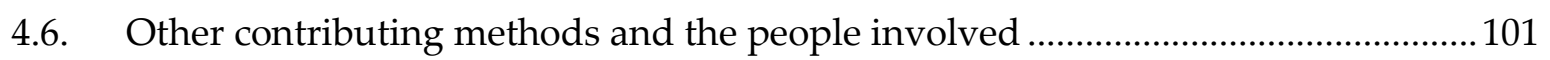

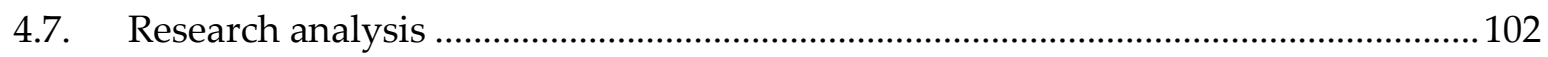

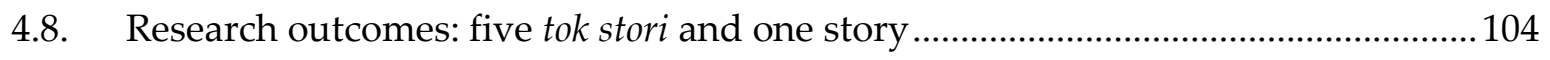

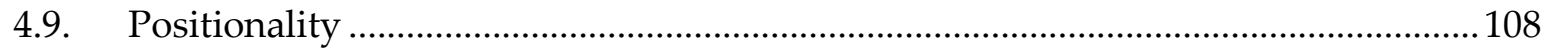

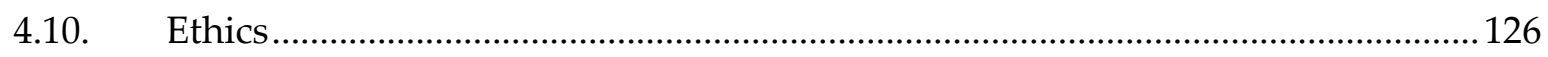




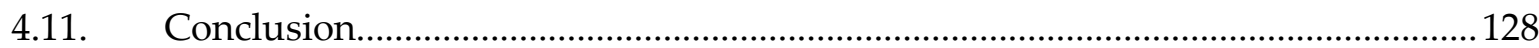

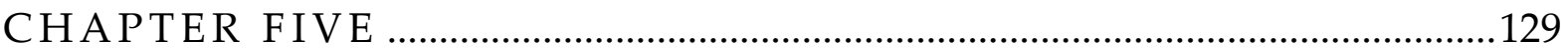

Theories of development, gender and the role of education ......................................129

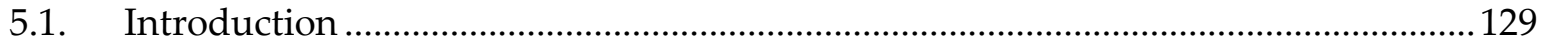

5.2. Thinking about development: notions of development and the role of education 129

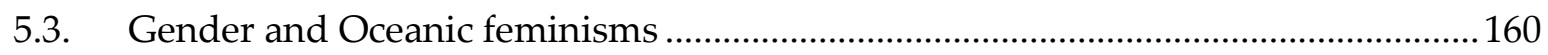

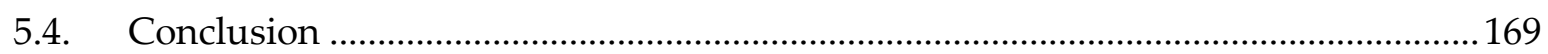

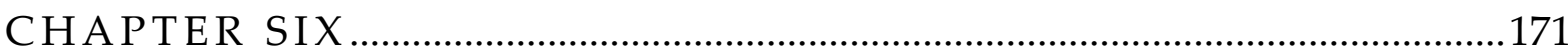

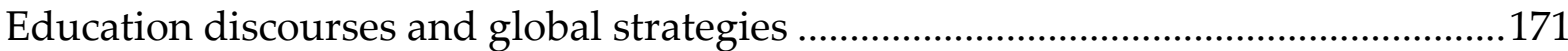

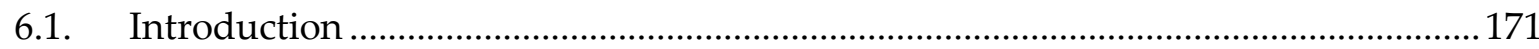

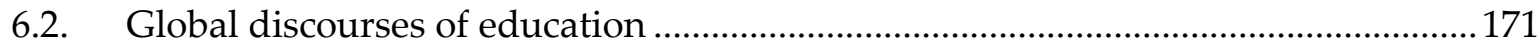

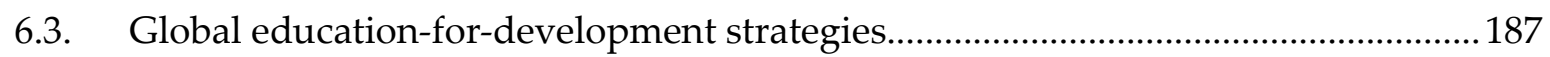

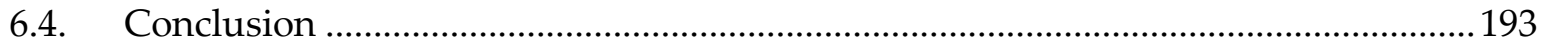

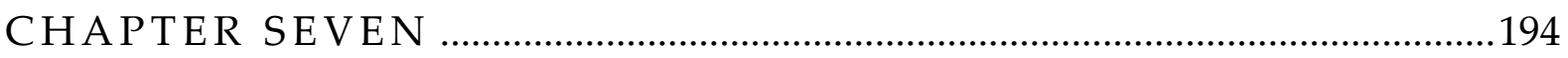

Storying place through relationalities in education and development in ENB .........194

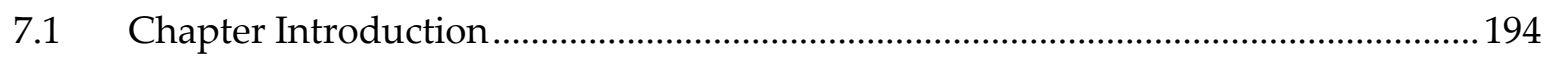

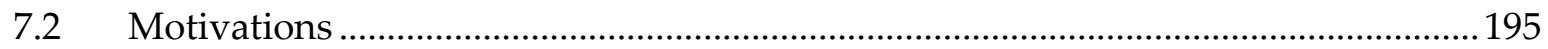

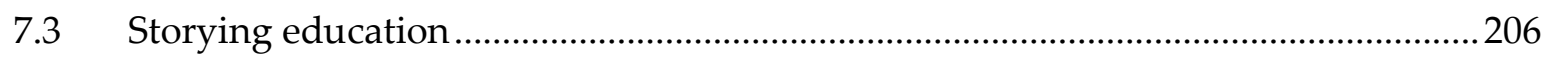

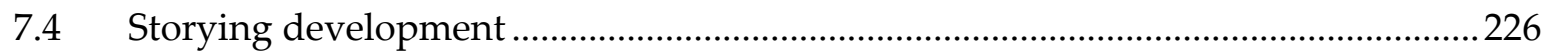

7.5 The purpose of education in relation to ples: mobility, education and development 241

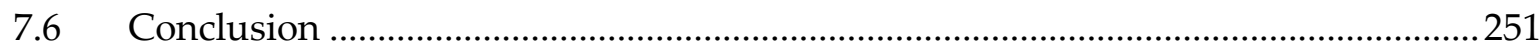

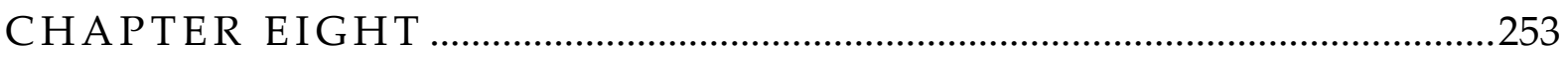

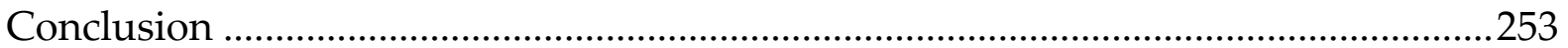

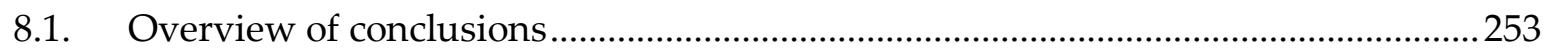

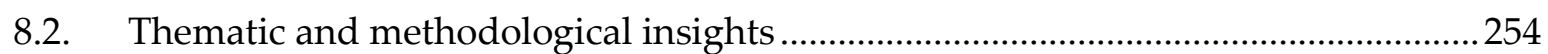

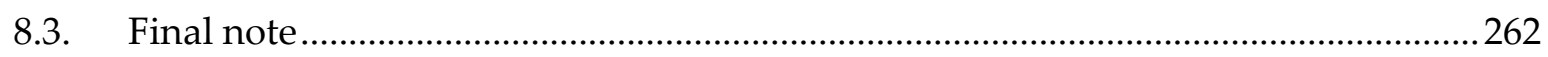

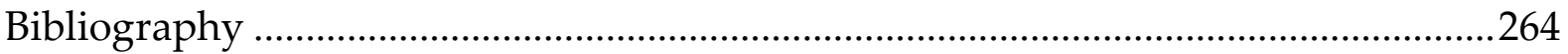

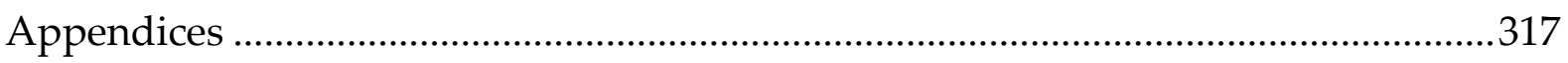

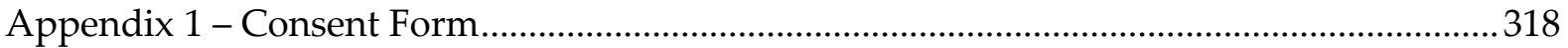

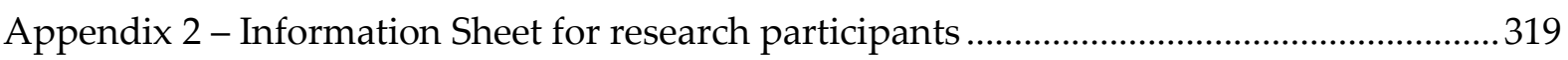

Appendix 3 - Semi-structured interview schedules ...................................................................321

Appendix 4 - Poem by Author: original version in Spanish ..................................................323

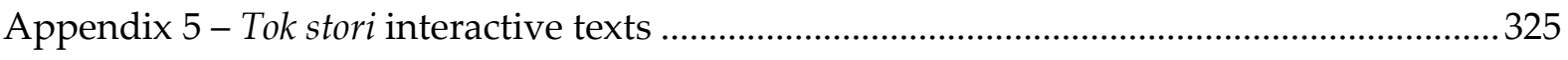

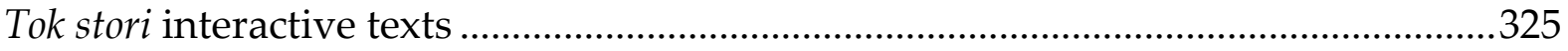

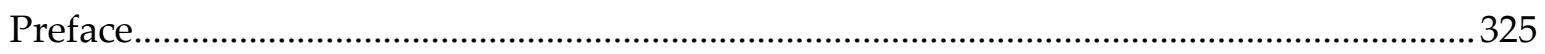




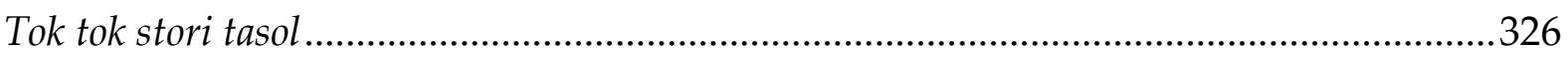

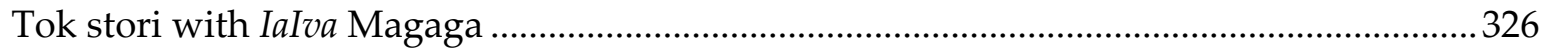

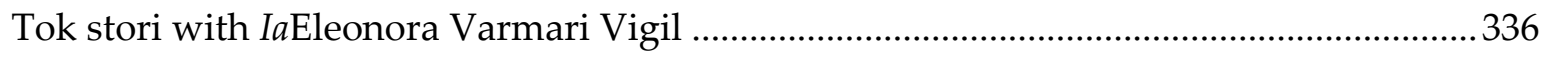

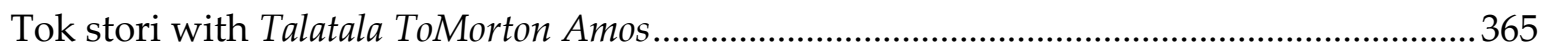

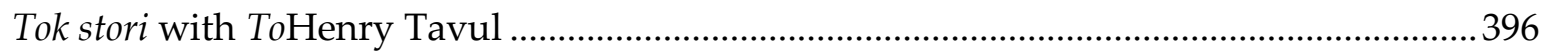

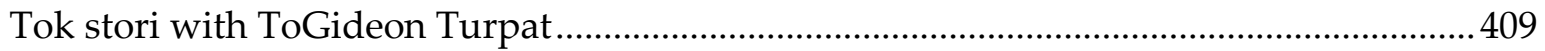

A homegrown curriculum for East New Britain - a story ................................................. 433

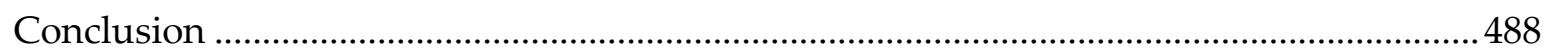

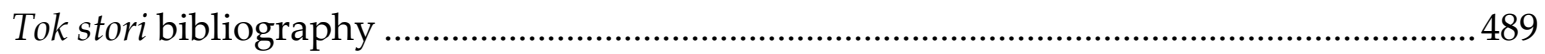




\section{Acknowledgements}

The genealogy of mind and heart of this work spans across the oceans and islands, it finds roots in mountains, and can be seen as constellations of all of those who have guided, supported and held me throughout the years it took to complete this research.

I am privileged to have the guidance of IaIva Peteva Magaga, whose wisdom and dedication to education and to the wellbeing of people in East New Britain, in Papua New Guinea and across Oceania are a source of continuous amazement and inspiration to many. Thank you for sharing this research journey with me mum, ngalana boina tuna for your care, for your unwavering love, every page of this work belongs to you and the labour of love behind it, is one way to honour you.

This research would not have been possible without the generosity of my participants. I am endlessly grateful to the Gunantuna/Tolai elders, leaders and educators that contributed to and guided this research process: IaIva Peteva Magaga, IaEleonora Varmari Vigil, ToHenry Tavul, Talatala ToMorton Amos and ToGideon Turpat. I am honoured to be in your presence and learn from your wisdom, to work alongside you and weave stories together throughout these years. Your contributions to education and to the wellbeing your communities inside and outside of East New Britain are powerful and transformational. I am humbled that you entrusted me with your stories. For me these stories are sacred, so I have carried them with love, respect and care.

I am thankful to the educators who contributed to this research. Throughout the time I have worked and lived alongside Carrie-Anne Karela, Jeddah Violet Gigi and Diana Pakar, I have been in awe of your abilities as educators, as curriculum writers and researchers, as professionals and visionary women. I am grateful that you shared your stories with me, and humbled to continue creating stories alongside you all. Thank you to also to Roselyn Onesu for the generosity of your time and 
experience in education. Thank you to my sister through adoption Rela Wawaneya, your expertise and ethical insights into development bring so much value and innovation to our work and communities. Thank you to Sevi Kaue, for sharing your stories with me. I have watched with admiration your commitment to linking education to civil society, by grounding them to place and people. Thank you to Sophie Marshall for your caring and generous ways of sharing your talent and stories. Thank you to Archbishop Francesco Panfilo for sharing your stories whilst reflecting on education with me.

I am especially grateful to John Overton, for being the most exacting and exciting of supervisors. John, many years ago, back in Ecuador and before I could speak a word of English, I heard your name. They told me that if I ever came to Aotearoa I could study under your guidance. Today I look back at my journey of education and feel honoured to have met you, learned from and worked with you. John, you have understood, supported and celebrated this mestiza woman in ways I have seldom experienced. Your insight, respect and care throughout these years have enabled me to grow in confidence as a researcher, alongside you I have grown in knowledge and capability, and also in spirit as you often reminded me that "love and health come first". My thanks also go to my second supervisor Warwick Murray, for almost a decade of constant encouragement at every step of my academic and professional journey, for contributing with your brilliance and unique flair to this $\mathrm{PhD}$ journey.

I am grateful for the support by the staff at SGDIA at USP Suva and to the staff at the Pasifika Library Collection for providing me access to the precious literary works. Thanks are owed to Georgia Kaipu (PNG NRI), I thank you for helping this research become a reality. Thanks also to Chris Sandbrook for arranging access to an inspirational working space whilst in the northern hemisphere.

I would like to thank Geoff Whittle for his unwavering belief in me. Your friendship is a constant source of inspiration and strength in my life. Tú eres primavera eterna en mi vida. 
I am privileged to navigate this doctoral journey with the support of people at Victoria University. Thank you to my friends Pete Williams and Kelle Howson for paddling alongside me yet in their own canoes towards completing our respective theses, I am grateful for your support and thoughtful comments. Thank you to Polly, Sara and GeoffH, Rewi, JamesR, SandraF, Luke, AlexH, Monika, Steph, Emily and Emma, at SGEES. Thank you to Patricia, Shona and Monoa at the Science Faculty. Also thank you to MAI ki Poneke for all your support, especially to Addreanne, Carrie, Te Nia, Jo, Arini and Pauline. And to those in the Faculty of Education who work in Pacific peoples education, to Pine, Fuapepe, and Cherie, you are all my inspiration and my benchmark.

I want to acknowledge the wonderful constellation of friends and family who have in many ways contributed, inspired and held me through this journey: I am honoured to be able to write the names and thank those whose love and kindness have grounded me to East New Britain. Thank you to my adoptive family, to my brothers and sister, Robert Magaga, Peter Teu Magaga, Blasius Magaga, Grace Magaga, and my tambu sister Janeth Magaga; my aunties and uncles Jacklin Madik Ezekia, Kubin Ezekia, Matalau Doreen Kauli, Rachel Bonnie Jona, Rakel Kunai Ainui, Lavinia. Also I want to acknowledge Marama Simaima Amos and Patavil Turpat, as well as Claude and Lidia Ezekia. Thank you to all the teachers in East New Britain I have worked and built precious friendships with.

Thank you to my loved ones, to the mountains and rivers that watched me be born and grow, to my grandparents, to my family and friends in Ecuador, especially to Paulina and Ximena. Thank you to my dear AnnaR for always being at the beginning and at end of every spiral. Thank you to all who selflessly opened their homes and hearts to me: Jonathan, Kirsten, Nataly and Tawhai, Lee-Anne and Todd (Aria and Awatea). To those who made homes with me in Aotearoa: to Gale, Deanna, Miranda (thank you for your care), Vik and Mark (Emil and Frida), Cam, AnnaM, Rich, Jasmine, AnnaC and Paul, Lisa, XimenaA, Gabriela and Francisca, 
Klaus and Maria, Mel and Karl. Thank you to Thomas for your labour of love and friendship, to Stefan for your creative brilliance, and to my dear Holly, to Winnie Laban, Gail, Helena, Amber, Aaron, Michaela, Chinnama, Meseret, Claire, Junior, Stephen, Katy and Janie for inspiring me and expanding the feeling of university to encompass a sense of family. Thank you also to Alison, Leila, Vicky, Robyn, Aneika, Natasha, Jana, Maz, Koha, Jeanie and Judith, and to JaneO, you women model effortless greatness. Thank you to Howard and Jacquie, and to Elizabeth, David, ThomasT and Vanessa.

I am thankful for the hospitality and support by people across ENB, especially to Dana Iseli and Jason Seeto for your friendship and support throughout the years; also, to Jelta and Mel Wong, Joyce and Oliver Bluett.

Thank you to those whose labour of care make it possible for me to carry on during and beyond this journey: to Matua Tau, Birgit, Rebecca and Liz.

Finally, my deepest gratitude goes to James Tremlett, my most encouraging and arduous of critics, my partner, my love. Your gentleness, your care and your brilliance reverberate in these pages. Thank you for finding ways, for pulling islands, and always taking us safely back to shore. I am deeply grateful to bathe in the ocean of your love.

This Ph.D. project was funded by the Royal Society Te Apārangi Marsden Fund and supported by VUW Pūtea Āwhina. 
For mum IaIva Magaga, who loved me open, your love is the path and the ink to every story.

To the educators of East New Britain province.

And to my grandparents: Teresa, Ariolfo, Herminia and Luis, you hold me from within. 


\section{Abstract}

Education and development are intimately connected and highly contested in Oceania, in theory and in practice. Indigenous Oceanic notions and practices of both education and development are fundamentally relational, and are expressions of culture, identity, kinship, and embeddedness in place. Oceanic peoples are engaged in ongoing resistance and negotiation with externally imposed models of education and development, at a variety of scales.

This study is an inquiry into relationalities at the intersection of education and development in Oceania. It is a body of work that has emerged from the author's extensive relationships in East New Britain province, Papua New Guinea. The research has an explicit decolonising agenda, reflected in the use of the relational practice of tok stori as the primary methodological framework, in order to centre the knowledge, practices and interests of Oceanic peoples. The relational space created by storying with Gunantuna/Tolai elders, educators, development practitioners, and other community members in East New Britain, brought forth uniquely placecentred insights about the ways development and education are articulated, contested, negotiated and reclaimed by Indigenous peoples at the local level. 


\section{CHAPTER ONE Introduction}

"I can feel that you are sitting there [...] thinking: 'is this right?'

Well, that's not the right question [...]

Because these are not your words, these are our words, so they are right.

Then, tell me who is going to dispute our words?

You didn't take them, you didn't find them in books, they were given to you, because we see your heart [...]

and because we want our stories to live on, because our names will traverse the Pacific.

And one day our descendants will find themselves in these pages, in our words, and they will feel proud of our stories, they will feel proud of themselves, because these are also their stories"

(personal communication with IaIva Peteva Magaga, 2020)

"What the community needs is relevant education with empowerment for community living. [...] Education should support our people to be able to progress from where they are physically, mentally, psychologically, financially, spiritually, and be elevated to another level.

When we are able to re-create our lives and become successful in all areas of our lives, then we are developing into a healthy and happy community. [...]

Learning then becomes a sacred pursuit, it is about values, it is about relationships" 
"There were a lot of us Tolai student teachers in the college, so we had a meeting [...] after reading [an] article [that] spoke about our people, our education system and the way ENB was doing education. There were a lot of criticisms, they compared us with other provinces. And so from there, some of us decided that when we graduate we must go back and develop [...] the education system of our province. For over 36 years I have been [teaching] here in my province.

Your contribution to the society is your presence in the community. Your contribution to the community is what counts, not your money."

(Tok stori with IaEleonora Varmari Vigil, 2016)

"We Tolai are educated people. Some go out and get big jobs after their studies, but you are to share the knowledge that you've gained. That is development [...] it is sharing what you have acquired, and sharing is not only about money, you also have to share your experiences, your knowledge.

[It is] developing a person intellectually, culturally and spiritually. We are not just talking about getting things like degrees, this is a very small piece of development.

When a person is properly developed it creates a good person who knows how to recognise the positive and the negative types of 'development'.

To me [...], personally, I am not against having 'big buildings', it might be a sign of 'development'; but again for me: 'development is a person'.

I'm not saying there will not be more problems, no... they will still come, but when you are a holistically developed person, even when you migrate, you know where to go and you know where you are going.

And education it's a way through, a doorway to knowledge."

(Tok stori with Talatala ToMorton Amos, 2016) 
"We want our people to have the wisdom, to think right. We want them to be healthy, because we need a healthy workforce, and then when these two are working hand in hand, you will develop a lot of wealthy people.

If we do not have [...] exposure, it is like imprisoning your thinking and imprisoning your capabilities. The sky is the limit! [So], get out there, enjoy it, and see what we can get out of the world. But we cannot replicate exactly what is [out] there, [our] challenge is: how can we make it happen on the local context, and based on the local environment?

There is no need for us to believe that we are poor, that we need programmes to come in from the outside. [...]

And here is when education comes in, for teachers are supposed to be the influencers, the agents of change. They tell us what we want to produce for our people."

(Tok stori with ToHenry Tavul, 2016)

"This is our home ground, education is our land, our land is our education.

If you've no land that you can cultivate, but you have lots of this (ToGideon Turpat points at his head), then you are lucky, you can earn your life.

From the beginning I told the people this story: 'push your kids to school, encourage them to have as much education as possible, that's your living, if you don't have land, education is your future'.

If you've got no land, your education is your land."

(Tok stori with ToGideon Turpat, 2017).

These are the voices of five Gunantuna/Tolai elders and educators. They, and others, took part in this research and addressed in depth, through tok stori, the issue of education in their community. They have led and provided the wisdom, inspiration and detail of this research. 


\subsection{A relational approach to development and education in Oceania}

Development as a concept and practice is a foundational driver of change in Oceania. It is closely tied to education in various ways: through context, expressed in this study as the tapestry of meanings and dynamics that make up 'place'; and through relationality, which highlights the connections between people, and between people and ples.

Concerns regarding the balance and imbalance of Indigenous values, practices, languages, and goals in education and development are voiced throughout Oceania at regional, national, provincial, local and village levels. This is heard in villages, classrooms, political and educational institutions, and discussed by community leaders and elders. Some of these voices are found in the works of Oceanic thinkers and scholars, who for many decades have questioned dominant discourses of education and development. Their work supports Oceania's multiplicity of peoples, epistemologies, worldviews, and their connections to place, environment, and kinship: a collective stewardship where strategies for education and development are in Oceanic hands and have an Oceanic vision.

\section{Place, ples, and relationality}

Villages [...] have rewritten history books and redrawn maps. They have renamed places and each other. And all the while, they listen to the inner voice that links them to the stars.

'It's like this,' their chief said. 'Everyone has stories. They come from what we call daily life and from the worlds between worlds that we dream and fly in. There is a tusitala in all of us, just waiting to get out. That's where they are. Our stories are within us.'

(Barford, 2006, p. 57)

Place is more than a physical or geographic location. Place is around and within us, imbued with meanings, histories, and genealogies. We are made of place and we 
make place. As Damon Salesa described, place is woven from our stories (2019). In this study the Tok Pisin term ples is used to encompass these meanings.

I use the term 'relationality' in recognition that identity, culture, knowledge, learning, spirituality, and all other aspects of life in Oceania, are defined by relationships: that is, by the sometimes strictly-defined webs of interconnection, reciprocity, agency, and mutual obligations to other people and the wider world. These relational connections are evident in the wantok system, complex kinship networks, intimate and intricate connections to place, and the nature of daily life.

In the context of development and education, relationality means equity in agenda setting, decision making, and resource prioritisation. This is especially important in the case of international development and educational aid, where an explicitly relational approach centres Oceanic peoples, places, values, and interests.

\section{The decolonising agenda}

This study has an explicit decolonising agenda. Decolonising scholarship means that the knowledge, experiences and interests of Indigenous and local peoples are no longer relegated to the margins. Rather these are centred within the dynamics of the research process.

In this study, the decolonising agenda is reflected in a research approach and methodology that is guided by Indigenous Oceanic ontologies and epistemologies, in particular as they relate to the relationships between people, and between people and place (Va'ai \& Nabobo-Baba, 2017)ํ. Decolonising research methodologies means that Indigenous people define the lines of inquiry, the modes of interaction, and the results and outputs of the research process. Tok stori is a culturallygrounded, context-specific methodology, and its appropriateness for this study is

\footnotetext{
${ }^{1}$ Va'ai \& Nabobo-Baba's (2017) edited book The Relational Self: decolonizing personhood in Pacific colonized spaces, provides some examples of a relational approach to decolonising personhood in colonised spaces, in social spaces, in theological spaces, and through poetry, from across Oceania.
} 
evidenced in its use by participants, especially elders. This approach has been particularly informed by the work of Kabini Sanga (2018) and Linda Tuhiwai Smith (2012).

In the case of this study, tok stori was utilised with constant reflection on my positionality and the importance of 'knowing my place' as an external researcher who has numerous strong and pre-existing relationships with the communities where I live and work. This includes being aware of the modes of interaction and kinds of knowledge that pertain to me, and the kinds that do not; what information I am able to share in an academic publication, and what I am not.

\section{The global development and education nexus}

Education is globally recognised as a vital prerequisite for meaningful, long-term and sustainable development (Colclough, 2012; Kanbur \& Hau'ofa, 1984; Thomas \& Bessell, 1999). Many development theorists and practitioners argue that education is fundamental for combating poverty, promoting socio-economic and gender equity, building national prosperity, equipping people with essential skills for participating in their society and economy, and improving people's capabilities and freedoms by gaining skills for higher education and employment-related mobility. From the 1990s Education For All goals (EFA) of education as a basic human right, through the launch of the Millennium Development Goals (MDGs) in the early 2000s, to the Sustainable Development Goals (SDGs) of 2015, countless multinational organisations, national governments, and aid agencies have pledged support for policies and implemented programmes geared towards globally agreed education goals (Gamlen, Murray, \& Overton, 2017; Kiddle, 2005).

There remains an unresolved ideological and applied conflict between a neoliberal approach that promotes education as a provider of 'human capital' for the expansion of economies, industries, and labour markets; and more radical and locallygrounded approaches that advocate for a consciousness-raising and liberating type 
of education. This debate between human capital and consciousness-raising as the central purpose of education-for-development permeates these strategies across Oceania. Both approaches agree that education is critical for providing a variety of economic and political avenues for individual and/or collective development (Freire, 1976; Gamlen et al., 2017).

I address these two approaches in this study, but present approaches that go beyond conscientisation. I explore context-specific notions of development and education, prioritising teachings and leadership from across Oceania with specific reference to Indigenous people's knowledge and action.

\section{Education and development in Oceania}

Throughout Oceania, government agencies and partner organisations generally regard education as a crucial strategy for development. Formal education is widely recognised as essential to development and nation-building, although the predominant educational models are colonial legacies which are antithetical to Oceanic ways of learning and knowing (Nabobo-Baba, 2006). Kabini Sanga observes that the function of education in Oceania is to transmit culture, thus ensuring the continuation of knowledge, worldviews, and relationships to people and place (2000). Similarly, David Welch Gegeo and Karen Ann Watson-Gegeo's observations on the rise of dominant colonial languages in Oceania through schooling indicates the eclipse of more locally appropriate Indigenous epistemologies, ontologies and linguistic traditions (1999) "in the quest for 'global' relevance and competitiveness into the globalising economy" (Gamlen et al., 2017). It can further be argued that "the balance of representation between the various functions of education in Pacific Island schools is also skewed against indigenous concerns" (Sanga, 2000, p. 5).

At the regional level a 'Pacific Vision' was endorsed in 2014 by Pacific Islands Forum (PIF) Secretariat Leaders. This vision shapes the 'Framework for Pacific Regionalism', including the deployment of the 'Blue Pacific' narrative to guide 
collective regional action (Pacific Islands Forum Secretariat, 2019). This vision and narrative of regional development helped to shape the Pacific Regional Education Framework (PacREF) 2018-2030, an intergovernmental education agenda aiming to deliver "sustainable, affordable and high-quality education goods and services that are accessible to all Pacific countries" (Pacific Islands Forum Secretariat \& USP, 2018, p. 6). The PacREF aligns with global development goals such as SDG4 and its implementation framework (UNESCO, 2015). At the time of writing in 2020, the first phase of implementation of the PacREF is taking place through a commitment to cooperation, collaboration, partnerships between regional agencies, and information sharing between national education systems and regional institutions.

\section{Education and development in Papua New Guinea}

Papua New Guinea (PNG) is the largest country in Oceania, and currently occupies leading roles in the PIF and the Melanesian Spearhead Group (MSG). PNG wields significant influence in shaping the diplomatic character of Pacific regionalism, and in promoting regional objectives around sustainable development, economic growth, governance systems and security. Its own internal dynamics relating to development, however, are likewise shaped and influenced by global trajectories of development theory and practice (NSTF, 2011). PNG's education system, both prior to and after independence, has cycled through numerous plans, policies, and implementation strategies which reflect decades of changing educational philosophies, political agendas, and international goals and pressures. Despite decentralisation policies that provide a level of autonomy in the delivery of policies at the provincial level, changing educational trends and budget allocations have a significant destabilising influence on the provision and delivery capabilities of provincial governments and their dependent educational institutions.

Each cultural group in PNG has "unique and meaningful histories, systems of knowledge, political and economic structures, beliefs and values that have underpinned their context and provided a sense of location and identity" (Mel, 1995, 
p. 684). Processes of 'teaching and learning' have historically been determined and performed according to specific knowledge frameworks and worldviews. A forty thousand-year education tradition in PNG ensured that children were taught relevant knowledge and technical skills, in village settings, by parents, experts and selected elders (McLaughlin, 1994; Le Fanu, 2013; K. H. Thaman, 1995).

Following independence in 1974, there have been several attempts at shaping a more culturally appropriate education system for PNG, based on a philosophy of supporting people's ability to live with dignity and actively participate in their society's development. These attempts included advocacy for elementary education to be delivered in vernacular languages, as well as a push for more culturally informed teaching programmes (Matane, 1986). The continuing colonial legacies within the education system, however, have meant that the production and legitimisation of knowledge, as well as the sanctioning of curricula and school policies, continues to be generally skewed against Indigenous values and concerns (Sanga, 2000).

Gunantuna/Tolai are one of several Indigenous peoples in East New Britain Province (ENB). They are a people with strong traditional systems of governance, spirituality, economic distribution, and social-political organisation. These exist in constant negotiation with projections and impositions of power by foreign and colonial entities, such as colonial invasion, external models of education, and exploitative capitalist processes of resource extraction. Although geographically remote from national centres of power, members of the Gunantuna/Tolai community have historically had considerable influence on national decision making and policy prioritisation processes, including those related to education and development. ENB and its people are renowned locally, nationally and internationally for their leading roles in education.

The cultural foundations of PNG societies have historically been viewed by colonisers and Western administrative bodies as an impediment to realising the 
'benefits and advancements' that education and development are claimed to bring to these Indigenous communities. ENB maintains relative autonomy in its political, educational and cultural systems, which has allowed for the conceptualisation, emergence and implementation of projects of change in the province, including initiatives at the intersection of education and development. This distance from national-level pressures has functioned as a tool of resistance to foreign- and nationally-imposed changes that might disregard ENB's unique societal systems and cultural paradigms. It has also at times been a challenge, as dependence on sporadic central governmental budget allocations to different provinces can prove disastrous to service delivery in education and development.

Nevertheless, across many localities in Oceania there are scholars, educators, elders, villagers, activists and leaders with critical views on education and active input into transforming the politics of knowledge production and dissemination within education strategising and delivery. At the regional level, initiatives such as the 'Rethinking Pacific Education Initiative for Pacific Peoples by Pacific Peoples (RPEIPP)' have been of vital importance in leading the re-thinking of education through a clear, long-term vision to ensure Oceanic ownership of educational development. These initiatives also demonstrate what is possible when educationalaid relationships and partnerships are founded on the premise that Pacific Islanders are the experts in defining the direction, purpose and outcomes of education for their own people. They are a testament to the potential of re-thinking relationships and methodologies, when transformations are permitted and encouraged to emerge from within (Nabobo-Baba, 2013; Sanga \& Taufe'ulungaki, 2003; Sanga \& Thaman, 2009).

At the local level in ENB province, active input into the discursive and applied dimensions of education and development is constantly present. This study took place through tok stori with Indigenous people and elders, mainly from the Gunantuna/Tolai tribe, with whom I have worked and lived with for several years. 
Their stories are a window into how their own re-thinking and re-enacting of education and development has contributed to appropriate leadership, processes and outcomes for their cultures, peoples and places.

\subsection{The line of questioning}

The core element of this study's decolonising agenda is my affirmation that the intersection of education and development is fundamentally relational. I maintain that locally appropriate concepts and practices of both education and development in Oceania emerge from a complex entanglement of people and place, woven together with stories.

The central line of questioning of this study thus revolves around relationalities, and how these contextualise the intersection of education and development in Oceania. To this end the study's central questions can be expressed as:

1. How are notions of education and development recognised and articulated at the local scale in ENB?

2. What type of education and development notions and strategies are currently being conceived and pursued in ENB?

3. How do these strategies contribute to asserting Indigenous epistemological and ontological traditions that meet locally appropriate and recognised ideas and needs of development?

4. How are place-based relationalities between education and development articulated in the design, development and implementation of education strategies in ENB?

These research questions trace diverse processes of change brought about by the conceptualisation, development, and implementation of education strategies in ENB. They consider the historical, cultural and social-political context of education and development, from local to global scales, and the ways that the reciprocal and 
evolving relationship between education and development at all these scales is manifested at the local level in ENB. I aim to offer insights into the complex and diverse dynamics between people and place that can inform education and development thought and practice in Oceania.

The education-for-development discourse is so taken for granted in policy, practice and research, that it can sometimes silence important stories. Throughout the course of this research, as well as in my wider work and lived experience in ENB, that discourse was disrupted, inverted and sometimes dismissed. This occurred principally through tok stori, as well as through work and everyday life alongside participants, colleagues, family and friends in ENB. The line of questioning of this research was shaped and influenced by literature by Oceanic thinkers and scholars, but principally it emerged from the storying of Gunantuna/Tolai people, especially elders. These stories tell us about their engagement in the creation of spaces (educational, spiritual, cultural, environmental, political, and economic), in which they feel comfortable and encouraged to share, teach and learn from their own cultural histories and ontological practices. Damon Salesa, referring to Albert Wendt's teachings on the fabric of history, has said that history has a way of silencing the past; it is full of untold and quietened stories (2019). Creating and maintaining these spaces requires reflection upon a diversity of articulations of history, in order to understand the marginalisation and prioritisation of different stories, as well as how agency is exercised.

The knowledge generated in this study, alongside Gunantuna/Tolai participants and under the guidance of elders, is intended to contribute to reclaiming history as an active and fundamental aspect of the decolonisation of Oceanic stories and ontological spaces, which have been historically devalued or considered unworthy in the creation of educational and development discourses, practices and goals (L. T. Smith, 2012; Thaman, 2003). This study acknowledges that decolonisation processes across Oceania have been conceptualised, led and enacted through Indigenous 
leadership and epistemological practice for centuries prior to this research; and will likewise continue into the future. This is reflected in the methodology, theory and the articulation of outcomes of this research.

\subsection{Thesis outline}

This thesis is organised into eight chapters:

Chapter 1 presents an introduction to the study's location, and to discourses about education and development in Oceania as the key elements of enquiry. It identifies and reflects on the study's line of enquiry, guided by the fundamental concepts of relationality and place through tok stori methodology.

Chapter 2 places the research epistemologically. It weaves together the concept of ples through context-specific notions of stories, relationality, place, time, and mobilities. It concludes by engaging with decolonisation as a language of possibility.

Chapter 3 places education and development in the context of Oceania. It reflects on work by Oceanic and Indigenous scholars, practitioners and educators about historical and current trends and trajectories in education and development. It presents specific examples of regional responses in Oceania, assesses the dynamic relationships between education and aid in the region, and addresses relevant elements of the country context of PNG.

Chapter 4 presents the methodological process of inquiry and the principles that guide the research. I explain my positionality and culturally appropriate guiding principles of interaction. This chapter links culturally relevant research methodologies such as tok stori, relationality and ples-based values to the research process, with an explicit decolonising agenda. It also introduces the research participants, explains the research analysis process, and the tok stori interactive texts as research outcomes in themselves. 
Chapter 5 discusses global theories and notions of development, highlighting the role of education. I reflect on recent turns in this debate with reference to Indigenous ontologies, diverse community economies, diverse education, analyses of the intersection of gender and development, and feminist viewpoints, mainly from Oceania.

Chapter 6 discusses global discourses, theories and strategies of education. It deals with how these are influenced by various notions and policies of development at a variety of scales, with particular relevance for Oceania and PNG.

Chapter 7 introduces country and provincial education and development contexts, before delving into an analysis of the study's central questions through knowledge that has emerged from participants' storying and my personal observations in ENB. This chapter reflects on the ways that the relational space created by tok stori enables the emergence of uniquely place-centred insights about the intersection between education and development in Oceania.

Chapter 8 concludes the study by summarising the lines of questioning in light of the research findings. I conclude this study with a summary of its contributions to education and development through the context of relationalities and place.

\section{Tok stori interactive texts}

Five tok stori interactive texts with Gunantuna/Tolai elders and leaders in education and development, are presented alongside a narrated story about a grassroots curriculum development initiative in ENB. These tok stori interactive texts are a fundamental element of a culturally appropriate research process. The words of participants are presented as said by them, with the final text being reviewed by a Gunantuna/Tolai elder and with its final destination being the hands of participants themselves. 
These tok stori interactive texts are presented as an appendix to comply with academic convention. However, these texts are an important outcome and the central source of inspiration to this study. 


\section{CHAPTER TWO}

\section{Placing the research}

\subsection{Introduction}

This chapter aims to 'place' the research by embedding it in an understanding of place as a concept constructed by stories, and entangled with the imperative to 'know one's place'. This research consequently places participants' stories and the relational practice of tok stori at the centre of the process. My research process and its lines of inquiry are strongly influenced by theoretical and applied principles of relevant critical approaches, with applicability in similar educational and development spheres. Most important to this study is how these approaches provide a decolonising language of possibility, because they prioritise, emphasise, acknowledge, and respect Indigenous ontological practices and ways of knowing, particularly for Oceanic peoples.

The terms 'Pacific' and 'Oceania' are both constantly evolving. Both terms are imbued with assumptions and categorisations, and are challenged by Indigenous peoples and other thinkers within the region. The term 'Pacific' is found throughout this study, in contexts where it is used by referenced scholars and research participants. However, echoing the words of Tagaloatele Peggy Fairbairn-Dunlop, I "acknowledge the diverse ethnicities this term represents and that the term Pacific itself is a contested term" (2008, p. 46; see also Salesa, 2018).

The term 'Oceania' is used in this study in association with the 'Oceanic regional model' which was advanced by Epeli Hau'ofa and other Oceanic scholars as an alternative to "the economistic and geographic determinist view" (1993, p. 6) thought to maintain colonial power relations in the region. This vision of Oceania brings with it a conceptualisation of the Pacific Ocean as a shared space "for both the revitalization of the pre-colonial interconnectedness of Pacific peoples and the 
development of extensive and expansive new connections with Pacific Rim countries" (Coxon, 2020, p. 4). This vision forges connections that are increasingly focussed on social wellbeing in addition to economic integration (Stone, 2011). I use this term to reflect my own commitment to Hau'ofa's vision of Oceania, where education and development are also woven from Indigenous epistemologies and ontologies.

This study, and myself as a researcher, are influenced by a range of knowledge systems and epistemological and ontological standpoints and practices. As described by Hviding, I find that "understanding a wonderful diversity of human life worlds [...] can hardly be interpreted within a single-discipline framework" (2003, p. 43). Neither single-discipline study nor multidisciplinarity is sufficient to encompass the aspirations of enquiry and research necessary for an Indigenous Oceanic context (Whimp, 2008). Further, from my own epistemological and ontological standpoints, it is crucial to emphasise that this study - primarily conducted in one locality and alongside predominantly Gunantuna/Tolai peoples - does not present findings on an overarching or singular 'Indigenous Oceanic identity', or equally wrongly presuppose a single Gunantuna/Tolai identity or epistemology. This would be arrogant and misguided given my positionality ${ }^{2}$ and further, it is epistemologically inconceivable. As argued by Wood, "there is no single, convenient Native Pacific identity into which scholars can slip, or with which they can collaborate. There is no single Native epistemology, and, even if such existed, no single Native language through which to gain some access to that epistemology" (Wood, 2003, pp. 346, 354356, 362-363 in Whimp, 2008). There is not a single 'East New Britain view' because the places and peoples are made of complex and diverse collective and individual identities. Moreover, I acknowledge and do not presume complete understanding of

\footnotetext{
${ }^{2}$ See Chapter 4 for more on positionality.
} 
the diverse and complex kinship affiliations through which Gunantuna/Tolai define themselves: a complex matrix of affiliations to different clans and extended families.

This study emphasises praxis embodied in the relational core of tok stori as a way to generate knowledge born in and for Oceania through the practice of storying, in ways that honour past, present and future, and which open culturally appropriate lines of enquiry. Such praxis can support the reclamation of an autonomous sense of future: an important part of decolonising discourses.

This study advocates for the analysis of colonialism within education and development, yet it aims to go beyond mere analysis of colonial struggles in ENB Province. As suggested by Firth and Wesley-Smith, in the Pacific one appropriate research question might be: "how can we understand the region in ways that will make people better off?" (2003, p. 140; 2016, p. 154). This study's research process addresses the 'how' of that question by advocating for culturally appropriate and respectful modes of communication and interaction within a Melanesian context, such as tok stori and upholding Indigenous notions of time and place. These modes highlight the importance of valuing people and their relationships in knowledge generation and learning, further supporting the decolonisation of educational and development relations, narratives and practices.

\subsection{Weaving ples: stories, relationality and place}

"Our stories are within us. You'll find them encoded in genealogies, embedded in our hearts, imprinted in our minds. They migrate with the tongues that tell them [...] Truly precious stories, those that hold sacred truths within them, can never be lost. They are kept intact by the universe itself. They exist beyond everything we can touch and name. They are in our blood, and like red hibiscus burnt by frost, recover and reveal themselves again"

(Cherie Barford, 2006, pp. 55-56)

"Place is constructed by stories, place is woven together of ongoing stories. Places are collections of stories" 
"[A] person can be anywhere and still be inextricably tied to place.

Place is [...] in our blood"'

(Gegeo, 2001a, p. 495)

The term "'indigenous' is problematic in that it appears to collectivise many distinct populations whose experiences under imperialism have been vastly different" (L. T. Smith, 2012, p. 6). This study upholds the importance of the diverse and powerful worldviews embedded in different terminologies related to 'Indigenous' ${ }^{3}$, including my own cultural framework, that of referenced authors and that of participants. For the purposes of this study, the term 'Indigenous' refers to People of the Land, their genealogies of knowledge and stories that emphasise 'place' and its links to kin (present, forward, and backward in time), language, customary land access through genealogy or marriage, social positioning, as well as kin-related obligations and responsibilities (Gegeo, 2001a; Narokobi, 1980; L. T. Smith, 2012; K. H. Thaman, 2003). It refers to the story-holders, whose concern is the transfer and furtherance of this knowledge, conducted within reciprocal relationships and exchange networks. In this study, the term 'Native' which just as 'Indigenous' has personal and collective varying connotations and powerful worldviews, is also present; however, it is only so when referenced authors or participants use it themselves (Diaz \& Kauanui, 2001; Gegeo, 2001a; T. King, 2005; Salesa, 2018; T. K. Teaiwa, 2001; Trask, 1993).

Indigenous peoples' cultural histories are long and enduring, changing and constant, and central to the wellbeing of their people. Contemporary historical narratives, however, have been subject to criticism by many Indigenous people who argue that it is primarily articulated from dominant social-political and economic perspectives. In a 2019 lecture entitled 'Into Native Seas: Europeans Encounter an Indigenous Ocean', Damon Salesa pointed out how "history produces silence in the making of history"

\footnotetext{
${ }^{3}$ Such as 'First peoples', 'Native Peoples', 'First Nations', ‘Aboriginal Peoples', 'Fourth World Peoples' (L. T. Smith, 2012, p. 6).
} 
(2019). History, Salesa said, has a way of silencing the past; a myriad of stories are untold and hushed in the practice of creating and archiving 'facts' for historical upkeep.

Reflecting on stories, I remembered Thomas King saying, 'the truth about stories is that that's all we are' (2005). And whilst revisiting his quote I later found Emalani Case's words in a story in which, reflecting on the way we act and interact with place, she said:

"We are our stories. We are stories in development, stories defying the assumed permanence of the page, stories proving theories of weakness and inferiority wrong, stories built on stories. Every story is made and remade as we interact with it, shape it, use it to suit our own agendas. Stories are power; they capture our histories, our triumphs, our tragedies, our hopes, and our futures"

Salesa talked about the stories of what is now called the 'Pacific Ocean', which he described as:

“an overlay across vibrant and changing 'Native Seas'. These Native Seas were indigenous Pacific networks of voyaging, relationships and commonality. Their existence meant that few peoples of the Pacific were isolated"

(Salesa, 2018, p. 52).

These Native Seas of Oceania have numerous Indigenous names, including the Massim (in eastern New Guinea), the Sawei (in Micronesia), Te Moana-nui-a-Kiwa (in Polynesia, including Aotearoa) and O le Vasa Loloa (encompassing Samoa, Tonga, Fiji, Rotuma, Futuna and Uvea).

This Pacific, whose seas, seaways, constellations and lands are storied and named by ancestors, brings to mind Konai Helu Thaman's warning that:

"to view the Pacific only from the perspective of European colonization does not do justice to the region's indigenous peoples" 
In her view, this would be an ahistorical representation of Indigenous lives, fixing them within the colonised-coloniser conflict, thus denying their millennia-long cultural history.

Salesa (2019) recalled Maualaivao Albert Wendt's powerful quote: 'history is the remembered tightrope that stretches across the abyss of all that we have forgotten' (1987, p. 79). This definition of 'history' challenges the current practice of walking up and down the same rope that stretches across an abyss of Oceanic stories. Scholars must acknowledge, embrace, and appropriately articulate (or choose not to articulate) these stories by giving regard to the millennia-long context of Indigenous connection across these seas. In recent history and literature these Native Seas have been reimagined as a 'Pacific' that is essentially foreign, and thus Salesa sees the urgency to affirm that this is and was an Indigenous ocean, a 'Brown Pacific':

“The Pacific was 'a Spanish Lake' (in the 1500s) and 'an American Lake' (post1945); there is a 'White Pacific', a 'Yellow Pacific', a 'Black Pacific'; and there are 'Pacific Worlds' that are integrated with either Asia or North America. It is easy to see the salience of the claims; but it should be as easy to see that each in some way or other diminishes or erases the indigeneity evident in the frame of the Native Seas.

In view of this, it has become even more urgent to affirm that there is, and was, a Brown Pacific: an indigenous ocean in which most indigenous people lived and continued to live"

(Salesa, 2018, p. 54).

Within the Native Seas of a Brown Pacific, long-held stories of 'place' are articulated and woven together by connections, negotiations, and transfers of knowledge and resources between Native peoples, lands and seas. These places are "an old world of Indigenous lands [where] Indigenous identity, worldviews, culture, and law all derive from these specific landscapes - our earth mother" (Jacinta Ruru, 2010, p. 247). These processes took place long before European imperial expansion and will continue long into the future. 
During the same 2019 lecture, Salesa explained that places are woven by collections of stories. Places constructed within these Native Seas hold genealogies of stories expressed through genealogies of language, which recall regular encounters with 'foreigners' from other islands (Salesa, 2018). 'Encounters' with Europeans were not the first, nor the most important. It is thus crucial to prioritise Oceanic stories, many of which have been marginalised or devalued for many decades by those gripping tightly to a colonial rope across the gulf of memory.

Therefore, when I refer to 'place' in this study I invoke meanings beyond AngloEuropean concepts of 'land'; a term which, as argued by Battiste ${ }^{4}$ (2002), De Santolo ${ }^{5}$ (2017), Thaman (1995), Ravuvu (1983) and Batibasaqa, Overton, and Horsley (1999), inadequately translates Indigenous concepts of the interconnected nature of place. Diverse Oceanic cultures, languages and worldviews emphasise place in notions such as gunan (Tinata Tuna/Kuanua), whenua (Te reo Māori), vanua (Fijian) and ples (Tok Pisin), alongside reciprocal relationships, exchange networks, and place-specific stories.

The meanings of the words 'Gunantuna' and 'Tolai', for instance, reflect such worldviews:

"Originally the people who lived on the Gazelle Peninsula and who spoke Kuanua or Tinata Tuna identified themselves as Gunantuna, meaning Gunan - place, Tuna - True. In other words, 'the true people of the Land'"

(Kakabin, 2018)

According to writings by ToGideon Kakabin, there are diverse stories about the origin of the word 'Tolai':

"'Tolai' first appeared in a publication [...] in 1933, and it was what men called each other at the Wau / Bulolo Goldfields when they knew that a person originated from the Rabaul Area, but they did not know the person's name. According to ingiat legend a man called 'Tolaii' sailed across on a stone to Mioko and then to New Britain to conduct wars.

\footnotetext{
${ }^{4}$ Marie Battiste, Potlotek First Nations, Canada.

${ }^{5}$ Jason De Santolo, Garrwa and Barunggum, Australia.
} 
His wars took several years and he fathered three men, one at 'Ra tungunana' - Malaguna area, one at 'Kininigunan' - Kokopo area, and one on the south coast. These three men were all called 'Tolaii' and the modern Tolai is their descendant. When Rev George Brown arrived at Mioko, he met Guriraram who was a descendant of 'Tolaii'.

The Baining's however, have a legend which says that the Tolai's are their descendant. Two brothers had a fight and one ran to the coast whereupon he fathered the Tolai"

(Kakabin, 2018)

The Tok Pisin term 'ples' will be used throughout this study to highlight the aforementioned notions of 'place' as integral to Indigenous processes of ontological assertion, negotiation and revitalisation in educational and development spheres. As a common Tok Pisin term, ples is used and understood by all the participants in this study, both Gunantuna/Tolai and those from elsewhere in PNG to convey the notions of place of origin or home village, of kinship bonds, reciprocal relationships and mother tongue.

Battiste pointed out that Indigenous processes of education are largely concerned with the transfer of Indigenous knowledge, which is inherently tied to land:

"not to land in general but to particular landscapes, landforms, and biomes where ceremonies are properly held, stories properly recited ${ }^{6}$, medicines properly gathered, and transfers of knowledge properly authenticated"

Indigenous concepts of place such as the Fijian vanua suggest an expression of Fijian values that combines different dimensions such as land, people, social-cultural and knowledge systems, tradition, custom, belief, and institutions for achieving harmony, solidarity and prosperity (Ravuvu, 1983). Vanua is a concept that conveys the notion that "Fijians are bonded to the land through their ancestors and guardian spirits [...] vanua contains the history of one's ancestors in the trees, rivers, and mountains where their spirits dwell" (Batibasaqa et al., 1999, pp. 101-102). Many Indigenous notions of place can also "direct us to think through land as 'more than a

\footnotetext{
${ }^{6}$ De Santolo explains how his people (Garrwa and Barunggum) know who belongs to their place/land by hearing them reciting the right songs lines: "our song lines are our authority on our land" (2017).
} 
site upon which humans make history or as a location that accumulates history' (Goeman, 2008, p. 24)" (Tuck \& Yang, 2012, p. 30), referring in part to Mother Earth's own voice, agency and life (Kawagley, 2010, p. xiii).

Indigenous processes of education also challenge the way "many critical pedagogies that engage emancipatory education, place-based education, environmental education, critical multiculturalism, and urban education often position land as public Commons" (Tuck \& Yang, 2012, p. 30). As pointed out by Tuck and Yang, at present it is precisely because of "this lack of fluency in land and Indigenous sovereignty" (2012, p. 30) that our collective work in decolonising educational spaces must centre Indigenous notions, stories, histories, and leadership.

The Papua New Guinean philosopher Bernard Narokobi argued that the diverse stories and practices of Melanesia should be prioritised, heard and upheld in history:

"Melanesians have had a civilisation with its cultures, values, knowledge and wisdoms which have guided them through the ages. These are their revealed truths.

Our history did not begin with contact with the Western explorers. Our civilisation did not start with the coming of the Christian missionaries. Because we have an ancient civilisation, it is important for us to give proper dignity and place to our history. We can only be ourselves if we accept who we are rather than denying our autonomy"

Furthermore, and crucial to this study, an ahistorical account of Oceanic stories and places denies Indigenous people's experiences with, and agency in, the many changes in their social realities.

With regard to ples, Anglo-European accounts of Oceanic peoples can create outdated categories and meaningless terminologies that are discursively divisive (Gegeo, 2001b; Salesa, 2019; Subramani, 2001). Gegeo argued that "category labels such as Melanesia, Micronesia, Polynesia, Indo-Fijian, Chinese-New Guinean, and the like... come with a host of assumptions that are deeply embedded in colonization" (2001b, p. 179). For instance, "as part of decolonization within the Pacific, there is a reclaiming of the indigenous name Moana [...] instead of Polynesia 
because Moana is an indigenous name for the Pacific Ocean in many of the islands. [The use of this name] highlight[s] the oceanic culture of people from the islands" (Ka'ili, 2017, p. 23). There is a need to develop "a new vocabulary that is more equalizing and respectful of cultural diversity and gender" (Gegeo, 2001b, p. 179). Until the establishment of such vocabulary, terminology such as 'Melanesia' will be used in this study only when referenced authors or study participants use it themselves, or in reference to knowledge generated whilst storying with participants.

Narokobi's work on "the Melanesian Way" for example, referred to the ontological agency of Indigenous Oceanic peoples:

"I am not the author of the phrase 'Melanesian Way'. I do not even know the meaning of Melanesia, although I believe it comes from a European language and probably means negroid or black. It might even mean native or kanaka.

[...] The popular view of Melanesia was that it consisted of thousands of hamlets, villages, clans and tribes which were closed to each other, and had no means of contact with each other beyond the hill, the valley, the river and the island, except through warfare. [...] Most Western writers and observers, basing their views on ethnographic works, study Melanesia from one angle or another.

[...] Over the centuries, Melanesians have come to see themselves as they are understood and written up by foreigners. Melanesians are walking in the shadows of their Western analysts, living under dreams and visions dreamt and seen by Westerners."

Narokobi's use of this terminology ('Melanesia' and the 'Melanesian Way') is from an Indigenous "philosophical base, founded on ancient virtues" (1980, p. 9), which he argued increases Indigenous 'Melanesian' peoples' ability to speak back to often dismissive metropolitan discourses about themselves. It is an evolving frame of reference used to prioritise the multiplicity of Melanesian ontological realities, where their people for millennia have guarded "with their lives great truths and virtues, [...] passed from father to son, and mother to daughter" (Narokobi, 1980, p. 9). 
Through his scholarship and work, Narokobi reminded the world that:

"while the Western world was busy exploring, exploiting and conquering, [...] Melanesians went on with the business of life and living. Without the benefit of the wheel or the gun powder [Melanesians] continued to travel and make links with the peoples of distant islands and mountains"

It is from this context of honouring the ontological multiplicity of Indigenous Oceanic peoples and the importance of careful discursive reference to historically imposed terminology that this study utilises the terms 'Melanesia' or 'Melanesian peoples' ${ }^{7}$

'The business of life and living' that Narokobi referred to is underpinned by relationality and movement; as is the agency of Melanesian peoples in relation to cultural change and renewal. He stated that "Melanesians are not and have never been slaves to their cultural practices, if they believed these were obstructing them. They liberate themselves by establishing new communities with new hopes and future" (1980, p. 7). 'The business of life and living' is further reflected in Melanesian agency of movement, through

"the intricate trade links that extend across the island, the seas, the valleys, coastlines and the mountains to agree. If you don't agree, take a look at the Enga man who gets his shell from the Sepik man or the Mendi man who gets it from the Gulf man, and you will agree"

More and more literature emerging from Oceania expresses this 'business of life and living' in reference to relationality within Melanesian contexts where,

"social relationships play a critical role in [...] Melanesian political, social, and economic life; individuals are constituted and bound by their relationships to others and as such are 'relational persons' embedded inextricably in social relationships (Spratt, 2011, p. 5)"

(Coxon, 2020, p. 8).

\footnotetext{
${ }^{7}$ The same context extends to related terminology such as Polynesian, Micronesian, etc.
} 
Epeli Hau'ofa's “The Ocean In Us” portrayed a new Oceania with a particular focus on the ancestral connections and cooperation between its peoples and places (2000). Hau' ofa wanted to raise the kind of consciousness that would help free Oceanic Indigenous peoples from the "prevailing, externally generated definitions of [their] past, present and future”' (2000, p. 32). Salesa's assertion of a 'Brown Pacific' (2018) and Narokobi's 'Melanesian Way' (1980), share much of Hau'ofa's commitment to fostering identity, belonging and guardianship of the 'world of Oceania' (2000), of its peoples, places, histories and stories.

At present, externally-derived definitions of Oceanic identities take a largely binary view of interactions between colonised and coloniser, between development agencies and local communities, between elites and ordinary people. Such binaries obscure the vast spectrum of Indigenous epistemological and ontological responses within these interactions. Silencing Indigenous Oceanic stories denies their understanding of and engagement with development. Oceanic localities hold longstanding, sometimes violent histories of development interventions, characterised by the often chaotic relationships between development policy and practice (GibsonGraham, 2005; McKinnon, 2007); and many histories of Indigenous-led negotiations and reformulations of those interventions and relationships (Gegeo, 1998).

Attempting to create fixed identities that locate Indigenous peoples within subordinate spaces does not allow for agency. During the "Educating for Critical Consciousness Symposium" at Te Herenga Waka Marae in 2019, Te Kawehau Hoskins pointed out that an identity raised in victimhood, oppression and ontological 'saming', can result in an addictive practice of repeating these positions (2019). Around the world, such positions are established and maintained by structurally unequal power relations. Freire's teachings on critical pedagogies encourage us to understand these processes, which have rendered some groups powerful and others powerless $(1970 ; 1973)$. Freire stressed the importance of 
naming and critiquing the politics of power through emancipatory popular education and other vital components of transformative practice.

Across Oceania, Indigenous scholars such as Konai Helu Thaman (2009c), David Gegeo (1998; 1999), Kabini Sanga (2000, 2016; 2003), Linda Tuhuwai Smith (2012) and Te Kawehau Hoskins (2019) call for wide-ranging critiques of these same power structures. Simple diagnoses tend to repeat binary formulations of power relations that give no room for sustained action. Instead, these scholars call for criticism that is brave and action-oriented, rather than condemnation alone. They caution, 'wait, that's not the whole story'. Narokobi reflected on this complexity:

"Melanesia has been invaded by a huge tidal wave from the West in the form of colonisation and Christianisation. Like any tidal wave, the West came mercilessly, with all the force and power, toppling over our earth, destroying our treasures, depositing some rich soil, but also leaving behind much rubbish.

[...] With the freedom we have, we can make conscious decisions to opt for what is best in both worlds.

Today, we Melanesians stand at the cross roads. More than any people in the world, we can choose. We can choose to ape the West and the East or we can choose to be ourselves in our philosophy, our life-styles and our whole beings"

(1980, pp. 4-5).

Throughout Oceania and the Oceanic diaspora, more and more people are engaging in the creation of spaces in which they feel comfortable, safe and encouraged to tell, share and learn from their own cultural histories and ontological practices. They create spaces - cultural, educational, spiritual, political, and economic - to conduct the ongoing weaving of their stories. Creating these spaces requires reflecting on different articulations of history, and reflecting on existing agency as well as the often difficult and marginalised spaces they may in turn have created. With this knowledge, history may be reclaimed: an active and essential aspect of Oceanic decolonisation (L. T. Smith, 2012; K. H. Thaman, 2003).

This study thus engages with stories that go beyond and actively reject the diagnosis of Indigenous peoples as oppressed and subordinated. Throughout the time I have shared space, food, work, and face-to-face interaction with Indigenous peoples in 
East New Britain, I have not observed victim or subordinate identities. To the contrary, I have encountered people who simultaneously live in a multiplicity of ontological worlds. These are people whose views, practices, and relationships cannot be labelled or reduced to a single canon. This study thus actively rejects the homogenisation of Oceanic and other Indigenous identities, lives, and stories. This study approaches people and their places in context, this is: 'context' "not as an entity of a collection of features to be categorized and defined against a predetermined 'norm of comparison', but as a lived dynamic which is inherently relational; [...] 'a process or set of relations"' (Coxon, 2020, p. 7).

There are also common factors within the multiplicity and richness of stories in connection to place. Some of these are stories of hope and resistance within educational and community development spaces. In this study, the participants and I stori together a few of them. Our storying aims to challenge discourses and practices that may marginalise or even abandon these stories half-way within the creation of education and development strategies. But first I will be clear about the kind of hope and resistance we refer to in these stories. This is not romanticised hope, this is not utopian one-size-fits-all kind of hope, this is not international development and aid recycled-rhetoric kind of hope. This is active hope, this is hope that lives in ancient and modern, central and marginalised spaces, this is relational and collective action and kinship-accountable hope. Our storying rejects prescriptive rhetoric of how 'resistance' is or must be practiced and articulated. Participants practice resistance and collaboration in active and passive ways. A myriad of internal and external negotiations inform resistance strategies, some of which require careful and selective collaboration. This collaboration may seem passive to outsiders but is imbued with agency, and is constantly, actively, and selectively negotiated and enacted.

Relationality is at the core of tok stori, as it is in education and learning. Storying as approach and education as practice require creating reciprocally beneficial relational 
spaces, where "mode[s] of learning" are culturally and contextually appropriate and enhancing (Sanga \& Reynolds, 2019). Kabini Sanga points out that such culturally and relationally grounded modes of learning and interacting are long-overdue in education and development contexts in Oceania (2020).

Relationality as a concept, practice and value is omnipresent in this study. Echoing the words of Konai Thelu Thaman, I also align with and celebrate

"[a] focus on relationality as a key value for all the things that are important for defining the indigenous people of Oceania. It is the main rationale for the different behaviors and performance of indigenous people - their relationships with one another as well as all things in the environment including the land, sea and sky.

Focusing on relationality has been the missing link in most educational and other interventions that developed nations had planned (or are planning) for our various countries. Better understanding the importance of relationships and the need to contextualize education, for whatever cause, is a key element for success"

(K. H. Thaman, 2020, pp. 167-168).

I invite you, reader, to join me in acknowledging and piecing together an important part of the whole story, to reveal that there are in fact many stories that are rooted in place and woven together through relationships. I invite you to sit with me while we listen to the stories of visionary women and men. Most of them are Indigenous Gunantuna/Tolai peoples, as well as Indigenous peoples from other places across PNG. These stories provide a chance to engage with their ontological worlds, where possibilities are built on ongoing and reciprocal relationships: worlds that require acknowledging different ontologies, logics, and pedagogical practices in order to exist. Worlds that require face-to-face and open engagement (Hoskins, 2019). Worlds with visionary humans and enduring relationships, that for generations have cared for their ples-specific knowledge and practices. Those that protect the sacred and respect the secret, as well as those that ethically and appropriately share the public realms of knowledge and practice. Worlds where IaIva Magaga, IaEleonora Vigil, ToHenry Tavul, ToGideon Turpat, Talatala ToMorton Amos and others, have guided transformational changes in their ples, their communities and their education system, beside their relations past, present and future. 


\subsection{Indigenous epistemology and Indigenous knowledge}

"My choice of the term epistemology is not lightly made"

(Gegeo, 1998, p. 290).

Indigenous epistemology "encompasses place, from which [Indigenous people] see the world, interact with it, and interpret reality" (Gegeo, 2001a, p. 493). In his writings about Indigenous epistemologies and development, David Gegeo described the way Indigenous people theorise about their own development, incorporating traditional and introduced knowledges in order to generate new Indigenous knowledge.

Indigenous epistemologies assist practitioners to align place-specific-strategies for development and education. Development and education practitioners, as well as scholars and researchers, have argued extensively for the 'incorporation' of already existing Indigenous knowledge into mainstream development and education discourse and practice (J Brohman, 1996; Hari Mohan Mathur, 1995). I believe this argument to be limited in its epistemological approach, because it overlooks the ways new knowledge is created by Indigenous individuals and groups. The interplay of Indigenous knowledge with development and education discourses and practices is not a passive scenario where Indigenous knowledge is static, universal, universally accessible or uniform; and where Indigenous people are simply the learners of new knowledge, skills and practices. There are diverse and complex scenarios with a multiplicity of interplays and negotiations that involve "learning and adapting introduced and locally created knowledge towards positive change that supports life and affects villagers' worldviews and systems of knowing, understanding, and reasoning" (Gegeo, 1998, p. 291). Furthermore, Indigenous knowledge is guarded by Indigenous philosophy, culture, custom and law (Jackson, 1992); and change occurs "from their own perspectives, cultures and languages" (Gegeo, 1998, p. 291). This speaks of the long-standing "weaving of old symbols and 
new symbols to create new narratives, not dismissing Indigenous protocol and customs, but adapting new ideas"' (Aperahama, 2017).

For many decades Oceanic thinkers and practitioners have been

"[c]alling for the centering of learning that embraces indigenous Pacific understandings and frameworks in international development [as] new and long-overdue [...] fresh ways of more relational engagements in south-south and north-south encounters"

(Sanga, 2020, p. VIII).

In order to imagine and practice transformative development and education strategies that go beyond classical modernisation theory (Watson-Gegeo \& Gegeo, 2014), many thinkers are challenging the assumption that Indigenous peoples are inherently trapped in a state of underdevelopment, and must "break free of 'traditional' institutional structures" (Tollefson, 1991, p. 82) to embrace Western values and social formations. These thinkers seek to make way for development and education strategies and structures that are directed by Indigenous peoples themselves, guided by their own frames of reference, cultural practices, values and languages (Coxon, 2020; Escobar, 2010; Gegeo, 1998; Sanga, 2020; K. H. Thaman, 2020).

\subsection{About time}

I have always questioned notions of time. Growing up I felt that somehow I was trapped in the present participle tense of this thing called 'development'. I am from a place labelled a 'developing country'; but what does that 'ing' even mean? What I know is these letters enacted discursive and applied violence on my land and people. In Ecuador, development as a linear and upward time-bound continuum (i.e. less developed - developing - developed) has been felt generation after generation as nothing more than political discourse; a verb whose tenses have no real connection to past, present or future. It does not represent the land and its peoples, or the stories that make us. Yet the form this verb takes in present participle tense keeps us runn-ing in supposedly the only direction available to us: 'upward and 
linear'. This simple conjugation makes us feel we are not allowed, or are too exhausted, to look back into our future.

And so, from early in my life I also experienced how Indigenous notions of time, enacting Indigenous concepts of development, provide a way to challenge the violence of those labels. While Indigenous concepts of time are diverse in their expressions, my own understandings of time and those I observe in Indigenous spaces in Aotearoa, Latin America and PNG respect that:

"[indigenous] creation stories cannot be locked into the distant past or relegated to the status of myth or folklore. The present is merged with the past and the future in a timeless cycle of repetition and reinforcement as each successive generation comes to appreciate the genius of stories in light of their own experience"

(Mikaere, 2011, p. 370).

Linda Tuhiwai Smith pointed out how "notions of past and present, of place and of relationships to the land" (2012, p. 57) are underpinned by a myriad of orientations towards, and positionings within, time and space; as well as by language systems that render space and time 'real'. For many Indigenous peoples the relationship between history and constructs of time in contemporary society is a contentious issue,

"because it is [...] a story which assumes that there was a 'point in time' which was 'prehistoric'. The point at which society moves from prehistoric to historic is also the point at which tradition breaks with modernism. Traditional indigenous knowledge ceased, in this view, when it came into contact with 'modern' societies, that is the West. What occurred at this point of culture contact was the beginning of the end for 'primitive' societies.

Deeply embedded in these constructs are systems of classification and representation that lend themselves easily to binary oppositions, dualisms, and hierarchical orderings of the world"

(2012, pp. 57-58).

Such constructs, and the violence they foster towards Indigenous cultures and knowledges, are themselves challenged by Indigenous peoples' notions of time. An example is through language. In Aymara language 8 , for instance, "the past is conceptualized as being in front of the experiencer and the future as being behind"

\footnotetext{
${ }^{8}$ Spoken in the Andean region of Peru, Chile and Bolivia (Yapita Moya \& Miracle, 1981).
} 
(V. Evans, 2003, p. 194). In PNG, although Tok Pisin draws much vocabulary from English, grammatical features and other vocabulary from Indigenous Austronesian languages such as Kuanua are also prevalent. Bihain taim for instance, the Tok Pisin enunciation of 'future', similarly to Aymara and many Pacific languages, reflects an Indigenous notion of time that entails looking forward to the past and back to the future.

In Damon Salesa's 'Island Time', he wrote that "the Pacific future has already happened" (2017, p. 7). A Samoan proverb in this book reads: 'O le ūa na fua mai Manu'a - the rain came from Manu'a'; according to Salesa, this "is said about something long known, but still unprepared for" (2017, p. 222). For most Pacific cultures, he explained, islands such as those of Manu'a are ancestors, people, or spiritual beings. Islands are inherently alive and connected to Pacific peoples' genealogies. Salesa evokes the wisdom of Pacific cultures, to anticipate what is to come, to be prepared for the rising of islands "before they break the water's surface" (2017, p. 230). Just as the rain coming from Manu'a and the rise and fall of islands are things long known, Pacific notions of time and space contain wisdom that merges past, present and future, which prepares people for whatever is to come, because it has already happened.

Furthermore, different notions of time and place have changed in their usages by Indigenous peoples themselves, over the years.

This is evidenced in Tēvita O. Ka'ili's (2017) use of Hūfanga 'Ōkusitino Māhina's now popular "Indigenous Moanan theory of reality $t \bar{a}-v \bar{a}$ " (Ka'ili, 2017, p.35; Māhina, 2004; 2010). Tā-vā (time and space) is a theoretical framework for understanding how Tongan diaspora negotiate life in Hawai'i. Through Māhina's theory, Ka'ili (2017) defines $t \bar{a}$ as "the beating of space," through "tempo, beat, pace, rhythm, and frequency" (p. 25), and $v \bar{a}$ "signifies the relational space between two time markers" (p. 26). Relationships that emerge from the intersection between $t \bar{a}$ and $v \bar{a}$ are made 'harmonious' and 'beautiful' when social practices are mediated through reciprocity, 
balance and symmetry. This symmetry, in reference to Tongan diaspora on Maui, is reached by way of tauhi vā or tauhi vaha'a, "the art of creating and maintaining beautiful sociospatial relations $(v \bar{a})$ through the mutual performances of social duties (fatongia)" (159). Ka'ili thus argues that in the context of migration, the maintenance of the harmonious, beautiful and reciprocal spirit of these relationships, is a way of 'marking indigeneity' (2017).

Appreciating the genius of stories means honouring the richness of learning stories of kin and ancestors, of land and values connected to place, as much as the happenings of the day, of the market, the road, the house, the garden: because all are foundational to, and have a simultaneous effect on, past, present and future; and intrinsically on place. It means learning that storying and language, relationships and connection to ples, can stretch or shrink time; can help us experience circular and spiralling essence.

From the perspective of this study, generating and articulating knowledge means 'to think cyclically, spirally' (Aperahama, 2017), reflecting Indigenous concepts of time (see also Lee-Morgan, 2017) and my own understandings. The collective and relational creation and articulation of knowledge through storying in this study challenges narratives that lock Indigenous people's histories into a linear notion of time, and in turn, of development.

\subsection{Oceanic mobilities: shaped by relationality and place}

The history of Indigenous Oceanic mobility reflects complex links that span the most distant atolls and remote mountains (Narokobi, 1980). Intricate trading and cooperation relationships with shared histories and languages link islands, seas and coastlines to valleys and mountains across Oceania and beyond (Narokobi, 1980; Salesa, 2018). Place encompasses, and is composed by, mobility. To speak of Oceanic mobility is to describe Oceanic life: millennia-long regional interaction and 
socioeconomic interchange among many and varied places and peoples (Chapman, 1991).

The Pacific ancestors - outstanding navigators and their crews - "were the first to name, and to story, the waters they crossed" (Salesa, 2018, p. 52). Voyaging canoes were guided by constellations and powerful gods (Hau'ofa, 1993), carrying the languages and oral histories of their peoples (Barclay-Kerr, 2006; Salesa, 2018). Seaways form part of the fabric of life of Native Seas, which shaped, and in turn were shaped by, life on land. "The Pacific Ocean was vast, but it was not empty" (Salesa, 2018, p. 53).

Epeli Hau'ofa advanced the notion of a much-enlarged world of Oceania that has emerged through the astounding mobility of Pacific peoples. Hau' ofa pointed out that this Oceania is made of social networks which criss-cross an ocean surrounding and sustaining its peoples $(1993 ; 2000)$. For the peoples of Oceania,

"the universe comprised not only land surfaces, but the underworld with its fire-controlling and earth-shaking denizens, and the heavens above with their hierarchies of powerful gods and named stars and constellations that people could count on to guide their ways across the seas. Their world was anything but tiny"

(Hau'ofa, 1993, p. 65).

Voyaging canoes story this ocean; they connect its peoples to their ancestral homelands.

The islands of the north coast of PNG, including New Britain, New Ireland and Manus, are regarded as the 'homeland' of a group of Austronesian speakers with a culture characterised by distinctive pottery; these were long-distance traders, fishermen and gardeners, who

"transported among their coastal settlements along the Melanesian chain obsidian for stone tools that ultimately reached New Caledonia, more than 1,000 miles from its source in New Britain.

By 1300 B.C. they were the first human beings in Fiji, having traversed a [...] gap that computer experiments show would have barred accidental drifts"

(Lewis, 1994, p. 9). 
Kuanua or Tinata Tuna language carries millennia-old stories of Gunantuna voyaging traditions. ToGideon Kakabin explained that the word nakanai was used to refer to "the people 'down there', usually by the voyagers who used to travel to the west to collect shell money" (2018). This refers to trading voyages particularly to Nakanai (a place in West New Britain) by coastal Gunantuna/Tolai men who loaded their canoes with goods and traded them for pala tabu, the important nassa shells used for the creation of tabu (shell money or shell wealth) (Simet, 1991).

European colonial vessels inserted themselves into the Native Seas and into the lives and mobilities of Indigenous peoples of Oceania. An 'imperial sea' both connected and severed relationships between Pacific peoples, and "even though the vessels were foreign or colonial, their movement and meaning was mediated by Indigenous connections" (Salesa, 2018, p. 54). In the 1700s, for instance, Tahitians such as Tupaia, Ahutoru and Mai voyaged aboard those foreign vessels, and were eventually followed by thousands of Pacific people (Lewis, 1994; Salesa, 2018). Traditional and new voyaging circuits intersected and connected, altering their nature and scale both by agreement and by imposition (Salesa, 2018; Steel, 2011). These changes were driven by many factors, including: Pacific people acquiring, constructing, and traveling on foreign vessels (Chappell, 2016; Conrad, 1969); the shipping of natural resources from colonial outposts (Morton, 1982; Sack \& Clark, 1979; Tateyama, 2006); and the establishment of currency, banking, education and taxation systems (Goldsmith, 1993; Nagai, 2001). Under colonial rule, however, Indigenous mobilities came to be considered threatening and in need of control (Salesa, 2018, p. 57; see also Salesa, 2003), with the decline of Indigenous navigational practices partly attributed to colonial bans on interisland canoe travel (Lessa, 1950; Lewis, 1994; Riesenberg, 1965).

With colonialism came the imposition of a new geopolitics on Oceania, rendering distant many previously close connections between its peoples; and simultaneously connecting geographically and historically unrelated places (Salesa, 2003, 2018, 
2019). Forging or severing these connections involved both voluntary and involuntary people movements, with the slave trade and blackbirding becoming key factors in the rise of plantation economies and the establishment and consolidation of colonial empires (Corris, 1968; Lange, Mahoney, \& Vom Hau, 2006; Maude, 1981; Munro, 1990).

The World War II period brought millions of outsiders into Oceania, alongside the accelerated purchase or dispossession of Indigenous lands for the expansion of ports and airfields across the region (Gamble, 2006; Sakaida, 1996). This had transformational impacts on Indigenous mobility, later (from the 1970s) amplified by the increasing availability and affordability of air travel. Physical proximity became less important, and

"the ocean was increasingly distant from experience: it became merely an interval [...] Cultural and political ties mattered most [...] waters and reefs gave way to journeys in the air"

(Salesa, 2018, p. 63).

With the political independence of Pacific Island countries and territories came further regulation of Indigenous mobilities. For many Oceanic peoples, emigration became regarded as a valued route to further the social-economic interests of their communities; in response, some colonial powers imposed restrictions on immigration from the Pacific (Salesa, 2018). More recent Australian and NZ relationships with the Pacific have been consistently skewed against Indigenous interests, disproportionally profiting from resources and services with detrimental impacts on Indigenous mobilities.

Regarding education and development, colonial ties between Oceanic and Western countries have opened the gates in both directions, but with varying effects: by allowing the importation of Western educational models into the region (Sanga, 2000), but also by expanding opportunities for education-related emigration and global engagement. Questioning the nature of the relationship between education, development and mobility is important to Oceania (Coxon \& Cassity, 2011), where 
the continuing engagement with colonial metropoles has mainstreamed Western cultural values and philosophies through both manifest and hidden curricula (Nagai, 2001). This engagement has also opened a range of educational and upskilling opportunities through migration that may not be available in people's places of origin, sometimes because of insufficient resources and infrastructure to sustain large-scale Western models of education. Various thinkers argue that these models of education are geographically and philosophically out of place; and are culturally undemocratic, as they do not reflect the ways Pacific Islanders learn, think and communicate (Nabobo-Baba, 2013; K. H. Thaman, 1995).

In recent decades Oceanic thinkers, scholars and voyagers have shed light upon the astounding history of mobilities in the region. They have reflected on the impact of historical and geopolitical processes that have influenced flows of peoples in Oceania and beyond. They have carried out critical analysis of the impact of international development thought and education policies on mobilities related to migration, labour, teaching and learning, as well as socio-economic and community wellbeing (Hau'ofa, 2000; Kaitani et al., 2011; Salesa, 2003, 2018).

Some prominent exponents are: the navigators and voyagers who have led the Pacific-wide renaissance of ancestral voyaging and navigation (including Pius Mau Piailug (in Finney, 1993), Nainoa Thompson (1989; 2010), Hekenukumai Busby (J. Evans, 2015), Hoturoa Barclay-Kerr (2006, 2016), Jack Thatcher (in Dattaray \& Keegan, 2016) and Ema Siope (2020); various writers of Indigenous histories and perspectives of Oceanic mobilities (Yates, 2018), including the impact of colonialism on their scale and composition (Lee \& Francis, 2009; Salesa, 2003, 2018, 2019; Steel, 2011; K. H. Thaman, 1985); added to voices articulating the multiple and diverse nature of Oceanic diaspora (Chappell, 2005, 2016; Marsh, 1998, 2013; 2006; K. Teaiwa, 2015a; T. K. Teaiwa, 1995, 2001); Vijay Naidu's various collaborations which have contributed to understanding the economic and development implications of international migration and remittances (Kaitani et al., 2011; Kumar, Naidu, \& 
Kumar, 2011; Reddy, Mohanty, \& Naidu, 2004); and writers focusing on labour mobility as well as on the links between migration, social transformation and educational achievement across Oceania (Bedford, 1981, 1988; Bonnemaison, 1984; Chapman, 1991; David Gegeo in Craig et al., 2014; Macpherson, 2004, 2008; 2000; 2008; Spoonley \& Bedford, 2003, 2012).

These thinkers' contributions highlight how the educational, mobility and development paths that people, communities, institutions and governments choose, constitute a huge diversity of notions of education, development and place, and are influenced by a range of opportunities and mitigating factors. They emphasise the complex relationships between education, development and mobility which harbour contradictions and unintended social outcomes, as well as philosophical, spiritual, political and logistical mismatches between peoples, families, institutions and nations. Importantly, their work emphasises the agency evident in Indigenous peoples' mobility, and the associated and reciprocal relationships with education and development spheres in Oceania.

\subsection{Decolonisation: 'A language of possibility'}

Linda Tuhiwai Smith states that decolonisation "must offer a language of possibility, a way out of colonialism" (2012, p. 204). When the collective work and writings of Indigenous peoples, anti- and post-colonial thinkers, and ethnic minorities is considered (see, for example J K Gibson-Graham, 2008; U. Kothari, 2019; Sanga, 2002, 2005, 2014; L. T. Smith, 2012), it becomes evident that:

"a language of possibility exists within our own alternative, oppositional ways of knowing. Even though these may not be seen to connect with current socio-economic realities, the fact that we adhere to, that we can imagine a connection suggests a resistance to being classified according to the definitions of a dominant group"

(L. T. Smith, 2012, p. 204).

This language of possibility supports the theorising, planning, strategising, and implementation of solutions. It centres the concerns and worldviews of peoples decolonising their own communities, their own cultural and social-economic 
structures, and creating space to understand theory, research and practice from their own perspectives and for their own purposes (L. T. Smith, 2012).

Reflecting on this language, I am reminded by Eve Tuck and Wayne Yang that 'there is no synonym for decolonization':

"When we write about decolonization, we are not offering it as a metaphor; it is not an approximation of other experiences of oppression. Decolonization is not a swappable term for other things we want to do to improve our societies and schools. [...] Our goal in this essay is to remind readers what is unsettling about decolonization - what is unsettling and what should be unsettling. Clearly, we are advocates for the analysis of settler colonialism within education and education research and we position the work of Indigenous thinkers as central in unlocking the confounding aspects of public schooling"

Sumak Kawsay, Kaupapa Māori and Pacific Studies ${ }^{9}$ are three approaches that have consistently offered a language of possibility to diverse peoples, particularly Indigenous peoples, across the world, as well as across cultural, political, academic, educational and development spheres. Here we look at these approaches in turn, and to their contributions to decolonisation efforts in education, development and research.

\subsubsection{Decolonising development discourses: Sumak Kawsay approaches}

The philosophical underpinnings of Sumak Kawsay (el buen vivir/good living) actively challenge development paradigms based on economic growth and neoliberalism. A Sumak Kawsay philosophical stance is foundational to this study, because it "does not assume a stage of under-development to be overcome, given that it refers to a different philosophy of life" (Escobar, 2010, p. 23). It conceives a different relationship between humans and their social and natural environments, which "incorporates a human, ethical and holistic dimension to the relationship of human

\footnotetext{
${ }^{9}$ The philosophical connection to these three approaches relates to my own genealogical connections to Ecuador where I was born and raised; and later to Aotearoa/New Zealand and East New Britain, PNG, the two places and their peoples who have nurtured me for the latter half of my life.
} 
beings, not only to their own history but with their natural surroundings" (Dávalos, 2009).

I acknowledge this philosophy as specific to certain Indigenous peoples of South America. I also acknowledge how it has influenced my own ontological processes and lived reality growing up in Ecuador. In recent decades, Sumak Kawsay has become the central paradigm of development throughout the constitutional transformation of Ecuador and Bolivia; it presents an alternative conceptualisation and practice of development, beyond the aspirations and impacts of neoliberalism (Dávalos, 2009). In the rewriting of these national constitutions, the fundamental philosophies, principles and institutions of development were reconsidered. The integration of Sumak Kawsay into both constitutions as a national development framework encouraged a new political order where "equity, democracy, participation, protection of bio-diversity and natural resources and respect for ethnic-cultural diversity serve as key elements of the framework" (Walsh, 2010, p. 16). Nevertheless, the criteria, assumptions, ambitions and specifically the applicability of Sumak Kawsay as a development framework at the national and transnational scales have opened the door for profound scrutiny (Walsh, 2010). This is because the philosophy of life inscribed in Sumak Kawsay is born of an ontological basis that values solidarity, fraternity, reciprocity and collective community-based relations, where the construction of knowledge and living is based on the communion of humans and nature (Walsh, 2010). This is often at odds or contrary to the individualistic, human-centred and neoliberal capitalist pursuit of a 'quality of life' that continues to guide the colonised constitutional and social realities of Ecuador and Bolivia.

Within this study Sumak Kawsay is considered beyond its constitutional-development policy-specific use. As one of the philosophical pillars of this study, it rather provides a source of language and principles that strengthen the decolonising agenda of the research process. It contributes towards a better understanding of 
narratives and action that challenge colonising and neoliberal discourses and practices of development.

\subsubsection{Decolonising educational spheres: Kaupapa Māori approaches}

The "intervention into theoretical spaces, particularly within the sphere of education" (L. T. Smith, 2012, p. 202) by Kaupapa Māori theoretical approaches and research praxis influence this study because of their transformational and decolonising agenda.

Kaupapa Māori is a "theory of transformative praxis" (G. H. Smith, 1997; 2000, p. 66), with robust applicability in educational and research spaces. For instance, it has been foundational to the success of Kohanga Reo preschools and Kura Kaupapa schools: Indigenous educational and resistance initiatives created by Māori, for Māori. These schools have seen "the revitalisation of language, knowledge, and culture; and the development of increased levels of academic achievement" (G. H. Smith, 2000, p. 66) for Māori children, youth and adults. Intervention principles and elements integral to this success include self-determination or relative autonomy, validating and legitimising cultural aspirations and identity, incorporating culturally preferred pedagogy, mediating social-economic and home difficulties, and incorporating cultural structures that emphasise collectivity rather than individuality (G. H. Smith, 2000, pp. 66-68). Tania Whakaatere Pohatu wroteabout the principle of growing respectful relationships, "negotiating boundaries, working to create and hold safe space with corresponding behaviours" $(2005$, p. 5). These practices have contributed to positive change for Māori in educational, health, research and other spheres within the colonised context of New Zealand (G. H. Smith, 2000).

Kaupapa Māori intervention principles and elements support this study's decolonising agenda. They are of relevance to educational spheres where Indigenous peoples, such as those of ENB, lead transformational, decolonising initiatives. As suggested by Graham Smith, "the lessons learned in the Māori context might have 
positive applications in other similarly colonised situations" (2000, p. 68). This is not to say that it is possible to take tikanga ${ }^{10}$ from one community and 'transfer' it to another.

Knowledge systems, customary practices, and sacred intricacies are place-specific and not interchangeable; with access being guarded and regulated to prevent misuse and misappropriation. ${ }^{11}$ Rather, this study draws inspiration from Kaupapa Māori principles and the ways that these articulate challenges to colonial and neo-colonial imperatives which force Indigenous peoples to prove the worth of their languages and values, and which dismiss, neglect and marginalise the ontological practices that Indigenous peoples "seek to expand and apply" (L. T. Smith, 2012, p. 202) in spheres such as education and research.

\subsubsection{The Pacific Studies approach to decolonising learning and research}

Leora Kava regarded decolonisation as:

"the critical consciousness of Pacific Islander representation within the ongoing legacies of colonial constructions; the translation of that consciousness into actions that reclaim our own representation; and the approach to that reclamation through creativity and imagination that have always been part of our genealogies and epistemologies as Pacific peoples"

(2015, p. 64 in Wesley-Smith, 2016).

Pacific Studies prioritises research of the Pacific, for the Pacific; and is deeply connected to decolonisation. It "emphasises reflexivity, indigenous epistemologies, and interdisciplinarity" (Wesley-Smith, 2016, p. 154). As asserted by Teresia Teaiwa, there is a need to "account for changes in indigenous ways of knowing and being" (2006b, p. 75; italics in original). Also essential is an awareness of the vast cultural

\footnotetext{
${ }^{10}$ Māori customary system of values and practices that have been developed over time and are embedded in the social context (Moorfield, 2011).

${ }^{11}$ Kaupapa Māori is particular to the tangata whenua (people of the land) of Aotearoa. As a resistance movement born from the emancipatory efforts of the Māori Renaissance, Kaupapa Māori is a response to sustained power imbalances that perpetuate deficit theory narratives "as seemingly logical explanations for the position that Māori occupy within society" (Mahuika, 2008, p. 6).
} 
and linguistic diversity that inundates the "plethora of native epistemologies animating the village communities of Oceania and no single language to access them adequately" (Wesley-Smith, 2016, p. 161). As inaugural director of Va'aomanū Pasifika $^{12}$, Tagaloatele Peggy Fairbairn-Dunlop helped initiate a programme highlighting the vital role of language in ethnic-specific research and social sciences, which in turn connects the many knowledges held throughout Oceania. FairbairnDunlop calls for research that reconnects Pacific peoples to Hau'ofa's notion of a sea of islands; she calls for drawing together the multiple communities of knowledge in the region - artists, craft experts, sports groups, church leaders, women's committees,

"to ensure that the knowledge and the stories we hold dear sit alongside the accounts of our lives written by administrators, traders, historians and anthropologists, missionaries, donor agencies and consultants".

(Fairbairn-Dunlop, 2008, p. 47)

Teresia Teaiwa's devotion to teaching and learning about the Pacific was rightly called 'oceanic', and as director of Va'aomanū Pasifika she established a vision for "any and all studies in or of the Pacific to help and guide appropriate forms of knowledge production about Oceania" (Wesley-Smith, 2016, p. 154). Teresia pointed out that:

"There will always be hierarchies of knowledge, and whether the Pacific as an area of study barely registers on the scale of scholarly importance in Europe or America, or whether our collective word counts in refereed journals would approximate the worth of stone money/shell money/feather money/fine mats/whales' teeth /greenstone or even a $10 \mathrm{~kg}$ bag of rice in the most isolated village on the remotest motu [...] whether we are studying/writing about/reflecting on the Pacific in the Pacific or far, far away, our work must matter to us. What links all students of the Pacific, is the belief that our enquiries matter"

(T. K. Teaiwa, 2006b, p. 72).

Pacific Studies calls for centring “indigenous voices, perspectives and epistemologies into the dominant discourses in such a way as to scrutinise disciplinary frameworks

${ }^{12}$ Pacific Studies Programme at Victoria University of Wellington, NZ. 
and identify ethnocentrism" (Wesley-Smith, 1995, p. 129; Whimp, 2008, p. 408). This is because:

"[m]ore often than not... the Pacific is not brought to the table as an equal partner in any conversation about the nature of humanity or society. When lucky enough to be noticed, the Pacific is presented as a freakish survivor of non-duplicable utopias (a la Bougainville's Nouvelle Cythera, or "New Paradise"), or as late and ultimately unnecessary confirmations of already established Hobbesian truths (e.g. Derek Freeman's Samoa (1983))"

(T. K. Teaiwa, 2006b, pp. 73-74).

Hviding calls for decolonisation and interdisciplinarity to be linked in Pacific research (2003). When talking about interdisciplinarity I am referring to an approach that goes beyond institutionalised disciplines, an approach that goes beyond a "methodological combination of existing academic disciplines" (Hviding, 2003, p. 43) and the hoped-for disturbance of disciplinary boundaries. I refer also to approaches that exist in localised, unwritten forms, which:

"can yield insights into different relations and processes ranging across the cultural, the social, the political, the ecological, and more. Interdisciplinarity implies the ability to combine different knowledges and their insights into significant projects and practices -formulating innovative, more proper research for reaching greater, more holistic understanding of how Pacific worlds have been, are, and will be constituted and remade"

(Hviding, 2003, p. 43).

Interdisciplinarity is a tool to unlock new approaches to matters concerning the Pacific: "it is not the answer, it is one way of asking the questions" (Whimp, 2008, p. 414). These questions are posed amid the sometimes messy partnerships of disciplinary (institutionalised) and non-disciplinary orientations. These can contribute to the language of possibility expressed in "the prospect of new articulations of lives, lands, identities, voyages, genealogies, histories, societies, cultures, languages, knowledges, and epistemologies in and beyond the Pacific" (Whimp, 2008, p. 414). Along these lines, in the relational and discursive practice of identifying local ways of knowing, I sought to respectfully "learn from, not just about" (Connell, 2007, p. vii) knowledge systems, values and practices (those which I 
am allowed and welcome to learn due to my positionality within custom). This learning requires constant and relentless reflexivity.

Pacific Studies encourages a grounded research process, with respect and emphasis on Indigenous experiences and ways of knowing (Fairbairn-Dunlop, 2008). Firth argues that these Indigenous experiences and knowledges go beyond 'tradition', that slippery and oftentimes troublesome term that has been tainted by the need to be "retrieved, restored or maintained" (Firth, 2003, p. 140; see also Wesley-Smith, 2016). When put into practice by colonial, neo-colonial, post-colonial and even decolonising projects in education and development, this need can fixate on the desire to "fix" the Native (Firth, 2003; T. K. Teaiwa, 2001).

The decolonising agenda of this research therefore aims beyond the mere scrutiny of systems and institutions, and beyond perpetuating romantic or nostalgic ideas of a 'return to the traditional'. It rather focuses on presenting some of the pathways carved by Indigenous peoples themselves towards locally relevant and beneficial approaches within education and development. It presents Indigenous peoples and their agency - who "despite colonialist attempts to incarcerate them within spatial borders, - primarily through cartography, military manoeuvres, cultural sciences like linguistics, and aesthetic representations - [...] have maintained a dynamic sense of place alongside a dynamic sense of history that allows for movement and change while demanding "return"'" (T. K. Teaiwa, 2001, p. 60). Like Teaiwa, by 'return' here I refer less to a literal, physical reoccupation of a 'traditional space', and more to a tangible display of respect: a political and spiritual acknowledgement of the historical significance of Oceanic places, practices, values and ontological traditions. It is a return to autonomy and sovereignty within those spaces, and about exposing the agency and "desire for freedom to continue their dynamic historical and spiritual relationships to places" (2001, p. 60; L. T. Smith, 2012).

2.6.4. The study's decolonising agenda: relationality, tok stori and values 
The decolonising agendas of the approaches above have provided Indigenous peoples, colonised peoples, and anti/post-colonial thinkers with a language of possibility that calls upon the imagination. As described by Linda Tuhiwai Smith, "[t]o imagine a different world [...] is to believe in different possibilities, ones that we can create" (L. T. Smith, 2012, p. 324). Respect is fundamental to this agenda, as is the acknowledgement of Indigenous places, practices, values, ontologies and stories in ENB province. This study stresses that such practices are not only essential for research, but for any work in education and development in ENB.

A decolonising agenda demands respecting and upholding values and practices that are important within a diverse ENB Indigenous context. ${ }^{13}$ The study is conducted largely alongside Gunantuna/Tolai participants, and therefore respects and upholds their customs and ontological traditions, such as the values of love (waramari), respect (wariru), trust (nurnur), and obedience (tinarom), as well as the appropriate protocol, custom and koko (do-nots/rules/taboos). ${ }^{14}$ It likewise upholds Indigenous systems of governance and leadership (e.g. Tubuan society), societal formations (which emphasise collective relationality, reciprocity and intergenerationality: kin, tribe, clan, extended family, wantok ${ }^{15}$ system), language (tok ples ${ }^{16}$, Tinata Tuna or Kuanu $a^{17}$ ), diverse and relational economies (such as those created by tabu), as well as worldview and ontological traditions (e.g. relational and discursive ways of

\footnotetext{
${ }^{13}$ This includes several Indigenous peoples from diverse groupings in ENB province, including diaspora from other PNG provinces that work locally or are married into local families.

${ }^{14}$ Specific values and koko have been taught to me by IaIva Magaga, Gunantuna/Tolai elder and leader in education and community development, who is my mother through customary adoption. ${ }^{15}$ Wantok: "The word wantok was developed to express connection in a context where labourers from various Melanesian language groups worked together on coconut and other plantations (Nanau, 2011)" (Sanga et al., 2018, p. 6).

${ }^{16}$ Tok - talk, Ples - place (in Tok Pisin), meaning the language of the place, the vernacular tongue. ${ }_{17}$ Tinata Tuna: "The language of the Gunan Tuna" (Kakabin, 2018). Kuanua: Is an Austronesian language spoken and understood by all Gunantuna/Tolai. Two groups speak two slightly different languages; the Duke of York Islanders and the Birara of the south-coast of the Gazelle Peninsula (Simet, 1991). According to ToGideon Kakabin, Kuanua refers to the language of Gunantuna/Tolai, but "it means "over there" [and] probably originated in the Duke of Yorks" (2018).
} 
negotiating and generating knowledge, such as tok stori ${ }^{18}$ and place-specific learning practices). These systems contain culturally appropriate articulations of the language of possibility. They support participants to strategise choices, theorise solutions, and create alternatives, thereby legitimising societal aspirations that emerge from many collective and individual standpoints.

Regarding systems of governance and leadership, ToGideon Kakabin referred to Gunantuna/Tolai leadership as:

"based on the 'patuana' meaning the 'elder'. The female matriarch is the 'Tubuan' or old woman. The word describing the Masked Dancer comes from this word for matriarch. The patuana or Tubuan has judgmental jurisdiction over clan members only. [Colonial] Administration created paramount chiefs whose authority not only transcended clans but transcended village and district boundaries as well.

It's fair to say then that the Chieftain system as far as the Gunantuna is concerned is a foreign system of government"

Furthermore, in regard to the wantok system, Sanga et al. explained that:

"Although the imperative for connective social networks of obligation preceded contacts with Europeans (Tanda, 2011), and despite the fact that the concept can mean "slightly different things to different people depending on the context and circumstances under which it is used" (Nanau, 2011, p. 31), the wantok system is a flexible embodiment of a firm tenet of Melanesian life. What underpinned family and village-based connections has been "purposefully transformed" (Repič, 2011, p. 78) into a layered approach to relationality where the basis and actual language of connection can vary between layers: being a wantok is a method for creating society in urban locations (Schram, 2015) as well as a reflection of the reality of village existence. Regionally, the concept of being a wantok is also an element underpinning notions of Melanesianism (Lawrence, 1975). As a relational network, the wantok system can sit uncomfortably with supposedly non-relational Western-based social structures (Mana, 1999; Tanda, 2011). However, as McLeod (2008) says, the wantok system points "to the ongoing importance of kin and the attached notion of reciprocity" (p. 8) in Melanesia, where relationality is central and language as tok is a key element in indicating the kinds of relatedness experienced and obligation due" (2018, pp. 6-7).

The stories shared by participants in this study articulate and enact some of the collective, individual, and relational visions of self-determination and autonomy in the spheres of their lived realities (socio-economic, political, educational,

\footnotetext{
${ }^{18}$ See Chapter 4 for comprehensive discussion on tok stori as a research method.
} 
developmental, spiritual). These stories and the engagement of tok stori share a language of possibility that pushes for a culturally preferred pedagogy, as well as culturally and locally appropriate development discourses, practices and outcomes. As argued by Sanga et al., advocating for a culturally fitting (known, familiar, ontologically appropriate and validated) research methodology within a Melanesian locality "is an act of decolonisation" (2018, p. 3). The relational nature of tok stori enables others to rethink the importance of relationality and "of valuing people in knowledge creation and learning" (2018, p. 3).

\subsection{Conclusion}

This chapter placed the research by rooting it in the understanding that 'place' in Oceania is constructed by stories; and presented epistemological and ontological influences on the research process. The philosophical currents of this study are influenced and supported by theoretical and applied principles of critical Indigenous theory and research. This research prioritised engaging with these bodies of work because they uphold Indigenous, and especially Indigenous Oceanic, processes of knowledge generation. Particular importance is given to Indigenous Oceanic scholars and anti/post-colonial thinkers, whilst centring stories by participants who occupy active and/or leading roles in political, spiritual, environmental, economic, educational, and community development spheres in ENB province. From this philosophical standpoint, tok stori is firmly placed as an appropriate, respectful, and effective mode of communication and investigation within a Melanesian context. Tok stori can also support the decolonisation of relational, discursive and tangible inequalities that exist in development and educational-aid spheres in Oceania. 


\section{Placing Education and Development in}

\section{Oceania}

\subsection{Introduction}

This chapter places education and development in the context of Oceania. It reflects on work by Oceanic and Indigenous scholars, practitioners and educators who are rethinking education and development, addressing education-for-development trends, and reshaping educational-aid relationships in the region. It later discusses regional Oceanic and national PNG trends and dynamics at the intersection of education and development.

\subsection{The purpose of education}

One of the purposes of education, as Sanga explains, is:

"to transmit the culture of the society within which education takes place. ... As a value-laden phenomenon, education has desired goals that epitomise certain worldviews"

(Sanga, 2000, p. 4)

With this in mind, I first attempt definitions of the concepts of 'culture and education', as a way to pay respect to this study's participants and my own cultural backgrounds, as well as to the teachings of Oceanic elders and scholars. I define 'culture' as the worldviews of a people and their links to place that yield identity, an identity reflected in their reciprocal relationships and kinship networks. Culture is the way of life of a people, which "includes language together with an associated body of accumulated knowledge, understandings, skills, beliefs and values" (K. H. Thaman, 1995, p. 723). Education is rooted in cultural continuity and survival (Cummins, 1977; Gutek, 1972; K. H. Thaman, 1995), and I therefore define 'education' as the process whereby a people search for answers to the questions of 
place, identity and relationships. To find those answers, social groups develop relevant knowledge, skills, language and values in accordance with their place/environment. Education aims at ensuring cultural continuity and survival through the transmission of such knowledge, skills and values, contained and reflected in patterns of language, performance and behaviour.

Traditional forms of education in Oceania are historically determined and performed in line with knowledge frameworks and worldviews specific to cultural groups. Information, insight and skills are transmitted and modified from one generation to another. The accurate intergenerational transmission of knowledge and authority depends on the upkeep of ceremonies and stories, and on maintaining the integrity of ples (Battiste, 2002). Processes of teaching and learning comprise their own methods for classifying and transmitting knowledge, and aim to form conscientious and productive members of society capable of deriving a livelihood from their environment (Mel, 1995). The expectation of everyone performing certain roles in their society is in accordance to these educational processes, which safeguard as well as segregate knowledge by gender, by profession or craft, by kinship relationships, and in many societies by rank (Crocombe, 2001). In Oceania, Indigenous education processes thus ultimately aim at the transfer and furtherance of Indigenous wisdom and "the interconnectedness and interrelatedness of all things and all people" (K. H. Thaman, 2003, p. 12).

In this study I distinguish types of education using the definitions of Konai Helu Thaman:

"Formal education is organized and institutionalized learning, such as that which occurs in schools and universities; non-formal education is organized but non-institutionalized learning; and informal education is unorganized ${ }^{19}$ and non-institutionalized learning"

(1995, p. 723).

\footnotetext{
19 The term 'unorganised' refers to its organic nature.
} 
Non-formal and informal forms of education throughout Oceania provide, advance and renew specialised skills and knowledge in a myriad of areas including navigation, warfare, fishing, medicine, craft and more; they are taught by specific people and/or elders who are responsible for holding and imparting these knowledges and skills (K. H. Thaman, 1995).

In $16^{\text {th }}$ century Europe both religious and secular currents of thought began to advocate for widespread adoption of formal education; this advocacy came from the Christian church, from governments, and from industries requiring compliant workers. The church, for instance, instituted schools as part of its evangelisation agenda, which included teaching their scriptures and European languages. The promotion of philosophy in schools came from the secular current which was involved in determining schooling curricula (Adamson, 2013). In territories colonised by European powers, formal education was largely administered by Christian churches and their representatives, whose role in the implementation of schooling meant that they also influenced curricula (Adamson, 2013). Crocombe points out that missionaries not only introduced formal education with the purpose of Christianising colonised peoples, but also as a means of 'developing' them to function within newly introduced Western-styled economic, social and political systems (2001).

For European colonial powers, education was regarded as a fundamental element for the development of the peoples of colonised territories. Formal education thus came hand in hand with political, social and economic pressures exerted by imperialist expansion. The introduction of formal education to most corners of Oceania took place in the early part of the nineteenth century, and both foretold and implemented the promotion of European cultural philosophies and values through manifest and hidden curricula ${ }^{20}$ (Nagai, 2001; K. H. Thaman, 1995). The progression

\footnotetext{
20 The hidden curriculum conveys the ideology that "what is not taught in school is of little value, and that what is learned outside of school is not worth knowing" (Illich, 1976, p. 258).
} 
of imperialist social-political and economic interests occurred through the claiming, possession, and extraction of natural resources and land, as well as the emergence of Western-styled governance institutions and judiciary systems in colonised territories (Crocombe, 2001). The propagation of formal education was part of the furthering of these interests, alongside the push to 'develop' local people. In time Western-styled education came to be considered as a cornerstone of development, in Oceania and globally (Colclough, 2012; Gamlen et al., 2017; Ulu, 2018).

Wendt argues that the purpose of these systems is not to educate Pacific Islanders for development, but to

"produce inexpensive [workers] for the colonial administrative machine. [...] the education was narrowly academic and benefitted mainly our traditional elite groups. [...] The elitist and academic nature of this education was not conducive to training us to survive in our own cultures. [It] helped reduce many of us into a state of passivity, undermined our confidence and selfrespect, and made many of us ashamed of our cultures"

(1982, p. 56).

For over two centuries Western educational philosophies and pedagogies have systematically "destroyed the values and belief systems underpinning Indigenous education systems in which the majority of Oceanic peoples were and continue to be socialized" (K. H. Thaman, 2003, p. 2). Throughout this process much effort was made to highlight the differences between Eurocentric and Indigenous knowledge, labelling the latter 'traditional knowledge', which the former regarded as a body of relatively old data passed between generations basically unchanged (Battiste, 2002). The differences between these two knowledge systems (their philosophies, values, educational methods, etc) were presented with the aim of emphasising the superiority of Eurocentric knowledge (Hibler, 1984), whilst trivialising Indigenous knowledge systems by treating them as purely normative or spiritual (Battiste, 2002). Such bias persists despite evidence of the accelerating social-economic and environmental collapse of Western urban-industrial, individualistic societies (L. T. Smith, 2012; K. H. Thaman, 1997). These inherited education systems remain in 
Pacific Island countries decades after their political independence, and are deeply ingrained as colonial legacies (Tauge'ulungaki, 2002; Sanga, 2002; Altbach \& Kelly, 1978; Bray \& Packer, 1993).

\subsection{What types of education, for what types of development in Oceania?}

So, what types of education, for what types of development, are taking place in Oceania? National investment in education by Pacific Island states over the last three decades has increasingly seen large budget allocations to both primary and secondary education, especially from the 1990s following the launch of the global EFA goals (Kiddle, 2005). After the commencement of the MDGs in the early 2000s, aid donors demonstrated increased willingness to commit long-term funding towards primary education for all boys and girls (Unterhalter, 2005). Additionally, "there has been considerable emphasis on tertiary education, from an early regional approach in the form of the [USP] to efforts to establish national universities in Papua New Guinea, Guam, Samoa, French Polynesia and New Caledonia" (Gamlen et al., 2017, p. 5). Nonetheless, high rates of aid alongside insistent requirements for Western-style governance systems in Oceania have resulted in models of education that mirror and reproduce dependent neo-colonial relations (L. T. Smith, 2012). In this context, two major models have emerged that reflect global educational trends: one focused on human capital generation, and the other on education for conscientisation. These will be discussed in chapter 6 , with further consideration of an approach that goes beyond conscientisation and advocates for education that champions locally appropriate notions of cultural development (Gegeo, 2001a; Taufe'ulungaki, 2000).

As pointed out by Sanga (2000), formal school institutions were introduced through colonisation across a region of multiple cultural groups with varying worldviews; 
this makes the question of appropriate education much more complex. Sanga argued that at large in the Pacific Region:

\begin{abstract}
"the extent to which the school represents the multiple cultural groups adequately is minimal. The degree to which the school is performing the ideological purpose of education for the various indigenous cultures is negligible. What appears to be happening is that the officially sanctioned values are those that are represented by the school structure, the approved curriculum, the policies, the regulations and the teaching profession. The behaviour of teachers within the school in their interactions with students and other may be Melanesian, Polynesian or Micronesian in nature, but, such culturally inclined behaviours, is not highly valued. The end result is that school and education are not necessarily synonymous in the Pacific Islands."
\end{abstract}

(Sanga, 2000, p. 4)

It can be argued that in globally dictated education systems (Narsimulu, 2007), education is a commodity rather than learning (K. H. Thaman, 2000b) where historically no space has been given for Indigenous knowledge. As a result, there is a limited presence of Indigenous, traditional and local knowledge in the various manifestations of formal education (school, curricula, policies) in Oceania. Passing such knowledge on to the young is a continuing concern of many Oceanic scholars, educators and leaders, who for generations have fought to 'find the islands' voices in the classroom' (Hereniko, 2000).

When speaking about Indigenous perspectives and knowledge in higher education, Thaman stated that as these peoples:

"reflect on the past and help shape the future, we, particularly those of us whose identities are closely linked to Oceania, need to interrogate the images and the representations that we have inherited or are creating."

(2003, p. 5)

Pacific Island children, as Nabobo-Baba notes, "have been positioned, named, branded and equated with either being too lazy to learn, or just simply deficient learners" (2013, p. 87). Indigenous perspectives have been silenced, misrepresented, ridiculed, and even condemned within education and development global discourses (Nabobo-Baba, 2013; L. T. Smith, 1999; K. H. Thaman, 2003). Educational 
and development models that Oceanic students and educators have been exposed to have largely lacked the concepts by which their lived experiences can be "appropriately represented, named, described and understood" (K. H. Thaman, 2009c, p. 5). Such deep-seated educational legacies are a result of a continuous colonising process that serves to perpetuate and justify imperial values, attitudes and interests in Oceania (Bargh, 2007).

Although Indigenous peoples" "stories local and global, the present, [their] communities, cultures, languages and social practices - all may be spaces of marginalisation, [...] they [are also] spaces of resistance and hope" (L. T. Smith, 1999, p. 4). Importantly, Oceanic thinkers identify that necessary changes in education do not simply involve rejections of Western-styled academic models of schooling (Crossley, 1984, p. 76), because many Oceanic peoples have in fact chosen to engage with and have benefited from this type of schooling. Rather, as illustrated by Thaman, across Oceania

"some realized that the tools that they were using belonged to those very models that they were trying to deconstruct and they realized that they were in danger of becoming equally oppressive themselves (Smith, 1999). Many decided that it was time to look towards their ancestral cultures for appropriate frameworks/spaces in which they could theorise their own indigenous knowledges and education. Over the past two decades or so, a number of pioneering works by Pacific scholars have emerged and are now recognized and accepted as relevant resources and frameworks for teaching and research in higher education in the Pacific region. These frameworks include: Kakala (Thaman, 1992); Fa'afaletui (Tamasese et al, 1997 in Thaman, 2009b); Kurakaupapa Māori (Smith, 1999); Tivaevae (MauaHodges, 2000 in Thaman, 2009b); and Vanua (Nabobo-Baba, 2006)"

(2009c, p. 5).

Other examples are: the work by Anna Joskin's work in Kibung PD framework a collaborative tool for curriculum implementation at the classroom level in Papua New Guinea (2013); and Tongan educator 'Amelia Folaumahina's (2018) teaching and mentoring models, which assert the need for culturally appropriate educational frameworks that uphold societal values such as integrity and accountability by 
drawing knowledge from family, elders, leaders and Indigenous people in educational formulations.

\subsection{Rethinking and reshaping education and development in Oceania}

Rethinking and reshaping education and development is a continuous practice for many Oceanic peoples. This is reflected in the work of thinkers and educators such as Albert Wendt's 'New Oceania' and Epeli Hau'ofa's 'Our Sea of Islands'. Hau'ofa equipped his students with an understanding of Oceanic existence no longer focusing on the smallness and remoteness of islands "much too small, too poorly endowed with resources, and too isolated" (1994, p. 150), but on a holistic perspective in which Oceania as 'a sea of islands' is seen in the totality of its relationalities (1994, pp. 152-153). It is also reflected in Kabini Sanga's efforts towards a relational contextualisation of education and development across Oceania (Sanga, 2016; Sanga \& Taylor, 2001; Sanga \& Thaman, 2009). Konai Helu Thaman removes Oceanic notions of development from global development institutions and rhetoric, adding critical context by noting that for Pacific people development and sustainable development is about survival: survival of our Earth and the cultural continuity of Pacific peoples (2018).

Unaisi Nabobo-Baba has questioned the way countries and peoples relate to each other in Oceania, and argued that it is the political economies of Pacific Island countries that 'dictate what we do in the Pacific' (2018). Such reflections on relationalities in the region extend to those who set the agenda of education-fordevelopment: using the example of a current USP curriculum that sought local communities' ratification to ensure that all voices are taken into account, NaboboBaba also urged those who want to be part of those relationships to sit in the villages, but know when to back off, that is the Melanesian way (2018). She thus calls for education in Oceania that tells their stories of looking after each other, stories of 
navigators and of ancestral and current patterns of migration, stories of education that give us hope (2018).

Centring Indigenous knowledge in educational institutions and content has proven to be a difficult but critical task for Oceania (Sanga, 2002, 2014, 2020; Sanga \& Thaman, 2009). This practice is also fundamental for development, because it legitimises local contexts and the knowledge derived from that context (Sanga, 2020), which in turn support "the spiritual as well as the economic security that for thousands of years had provided Indigenous peoples with a sense of place and purpose" (K. H. Thaman, 2003, p. 9). Such considerations are central to this study, as participants share their own knowledge about the importance of diverse community economies; of collective protection of land as ples; of the redistribution of wealth and resources; of culturally-specific values of reciprocity; and of labour that nurtures tribe, clan and family identity for the cultural, spiritual, environmental, socialeconomic and political wellbeing of their societies.

Below I discuss several Oceanic regional responses to education-for-development trends, alongside an assessment of aid and education relationalities in the region.

\subsection{Regional context: Responses to education-for-development trends}

At the regional level in Oceania, education is generally regarded a crucial component of development (C. Brock \& Crossley, 2013; Crossley, Bray, \& Packer, 2009; Gannicott, 1990). As such, governments throughout the region have committed themselves to achieving a constantly shifting set of global goals on education (Taufe'ulungaki, 2003). This education-for-development commitment is reflected in regional policies and plans directed by bodies such as the Pacific Islands Forum (PIF), whose 'Basic Education Plan' considered education the key foundation "for vocational calling, higher education, and lifelong learning" (in Randell, 2003, p. 21). Likewise, a key goal of the 2013 Pacific Plan was "improving access to opportunities 
afforded through stronger education systems at all levels" (Pacific Islands Forum Secretariat, 2013, p. 17). The PIF's latest Pacific Regional Education Framework 20182030 includes a change in direction of education philosophy, policy, strategising and programme implementation, being embedded in a 'Pacific Regional Vision' and a 'Blue Pacific' narrative (Pacific Islands Forum Secretariat \& USP, 2018). I will discuss this in the next section.

Decade after decade, prescriptions for education, development and economic growth through global targets and policies have urged the expansion and improvement of educational systems in countries of the Global South including Oceania, yet have ignored the historical underpinnings of these same systems. They have failed to identify the fundamental purpose of education within national and local contexts. Hickling-Hudson (2002) argues that these internationally agreed prescriptions emerged without the depth of analysis necessary to understand either the assumptions behind the model of education to be expanded or improved, or the social-economic and political implications of development frameworks at local, national and regional levels. It follows that global development rhetoric should not mislead or produce a sense of false hope in relation to specific models of formal education and their expected benefits for different regions, countries and localities. Indeed, within the body of knowledge generated throughout decades of shifting development agendas and targets, big questions remain regarding the theoretical and applied effects of this global education-for-development consensus (HicklingHudson, 2002; Tolley, 2005).

Dore's argument around 'diploma disease', for instance, raises concerns about an overproduction of universal and undifferentiated education that in many countries does not match the skills the labour market demands (1980). Likewise, many authors point out the inappropriateness and "dysfunctionality, of traditional Western education models in non-Western societies" (Tolley, 2005, p. 415). Justified by the quest for 'global' relevance and competitiveness (Gamlen et al., 2017, p. 6), such 
models are increasingly eclipsing more locally appropriate Indigenous epistemologies (Gegeo \& Watson-Gegeo, 1999). These trends neglect vital functions of education, such as transmitting cultural identity and knowledge, and articulating the worldviews of the society within which education occurs (Sanga, 2000).

\subsubsection{The Pacific Regional Education Framework 2018-2030}

Several regional discourses, strategies and policies of education and development are currently being identified, generated and enacted in Oceania. The 'Pacific Vision' endorsed in 2014 by PIF Leaders operates within a framework of 'Pacific Regionalism'21, in 2017 the Leaders ratified the 'Blue Pacific' narrative ${ }^{22}$ which became central to advancing the Pacific Vision. Through the 'Blue Pacific', PIF Leaders:

"seek to reaffirm the connections of Pacific people with their natural resources, environment, culture and livelihoods. Forum Leaders recognise the Blue Pacific as being about all Pacific peoples, who recognise their needs and potential, who plan and own their development agenda, and who can act collectively for the good of all, rather than a few"

(Pacific Islands Forum Secretariat, 2019). Under this regional vision, narrative and framework, Forum Education Ministers have adopted the Pacific Regional Education Framework (PacREF) 2018-2030 which builds upon the achievements and lessons from the preceding Pacific Education Development Framework (PEDF), as well as the conclusion of the MDG2 and EFA agendas in 2015. PacREF 2018-2030 outlines "a transformative and sustainable regional education agenda aligned with global agendas such as the [...] SDGs particularly SDG4, the education goal and Education 2030: Incheon Declaration on

\footnotetext{
${ }^{21}$ Pacific Islands Forum Leaders embrace Pacific Regionalism as: "The expression of a common sense of identity and purpose, leading progressively to the sharing of institutions, resources, and markets, with the purpose of complementing national efforts, overcoming common constraints, and enhancing sustainable and inclusive development within Pacific countries and territories and for the Pacific region as a whole" (Pacific Islands Forum Secretariat \& USP, 2018).

22 "The Blue Pacific seeks to re-capture the collective potential of the region's shared stewardship of the Pacific Ocean based on an explicit recognition of its shared "ocean identity", "ocean geography", and "ocean resources" (Pacific Islands Forum Secretariat, 2019).
} 
Education for All Framework for Action" (Pacific Islands Forum Secretariat \& USP, 2018 , p. 4). As of 2019, the first phase of the implementation of this framework is in motion, aiming to deliver sustainable, affordable and high-quality education goods and services that are accessible to all PIF member states. PacREF's four key policy areas are: quality and relevance, learning pathways, students' outcomes and wellbeing, and teacher professionalism; all of which are intended to support the Pacific Vision over the next decade. PacREF promotes human rights, gender equality and inclusion values rooted in the Pacific Leaders' Gender Equality Declaration (PLGED), Pacific Platform for Action on Gender Equality and Human Rights, Pacific Framework for the Rights of Persons with Disability (PFRPD), and the Framework for Resilient Development in the Pacific (FRDP). Implementation is dependent on partnerships among regional agencies, collaboration and cooperation among national education systems and regional institutions, including partner agencies such as UNESCO.

A central feature of PacREF is a commitment to ensuring national leadership and ownership by Pacific Heads of Education Systems (PHES) in the development of policies and programme implementation strategies, through a Small Working Group (SWG). The current implementation phase is facilitated and overseen by USP as the Chair of the Council of Regional Organisations in the Pacific (CROP) Human Resource Development Working Group. Both mechanisms are intended to ensure the success of the framework, translated into the educational outcomes of 'a Pacific, for the Pacific' vision.

\subsubsection{Rethinking education and reshaping educational aid relationships}

The Rethinking Pacific Education Initiative for Pacific Peoples by Pacific Peoples (RPEIPP) is a transformation from within, with roots in the need to ensure Indigenous ownership of education and to re-examine curriculum processes. RPEIPP is an initiative across universities in Oceania (including USP and VUW), by "a group 
of Pacific educators - 'insiders' who have undertaken various activities and work of embedding Indigenous graduate attributes into teacher education courses, in leadership training of young [...] and in communities" (Nabobo-Baba, 2013, p. 82). Initial funding assistance came from the New Zealand aid programme, and is almost entirely "internally driven, implemented and progressively evaluated" (p. 82). RPEIPP's approach is the rethinking and redefining of education and schooling in the region. It aims to ensure "that aspects of Indigenous peoples' cultures and related worldviews and life values and philosophies inform the work of educators" (Nabobo-Baba, 2013, p. 82), alongside the provision of global knowledge, skills and values that currently dominates schooling, particularly higher education.

Upon analysis it appears that the authors of RPEIPP have reflected on the limitations presented by universalistic and undifferentiated approaches to education that do not consider cultural and social-political contexts or different styles of learning. This is seen in the re-examination of the relationship between teaching and learning, curricula, assessment and the cultural contexts of Indigenous and other Oceanic peoples, as well continuous work on mentorship approaches and programmes (e.g. Appreciative Mentoring Framework (Chu, 2009)), publications, research training, conferences and symposia, national advisories and leadership training (NaboboBaba, 2013; Sanga, 2017).

RPEIPP addresses key education issues in Oceania at a strategic level, seeking to contribute to the indigenising of education and achieving regional self-sufficiency in terms of human development capacity and funding (Nabobo-Baba, 2013; Sanga, 2014). This takes place within in a context where many Oceanic leaders have worked towards the strengthening of higher education courses and programmes, such as Pacific Studies, across the region. The indigenisation of education does not refer to essentialism but rather to engaging in work at different levels and groupings of society, examining and critiquing local systems as much as external education models. Indigenising education is thus the work towards defining the right 
education for diverse Oceanic contexts (Sanga \& Taufe'ulungaki, 2003), whilst taking into consideration the influences and impacts of an increasingly globalising, technology- and economic development-driven world (Obed, 2004; Wang, 2006).

RPEIPP has been important for re-thinking the values, development and implementation of curricula, and to re-establishing and reshaping educational aid relationships across the region. As highlighted by Sanga, the philosophical and practical aspects of educational aid are consistently devoid of Indigenous Oceanic epistemological and ontological dimensions (2005). Oceanic thinking and perspectives on educational aid, even when clearly articulated by Oceanic experts, "have not been included in policy formulation by donors and governments" (Huffer \& Qalo, 2004; Sanga, 2005, p. 13). What is more, the value placed by Pacific Islanders on relationships is not reflected in the 'aid business', which has been traditionally devoid of relational considerations (Sanga, 2005).

The foundations for RPEIPP's work and successes were laid in the early 2000s by leading Pacific educationalists including Kabini Sanga, 'Ana Taufe' ulungaki and Konai Helu Thaman (Chu, 2009). Arriving at the consensus that changes in education are essential for the region, these leaders aimed to provide the foundations for future Oceanic educational leadership by re-examining the effectiveness of educational development. They identified that clear and long-term visions for education, as well as ownership of educational development, were limited in communities across Oceania. Thus, they support the transformation of curriculum development and implementation processes which are largely donordriven, and have historically lacked considerations of the socio-cultural context of learners and educators, are insensitive to gender dimensions and vulnerable peoples' requirements, and have limited stakeholder collaborative approach to their development (K. H. Thaman, 2009b). 
RPEIPP therefore has an important role in strategising for long-term and sustained capability development of Oceanic educators and educational institutions, implemented by Oceanic educators themselves (Chu, 2009; Nabobo-Baba, 2013). Its advisory group brings together prominent Pacific leaders and educators (Sanga \& Taufe'ulungaki, 2003) with a focus to address the region's major education issues at a very strategic level.

According to Van Peer, RPEIPP is unique because it represents an atypical donorrecipient relationship (2006). Although funded by NZAID, the identification, design, management and evaluation of the framework was carried out by the recipients of international aid funding. By adopting a largely hands-off approach, NZAID in this case demonstrated a commitment to form collaborative partnerships (Van Peer, 2006). Similarly, the Japan International Cooperation Agency (JICA) has contributed by funding a variety of books by Oceanic scholars as part of by RPEIPP activities (Nabobo-Baba, 2006; Nabobo-Baba, Naisilisili, Bogitini, Baba, \& Lingam, 2012).

Nabobo-Baba observed that RPEIPP has faced a number of challenges and difficulties, some to do with the emotional toll that emerges from new ideas and reform agendas being met with "disdain by hegemonic forces that dominate academia" (2013, p. 94). Nevertheless, as reported by Van Peer, this initiative represents a time in the formal education history of the region without precedence: at no other time so much has been led, transformed and produced by Oceanic educationalists and scholars, and owned by the benefiting communities, institutions and peoples (2006). Through initiatives like RPEIPP, Pacific peoples are defining the direction, purpose and outcomes of education for themselves, by themselves. This is supported by partnerships with like-minded organisations, as well as with the support of people who by living and working in Oceania have demonstrated a deep sense of understanding and care about its places and peoples (Sanga, 2005). 
RPEIPP demonstrates what can happen for educational directions and outcomes as well as educational aid relationships in Oceania when re-thinking occurs. More importantly, it demonstrates what is possible when transformations come from within. With these possibilities in mind, it is now necessary to turn to examine the context of PNG to appreciate the way education is shaped by national-level considerations.

\subsection{Country context}

In recent years the PNG government has promoted education, human capital development, and gender inclusiveness and empowerment, to achieve 'inclusive sustainable growth'23 at the national and regional levels (NSTF, 2011).

PNG's governance system is intricate, comprising 22 provinces, 89 districts, 313 local level governments and 6,131 wards: "[t]his decentralized system is complex, with multiple tiers of government and administration. Each tier of government is funded largely from the national budget" (UN-PNG, 2018, p. 16). It can be argued that this complexity reflects negotiations between the interests of a culturally diverse population "which retains a stronger allegiance to and trust towards sub-national levels than national" (UNDP, 2014, p. 39). However, it is also reported that provincial and district governments have "historically performed relatively poorly in terms of delivery of services and development to their respective populations" (2014, p. 39).

Since independence from Australia in the mid-1970s, development efforts have increasingly recognised PNG's traditional social structures and the value of kinship networks, relationships, and the strong sense of belonging to place which is rooted in village life (ADB, 2008). Development thought in PNG has thus evolved from the 1960s plans that were World Bank-designed, UN-deployed, and Australian-

\footnotetext{
23 'inclusive sustainable growth' was a concept referred to by former PM O'Neil during a 2018 public lecture on Pacific Regionalism held at the USP, Suva.
} 
implemented. It now includes advocacy for the political and economic participation of Indigenous people, setting objectives on ethnic and gender-based equality, and greater attention on rural and village development and self-reliance (Department of National Planning and Monitoring, 2010; NSTF, 2011).

For generations, local notions and practices of development have provided contextspecific, culturally grounded, tangible, and ongoing pathways to better the lives of peoples across PNG (Nazareth Rehabilitation Centre; Pavol, 2016, 2018; WideBay Conservation Association, 2015). Lessons from local and grassroots development initiatives and leaders, I believe, can be an invaluable source of wisdom to national and international bodies involved in the design and implementation of development strategies. Throughout this study I touch on some of these.

PNG's forty-thousand-year long education tradition includes processes of teaching and learning defined and performed in line with worldviews and knowledge frameworks specific to cultural groups. Western-styled education models, however, have dominated teaching and learning practices in the country since colonisation. As pointed out by Carrier (1982), in PNG this has produced a growing conflict in the value system of Indigenous cultures:
"While the western value systems emphasize individualism and competition, the indigenous value systems emphasize communal co-operation [...] The more children learned about western culture, the more indigenous culture was forgotten. Communication breakdown [...], and the alienation of children from village life, became common problems through PNG. Children's success was based on their academic achievement at school, although they failed to become useful members of local communities. No matter how expatriates tried to improve western education, these problems persisted. The more the English language and its concepts were taught, the more the alienation of the children was accelerated"

(Nagai, 2001, pp. 70-71)

Mel (1995) has argued that the failure of these models to understand and respect existing local cultural systems has at best devalued, and at worst annihilated, 
important aspects of their cultural traditions, including those concerning education. Similarly, Nagai stated that:

"[a]s western education aimed at the development of indigenous societies to the standards of western civilization, indigenous people were expected to learn European culture and languages and so the curricula in PNG reflected that of the western nations."

The proffered curricula rejected the fact that children and learners in PNG are part of complex, pre-existing systems of knowledge analysis and transfer (Mel, 1995).

Education became a process of socialisation of students into institutions away from their family networks and villages, during their formative years and in a foreign language (K. H. Thaman, 1997).

Colonial formal education contributed to the ongoing denial of Indigenous peoples' rights and sovereignty, and to the devaluation of cultural patterns of traditional societies (Bodley, 2014; Goldsmith, 1993). This is exemplified in ENB province, where Gunantuna/Tolai people have fought for and negotiated the maintenance of their Tubuan, which is central to their self-determination, governance and cultural traditions of knowledge transfer, in the face of imported religious ideologies ${ }^{24}$ and of colonial educational directives that sought to demean or even demonise the Tubuan.

As explained by the renowned Gunantuna/Tolai elder, artist and historian ToGideon Kakabin:

"[Away] from the Western World, the Tolai Society developed their Tubuan in order to satisfy their social need and more importantly as a regulator and government for the people. The Reverend George Brown eventually, after

${ }^{24}$ Tateyama (2006) gave a detailed description of the colonial European view of, and opposition to Tubuan values as well as the subsequent impacts on their cultural traditions amongst Gunantuna/Tolai societies. Early missionaries argued that Tubuan was their greatest enemy, issuing documents calling for its total abolition. "Both the Methodist and Catholic missions, thus, persistently fought against the Tubuan, though in different manners, but it is important to stress that their fights continued because many Tolai Christians kept on resisting the hegemonic view of the Tubuan as incompatible with the lotu. The missions' attitudes towards the Tubuan, however, began to change in the 1960s and 1970s as the lotu became increasingly indigenized as a result of changes in a wide society" (Tateyama, 2006, p. 95). 
being in opposition to the Tubuans admitted that if ever there was to be a Government in New Britain it should be modelled on the Government of the Tubuan"

One of the children that went through the colonial education system is Nelson Giraure, a Gunantuna/Tolai man, who as director of Cultural Activities of the PNG Department of Education, wrote a powerful personal reflection on "The Need for a Cultural Programme" (Giraure, 1974). His writings revisited his journey in education, first as a learner and later as an educator, and concluded with this piece:

"A few years ago. I was made to realize how impractical my own education was. I was on a boat sailing between the islands along the Manus Coast. A European teacher and I were relaxing at the back of the work boat watching an uneducated Manus Islander trolling for fish. He had three lines spinning from the back of the boat. Suddenly fish struck at all three lines. Grabbing one line, the islander immediately started to pull in a fish. Then ignoring the European teacher, he thrust another of the lines into my hands. Immediately, I started to pull although probably I was struggling as much as the fish. With rapid movements, the islander hauled in his first fish. This was soon followed by another. I was still struggling with my line when he reached out and pulled in my fish as well. Then turning to the European and back to me he raised his eyebrows, shrugged his shoulders and said laughingly, "tu mas skul".

Afterwards. I spent many hours thinking about this incident. Had the Manus fisherman been right? Had I too much school or was I given the wrong type of schooling? How was it that I, Giraure, a Tolai whose home is only twenty yards from the sea and whose people had always been fishermen grown up without knowing how to pull a fish in?

Looking back, I think that I didn't have too much schooling but that the school curriculum was not balanced. It contained too much that was foreign and not enough about the background of my people.

Perhaps a new curriculum whose content contained not only the knowledge of the overseas people but also the knowledge of the people of Papua New Guinea might be more useful. It might foster a pride in and an understanding of this country's way of life. Although this will not do away with juvenile delinquency, it will certainly give both parents and children a better chance of making the best possible use of education -but a new education- an education for their needs."

(Giraure, 1974, p. 17). 
The 'dualism stage' of education in PNG saw the education system of the Australian colonial administration operate alongside independently-run church systems, beginning in the 1940s. However, school curricula were still delivered through a mission-based philosophy, until the early 1970s when the current educational system was effectively established (Watson, 1984; Weeks, 1993).

In the 1980s, as Papua New Guineans grew concerned about the alienation of children from their cultures, communities and villages, Paulias Matane reassessed the purpose of education in a recently independent PNG, and stated:

"Education has a purpose, it is the preparation of young people for their future life in society, so that they can live and actively participate in the society's development"

(1986, p. 27)

However, 'going back to the village' is sometimes still today regarded as "a fate worse than death" (Giraure, 1974, p. 15). Parents and students sacrifice much to remain part of a narrowly academic educational pathway after being told that "only the fools and the 'bush kanakas' return to the village. The bright children continue on [onto high school and higher education], get jobs and earn big money for their parents" (p. 16). The experience shared by many young students of looking with horror upon village life illuminates the long-lasting effects that colonial formal education has had on the value placed on ples and on kinship connections. Students who return to the village and/or cannot go further on their academic journey are labelled "failures" and "drop-outs" (Nagai, 2001, p. 78). Their options thereafter are limited as social stigma and loss of self-confidence alienates them from both the formal education system and from their villages; this stigma occurs even when students choose 'alternate pathways', such as community and vocational schools (NDoE, 2018b).

It is widely recognised in PNG that a degree of externally-derived content in education is necessary to assist engagement with the outside world. "[A]t the same 
time they also recognize the need of an education programme that can produce successful members of the community" (Nagai, 2001, p. 78). Mel (1995) pointed out that:

"Papua New Guineans are now looking to establish more valid systems of education which are based on their own cultural maps. Such models of education will make teaching and learning more meaningful and provide a launching-pad for specific cultural identities within the modern nation of PNG"

(Mel, 1995, p. 684).

The PNG education system has undergone major reforms since independence, and expanded dramatically over the last forty years (NDoE, 2020). A new philosophy of education based on integral human development and culturally relevant teaching and learning, has influenced "education planning, policy development and practices" (NDoE, 2004; 2015, p. 20). This philosophy influenced the 1989 adoption of a policy whereby initial literacy had to be instructed in students' vernacular languages; this stimulated the establishment of village schools, and promoted vernacular and cultural instruction at elementary, secondary and tertiary schools, alongside local language literacy programmes for adults. It also influenced changes in school curricula in the 1990s and 2000s, opening alternative post-Grade 8 educational pathways. All these policies aimed to improve the quality of teaching and learning and the development of life skills (AusAID, 2002; NDoE, 2003). The expansion of the education system was supported by relatively generous national budgetary allocations, and various education programmes were assisted by international development agencies (World Bank, 2016).

Across PNG, "Church Education Agencies, with the Provincial and Local-Level Governments, own and operate provincial institutions. Hence, education is a highly decentralized system involving many partners working together to manage schools, teachers and students" (NDoE, 2020, p. 3). Decentralisation policies in PNG have created an administrative division of labour. Whilst the NDoE is responsible for implementation of national "policy and planning, developing curriculum, 
maintaining standards and facilitating teacher education and providing vocational training" (2020, p. 3), the PDoEs "are responsible for the administration of elementary, primary, secondary and vocational education. Local Level Government responsibilities include the establishment and operation of elementary schools" (2020, p. 3). Decentralisation policies

"have long been considered an important means to achieving better educational outputs and outcomes; this includes improving participation, financial management, pedagogy, and equity"

(Bray, 1996; World Bank, 2007; in Walton, 2019, p. 176).

The implementation of Tuition Fee Free (TFF) policies in PNG from 2012 focused on abolishing school fees in basic education and subsidising fees for post-basic education, except tertiary. TFF aligned with two international development agendas: the decentralisation policies which were thought to facilitate the effective delivery of resources to people on the economic and geographical margins (Sasaoka \& Nishimura, 2010); and MDG2, which sought to achieve universal primary education and improve gender equity in enrolment (Walton, 2019). However, the resulting "increase in enrolment in basic education has led to considerable challenges to ensure continuing access to education for the significantly increased enrolment" (NDoE, 2015, p. 20). Challenges arise from the late arrival of some TFF subsidies, with some schools not having enough time or funds to implement the policy, as well from as the changing decisions on abolishing fees levied by schools to fund particular projects. Project fees have been argued to support the 'betterment potentials' of schools, but also impose annual financial challenges on parents (Walton, 2019).

In 2018 the NDoE established a standard-based education system with three kinds of educational pathways: a non-formal (flexible, open and distance learning); a formal (basic, secondary, technical and tertiary); and an alternate (community and employment, and community and vocational schools) (NDoE, 2018a). This structure works within the Education Sector Plan 2010-30, focusing on: universal education 
accessibility for all; building capacity (teacher training, infrastructure); locally relevant curricula; increasing partnerships with the private sector; system transparency and accountability at all levels; and observing international (SDGs) and national (PNG Vision 2050) development commitments (NDoE, 2014).

Despite some successes, at present much remains to be done for PNG to realise these commitments and to provide services that live up to national standards of quality, inclusion and safety. Female participation rates, for example, have generally improved; yet barriers to female participation in education are still prevalent in many provinces. Student retention rates remained low, with girls being overrepresented in low transition rates following national examinations. The need to expand the system capacity to cope with rapid population growth, the remoteness of communities, complications in coordination between national and sub-national levels, social complexity, poor sanitation and water services to many schools, gender-based violence, and declining investment in the education sector, is likely to significantly impact the achievement of education and development objectives (NDoE, 2015; UN-PNG, 2018).

Local and grassroots education initiatives, as well as Indigenous peoples' wisdom can, however, provide context-specific and culturally appropriate strategies to achieve educational goals. In chapter 7 I discuss some of these with specific reference to educational and development experiences in ENB.

\subsection{Conclusion}

The work of thinkers, educators, community leaders and scholars across Oceania has questioned the nature and validity of imported educational structures, policy and curricula (Sanga, 2002; Taufe'ulungaki, 2000; T. K. Teaiwa, 2006b; K. H. Thaman, 1995, 1997, 2009b; Van Peer, 2006; Nabobo-Baba, 2013), as well as the cultural coherence and relevance of international development rhetoric and the goals of international aid practice (Coxon \& Tolley, 2005; Gegeo, 1998; Hau'ofa, 1993; Naidu, 
2006; Sanga \& Taylor, 2001; see also the Blue Pacific Narrative, Pacific Islands Forum Secretariat, 2019). These questions reveal strong links and complex interplay between education and development in Oceania, and within PNG, particularly in the relationships between education and aid. The literature demonstrates that Oceanic thinkers have sought to find answers to these questions that honour and reflect the region's rich worlds of praxis, whilst continuing to engage geopolitically, economically and culturally with the rest of the world. It is important to note that this work, whilst transformational across the region, does not necessarily represent the perspectives or priorities of all Oceanic peoples. External notions of economic development and education are and will continue to be important for Oceanic communities; I explore these complex interactions in chapters 5 and 6.

The focus of this study is on participants' theorising and action reshaping the way development and aid, as well as education and learning, are conceptualised and practiced in ENB. They challenge taken-for-granted theoretical and policy formulations and practices, which have historically marginalised their philosophies, beliefs, methodologies and praxis. It also highlights their agency and ability to negotiate local and introduced knowledges and viewpoints whilst advancing a decolonising agenda. This ultimately contributes to a more culturally democratic and nuanced literature that serves to inform and educate scholars, practitioners, government officials, and education authorities about the diversity of philosophies of education and development that exist and thrive in Oceania; and about the effectiveness of placing relationships and relationality at the centre of their praxis.

Although I have attempted in this chapter to comprehensively engage with literature born of Oceania, there remains a call for further exploration into the emerging Indigenous Pacific research literature which is an exciting feature of Pacific research. 


\section{CHAPTER FOUR}

\section{Methodology}

\subsection{Introduction}

This study required me as a researcher to carefully engage with a diversity of knowledges, worldviews and values. To do so, I had to be welcoming and open to new worldviews and knowledge systems. I had to be constantly reflective about, and accountable to, my participants' values as well as my own. These worldviews and values guided a process that could not be framed within Western methodological research practices. Rather they opened methodological possibilities that are grounded in place and context, are built on relationships, are respectful to this study's participants, and hold up to the aspirations and outcomes of this research.

This chapter presents the organised process of inquiry that has guided this research (Williams \& Ormond, 2010). Epistemologies and ontology presented here contextualise the process of qualitative research inquiry, and the final outcomes of this study. This chapter describes how the imperative of a context-specific research process (L. T. Smith, 2012), placed relationality as well as culturally appropriate values and principles of interaction, as the overall research framework for a study conducted in a Melanesian context. Arriving at this framework meant a continuous re-framing of the research process to methodologies, forms of interaction, knowledge systems, values, places, peoples and relationships which cannot fit within Western academic research practices.

My positionality, my cultural background, my worldview, and values, my lived experiences of education and development, and my personal relationships with research participants, made it impossible for me to adhere to conventional Western methodological research framings. I was thus supported, encouraged and inspired 
by various scholars within the university to pursue culturally and place-specific methodological approaches. Importantly, I was guided by my elder and adoptive mother IaIva Magaga to find ways to articulate knowledge that honour my participants and our relationships, as well as their ples, genealogical histories, kinship networks, values and stories.

\subsection{Epistemology and ontology}

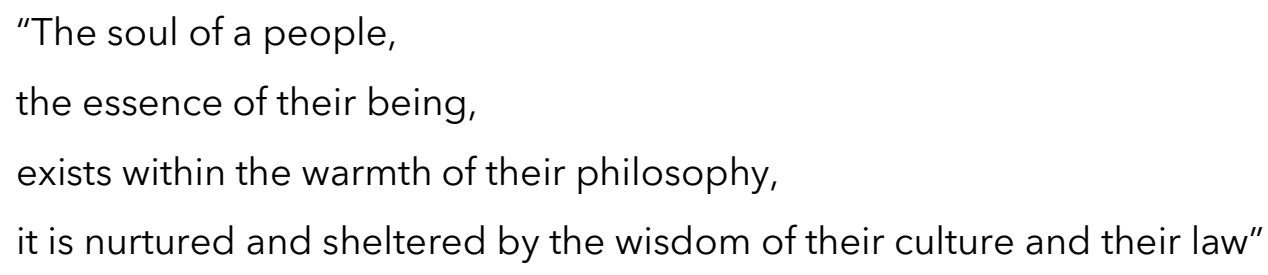

"The soul of a people, the essence of their being, exists within the warmth of their philosophy, it is nurtured and sheltered by the wisdom of their culture and their law"

(Moana Jackson, 1992)

Epistemology is the distinctive way in which people make sense of their world. It represents their interconnectedness with their environment and each other, reflected in their framework of shared understandings about the universe (Mikaere, 2011). The practice of socially constructing Indigenous knowledge is guided by Indigenous epistemology. Indigenous epistemology "refers to a cultural group's way of theorizing knowledge" (Gegeo \& Watson-Gegeo, 2001, p. 55); it is

"a cultural group's way of thinking and of creating and reformulating knowledge using traditional discourses and media of communication (e.g., face-to-face interaction) and anchoring the truth of the discourse in culture"

(Gegeo, 1998, p. 290).

In their writings on Kwara'ae epistemologies, Gegeo and Watson-Gegeo pointed out that "people's practices may to some extent be affected by interactions with other cultures" (2001, p. 59). Nevertheless, the terms of negotiation are very old Indigenous terms, "and testify to the indigeneity of indigenous epistemology" (2001, p. 59). 
They demonstrate the praxis of

"people's own critical reflection on culture, history, knowledge, politics, economic and the sociopolitical contexts in which they are living their lives; and then their taking the next step to act on these critical reflections [...] It flows from and it is rooted in indigenous epistemology. By engaging in indigenous praxis, villagers transform their epistemology and in the process are themselves transformed"

(Gegeo \& Watson-Gegeo, 2001, p. 59).

Narokobi likewise stated that Melanesians have never been slaves to their cultural practices if these become obstructive (1980). An example is the way Gunantuna/Tolai people have adjusted their custom of collecting nassa shells for producing their culturally and spiritually valued tabu or dewarra. Whilst this practice traditionally depends on shell availability in ENB, Gunantuna/Tolai people later decided to accept shells from as far as the Solomon Islands. These shells were not used traditionally, but are nonetheless transformed into tabu through traditional practices (Simet, 1991). This change in practice is grounded in tradition and ples.

Scholarship in the Pacific has historically been undertaken predominantly by Western researchers, whose largely Eurocentric approach has marginalised and devalued Oceanic stories and Indigenous ways of knowing. The intensifying hegemony of this mainstream epistemology is continually challenged by Oceanic peoples who assert the validity of their own ways of knowing, being and doing (Hau'ofa, 1993; Salesa, 2018; T. K. Teaiwa, 1993). As explained by Gegeo and WatsonGegeo:

"This assertion is not happening only among third-world scholars familiar with the challenges to Anglo-European cosmology and epistemology [...]. It is also happening among rural villagers with little or no schooling or awareness of the debates going on internationally in philosophy and the social sciences.

Moreover, the assertion is not only about ethnic identity and revitalizing culture. Villagers are also themselves exploring how they construct knowledge: instead of always being the subject of research by outsiders, which they often see as exploitation, they are undertaking the recording and writing of their own cultures based on their indigenous epistemologies"

(2001, p. 55). 
Linda Tuhiwai Smith's teachings on decolonising methodologies urged researchers to engage culturally appropriate practices, and for the active development of Indigenous peoples as those creating and conducting their own lines of inquiry (2012). Indigenous and anti-colonial thinkers express strong opposition to researchers who assume ownership of Indigenous imagery or ways of knowing, and who deny the people who own and guard that knowledge the opportunity to guide or further their own ideas and research (L. T. Smith, 1999). Meanwhile, a growing number of non-Pacific Islander researchers and practitioners are engaging with the ontologies of Pacific peoples (Crocombe, 1976, 2001; see: Martyn Reynolds, 2019; 2019; 2018; Sandra Tarte, 2014; Randy Thaman, 2009; 1993). They

"have lived in Pacific societies, worked with Pacific Islanders, and have demonstrated deep understanding of Pacific peoples. These non-Pacific Islanders empathise with Pacific peoples, have friends or families that are Pacific Islanders, speak at least one Pacific language, and gladly return to Pacific peoples either for work or holiday"

(Sanga, 2005, p. 16).

Ontologies "are our worldviews, the values that guide us" - I wrote this in a notebook over a decade ago. Ontology is concerned with the process of constructing worlds and weaving a cloak of values to wrap around those worlds. Ontology is a process, through which knowledge is constructed and also validated, shaping thinking and behaviour (Uphoff, 2005). Tok stori, the Melanesian process of storying, can thus be considered a relational ontology (Fasavalu \& Reynolds, 2019; Sanga et al., 2018). Storying contributes to relational closeness, because, as pointed out by Sanga and Reynolds (2019), through story, a shared reality is constructed.

The diversity of perspectives about education and development that I encountered through this study are testaments that knowledge is the product of social construction and placement, rather than 'universal truth'. Epistemological systems are contextual and processual, and are informed by social-political, economic and historical context and processes (Gegeo, 1998). 
Social constructivist thinkers advocate for context-specific epistemological approaches in the worlds of education and development (Kim, 2001; Vygotsky, 1967). Social constructivism in the field of education promotes the concept of the classroom as a community. These education models encourage student and community input, where inclusivity and support are an antidote to the individualistic focus on students' educational underachievement (Vygotsky, 1967). In Oceania these thinkers advocate for education that centres Indigenous ways of learning and thinking about society ( Nabobo-Baba, Naisilisili, Bogitini, Baba, \& Lingam, 2012). In these educational models, Indigenous languages are prioritised, rather than exceptions, and the curriculum and processes of schooling are built upon the principles and knowledge of communities. Language plays a central role in the development of thinking and understanding, as well as in the strategising of teaching and learning ('A M Taufe'ulungaki, 2000). Utilising Indigenous languages in appropriate ways provides Indigenous peoples with expressions of dignity and cultural pride, and facilitates the passing of vital and sacred knowledge from one generation to the next.

\subsection{Indigenous knowledge: values, domains, and knowing your place}

The role of Indigenous knowledge in development, social change and education has gathered increasing attention in recent years. This is especially the case in relation to how Indigenous knowledge is distributed, and ways that Indigenous knowledge systems are being "(re)constituted in a globalised world" (Gegeo \& Watson-Gegeo, 2001, p. 60).

It is important to note that for Indigenous peoples "knowledge itself was never held to be universally available" (L. T. Smith, 1999, p. 172; Whimp, 2008).

Gunantuna/Tolai people, for instance, have detailed systems for maintaining and 
safeguarding public and private domains of knowledge. Ownership of Gunantuna/Tolai knowledge

"is highly regulated, and the ways of acquiring it are clearly defined. Knowledge is owned either by an individual, a group or the wider public and may be protected by means of pidik (secrecy). A particular class of spirits known as turangan are present in the creation, transfer and use of knowledge"

(Simet, 2000, pp. 64-65).

Awareness of and respect to these Gunantuna ples- and people-specific systems of owning and acquiring knowledge help "to refute the assumption that all traditional knowledge is communally owned in Papua New Guinea" (Simet, 2000, p. 64), or that it can simply be made available for outsiders.

Knowledge is precious to the participants in this study; a cultural, spiritual and personal certainty I also share. Whilst writing this thesis, I have uncompromisingly reflected on my positionality, on the associated limits and openings, and the responsibility to respect knowledge that is sacred, secret, or which does not pertain to me. I have thus intentionally left unsaid and unwritten a great deal of knowledge shared with and by participants, as well as the knowledge I have been privileged to learn through my relationships in ENB province.

The act of sharing knowledge is intertwined with the strengthening of relationships. For many Gunantuna/Tolai people, generating and sharing knowledge requires values that are essential for enduring relationships, such as love (waramari) and trust (nurnur); it requires obedience (tinarom) in the labour of learning to listen and decode silences and whispers, hidden and double meanings; and respect (wariru) expressed in knowing what pertains to you and what does not (Tok stori with mum IaIva Magaga, 2016).

Knowing one's place in the generation and sharing of knowledge is essential for what Kabini Sanga calls 'knowledge domains in Melanesian intellectual traditions'. 
At a conference on Oceanic relationalities ${ }^{25}$, Sanga engaged participants in "an ontological exploration of the domains of knowledge in Melanesian intellectual traditions" through tok stori (2018). Here he referred to the 'public' and the 'private' domains of knowledge, the latter containing 'secret' and 'sacred' domains.

Sanga's explanation of Melanesian knowledge domains is an integral part of this research process, as it shares substantial similarities with Gunantuna/Tolai scholars' writings on the topic (e.g. Simet, 2000), as well as accounts by Gunantuna/Tolai participants, especially elders. All agree that maintaining and safeguarding knowledge domains depends on strong cultural values, ontological practices, and strengthening relationships; these all help regulate the access, acquisition, and ownership of individual and collective, as well as public and private knowledges.

Finally, regarding knowledge, mum IaIva Magaga often reminds me that 'sometimes is better not to know, than to know'.

\subsection{Methodology: Qualitative Research}

"Students of the academy must also be students of life

For they are in a particularly privileged place

To observe [...] as our planet and our minds spin through tie and space

(O'Leary, 2017, p. 69)

This is a qualitative research study. Qualitative research methods have changed and evolved over time (Lichtman, 2012; Maxwell, 1992, 2012). Academia has historically been dominated by scientific methods (Lichtman, 2012), and academic debates around process and rigour have sometimes framed quantitative and qualitative methods as oppositional approaches (Della Porta \& Keating, 2008). Like many contemporary scholars, I find this framing simplistic and misguided; quantitative

\footnotetext{
${ }^{25} 46^{\text {th }}$ Annual Conference of the Oceania Comparative and International Education Society (OCIES), I Wellington, 2018.
} 
and qualitative methods are simply different ways of finding out about the world (Brockington \& Sullivan, 2003; Lichtman, 2013).

Qualitative research is fluid, evolving, and ever-changing (Lichtman, 2012), with approaches that resist fixed meanings (Ritzer, Zhao, \& Murphy, 2001) and a wide variety of research techniques (Brockington \& Sullivan, 2003). It does not lend itself to static methodologies, since qualitative research processes cannot necessarily be replicated, developed, upscaled, or designed in advance (Lichtman, 2012; Maxwell, 2012). Despite critiques of the robustness and credibility of qualitative approaches (Merriam, 1998), researchers have established and implemented criteria to effectively conduct, organise, write and evaluate qualitative studies (Creswell \& Miller, 2000; Lichtman, 2012).

This study centres tok stori as the context-specific and culturally appropriate method of research with most participants. It also engages other research techniques including participant observation and semi-structured interviews, both used when contextually appropriate (Maxwell, 2012). Relational positionality is also discussed because its approach to "positionality in relational terms in the context of intercultural spaces" (Fasavalu \& Reynolds, 2019, p. 12) is appropriate to this study. I utilise some principles of constructivist grounded theory (Charmaz, 2014) and informed grounded theory (Thornberg, 2012) for research analysis.

Lastly, the final articulation of the research outcomes is in the form of tok stori itself. This is because, as argued by Fasavalu and Reynolds (2019), although text is commonly presented in written from, "oral performance is text" (p. 14). As a research forum centred in relationally, tok stori can therefore produce "an interactive text focussed on the relational aspects of experience and learning" (p. 14). 


\subsection{Tok Stori as method}

"Tok stori can be understood as a relational ontology (Sanga \& Reynolds, 2019). [...] As a method within that ontology, tok stori affects the kinds of data produced and is helpful in developing data which values the whole person. The tok stori space values vulnerability, emotionality, personal experiences, relational encounters, and narrative intersections"

(Fasavalu \& Reynolds, 2019, p. 14)

This study centres tok stori as method: as the process of storying, of Melanesian relationality in action as research (Sanga et al., 2018). Because the act of storying encourages relational closeness (Sanga \& Reynolds, 2019), it allows for a research process that upholds culturally appropriate values and principles of interaction in the construction of a shared reality. As affirmed by Fenton Lutunatabua, "the courage of Pacific people is in their story!" (2016). Storywork is unembarrassed by the labels 'radical' and 'collective', as it has the potential to produce drastic social change. This is central to this study's decolonising agenda, because as argued by Sanga et al., "advocating for Melanesian methodology as a fit with Melanesian research is an act of decolonisation" (2018, p. 3).

Tok stori is a "form of communication organised around a relational core, [...] the process of tok stori involves interactions - it is about relationships" (Sanga et al., 2018, p. 11). My personal relationships, my work in education in ENB, and the research process of this study have largely involved tok stori as a natural way of being and doing; there are therefore stories, knowledge, events, and situations that have arisen from these relational interactions which I am able to speak about publicly, and others which will remain private.

Negotiating relatedness in an ongoing way is essential to the practice of tok stori. As a relational network in Melanesia, the wantok system reiterates "the ongoing importance of kin and the attached notion of reciprocity" (McLeod, 2008). As explained by Sanga et al. (2018), relationality is vital, and language as tok is a key 
indication of "the kinds of relatedness experienced and obligation due" (p. 7). In some of my interactions in ENB, speaking in a common tok meant that whilst engaging within wantok systems through tok stori, I was also "involved in the creation of a negotiated understanding of the world" (p. 7). Understanding the kind of relatedness and reciprocal obligations I was engaging with is crucial for my practice of tok stori, which is largely guided by my adoptive mother IaIva Magaga, and by other elders, leaders, colleagues, and friends in ENB.

Regarding education and development, I adopt Sanga's idea of "storying as pedagogy" (2017, p. 101), something he has given account of within the Oceanic, particularly Melanesian leadership development context. I believe this contains aspects that are relatable and relevant to the evolution, implementation, and implications of Indigenous-led education initiatives in ENB. Tok stori as pedagogy, Sanga et al. explain, can encompass: friendship as basis for interaction; leadership as a relational activity; inclusiveness; and validation for those whose ontological tradition is generally mediated through storying (2018). Storywork is "a practical research method within learning and teaching processes and is a powerful means to convey, communicate and retain information" (Finau, 2016). Storying thus becomes a process where people's notions of development and education inhabit an antithetical world to "the forced separations" (Sanga, 2017, p. 102) of abstracted theory and lived experience, found in many pedagogical and development approaches.

Tok stori requires group activity which enables the development of knowledge: the creation and continuation of fluid realities. This collective experience as described by Sanga and Reynolds is "the stuff of life in Melanesian societies: this truth is embodied in the everyday nature of tok stori" $(2019$, p. 12). 
Storying is thus a powerful way of sharing knowledge about education and development,

"since it focuses collaboration, cooperative activity, action through talk, innovation through contextual reshaping and construction of new, fluid realities. Tok stori is the Melanesian form of this"

(Sanga et al., 2018, p. 8).

These aspects are recognisable in positive education and development outcomes in ENB, which are discussed in chapter 7 and later fully presented through tok stori as a relationally focused "interactive text" (Fasavalu \& Reynolds, 2019).

Tok stori as method also provides a context-specific and decolonising approach to gendered power relations. It can support knowledge generation that rejects a singular story and rather acknowledges a diversity and complexity of collective and individual stories. For example, it can help acknowledge the positionality and adaptive power of Indigenous women as well as gender non-conforming peoples in Oceania - their centrality and relationality to the construction of kin, family, community, custom, ples, wantok systems, and so on (Fairbairn-Dunlop, 1998; Pollard, 2003; Slatter, 2010). Acknowledging and respecting a complexity and diversity of stories is instrumental in supporting the struggle for gender equality in Oceania, and in the strengthening of feminist discourses, feminist political organising and feminist praxis.

Sanga et al.'s guidance on tok stori is important to this study, because it presents a kind of learning, of knowledge generation and collective action, which based on relationality posits that "storying itself invites listeners to open their worlds to each other and become part of each other stories" (2018, p. 8). This has been on many occasions my personal experience in ENB, and I invite those reading these stories to engage with a sense of commitment. At the heart of tok stori is the "commitment to togetherness manifest through engaging in stori" (p. 8). This 'commitment to togetherness' is ultimately the centre of the process of storying about education and development in this study. 


\subsubsection{The tok stori process and the people storying}

Prior, during, and after tok stori, I was guided by culturally appropriate values and modes of interaction. I followed the guidance of my elder and mum IaIva Magaga regarding when, where, and with whom I could engage in tok stori sessions, particularly when these involved elders in Gelegele-Matalau village ${ }^{26}$, where I live alongside mum and my adoptive family. I engaged in other tok stori sessions with friends and colleagues in the education and development sectors in ENB.

In total I engaged in tok stori with ten participants: two women and three men elders and experts in the education and development sectors; one woman working in civil society and four women educators. Eight participants are Gunantuna/Tolai people. The five Gunantuna/Tolai elders are:

IaIva Peteva Magaga, of Matalau Village, Rabaul District, is a respected elder, and former principal of Malaguna Technical Secondary School, co-creator of a community college which facilitated training of students affected by the $1994 \mathrm{Mt}$ Tavuvur eruptions; as well as the leading facilitator and elder in charge of the ENB homegrown vocational curriculum initiative; with over forty years of leadership in education and vast expertise in community development inside and outside the province.

IaEleonora Varmari Vigil, of Ulaulatava Village, Kokopo District, is a respected elder with over thirty years of leadership experience educating women in ENB in her former role as principal of Our Lady of the Sacred Heart Secondary School, which hosted the creation process of the ENB homegrown vocational curriculum.

Talatala ToMorton Amos, of Matalau Village, Rabaul District, respected elder and wise spiritual leader who has served communities across New Britain island for over thirty years as a minister for the United Church in Papua New Guinea.

\footnotetext{
${ }^{26}$ Gelegele-Matalau is the resettlement village for people from the original Matalau village following Mt Tavurvur volcanic eruptions in 1994.
} 
ToHenry Tavul, from between Kokopo and Vunamame, Kokopo District, is a respected elder, who through his extensive expertise has occupied key leadership positions in education and development inside and outside of ENB and PNG; he is currently the Provincial Advisor of the Division of Commerce and Industry for the ENB Provincial Administration.

ToGideon Turpat, from Matalau Village, is a respected elder who has dedicated over five decades to delivering, improving and leading in education in Matalau Village, and across ENB and PNG. He was also actively involved in the response, evacuation and relocation efforts that followed the volcanic eruptions of 1994.

Other participants who are educators in ENB and were part of tok stori sessions are: Carrie-Anne Karela, her parentage is from Gulf and Oro, grew up in ENB and married into a Gunantuna/Tolai family; Jeddah Violet Gigi, from Tinganavudu Village, and Diana Pakar, from Kokopo District; all are vocational education and training teachers as well as writers, researchers and facilitators for the ENB homegrown curriculum initiative. Roselyn Onesu, from Tamanairik Village, Toma, is an academic educator in ENB.

Another participant is Rela Wawaneya, from Goodenough Island in Milne Bay Province, married into a Gunantuna/Tolai family, has held several leadership positions in the civil society sector in ENB and across PNG, including international development. She is also my sister through adoption.

When introducing each participant through tok stori in this study, I have ensured that their genealogy and kinship networks (through birth and marriage) are present and honoured. Tok stori sessions took place in Gelegele-Matalau village and Kokopo town over two years.

During tok stori sessions, as in my everyday life in ENB, I observed all relevant customary rules, laws and regulations; including obeying koko, the cultural 'do nots' and taboos in Gunantuna/Tolai societies that were taught to me by mum IaIva 
Magaga. All koko are important to relationality, and for the process of storying three koko are particularly relevant. The first, 'koko una tatalikun ba babali tuk aura ngalum, tabum, a patuana ba a melem tara gunan, ba tatikai tara lotu i pitu ba ivatatenu', is central to my relationship with close friends and my adoptive family because it means 'love, respect and obey those who watch over you; love, respect and obey your elders'. The second, 'koko una tata I kun ba tata vakuk', means 'do not speak unless spoken to': when coming together to story we are engaging all our senses, yet to open a way to the deepest knowledge we listen, and for me it is crucial to listening respectfully and responsibly (Atkinson, 2001; Brearley, 2015). The third, 'koko una kari ra langun', means 'do not move the boundary' which reiterates the importance of knowing my place, what pertains to me, and what does not; knowing when I need to back off; and respecting people's ples and ontological boundaries.

My relationships with participants long preceded this study. Their participation in our tok stori was firstly an act of generosity to me of their time, knowledge and trust, which I must reciprocate beyond the limits of this research. Tok stori sessions occurred naturally with participants whom I worked and lived with for several years, because storying has always been our way of personal and professional interaction. Tok stori sessions involved forms of interaction we were all accustomed to, which included: not having a time limit for sessions; conducting sessions at times and in places that my participants chose and where they felt comfortable, such as their own homes, our common friends' homes, and the schools they direct or where they teach. Sometimes we stori amongst our daily activities whilst cooking, doing home chores, looking after children, or working together; particularly with my close teacher friends and colleagues, and with mum IaIva Magaga. There was food involved, because this is a cultural way of relating others across ENB which also resonates with my own cultural and personal practices of interaction. This reminds me of a comment by Unaisi Nabobo-Baba when referring to forming relationships in education and development in Melanesia: "in relating to each other, we need to 
always check the food provided by those who want to be friends" (2018). I shared my own lived experience during our tok stori sessions with constant self-reflection (Pohatu, 2005), whilst respecting Gunantuna/Tolai systems of governance; and whilst observing culturally appropriate ways of interaction which change depending on participants' gender, social-cultural positioning, age, kinship and wantok connections, as well as our personal and professional relationship.

I asked my participants' permission to record our tok stori with the knowledge that our close relationships entail responsibility, reciprocity and mutual trust, and that they could ask me at any time to stop recording parts or the whole process. I decided not to take notes because I did not want to miss any non-verbal communication cues or interrupt the flow of our stori. Nor did I want to miss the names of people in our stori because mum IaIva Magaga always reminds me that for Gunantuna/Tolai peoples, names are crucial to kin, to honouring genealogy and to carrying stories. Non-verbal cues are very important when we are engaged in many activities at the same time, and when using a combination of different languages (Kuanua/Tinata Tuna, Tok Pisin, English), which were either my second, third or fourth language. 'Storying is labour', Kabini Sanga reminded me whilst chairing a 2016 conference session in which I delivered a presentation alongside mum IaIva Magaga. I affirm this to be true after working in education settings in ENB, and through this research where some tok stori sessions might take five or six hours of relational, committed and focused labour for participants and myself. Participants at times prioritised our tok stori sessions, which also required the support of their extended family and institutions to tend to their various village, personal or professional responsibilities. Other times they stayed up late, which made it harder for them the next day with work and home duties. Once, our elder Talatala ToMorton Amos stayed to stori with me and I only knew later that he did not attend one of the days of a funeral in Matalau village; I will always be humbled by this generosity. I became acutely aware of when our elders started to become tired and on occasions I checked with mum 
IaIva Magaga to know when to stop the session. My participants' generous gift of time and effort in our shared labour is precious to me.

When we started storying, participants related their experiences and recalled memories. As our storying continued, they often surprised themselves with all they had done leading and contributing to transformational action in educational and community development spheres, and with their positive impacts on their province and their peoples. For instance, whilst storying with the elder and education leader IaEleonora Vigil she said to me:

"I have been teaching for over 36 years. I have been here in my province, I haven't gone out [...] because of [an] article that was written about us Tolai. We all had broken hearts, [...] and so we just told ourselves: 'let's go back and develop the education system of our province'.

In my husband's place they call me Warmari, and in my village my name is Varmari: 'to make something beautiful'. Warmari is a person with a lot of mercy, I am always proud of both names and I try to live up to them.

I am very proud to share this with you Lorena, tell you stories from my past experience. I only wish that my health could stretch me a little bit more".

(Tok stori with IaEleanora Vigil, 2016)

People from ENB province are nationally and internationally recognised for their leadership roles in politics, education and academia, community and international development, as well as environmental and social movements. Indeed, in-depth expertise and outstanding leadership was evident whilst storying with Gunantuna/Tolai elders and leaders. Participants, particularly elders, are exceptional orators and storytellers. A strong sense of honour and humility accompanied their 
oral tradition, memories, and experiences, especially when they talked about contributing to the wellbeing of their people.

Five tok stori interactive texts corresponding to individual tok stori sessions with five Gunantuna/Tolai elders came from this process. These, alongside tok stori sessions with the other four participants (one group session with three participants, and three individual sessions) also contributed to the curriculum development project story presented in this study.

\subsection{Other contributing methods and the people involved}

\section{Semi-structured interviews}

I engaged in semi-structured interviews with three participants. A mix of tok stori and semi-structured interview was used with one participant, Sevi Kaue from Gulf Province who married into a Gunantuna/Tolai family, is the manager of Kokopo Village Resort, and is also my good friend. We discussed his work in civil society, and storeyed about his family, his life, and our shared experiences working together in education. The other two semi-structured interviews were with: Sophie Marshall, an Australian woman entrepreneur who through her health and wellbeing focused enterprise trained and provided employment to local women, she first studied at a local college to learn locally relevant training methods; Sophie also supported the ENB homegrown curriculum. And Archbishop Francesco Panfilo, from Italy leads the Catholic Archdiocese of Rabaul, has extensive experience in education worldwide and across PNG. Knowledge generated through these semi-structured interviews can be found throughout the thesis, however, they are largely presented in the narrative story of the ENB homegrown curriculum (Appendix 5).

\section{Participant Observation}

Participant observation requires that as a researcher I immerse myself in the place the study is occurring. Brockington and Sullivan (2003) argue that living closely with 
people facilitates empathy with the ways participants look at and interpret the world. Participant observation may help identify and guide relationships with participants, as well as cultural and political parameters; it may also provide time and space for research in culturally relevant settings, using vernacular language and through locally relevant interaction modalities (i.e. tok stori) (Kawulich, 2005; Schensul, Schensul, \& LeCompte, 1999). Prior to assuming my role as researcher, I fully immersed myself in processes of change that led to the development of a grassroots educational project in $\mathrm{ENB}^{27}$. My work on this project was alongside people from public, private and civil society sectors, and was undertaken in subordination to their vision, interests, and goals. My relationships flourished through this work, and I gained knowledge and made observations. Yet although the theory of participatory observation contributed to this study, it was not used as a research framework as it does not accurately represent my situation and positionality. My role as researcher emerged after this other work, and is only one of many facets of my life and relationships in ENB. Most knowledge related to participant observation can be found throughout the narrative story of the ENB homegrown curriculum (Appendix 5).

\subsection{Research analysis}

A constructivist grounded theory (CGT) analytical approach highlights methodological flexibility (Charmaz, 2014, p. 13). CGT emerged from critiques of the grand research metanarratives of science, truth, universality, human nature, and worldviews, and advocates that researchers should interact with data through a process of questioning without presumptions (Charmaz, 2000, 2014). In CGT approaches, data collection and analysis happen simultaneously and inform each other (Ramalho, Adams, Huggard, \& Hoare, 2015). Researchers can combine coding strategies, such as line-by-line codes, with more abstract coding patterns (Corbin \&

\footnotetext{
${ }^{27}$ For more on participatory methodological approaches see: Sara Kindon's (2007) "Participatory action research approaches and methods connecting people, participation, and place".
} 
Strauss, 2014). This can be useful for understanding relational patterns between participants, as well as the relationships between individual experiences and largerscale patterns.

Although CGT as a qualitative method seeks to avoid pre-supposition, it also acknowledges that everyone comes to data with assumptions (Charmaz, 2014, p. 13). Here I follow Fasavalu and Reynolds' guidance on informed grounded theory (IGT) analysis developed by Thornberg (2012), as it acknowledges the advantage of adding sensitising concepts derived from relevant literature to coding as a way to navigate through data (2019, p. 15). Of relevance to this study, IGT is valuable in "research which seeks to understand relationality because it allows a literature-driven relational lens to inform coding as a way of understanding the relational configuration of apparently individual experiences" (Fasavalu \& Reynolds, 2019, p. 15). The literature influencing my analysis centres on: relationality-focused contextualisation of education and development in Oceania (Johansson-Fua, Jesson, Spratt, \& Coxon, 2020; Sanga, Chu, Hall, \& Crowl, 2005); storying as pedagogy (Sanga, 2017); relational positionality (Fasavalu \& Reynolds, 2019); and respecting Melanesian knowledge domains, ontologies and values (Sanga, 2018; Simet, 2000). This literature contributed to identifying sensitising concepts to use in a line-by-line analysis of tok stori performative text as data. These included: identifying public and private (secret/sacred) knowledge domains; relationships (kinship and wantok networks, community economies, and professional connections); agency (motivations, inspirations, and aspirations); ples-based notions of learning and development; and positionality.

These sensitising concepts were ultimately determined by my own lived experiences in ENB and through the teachings of my elder and mum IaIva Magaga. This analytical approach might thus be called 'immanent grounded theory', a term coined by my doctoral supervisor and I (Overton \& De la Torre, 2016), to illustrate how 
these relational positionalities have an immanent overall influence in the design, analysis and outcomes of the research.

Analysis of tok stori text and semi-structured interviews contributes to discussions about the relationship between participants' experiences and global patterns of education and development presented in chapter 7 . This analysis also contributes to constructing the story of a grassroots education initiative in ENB. Post-analysis, however, it was crucial for me to reconstitute the tok stori text data into five tok stori interactive texts, as detailed in the following section.

\subsection{Research outcomes: five tok stori and one story}

\subsubsection{Five tok stori as 'interactive text'}

Tok stori "involves people meeting and storying their experiences as experts in their own lives" (Fasavalu \& Reynolds, 2019, p. 14; Sanga \& Reynolds, 2019). After analysis, I reconstituted tok stori text data to honour its ontological origins. Tok stori in the form of relationally-focused interactive text is a research outcome that validates ontological traditions which are generally mediated through storying (Sanga, 2017), instead of presenting research outcomes merely as findings that are given meaning through academic analysis.

Five tok stori interactive texts in this study present participants' stories and expertise shared during tok stori sessions in a contextualised and ontologically respectful manner. They correspond to five tok stori sessions with Gunantuna/Tolai elders and leaders in education and development: IaIva Peteva Magaga, IaEleanora Varmari Vigil, Talatala ToMorton Amos, ToHenry Tavul, and ToGideon Turpat. The structure for this interactive text presents participants voices on the left of the page slightly indented; and my voice indented to the right of the page. Both are in italic font, so that they are also recognisable when in other parts of the thesis.

Once participants started storying about their lives, their ples, their kinship connections, their relationships and their work, a clear relational weaving began to 
be formed. This weaving revealed the interconnectedness of the participants, some of whom were related through kin; some were each other's teachers and mentors, and later became colleagues in the education sector; some were professionally connected through education and development initiatives, over decades and across generations. What became clear is that each of the participants' stories had in one way or another influenced the others' stories, including my own. Tok stori interactive texts make these relationalities evident and vibrant.

My qualitative research approach is flexible and changes in response to interactions with participants (Brockington \& Sullivan, 2003; Maxwell, 2012). The decision to present these five tok stori interactive texts was influenced by my relationships with, and respect for, these five elders. Once the tok stori interactive texts were completed, I travelled from Aotearoa to meet mum IaIva Magaga in Australia, where we spent many days together reviewing them. She helped me ensure that the tok stori texts respected and upheld public and private knowledge domains, cultural values, social norms, and koko. We met half-way between ENB and Aotearoa because my health was suffering; I had just recovered from being bedbound for two months, so doctors and loved ones alike did not want me moving too much. This was very hard for me, as I had envisioned going back to ENB at that time. Thankfully, upon her return home, mum IaIva Magaga kindly conveyed the progress of this study and my situation to our participants, elders, and extended family.

One night whilst editing this thesis, I kept re-reading the tok stori interactive texts, and repeatedly returning to this methodological chapter. That night mum IaIva Magaga called unexpectedly to tell me she had been thinking of me, and said:

"I can feel that you are sitting there now daughter thinking:

$$
\text { 'is this right?' }
$$

Well, that's not the right question Lorena.

Because these are not your words, these are our words, so they are right. 
Then, tell me who is going to dispute our words?

You didn't take them, you didn't find them in books, they were

given to you, because we see your heart, we see you belong,

and because we want our stories to live on, because our names will traverse the Pacific.

And one day our descendants will find themselves in these pages, in our words, and they will feel proud of our stories, they will feel proud of themselves, because these are also their stories"

(personal communication, 2020).

Her words reaffirmed the decision to present these tok stori interactive texts as the central outcome of this research. Whilst reflecting on what tok stori as research method and outcome brings to this study, I concluded that it was not about what it brought to the research process, but rather that this entire undertaking depended on it.

\subsubsection{A story}

Sister, teachers could together write their own teaching

programme... Marcella says.

"Now that's a big job sister..." I respond.

Marcella and I sit at home one day after school. In front of us, a mountain of books and papers lies heaving with life and possibilities. From deep in the belly of that mountain the stories that started flowing from the mind and heart of a passionate educator Marcella Vovovon marked the origin of an idea with transformational possibilities for the education system in East New Britain Province (ENB), Papua New Guinea. In ENB I have been mentored and inspired by several educators whose vision, dedication and love for the transformational power of education is truly Oceanic. They seamlessly negotiate local and outside knowledge, information and 
demands for education. The teachers I have worked with are magicians. This is the only explanation I could find as to how they manage to teach hundreds of students year after year, with the limited teaching resources available to them and the heavy workload that characterised their every teaching day. All the while also tending to their home, family and village responsibilities.

The 'ENB provincial curriculum development project' story is a narrative story about the collective action and relationalities involved in the making of the first-ofits-kind Indigenous-conceptualised, -created, -led and -implemented vocational curriculum and teaching resources in ENB province.

For this story I engaged in tok stori sessions with four participants: three educators and curriculum writers whom I worked with in the creation of the curriculum; and one participant who worked in the international development sector and whom actively supported this initiative. All four women are my colleagues and close friends; we call each other sisters and one is also my sister through adoption. Just as the strands of a woven basket need one another to become whole and to hold what is contained within, no individual story can be told in isolation. Therefore, three of the tok stori sessions with elders described in the previous section also help construct this story, because these elders are our guides, advisors and leaders in the curriculum development process. Further data for this story came from a combined tok stori and semi-structured interview with one participant, and from semi-structured interviews with two participants. These three participants are from the civil society sector and have either supported or worked closely with us in the project. In telling this story I also wrote about my own relationships and recalled my own experiences and memories about this work.

The final text of this story was examined by mum IaIva Magaga, who is the lead facilitator and elder overseeing this project. She was happy to see that the stories and names of those who worked on and supported the project were honoured. She also reminded me that when referring to Gunantuna/Tolai peoples, I must write their 
family name every time; this honours their cultural values, genealogies and kinship networks.

\subsection{Positionality}

\subsubsection{Relational positionality and insider/outsider view}

Finding literature on positionality that aligned to this research was not easy. In 2019 I came across Fasavalu and Reynolds' (2019) discussions on positionality in relational terms in the context of inter-cultural research spaces. Positionality is relational, multileveled, reciprocal and changes over time (Carling, Erdal, \& Ezzati, 2014). Categorical markers such as gender, race, age, education, profession, as well as a person's inherent characteristics and genealogical history, can construct a researcher's position in participants' worldviews. The category of insider-outsider, for instance, is important in research dynamics where the researcher may or not be seen to 'belong' (Merriam et al., 2001).

Power is negotiated in research dynamics, and researchers can and do exercise agency over their positionality by performing actions and displaying behaviours that are valued by participants, such as respectfully contributing to their communities and following cultural norms (Fasavalu \& Reynolds, 2019, p. 13). Through relational positionality we can consider how a researcher's identity is "shaped by multiple mobile and flexible relations and how that makes a difference to the research process" (Crossa, 2012, p. 110).

Changes in contextual and interpersonal relationships can shift the researcher's positionality, as can interactions between the researcher's multiple identities. Positionality can thus be negotiated not only by the researcher's own agency, but also by other people; all this ultimately influences the researcher's theoretical and methodological approaches. This indicates reciprocity between positionality and all elements of research (Carling et al., 2014). 
Relational positionality is appropriate for research contextualising education and development in Oceania, because it can uphold values of reciprocity and obligation:

"[it] involves understanding position in relation to complex multi-level culturally fluid and diverse communities. In turn, nuanced obligations of relational care are placed on researchers"

(Fasavalu \& Reynolds, 2019, p. 13)

In order to bring attention to relational elements as well as to my own experiences of agency in positionality, I here discuss the insider-outsider category (Carling et al., 2014; Merriam et al., 2001), and then I tell my own personal story through an autoethnographic process (Butz \& Besio, 2009).

Negotiating the positions of 'outsider' and 'insider' is a constant and reflective exercise not only in my role as a researcher but as part of the multiple elements of my identity in an ENB cultural context. These negotiations are guided by (and subject to) relationships, and cultural, political and professional contexts. As researchers, we are positioned by our gender, age, race, life story, and so on, "all of which may inhibit or enable our research in the field" (England, 1994, p. 249). Researchers thus cannot conveniently hide the personal behind the professional, or the relational behind the academic; research can be very personal, and in my case has been intrinsically relational.

Understanding my evolving positionality in the context of this research requires understanding my positionality in ENB before I became a researcher. I was offered this PhD opportunity when I had been in ENB for some time; what a surprise this was to me. I had worked incredibly hard to finish my university degree before leaving for PNG, simultaneously studying full-time and working full-time, sleeping no-time. But I would never have dreamed of being offered this opportunity, because only a decade prior I boarded my first ever plane and arrived in NZ without a word of English. I knew I was stubborn, driven and hardworking, but this made me feel fortunate and valued. 
An important aspect of my positionality early in my life in ENB is that it was strange for me. I was a volunteer with a NZ organisation, but foreign development workers or researchers in PNG are usually of European descent or from Western countries. As a migrant Ecuadorian mestiza woman, I found that most people in ENB had no preconceived notion of 'me' or 'my people'. I felt often that when people knew I was born and raised in a tropical, non-Western country, they were intrigued about my story, and became open and relaxed with me. I recognised many fruits and vegetables in the market, such as varieties of plantain, so I was able to cook my traditional food and swap recipes with local people. Yet one day I was reminded that this market was different to the markets of my childhood, when I was unable to buy one single kaukau (kumara). 'They are only sold by the bunch', I was told by a woman in the market, who looked very worried about me being on my own; after all, why else would you buy only one kaukau?

People in ENB have a long history of Western people in their land: stories of hardship and dispossession, alongside friendship and negotiation. I met many Western people in ENB, and worked alongside some of them. Some showed a great sense of cultural aptitude and respect, and several became my good friends. Yet in many interactions with Western 'expats' - largely working in extractive industries, and even in international development - I found them to be derogatory, racist and patronising towards local people. This was deeply distressing, because it reminded me of Western people speaking like this to me and people like me in Ecuador, in NZ, and in Australia. It was a hugely revealing experience to be in this indeterminate space where for the first time in my life Western people would approach me and feel free to belittle, complain about, and discriminate against local peoples. At one lunch in ENB I was told by a white man, who works in an extractive industry and whom I confronted for flaunting his racism and the damage done to lands and peoples in PNG and Australia, that I should simply shut up; he then said "darling, we are a Western developed country, we know better". 
I am used to confronting people like these. I deploy a calm and composed response to make them stop and think. But year after year it gets harder, because as a woman of colour with an accent when I speak English I am not allowed to raise my voice without looking crazy, or as if I have a chip on my shoulder, and being ridiculed or dismissed. Year after year I am more and more exhausted from the emotional labour that goes into keeping my cool whilst confronting these people. I am tired and I want to scream until there is silence.

I have talked about these experiences with people in ENB, especially those close to me; we compare notes, we laugh, shake our heads, roll our eyes; we are all tired of it. I have learnt the most from Gunantuna/Tolai elders regarding how to deal with these experiences and emotions. However, whilst we may have similar emotions and interactions, I know these are not the same experiences. I have been confronted with challenges in ENB; I have witnessed and been affected by the consequences of corruption, violence, and the mismanagement of development projects.

Nevertheless, in this indeterminate space of my positionality in ENB, my privileges easily eclipse my challenges. I am a tertiary educated woman; I have learned to navigate professional, academic, and cultural contexts in several continents. I have the support and love of many people in all those places, I have countless privileges. Yet my upbringing has taught me to never ever take these for granted.

Today I recognise the greatest of privileges afforded to me: I feel for the first time in my life that I am able to stand up to discrimination, racism and sexism, to corruption and violence, as well as to greedy people and well-intentioned wannabe-saviours, without terror and with the certainty that I will survive them all.

I am an insider and outsider in so many more ways than one. I remember when some Ecuadorian people began entering ENB to operate extractive forestry industries. Someone said to me 'em wantok bilong yu?' (is that your wantok?) and I immediately replied, 'no gat, em no gat wantok bilong me' (no, that's no wantok of mine) because although we might speak the same language, we Ecuadorian people are also 
diverse, and remarkably different in our class divisions. Those in the class I grew up in do not travel to the other side of the world to cut down trees. I felt a sense of dread and shame when I heard that this industry had been dumping sawdust which clogged up coral reefs and people's lungs. Those are not my people.

My positionality in ENB is constantly evolving. I no longer volunteer. I continue supporting work in education, guided by local leaders and elders. I am very close to my adoptive family and to my friends and colleagues. I see them as much as I can, I do as much as I can, whilst negotiating my recovery from illness and now a global pandemic.

My positionality enables me to share some of my experiences from my time in ENB. However, there are knowledges, relationships, meanings and happenings that I am not allowed to share (or feel comfortable sharing), as they are private; they are part of secret and/or sacred knowledge domains and do not pertain to me. I am cognisant of my own restrictions in 'knowing' and 'interacting' in these ontological worlds. Despite time and relationships opening countless doors for interaction and mutual understanding, I was not born in ENB. I have been honoured to share public and private knowledge and spaces of interaction open to women, with elders, and with family following my adoption. Yet my knowledge and understanding of these epistemological and ontological worlds remains limited, and rightly so, because at large they are intended for the Indigenous people of the land and them alone. The secret and sacred domains of our storying, as well as the cultural coding at the core of our relationality, are thus fully and duly respected and upheld in this study.

I remember storying with mum IaIva Magaga and other leaders about the feeling I experience every time I arrive to ENB: 'it feels as if I collect my heart back at Tokua [local airport] and I am able to reconnect to the tropics again'. I am after all a child of the tropics, born directly under the equatorial sun and embraced by the Pacific Ocean. Yet my canoe is not the same as other canoes in the Pacific; mine is made of different wood, by different hands, under different skies. I know my canoe is welcomed to 
rest in the shores of these islands, where it is firmly and safely anchored to the land and to its people. Yet when navigating in the depths of its surrounding seas, the wood that my canoe is made of might sometimes be too heavy or too light for the currents. The hands that made it and those that continue to chisel it into shape will undeniably take me on different voyages; sometimes leaving me stranded in the middle of the ocean, sometimes taking me safely back to shore. My oaga, waka, vaka, nuca kanuwa, mi canoa, my canoe, navigates as many seas as the languages I use to refer to it. It contains the knowledge and memories of many homes and of many tongues, yet it cannot contain them all. It is a small canoe, yet it navigates big seas, and what it contains, although might seem small, is precious. It contains all my relationships as lashings, as sails, as food, and as guiding constellations.

Undeniably, the biggest of oceans my canoe has navigated, is Oceania. A place 'so vast, so varied' that even after half my life here, I can confidently say I will never even begin to grasp it. To present any of the knowledge generated by this study as the fruits of "detached/objective analysis" (Wendt, 1982, p. 49) would be a feat of immeasurable arrogance. As we all well know, arrogance is the dazzling, alluring monster that sinks our canoes at sea. In agreement with Albert Wendt who, in his 1982 chapter 'Towards a New Oceania', addressed academic objectivity as a narrow and impersonal vision, neither my own story nor my relationships and obligations to ENB and my participants, will allow me the indulgence of academic arrogance nor the confinement of a narrow vision.

\subsubsection{My story}

Qualitative tok stori research requires the researcher to actively participate in a relational knowledge generation process. My positionality and relationships with participants are essential to this research. My birthplace, cultural background, gender identification, age, personal and professional histories, and relationships help illustrate my positionality and ontology. 
This study's storying process demanded deep engagement and reflection on my own story. This autoethnographic process helped me to "scrutinize, publicize, and reflexively rework [...] self-understandings as a way to shape understandings of and in the wider world" (Butz \& Besio, 2009, p. 1660). Over the years of this research my attempt to describe my positionality evolved into the reclamation of my narrative; a process both gruelling and empowering that precedes and continues after this study. Reflecting on my positionality led itself into a poem to my grandparents, and to their place on the slopes of Ruku Pichincha. For the English translation see Appendix 4.

\section{Los colibríes de tu jardín}

Acostada a la sombra de tus rosales, entre dormida y despierta, el sol filtrándose entre pétalos rojos, amarillos y tomates me despertaban los colibríes de tu jardín.

A mi alrededor flotaban sin esfuerzo, revoloteando de flor en flor, envueltos en la suma del color de tus rosas, así como un atardecer, a pesar de que era tan solo medio día. Volando, sus alas imperceptibles, rápidas, sus cuerpos pequeños, coloridos, casi inaudibles.

Tanta gracia y delicadeza.

Pero cuando los colibríes me despertaban, por menos de un segundo yo escuchaba sus aleteos, yo podía ver sus alas.

Cuánto movimiento, cuánto esfuerzo disfrazados de inercia.

Yo, tu nieta, a la que la abuelita llamaba colorada, una niña chiquitita acostada debajo de tus rosales pensaba solamente que el rojo era rojo, el amarillo era amarillo, el tomate era tomate, y que esos colores juntos a la luz del sol urdían el atardecer.

Allí, de pequeñita y en tu jardín fue el último lugar en el cual recuerdo existir sin lucha.

Tú, abuelito con tus manos diestras me regalaste el atardecer al medio día, y con cada nota de tu charango me pintaste el alma.

Pero los colibríes de tu jardín me ofrecieron algo más: una visión que va más allá de esa imagen delicada, colorida, inaudible, casi inmóvil, una realidad hecha de miles de aleteos por segundo una nueva forma de entender nuestra existencia. 
Y así yo curiosa, siempre preguntando lo que nadie quería o podía contestar,

les pregunté a tus rosas si se llevarían el atardecer a cambio de que el tiempo pasara más lento.

Porque yo, abuelito, yo quería verles las alas a los colibríes.

Y entonces desde ese día ya no me acosté a la sombra de tus rosales,

y perdí el atardecer al medio día,

y ya no pude vivir sin lucha o sin preguntas.

Y pregunté, pregunté todo y a todos.

Le pregunté al rojo porqué estaba detrás de las costras que no debía rascarme, pero también en las banderas de las plazas.

Le pregunté al amarillo porqué estaba altísimo en el cielo, pero también cubría catedrales y a hombres barbudos hechos monumentos.

Le pregunté al tomate porque estaba en el aceite de achiote y en la papaya, pero poco a poco fue despareciendo de nuestra mesa.

Y así curiosa crecí más y más confundida,

porque los signos de interrogación crecían como kikuyo dentro de mis venas,

y las respuestas dolían como la punta de la guadaña.

Porque los colibríes así en cámara lenta ya no eran tan delicados:

los colibríes eran ruidosos, apurados e incansables,

llenos de contradicciones e incertidumbres,

inquebrantables.

Y así curiosa dejé tu jardín y perseguí a esos colibríes a los altos páramos.

Allí, cansada, me recosté en la paja larga,

cuando abrí los ojos ya no eran rosales, sino cielos azulísimos

y el sol quemaba así, exactamente como debe quemar al medio día.

Allí, en ese silencio ancestral, el aleteo de los colibríes sonaba como relámpago,

cada aleteo resonando como pregunta propia

hasta que ya no pude conciliar el sueño.

Y así entendí que no hay silencio sin relámpago

no hay delicadeza sin movimiento

no hay gracia sin preguntas

no hay rosas sin cielo

no hay atardecer sin medio día

no hay descanso sin lucha.

Al tener que dejar el jardín de tu casa a las faldas del Ruku Pichincha

yo perdí el refugio de tus rosales, perdí la calma, la niñez sin esfuerzo.

Pero entre tu casa y el páramo

aprendí que dentro de mí nunca habitó el silencio,

entre tu casa y el páramo

aprendí que estoy llena de preguntas

y que no puedo encontrar calma sin respuestas.

Entre tu casa y el páramo

aprendí que estoy hecha de sangre y de sol. 
Entre tu casa y el páramo aprendí

que en mí se anidan los colores del colibrí y los de la rosa.

Y ahora aquí con los pies cubiertos de arena al otro lado de nuestro océano,

después de andar de balsa en balsa siguiendo corrientes

a lugares donde también crece el camote bajo el destello de las mismas nueve estrellas,

lugares donde también hay historias de grandes veleros y de rondadores;

aquí, con las alas cansadas de tanto aleteo,

la piel quemada alrededor de las costras,

el alma aún más colorada, la visión todavía en cámara lenta,

y fundamentalmente con muchas más preguntas que respuestas:

pre(siento) que algo de mí sabe a mar,

que en mí crece la paja de páramo y crece el kikuyo,

pero que también en mí habita la guadaña.

(la autora/the author)

I (she/her) was born in Quito, in the Andes of Ecuador, nestled high between the clouds, in the place they call the country of hummingbirds. I grew up under scorching equatorial sun; blemishes in my eyes mark its power. Giants wrapped in long white cloaks sit side by side, telling stories, watching us grow at their feet: each of them an eternal snow-covered volcano in the Andes ranges. These mountains and valleys hold countless stories extending over epochs; they precede and embrace our human stories, my own only one of them. My story is made of all that grows in these mountains and valleys and all I learned from its surrounding ocean. My story is also made of stories from many who came before me; their love, struggle, peace, despair, fight and loss.

At a very young age, at home and at school, I realised that many stories that made 'me' and 'us' were hidden, quietened, distorted. Home was a solitary place, away from our extended family where both our parents worked long hours to make ends meet. I am one of three daughters. My maternal grandparents are Teresa Viteri and Ariolfo Parra; Maria is their daughter. My paternal grandparents are Herminia Rocha and Luis de la Torre; Jaime is their son. I have 16 aunties and uncles and an ever-growing number of cousins, their children, and their children's children. 
I grew up in Valle de los Chillos, a vast, green and silent valley. In this quiet I did my homework, submerged myself in books, played old vinyl records and listened to the one 'radical' radio station. I learned vastly different stories from school, books, home, friends, the market, the streets and the radio, which often contradicted each other. As I filled silence with questions, I uncovered persistent injustice and imbalance in my country's education system.

My education focused on the terrifying pressure to perform. I excelled at subjects that never answered my questions. The more I learned history, literature, science and geography, the more gaps and dead ends I encountered. I grew up where Indigenous peoples, cultural practices, languages, knowledge and places were strong, part of my own practices and at the forefront of political, economic and cultural change. Yet history class taught me that our Indigenous peoples, cultures and lands belonged to 'pre-historic' or 'pre-hispanic' history. Every book and lesson used these terms interchangeably to claim that colonial Spanish invasion marked the 'true' start of 'history'.

It will always affect me that our schools celebrated Columbus, bringer of genocide and false sovereignty over Indigenous peoples and places under the doctrine of discovery, year after year on 12 October, without fail. This is 'The Day of the Race', when primary school children dressed in Spanish military uniforms carry the imperial flag and pose for photos with other children dressed in ad hoc imitations of Indigenous clothing. One year, however, some teachers changed the script. They asked us girls to perform a play about an event, when sacred Indigenous women called acllas (the 'chosen ones', the 'virgins of the sun') were killed by their own people, after realising these women could not be protected from the colonial invasion. In my white dress with a big golden sun painted on my chest and another cardboard one above my head, I played along at dying in terror and in kindness. This simple act of defiance had a deep influence on me and my educational journey. Lying on the grass playing dead, I asked myself: where were the stories of the 
Indigenous women we portrayed? This day I also asked myself what it meant to be mestiza; a question that no one could answer and overwhelmed me as a girl. Today some insights grow alongside more questions.

I did not learn the histories of Caras, Quitus or other Indigenous peoples living where I grew up before the Inca Empire. We simply recited Indigenous groups' names and saw a few pictures. Most teachers superficially engaged with colonisation and we students spent years learning about the achievements of colonisers and postindependence mestizo elites, who once in power used legislative and religious tools to oppress and stratify as well. I memorised the name of every Spanish 'conquistador' that ever 'founded' a town or city. I seldom heard the names of Indigenous leaders, other than to say they largely perished or surrendered during colonisation. We did not learn that many were sentenced to death after refusing to convert to Catholicism, or that the Catholic church was so intertwined with state powers that national constitution after constitution bore its mandates, classifying Indigenous and Afro-Ecuadorean peoples as non-human and later as inferior; needing 'civilisation', salvation and assimilation.

Since colonisation many mestizos and mestizas, including women and men of faith, joined independence struggles and fought alongside Indigenous and AfroEcuadorian leaders for social and environmental justice. Nonetheless, mestizaje history goes beyond mixing races, cultures and causes. From the 1920s onwards, the mestizaje or mulataje programme consolidated assimilationist and monoculturalist rhetoric into policy in order to neutralize cultural and racial pluralism - regarded by political elites as counterproductive to the nation-state project (Martínez-Echazábal, 1998). While today's national constitution recognises a plurinational and pluricultural state under buen vivir development, in practice it is far from truly honouring Ecuador's 14 nations and Indigenous development concepts (Dávalos, 2009; Walsh, 2010). 
It still baffles me that students, daughters and sons, were expected to be proud of men who steal and exploit these lands, dispossessing Indigenous and marginalised peoples. We were made to celebrate them; to kneel in churches and never ask questions. I asked, why would they not allow Indigenous elders to sit in the front rows at church?, why only silence after my school's priest was jailed for molesting children? I was told to keep quiet, and never got answers.

School subjects defeated, annihilated and erased Indigenous places, stories and knowledge from our collective memory. Afro-Ecuadorian histories were an appendix teachers could choose to ignore. Apart from a few great teachers, education delivery overlooked millennia of Indigenous and Afro-Ecuadorian histories and bolstered stories from translated European and US textbooks. This system was one of many legacies of centuries of colonisation and neoliberalisation.

Today, over three decades later I recall my discomfort and reluctance as a girl to view Columbus and his mob of 'conquistadores', or leaders and literary characters from faraway places, or the national political and military elites, as role models. As a young mestiza I needed to learn mestiza stories, and of Indigenous and AfroEcuadorian women. I needed female role models that walked the same lands as me, who confronted patriarchal, sexist, racist and classist social-political and educational systems. I needed to learn about the centrality of Indigenous women in transforming and oftentimes tearing down those systems. I needed to learn what made our mestiza, Indigenous, Afro-Ecuadorian and diaspora women lived realities profoundly different to each other, and sometimes similar.

I will never forget the 1990s and 2000s. Ecuador's brutal financial crisis in the late 1990s was the worst recorded in its history, with hyperinflation, the US dollar adopted as national currency, and private bank accounts frozen and seized as the government ran out of funds (Ayala Salcedo \& Ruiz Guaricela, 2009). While this is not even a footnote in global 'history', for us growing up amidst the resulting widespread social-economic and political instability, it defined much of our stories. 
Two thirds of our people plunged into poverty, children living in poverty went from $37 \%$ to $75 \%$, and the impacts were worst on rural peoples (Ayala Mora, 2002).

Our teachers left classrooms to go to war and the government declared national states of emergency. I will never forget our colourful currency buying us less and less in the market; later replaced by foreign bills and empty food baskets. The desperation in my parents faces after realising all what little they had was lost. The chaos growing around and inside me. The mass migration of friends and family to the US, Spain and Italy. The military coups, the string of presidents, the many protests on the streets, the activism and leadership of Indigenous peoples and organisations.

Amidst these crises I found parts of the hidden history of my country; stories of resistance and hope. Stories not about, but by Indigenous leaders, and by Indigenous and mestiza women challenging unjust educational, political and economic systems. These systems have deeply divided us and pitched us against one another in the fight for one of the very limited chances of something resembling a future. Systems that have systematically pulled our roots so violently that our genealogies and sense of place have become blurred and silenced. Generation after generation, the time our parents spend struggling, surviving and trying to fit at the very thin edges of these systems, leaves them with no time, nor energy to share the sometimes very limited knowledge they might have about our stories and our ancestors. Time for our parents becomes the understandable denial to look back at a devastating past, a terrifying vision of future, and the emptiness of hope, food, land and opportunity. So, whilst our parents grow worried, lines grow as crevasses and wound their foreheads, their desperation and anger also grow and wound us; we all grow hungrier, more confused, and alongside their debts and sometimes their violence, in time, we grow apart.

In order to learn more about the hidden history of Ecuador I worked to support myself and attend a university with a record of supporting social justice. I learned 
from and participated in campesino- and Indigenous-led activism. I learned from Indigenous women such as Dolores Cacuango Quilo, who established the first intercultural and bilingual schools to revitalise Indigenous languages, science, knowledge and traditions, and Rosa Elena Tránsito Amaguaña Alba who led political organisations fighting for the rights of Indigenous and marginalised peoples. I learned the stories of mestiza women such as Luisa Gómez de la Torre Páez who supported transformational changes in education, politics and gender equality. I learned from the stories of Indigenous, Afro-Ecuadorian and mestiza women working for the protection of Mother Earth and for the wellbeing of their communities across the country.

These stories helped me fight and taught me to learn what was behind our deeply divided society, behind our struggle to put food on the table, behind the exodus of millions of our people, behind the violent rupture of our families, behind the loss of sanity, hope and sense of future. They helped me to survive the violence inflicted on me by a man that threatened and then physically attempted to take my life when I wanted to end a relationship at only 18 years old. They helped me to survive the impacts of rape by another man known to me, and years of sexual harassment, fear, and demeaning treatment as a woman. To have the courage to remove myself from violence and to reclaim the narrative of my own story.

Reclaiming my narrative also means critically reflecting on my place in the world as a mestiza woman of the Ecuadorian highlands. I am distilled from many vines into an essence created and recreated over hundreds of years, throughout hundreds of generations. I carry deep ancestral memory of centuries of intergenerational trauma; genocide, dispossession, rape and colonisation - but also resistance, power and agency. I carry ancestral memory of millennia-long stories carved into these lands, seas and oral histories; those resisting, those struggling to find their place, and invaders and perpetrators. 
Among my confusion, alienation and fear I also carry the knowledge that survived, the courage that escaped, and the strength that shielded a fire stoked by generations before me. This fire continues to inspire our minds and fuels our bellies towards social, educational and environmental justice in Ecuador, in Latin America, in Oceania and across the world. The heat of this fire feels familiar to me; perhaps it is the closest I feel to understanding and explaining my sense of place as a young woman. Amid external turmoil, internal chaos born of violence, and the complexities of migrating to the other side of the Pacific Ocean, this fire felt like home, purpose and lifeline.

Through my relationships I learned that my story is also made of waters I traverse, that wash and embrace me, and of lands that hold and sustain me. I learned we are ultimately made of places and stories laced together by our relationships.

Reclaiming my story happens gradually with deepening relationships and connection to places. While every relationship in my life is of importance, for this writing I must focus on a few people who have transformed my sense of place and educational journey.

Paulina Moscoso Ochoa, my cousin and mother figure, is crucial to this story. She used to take me around the Pacific coastal countryside when I was young, encouraging my love for the ocean, and teaching me to be strong, capable and kind. She also taught me how to cook rice and patacones; very precious gifts for an Ecuadorian girl.

In the mid-2000s I boarded a plane for the first time and crossed the Pacific Ocean, arriving in Rotorua, Aotearoa. This ocean has inspired me since I was a young girl; an ocean of islands calling me that I remember painting using my mother's blue eyeshadow, tracing contours with my fingertips. I heard stories about people from these islands coming to our side of the ocean, and read all I could find about its peoples and their places. In Rotorua, without a word of English, I found 
myself unable to comprehend the language, the silence on the streets, or the cold depth of winter. I discovered the joys of changing seasons and that they called diaspora women like me 'Latina'. I met Gale Willcocks (nee Hart) who became a mother to me and showed me the beauty of Aotearoa's bush and my friend Deanna Harris (nee Walmsley) who supported my journey from cultural shock to understanding. They all supported me in my dream to go back to university.

In 2010 I moved to Wellington to attend Victoria University of Wellington (VUW). I missed the strong Māori cultural presence and daily use of reo Māori I was so used to in Rotorua. Whilst working full time I completed a Bachelor of Science degree as well as a postgraduate diploma in Development Studies in 2013. I went on to teaching and mentoring in undergraduate, postgraduate and masters programmes. I was privileged to build relationships with and learn from remarkable Pasifika, Māori and Pākeha academics and classmates. Their teachings and stories influenced my personal, educational and professional life. I was fortunate to meet Geoff Whittle, whose unwavering friendship has taught me much about peaceful courage and honouring one's story.

In 2014 I returned to the tropics, different from my own yet familiar and welcoming. In PNG I volunteered in a remote vocational centre for young women, later working alongside the ENB Provincial Division of Education, where I built strong relationships with local leaders, elders and communities. Their educators became my close friends whilst collaborating on locally led vocational curriculum, centering Indigenous knowledge, science and traditions in the content and delivery of education.

Here I started working alongside IaIva Peteva Magaga, educational expert and head of Malaguna Technical Secondary School in Rabaul. She is the elder who guided this curriculum's development, launched in 2017. Working beside her and under her guidance consolidated our strong relationship and with her extended family in Matalau and Gelegele-Matalau. In 2017, I was deeply honoured to be adopted by 
mum IaIva Magaga and the Marmar28 parpar.29 Respected elders and men masterfully prepared wheels of tabu for my adoption, given to me in ceremony alongside mum's tabu and family and clan members' tabu, baskets, bilums, cash and other gifts. We all shared food, told stories and celebrated.

Mum IaIva Magaga's late parents are ToPeter Teu Puang and IaPirida Palum, her late husband is ToBlasius Magaga. Her children and my tambu brothers and tambu sisters are ToRobert Magaga a highly qualified engineer and dedicated son and older brother; ToBlasius Magaga married to my tambu sister and colleague IaJanet Magaga, and IaPauline Magaga all three are involved in the provincial education sector; ToPeter Teu Magaga holds a science degree and works in education at the national level in Port Moresby; and IaGrace Magaga will soon graduate from secondary school an expert in science and languages. I am close to my adopted tambu sister IaRela Wawaneya and auntie IaJackie Ezekia and her husband uncle Ezekia, who run an elementary school in Gelegele-Matalau; to auntie IaMatalau, auntie IaRachel who live in the land of origin Matalau village, and auntie IaLavinia in Australia. In Gelegele-Matalau I was honoured to meet Talatala ToMorton Amos and ToGideon Turpat, both highly respected elders across the province and country. All of them hold precious knowledge of their place and people, all speak an average of three to four languages with respective dialectic variations, all have been generous, welcoming, and patient with me learning Tinata Tuna/Kuanua language. Mum's vunatarai is Kamrai Label and the roots of mum's ancestors are Siar, Namatanai District, New Ireland Province. Matalau village is the land cleared and occupied by mum IaIva Magaga's ancestors. Gelegele-Matalau is the resettlement area following the 1994 Mount Tavurvur volcanic eruption.

\footnotetext{
${ }^{28}$ Gunantuna/Tolai people have two parpar: the Pikalaba and Marmar, or Taragau and Minigulai, after two kinds of sea eagles or hawks, or Makadao and Kubar/Ngenge after two kinds of coconut (Tateyama, 2006).

${ }^{29}$ Papar: Marmar is one of the two matri-moieties or parpar, meaning 'half'.
} 
These relationships transformed my story, teaching me new depths of unconditional love for people, place and knowledge. My relationship with IaIva Magaga, her place and people, carries enormous privileges and responsibilities. Thus, it is important to honour mum IaIva Magaga's genealogical histories here. She expands on her histories later in this study. Her wisdom, support and love inspired my work in ENB, these pages, and reach every corner of my life.

I am woven by relationships and places. I knew early on that I wanted to challenge the social-economic and political struggles that impact my life and the lives of people in the places I call home. Building this life brings strong relationships, joyfulness, resilience, opportunities, privileges and challenges. Many have kindly opened their homes and arms to me. In 2018 back in Aotearoa, a decade long chronic pain condition I had ignored incapacitated me, stopping my work for ENB and my PhD. While bedbound my late grandparents appeared in my dreams and mum Ia Iva Magaga on the phone. My partner James Tremlett lovingly cared for me and my chosen and found family in Aotearoa surrounded me with care throughout those months.

There, in that deep silence, in that enforced reflection and stillness, I finally learned that the stories of us women are not only that of survival and fight; they are also filled with softness, vulnerability, compassion, silence and stillness. We are not made of hope alone-we are made of stories to be lived. I learned that throughout our lives, our stories will sometimes be woven tightly and sometimes softly. That we women are not only warriors and leaders, we are also poets, gardeners, lovers, mothers, daughters, granddaughters, creators and holders of stories and of places. In that renewed relationship with self, I gained a renewed sense of courage. The courage to reclaim this, my story. 


\subsection{Ethics}

This research received Human Ethics Committee approval and abided by VUW Human Ethics Policy throughout the research process. The University expects the protection of the safety, health and welfare, as well as the privacy and cultural sensitivities, of participants. Power dynamics between researcher and participants require ethical and responsible interactions. In accordance with these requirements, participants' confidentiality and anonymity have been observed when required. An information sheet was provided to participants with the purpose of the research and a consent form to sign prior to our tok stori sessions and semi-structured interviews (Appendices 1 and 2). My relationship with all participants allowed us to have proper conversations about the research aims, and why their expertise and support were important and valued. On some occasions mum IaIva Magaga discussed with elders in Gelegele-Matalau village before I was allowed to tok stori with them. They then all confirmed their willingness to take part in the research. We started by talking about our work or lived experiences together, and about my journey and motivation towards gaining a PhD. For them it was a privilege they were affording to me, and they made clear that my responsibility to write these stories came with obligations to honour and make them (and all their kin) proud.

I began every tok stori session and semi-structured interview by respecting participants' choice of time (when will it eventuate), place (quality of space), and situation (co-creating and holding safe space). Although I had a series of lines of inquiry at hand, I did not use them during tok stori sessions; this would have felt artificial and counterproductive. Rather I participated in a process of storying that opened a comfortable and cyclical space to reveal, negotiate, validate and reaffirm knowledge. During semi-structured interviews I referred to prepared questions, when it suited interaction with participants.

Initially I struggled with the disconnection I felt between the human ethics process and my research methodology and topic. I found however that there were aligning 
principles between the way I conduct research and VUW's Te Tiriti o Waitangi policy. I have seen the tokenistic approach to Te Tiriti across many sectors in NZ, so I wanted my research to be more than a tick-box exercise to comply with institutional requirements. Te Tiriti must be honoured, not simply complied with. Te Tiriti demands taking an honest look at ourselves. As a mestiza woman of the Andes of Ecuador, self-reflection within inter-cultural relationships is central to my worldview and lived experience. As a migrant woman of colour who has made Aotearoa my home, I constantly reflect on the privileges and responsibilities associated with being tangata tiriti: living on the lands of, and in relationship with, tangata whenua. I respond to these by upholding principles of respect, humility, generosity, accountability, trust and reciprocity. Centring Te Tiriti makes us more conscious and reflective about our relationships across Oceania. My ability to form genuine and lasting relationships with Oceanic peoples has been informed by my understanding of Tiriti-based rights, obligations and reciprocity here in Aotearoa. It is also shaped by whakapapa connections between Māori and Pacific peoples that far pre-date Te Tiriti o Waitangi, and which extend to my own people on the other side of our shared ocean.

As a researcher in Oceania I must thus respect local systems of governance, Indigenous values, cultural norms and regulations, as well as kinship networks and genealogical histories. I must know what pertains to me and what does not. In every role I occupy in ENB I must ensure the careful maintenance of relationships and obligations due. An ethics process is not just a formal requirement but is integral to every aspect of this research.

Some of the elders reminded me of two things recently: one, that when I receive this degree I will be collecting it on their behalf; and two, that the stories that belong to them will return to them, to their homes, libraries and descendants. I knew then that this ethical obligation not only strengthens but surpasses any formal ethics process. 


\subsection{Conclusion}

Piecing together a methodology appropriate to this research was no easy task. Once I recognised that relationality was both the focus and the framework, however, then the methodological pieces came together effortlessly. Upholding ples and the cultural values of participants was central to choosing context-specific methodology. Tok stori provides academia with "opportunities for researchers and others to follow a relational path in their investigations, one which recognises the connectedness of humanity" (Sanga et al., 2018, p. 5). As a relational forum tok stori validates ontological practices that are usually negotiated through storying, and is thus entirely appropriate to this research.

This study reflects the coming together of multiple freedoms, opportunities, limitations and experiences: that of participants, of myself as researcher and in multiple other roles, and of our reciprocal relationships. My relationships with participants are long held, multifaceted, closely bounded, based on trust and a shared history. Tok stori as a method required that as a researcher I assume this process as labour: engaging responsibly with participants, constantly reflecting on the intent of the work, and being self-reflective about the relational nature of my own positionality. This was reflected in following elders' guidance and drawing on personal relationships for participants selection; undertaking tok stori sessions without time limits and in places of participants' choosing; and conducting semistructured interviews when ontologically appropriate. It was also reflected in the analysis of tok stori performative text which focused on upholding private and public knowledge domains; and in the final presentation of tok stori as interactive text, as a way of honouring participants' relationalities, epistemologies and genealogies. 


\section{Theories of development, gender and}

\section{the role of education}

\subsection{Introduction}

Having placed the research in Oceania, I now broaden the scope and discuss different notions of development. I highlight the role of education, and reflect on Indigenous perspectives, diverse community economies, diverse education, and feminist viewpoints, mainly from Oceania. I comprehensively analyse the intersection of gender, education and development, and prioritise Oceanic and Indigenous feminisms.

This chapter lays the ground for chapter 6, which deals with how global discourses, theories and policies of education are influenced by different notions and international policies of development.

\subsection{Thinking about development: notions of development and the role of education}

I have said this to you, and this is from my heart: our Melanesian societies do not have room for poverty.

Poverty was something that was brought in. Melanesian societies historically, we were people that took care of ourselves, of our relatives, and fellow travelling men.

There is always somebody, you were not to be begging on the streets, you are supposed to be looked after by your relatives.

They are always there, there is land.

(Tok stori with ToHenry Tavul, 2016)

Notions of what development means and does not mean are disputed, contradictory, chaotic, undefined and ever-changing. Nonetheless particular notions of 
development, and their theoretical, discursive and applied features, exert powerful influence throughout the world. They are also closely tied to education, which has been and is central to the theories and practices of development.

It has been argued "that 'development' is a cultural construct - a set of organising assumptions through which we order the world and understand our place in it" (Bulloch, 2014, p. 177). This line of reasoning is critically important for appreciating the lived realities of colonised and Indigenous peoples worldwide, whose own multiple notions of development often reject singular understandings (U. Kothari, 2019). Walsh (2010), for instance, conveyed that for many Andean Indigenous peoples,

"the very idea of development itself is a concept and word that does not exist in the cosmovisions, conceptual categories, and languages of indigenous communities"

This 'very idea of development' is a paradigm centred on furthering the human condition, correlated with principles of 'progress' and 'living better' (2010). The underlying principles informing the ideas and practices of many contemporary development theorists, policy-makers and practitioners largely originate from Western metropolitan worldviews; these have framed the world in ways which compel the peoples of the Global South to be measured, and to measure themselves, against Western models of progress (Bulloch, 2014, 2017). This situates humanity within lineal notions of civilisation and progress, entangling ideas of modernity together with its underside: coloniality. Such a framework is antithetical to the cosmovision, philosophy and structure of life of many Indigenous peoples, who "denote, organize, and construct systems of knowledge and living based on the communion of humans and nature and on the spatial-temporal-harmonious totality of existence. That is, on the necessary interrelation of beings, knowledges, logics, and rationalities of thought, action, existence, and living"

(Walsh, 2010). 
By tracing the genealogy and trajectory of development thinking to some of its Western origins, this chapter also prompts reflection on the work of thinkers who address the culturally constructed and historically specific nature of concepts and practices of development (Bulloch, 2014; Cowen \& Shenton, 1996; Crush, 1995; Escobar, 1995; Rist \& Camiller, 2014; Sachs, 1992).

Development as an idea, framework and goal is complex, multi-layered, and continues to be debated. Below is a brief overview of global development theory that provides some theoretical background to the context of this research. I look at these theories in turn, and then turn to the role of education in each body of thought.

A brief section on Indigenous epistemologies and development opens this dialogue, with the aim of establishing Indigenous knowledge, scholarship and practice as central to analysing global notions, practices and impacts of development. This aim is reflected in the practice and process of this study.

\subsubsection{Indigenous epistemologies and development}

Many Indigenous thinkers, scholars and practitioners have rejected attempts at universalising development discourses (Fairbairn-Dunlop, 2005; Gegeo, 2001a; Sanga, 2020; 2001; T. K. Teaiwa, 2006b; K. H. Thaman, 1997). As explained by Gegeo (1998, 2001a), Indigenous peoples' exchanges, learning, rejections, negotiations, changes, and decisions in the past, present and future, are all situated and generated within Indigenous cultural perspectives, practices and languages.

Gegeo's writings on development and Indigenous epistemologies refer to millennialong complex and diverse scenarios where Indigenous peoples deploy both introduced and local knowledge towards positive change and the continuation of life, with various effects on their knowledge systems and practices (1998, p. 291). These scenarios have occurred for a long time prior to the advent of 'development'. 
Scholarship on development and education by Indigenous people, mainly from Oceania, is central to this study. This scholarship shares an approach to research which Gegeo regards as emerging from a communitarian perspective,
"that is, research that is not only applied (targeted to making positive changes) but is firmly anchored in Indigenous or Native epistemologies and methodologies (see: L. T. Smith, 1999). Such research is carried out for the good of the whole community and emanates from the community's Indigenous epistemology/ies and methodologies"

(2001a, p. 492).

For these scholars, therefore, development-related issues must be "truly solved in a manner that meaningfully benefits the communities" (Gegeo, 2001a, p. 492). Their scholarship also highlights that the education-development relationship, which shapes educational aid discourses and practices, has largely been devoid of Indigenous Oceanic knowledge, epistemologies and skills (Giraure, 1974; NaboboBaba et al., 2012; Sanga, 2005; 'A M Taufe'ulungaki, 2002; K. H. Thaman, 1999).

Oceanic scholars such as Hau'ofa (2008) Gegeo (1998; 2002), Sanga (2000, 2005), Thaman (1997, 2020), and Taufe'ulungaki (2002), have incessantly encouraged respect, recognition, and centring scholarship which emerges from Pacific peoples. Some of this scholarship conveys knowledge from people who have personally witnessed the massive, often harmful changes occurring in their places under the rubric of 'development'. Some conveys knowledge from Pacific scholars examining topics of development from an Indigenous standpoint and based on Indigenous epistemologies: a praxis that has long endured caustic treatment from AngloEuropean academia (Gegeo, 2001a, p. 491). This scholarship is central to a respectful understanding of the way Pacific peoples are reframing notions of development through their work in villages, classrooms, universities and meeting rooms; and how this in turn is reshaping development's scholarly and applied relations across the region (Naidu, 1991, 2006; Sanga, 2000; T. K. Teaiwa, 1995). 
Oceanic scholars have shed light on the gap between the intentions and the experiences of development. In 2000 'Ana Maui Taufe'ulungaki remarked that decades of development aid have brought no improvement to the qualities of life of Pacific Islanders. Others have criticised the business of donor-aid in education and development, which positions education as 'exportable' to Oceanic countries (Baba, 1989), and forges inequitable relationships between consultants and in-country counterparts at the local level (Nabobo-Baba, 2000).

Speaking in Suva, Konai Helu Thaman stressed that

“development and 'sustainable development' for Pasifika people is survival. It is the continuation of their cultures, not what [international development] agencies call it. [...] Sustainable development for Pasifika people requires of new ways of looking at the world, for the survival of our Earth"

These scholars' work points to the need for Pacific worldviews, ideas, skills and values, such as inter-relatedness and mutuality, in development and education (Sanga, 2005). This work is conducted with the certainty that "Pacific cultures and their accumulated knowledge, skills, [...] values" (K. H. Thaman, 1999, p. 27) and stories are central to rethinking development discourses and reshaping educational aid practice across Oceania (Fairbairn-Dunlop, 2008, p. 47).

Moreover, many Oceanic peoples have skilfully engaged with economies that are influenced by modernisation theories. Many have found aspects of modernisation and capitalist economies that are of interest to them, such as attaining material wealth, engaging in entrepreneurial ventures or furthering their education for cashincome related employment; by coupling this with their own knowledge and economic systems and by centering community and family interests: they have found ways to not only survive, but thrive in all worlds (Ulu, 2018). Furthermore, "what is clear is that many Pacific peoples, when forced to choose between economic business success and family reputation or status, seem to put family first in order to enhance their 'social and cultural capital'" (Salesa, 2017, p. 117). What is needed, 
according to Salesa, "is the development of entrepreneurship and businesses that align with and build from the kind of family, cultural and social values Pacific people hold" (2017, p.117).

The engagement at the development-education intersection in Oceania necessitates reciprocity, accountability and respect regarding Indigenous knowledge, worldviews, practices and places. Indigenous epistemologies thus present development with a "holistic perspective in which things are seen in the totality of their relationships"' (Hau'ofa, 1994, pp. 152-153).

\subsubsection{Modernisation theories}

European ideas of development can be traced to the early $19^{\text {th }}$ century, when the management of resources and populations within imperial states and their colonised territories led to the consolidation of development as a global inspiration and effort. Prior to this, development was largely regarded as a cyclical and organic process of growth and decay, the tenets and dynamics of which were beyond intervention. With Europe's Enlightenment and Industrial Revolution came the 'modernisation' of the concept, characterised by ideas of progress and of linear, upwards, and potentially infinite growth trajectories powered by human labour (Cowen \& Shenton, 1996, pp. 8-9). The "appropriation of the idea of progress, of higher and lower stages of human improvement and notions of superior and inferior knowledge" (Gibson-Graham, 2005, pp. 4-5), profoundly intertwined with ideas of civilisation and social evolution, served as justification for colonial expansion (Bulloch, 2014). These ideas were put into motion by colonial powers, which whilst working to ensure Indigenous peoples' participation in and contribution to colonial economies, simultaneously worked towards eliminating the cultural patterns of traditional societies: principally those patterns that prevented social, ecological and spiritual subordination to the interests of extraction and profit (Bodley, 2014;

Goldsmith, 1993; K. H. Thaman, 1995). 
Modernisation theories of development identified Indigenous values and institutions as a reason for the lack of 'progress' and 'development', especially but not solely in the Global South. Intervention by 'developed' countries was regarded as imperative for improvement of so-called 'backwards regions' (Almond, 1964; Almond \& Coleman, 1960; Black, 1966; Eisenstadt, 1970; Lerner, 1964; Moore, 1963; Parsons \& Smelser, 1956; Smelser, 1967). To this effect, in 1960 Walt Rostow proposed the 'five stages of growth' as a formula for underdeveloped countries to develop in the image of the West.

Classical and Keynesian economic principles were foundational to the consolidation of modernisation theory as a core component of Western liberalism (Greenwald \& Stiglitz, 1987), which steered development discourses from the WWII period through to the 1990s. President Harry Truman's inaugural speech in 1949 sought to oppose the old imperialism that had sustained colonial economies. However, his speech is also thought to mark the rise of the idea of official development assistance based on a binary logic of the world. This logic divided the world into 'developed' and 'underdeveloped' areas, which were "held together not through the political dominion of colonial times, but through economic interdependence" (Sachs, 1992). According to Truman (1949), the developed world's role was to promote world prosperity and peace by assisting in developing the underdeveloped world: fundamentally reshaping it in the image of the developed West. The assumptions of modernisation theory saw 'traditional' societies as being in an original state of underdevelopment, whose development was dependent on their effective assimilation into the values and structures of 'developed' nations. These assumptions informed most global development efforts (Naidu, 1991).

Sachs (1992) explains that Truman and his contemporaries saw greater production as key to their idea of development; Truman therefore initiated a programme of assistance to free the peoples of the world, relieving their suffering through industrialisation and higher standards of living. Such ideas were propagated and 
implemented by governments and international organisations following modernisation rhetoric, which converged into a view of the world as a largely economic arena operating under the imperative of economic development. The focus thus changed from a basic needs approach to building the New International Economic Order (Hart, 1983). Modernisation's core principles still exert influence in current development and aid discourse and practice (Coxon \& Tolley, 2005).

'Modern', scientific and rational education was central to the policy implications of modernisation theory, being seen as an instrument for transforming attitudes and values from traditional to modern (Little, 2000). Parkyn argued that in the context of the great educational expansion of the second half of the twentieth century, the purpose of what is referred to as 'development education' was:

"education aimed at the modernization of [developing countries'] technological activities in order to provide better for their material and cultural needs, and at the adaptation of their political machinery and other societal institutions in such a way as to make possible the most effective use of this modernization in the satisfying of those needs" (1977, p. 89).

Under modernisation theory, education focused on transmitting Western liberal values with all their implications for economic and technological growth: deliberately encouraging individuality and motivation for achievement (McClelland, 1961). Little (2000) examines the way some Western academics in the 1960s and 1970s accepted the logic that modern values (rational, scientific abstract, secular, universalistic) lead to modern behaviour, modern society and ultimately to development (Inkeles \& Smith, 1974); some like McClelland even stressed "the role of modern institutions such as the formal school and the factory in the formation of modern values and attitudes" (p. 276). This helped instigate and justify the application of human-capital theoretical values to education, through the notion that 
education creates skills and knowledge as a form of capital ${ }^{30}$ for economic growth (T. Schultz, 1961).

\subsubsection{Dependency and underdevelopment theories}

The logic behind modernisation and human-capital theories was challenged by the emergence of dependency and underdevelopment schools of thought. These gained momentum in the late 1960s and early 1970s, challenging modernisation theory's explanations for the 'economic backwardness' of the Global South. Structuralist economists such as Raul Prebisch (1950) of the United Nations Economic Commission for Latin America (ECLA) had long been questioning the classical theories of trade and comparative advantage. Using a centre-periphery model, ECLA economists argued that the benefits of trade were not shared evenly throughout the world; rather they favoured the centre by exploiting the periphery. They advised considering global social-political-historical structures to understand the economic disadvantages of the periphery. They also suggested that development should advocate for the role of the state in promoting industrialisation, protectionism and self-sufficiency (Conway \& Heynen, 2014).

Little described dependency theory as addressing "the extent to which poor countries were dependent on rich countries and the mechanisms through which economic dependency was maintained" (2000, p. 287). Dos Santos referred to the notion of dependency as:
"a situation in which a certain number of countries have their economy conditioned by the development and expansion of another [...] placing the dependent countries in a backward position exploited by the dominant countries"

(1970, p. 180).

\footnotetext{
30 This is explained in detail in chapter 6.
} 
Core tenets of dependency theory feed into underdevelopment theory, also incorporating ideas from Marx, Lenin, ECLA (in Prebisch, 1950), Baran $(1952,1957)$, Frank (1966; 1967, 1975), Wallerstein (1982), Dos Santos (1970) and Cardoso (1972). The apparent limits to peripheral capitalist development (Dos Santos, 1970) prompted analysis of the historical specificity of underdevelopment (Naidu, 1991). Underdevelopment was perceived as an inevitable outcome of the systematic exploitation and manipulation of peripheral economies by central ones (Little, 2000). For Wallerstein (1982), the central mechanism behind the modern world system was the incorporation of all countries into the global market, linked by systems of exchange. Frank, Wallerstein and Amin (1972) observed that the contemporary international economic system is the result of 400 years of capitalist development, further arguing that capitalist relations infiltrate all corners of the globe: creating, accentuating and thriving on inequality (Griffin, 1977). According to Frank, economic development and underdevelopment are not two opposite poles on a 'development continuum', but 'opposite faces of the same coin': "the product of a single, but dialectically contradictory, economic structure and process of capitalism" (1969, p. 9). Underdevelopment, they argued, is not a condition but a process; a fundamental characteristic of capitalism which means that the development of one part of the system necessitates the underdevelopment of another.

Dependency theorists also influenced discourses of education. They drew attention to countries' post- and neo-colonial relations by analysing the restraints these place on development and stability, alongside other negative social-economic effects. They focused on the role of education for domination rather than for development, by questioning the role of education in:

"the legitimation of elite social and economic status, through qualification systems, through curriculum and learning materials developed through international publishing projects, and through crossnational and inter-national professional networks"

(Altbach \& Kelly, 1978; ; Little \& Lewin, 1984; Mazrui, 1975; Watson, 1984 in Little, 2000, p. 288). 
Education was seen by dependency theorists as a mechanism for imposing Western values and worldviews, therefore strengthening structures of dependency. Questioning the role of education revealed patterns in the negative impacts of development, including: income disparities between countries and social groupings, and resulting consolidation of underclasses; the increasing influence of multinational corporations economic interests; the strengthening of transnational elites; and the shifting values of different social groups (2000).

\subsubsection{Neoliberalism}

Neoliberalism emerged partly as a response to the economic crises of the 1970s. It has influenced development and aid discourse and practice since the 1980s, "and has since continued as the globally dominant economic orthodoxy" (Bulloch, 2017, p. 6).

Many countries, including those in southeast Asia and Latin America, borrowed billions in petrodollars throughout the 1970s during a growth period equated to the "takeoff" phase of development, but loan repayments became unfeasible when oil prices and interest rates increased in the same decade. This resulted in the debt crisis of the 1980s and what was later termed the 'lost decade of development' (Kapur, Lewis, \& Webb, 1997).

The IMF, World Bank and US Department of Treasury stepped in to protect the interests of Western banks by taking over loans and facilitating repayments through the Washington Consensus, a set of policy prescriptions to reform developing countries, including liberalisation, privatisation, deregulation, and structural adjustment programmes (SAPs) with attached conditionalities.

As explained by Murray and Overton:

"[Neoliberalism] was associated with radical reform, restructuring and diminishing the role of states in order to place the market at the centre of development strategies. Poverty elimination was not an explicit concern; rather, it was believed that aggregate economic growth should be promoted and that this would eventually filter down to the poor. Critics observed that neoliberal reform created new forms of poverty and inequality, that welfare cuts created 
much hardship and that market led strategies merely favoured wealthy and powerful countries and classes at the further expense of the poor.

(2011b, pp. 307-308)

After much scrutiny, by the mid-to-late 1990s SAPs were replaced by Poverty Reduction Strategy Papers (PRSPs), with new elements that included 'good governance', 'ownership', 'equity and employment generation' as well as 'reregulation' of the market by the state (Craig \& Porter, 2003). This was a prelude to the late-1990s UN poverty alleviation agenda and the adoption of the MDGs in the 2000s. These agendas may also be seen as components of an aggressive neoliberal globalisation process that largely omitted "questioning the sources of poverty in the accumulation-driven economy of the affluent global North. [...] So, economic 'growth' was redefined as a necessary step" (A. Kothari, Salleh, Escobar, Demaria, \& Acosta, 2019, pp. xxv; see also: Gómez-Baggethun \& Naredo, 2015).

Neoliberalism has significantly influenced development practice through the principles and mechanisms of international aid (Bulloch, 2017; A. Kothari et al., 2019). Aid is not a uniform set of practices or resources, and 'developing' and 'developed' countries do not necessarily share understandings about delivery approaches (Bermeo, 2009; Sanga, 2005). Development aid does, however, comprise a multibillion-dollar industry that has permeated and shaped international relations for decades (R. E. Wood, 1986, p. 2).

Neoliberal economic theory can also be argued to underpin the 2030 Agenda for Sustainable Development. At the 2012 UN Conference for Sustainable Development, the guiding framework for multilateral discussions relied heavily on a "pro-growth policy of sustainable development [which] conceptualized all living natural forms across the planet as 'natural capital' and 'critical economic assets', so intensifying the marketable commodification of life on Earth" (A. Kothari et al., 2019, p. xxvi; Salleh, 2016). The Agenda calls for 'sustained economic growth', contradicting many of the SDGs by presenting an impossible goal of perpetual economic growth without 
environmental or social harm (Kallis, 2015). It thus fails in its analysis of "the structural roots of poverty, unsustainability, and multidimensional violence [that] are historically grounded in state power, corporate monopolies, neo-colonialism, and patriarchal institutions" (A. Kothari et al., 2019, p. xxvii). Such criticism emphasises that despite the many positive elements of the SDG framework, technological and managerial innovation will not lead us out of crises built upon neoliberal foundations.

Education has become a central component of the advancement of neoliberal economic theory and policy across the world (Becker, 1994). Critics point out that this position has permeated global political and development discourses, meaning that education is largely treated as an economic sector, with primarily economic functions including maintaining growth (Field, 2000; Fine, 2002; Stuart, 2005). Some have critiqued policy makers' approach to education for regarding it as an instrument for social control to move people into the labour market (Coffield, 1999).

Critics recognise that education should contribute to individual and societal wellbeing by increasing skills, mobility, adaptability and reducing unemployment. They decry that education is no longer conceived as a means of human development, or of individual and collective freedom, but rather as a marketable commodity and a business activity driven by profit (Ball, 2010; Nussbaum, 2010). To these critics, economy-driven education policies do not contribute to wellbeing, but rather reduce the role of (and cost to) the state by vesting financial burden and risk with individuals (Field, 2000). As pointed out by Tan:

"One of the ways to positively intervene production functions is to increase labor quality. This brings the question as to what is the most efficient way to increase labor quality and productivity. Education is the most appealing answer to this question for many. This answer is vehemently supported by human capital theorists and readily accepted by policy makers"

(2014, p. 429). 
In many cases the outcomes of neoliberal approaches reveal that the commodification of higher education, for instance, has not brought the predicted economic benefits. Rather the result has been inflation in academic degrees and the production of "overeducated but underskilled or overeducated but underutilized individuals who can barely find a job" (Tan, 2014, p. 430; I. Walker \& Zhu, 2008).

These situations are replicated in many Oceanic localities where neoliberal approaches to national educational policy and international educational aid have resulted in the implementation of undifferentiated education models. This "often reproduces dependent neo-colonial relations (Murray \& Overton, 2011a; Overton, Prinsen, Murray, \& Wrighton, 2012) - with modernization being the principal objective and imported syllabi and overseas scholarships the main means" (Gamlen, Murray, \& Overton, 2016, p. 9). For critics, education is perceived to function as an instrument of the economic and cultural colonialism entrenched in neoliberal aid regimes. These thinkers provide a critical view of development, educational policy and the nature of curricula (Sanga \& Taufe'ulungaki, 2003; K. Teaiwa, 2014; T. K. Teaiwa, 2017; K. H. Thaman, 1992, 1993a). Whilst the "investment in orthodox educational programmes - in schools, teacher training, universities and technical training - has remained a key development priority supported by governments and external aid donors alike" (Gamlen et al., 2016, p. 10), Oceanic thinkers' work continues to sustain the emergence of culturally appropriate education strategies and development relationships in the region (Gegeo \& Watson-Gegeo, 2002; Hau'ofa, 1994; Sanga, 2020).

\subsubsection{Alternative development}

A growing dissatisfaction with mainstream development's preoccupation with economic growth laid the ground for to alternative definitions of development (Ekins, 1992; Sachs, 1992. Alternative development approaches that gained momentum in the 1990s are concerned with alternative practices of development, 
aiming to both critique and redefine the goals of development through participatory, people-centered approaches, with a strong focus on gender (Moser, 1991) and the environment. Alternative development approaches are aimed at empowerment (Friedmann, 1992), participation (Chambers, 1994) and capacity building (Pieterse, 1998) of local communities, NGOs, Indigenous peoples and others in the civil society sector, in order for them to exercise their agency in the direction and implementation of development strategies in their countries and localities (Breheny, Gent, \& Lock, 1993; Carmen, 1996). Friedman (1992) for instance, advocates for an empowerment approach to development in order to emphasise autonomy in community decisionmaking, self-reliance, direct democracy and social learning.

However, many thinkers have argued that these 'alternatives' have been selectively incorporated, appropriated, co-opted or subsumed into mainstream development in a process of hybridisation between mainstream and alternative (K. Brock, Cornwall, \& Gaventa, 2001; R. Kothari, 1993; Pieterse, 1998; Storey, Bulloch, \& Overton, 2005). Escobar (1995) has observed that despite this hybridisation, alternative concepts of development have not altered the fundamental elements of the poverty reduction agenda: the market is still seen as instrumental to poverty reduction, with persistent dominance of economic growth, globalisation, stabilisation and the rolling back of the state. Critics also note that in terms of aid, alternative development approaches do not necessarily challenge ideas and policies that depict aid donors as essential to poverty reduction, rather than highlighting that they are also as essential "to the dynamic of poverty creation as, say, the Third World state" (DAC, 2001; Eberlei, 2000 in Storey et al., 2005). Below is a brief description of different alternative development approaches.

Since the 1990s, advocates for participatory approaches have presented these more as paradigm shifts rather than development paradigms in themselves (Pretty \& Chambers, 1993). These approaches search for alternatives to better people's quality of life through decentralisation, democracy, pluralism and diversity in development 
research and practice. Many of those advocating for the effectiveness of participatory approaches also emphasise the need to recognise Indigenous knowledge and practices as central to development planning and practice (John Brohman, 1996; Hari Mohan Mathur, 1995; Sillitoe, Bicker, \& Pottier, 2002).

Participatory approaches are largely driven by the work of community development practitioners, with applications in fields such as natural resources management, conservation and in programmes for food security, health, women and agriculture. These participatory methods inform approaches in the field work of NGOs and some government organisations, as well as training institutions and universities. Their proponents regard them as enabling empowerment in practice, since learning occurs through expression, sharing and implementation in which local people participate. However, when participation is viewed as positive regardless of who participates and who benefits (Scoones \& Thompson, 1993), empowerment and equity may not always meet. If those participating and benefiting are social-political elites, for instance, such programmes might further disempower those in lower socialeconomic situations. Differentiation between groups, requirements and gender is thus essential to the effectiveness of participatory approaches.

The debate about the purposes of participation - whether it is a means or an end emerges from the varied objectives of development initiatives and policies, as well as to the strategic context of funding and to the implementing bodies. For instance, ElGack (2007) refers to the OECD's views of participatory development in the early 1990s as essential for strengthening civil society and the economy, empowering communities, influencing public policy, increasing government accountability and enhancing the efficiency, effectiveness and sustainability of development programmes. The introduction of participatory approaches as alternative development models also prompted scrutiny from thinkers such as Cooke and Uma Kothari (2001), whose poststructural analysis asserts that participation does not enable empowerment, being imbued with authority and thus not fundamentally 
different from externally imposed forms of development. Additionally, being largely based on practitioners' experiences, some scholars argue that participatory approaches are neither theoretically coherent nor sufficiently robust, and can lead to participation being tokenistic in practice (Kapoor, 2005; Mohan, 2002). Conversely, whilst acknowledging that participation must be recognised as a form of power, other practitioners, academics and theorists argue that it can also be viewed as a resource for human agency, one that can invite both reflection and social transformation (Cameron \& Gibson, 2005; Kesby, 2007).

Participatory approaches have philosophical roots in Freirean praxis that advocates for empowerment and equity in education. For instance, participatory approaches in educator learning "can position educators as experts on their own lives to inquire into and act on issues of social justice through democratic, participatory procedures" (Strand, Cutforth, Stoecker, Marullo, \& Donohue, 2003; Torre, 2009 in Kaplan, 2018, p. 9). A combination of participatory approaches to socially and culturally appropriate teaching and learning (Gutiérrez \& Rogoff, 2003) and commitment to participatory action research (McIntyre, 2008) are said to support educators' learning, agency, and action. Participatory approaches can lead to shifts in teaching and learning practices to focus on collaboration, inquiry, and community. All these factors may be regarded as integral to supporting educators and education leaders at every level of the system, whilst working towards social change (Kaplan, 2018).

\subsubsection{Sustainable development}

Sustainable development discourses emerged from attempts to merge environmental concerns with development imperatives through the recognition that poverty and environmental degradation are deeply linked. Within these discourses, education is seen as an important tool to establish and maintain public awareness, participation, and increased access to knowledge and information, all of which are thought to facilitate cooperative action on interconnected environmental and 
development issues (UNDP, 2017; UNESCO, 2018). Sustainable development discourses have been critiqued as inadequately addressing the West's historic responsibility for environmental crises such as biodiversity loss, climate change, sea level rise and ozone layer depletion; and for sometimes suggesting costly Westerninspired environmental regulations as yet another means of control over the Global South (Davierwalla, 1996).

In 1992 the United Nations Conference on Environment and Development (UNCED) institutionalised 'green economy' narratives about sustainability (Pieterse, 1998) through Agenda 21, a worldwide action plan for sustainable development which stipulated development goals, strategies and actions to "meet the needs of the present without compromising the ability of future generations to meet their own needs" (UNDP, 2017). These narratives have been widely critiqued on the basis that they "remain within capitalist rationality" (Brand \& Lang, 2019). The 1990s and 2000s saw numerous world summits on sustainable development (including: Barbados, 1994-1999; New York, 1997-2000-2015; Johannesburg, 2002; Mauritius, 2005-2010; Rio de Janeiro, 2012; and Apia, 2014). The MDGs of 2000 and SDGs of 2015 emerged from some of these fora, incorporating global concerns about, and later goals targeted at, education - especially education for girls ${ }^{31}$. The UN Decade of Education for Sustainable Development (ESD) 2005-2014 signalled the global reorientation of education to address linked environmental and development challenges. In 2014, building on the efforts of the previous decade, UNESCO endorsed and promoted the Global Action Programme on DESD through formal, non-formal and informal education (UNESCO, 2018). During the UNESCO 2014 Nagoya Conference, shortcoming were noted which are directly related to countries including those in Oceania facing problems in meeting the goals of the Decade. Many UN instruments including DESD, assume universality of knowledge and

\footnotetext{
${ }^{31}$ MDGs and SDGs education goals are explained further in section 6.3. 'Global education-fordevelopment agendas' in chapter 6 .
} 
oftentimes foretell failures of many non-Western countries to properly contextualise said instruments, especially their underlying values and philosophies. It is thus crucial to continue advocating for the importance of contextualising UN instruments relating to education and development, so that they also support the centering of local values and philosophies in order to make education and development more culturally democratic. Meanwhile, global environmental awareness and international commitments have continued to rise (e.g. Kyoto 1997-2005; An Inconvenient Truth, 2006; Copenhagen, 2009; Paris, 2015). The 2015 Paris Agreement helped frame the threat of climate change as a development issue and further affirmed the importance of education and training in increasing public awareness, participation, and access to information to cooperatively address the issues of climate change and climate justice (UNDP, 2017).

There have been considerable achievements related to the implementation of the SDG agenda that aims to promote prosperity while protecting the environment: ending poverty through strategies that do not approach economic growth in isolation, but by addressing social needs such as education, health, jobs, and gender equality, whilst taking action on the climate and biodiversity crises. The SDGs have a strong 'education for all' element, which aims to ensure inclusivity, equitability and quality of education and to promote lifelong learning opportunities. However, societal differences in the meanings of sustainability and development, as well as the social-economic, environmental and cultural effects on the Global South of shifting global goals and agendas, is also of concern to scholars, development practitioners and communities. Some have even argued that the term sustainable development involves a fundamental contradiction, as the dominant Western-styled models of development can never be sustainable, especially when considering their ecological consequences (McManus, 1996; Sachs, 2013). 


\subsubsection{Post-development}

Post-development theory emerged in the 1990s with critiques of the view of development as a project of hope, one that had social justice and the emancipation of the poor and disadvantaged at its core (Cowen \& Shenton, 1996). Critics argued that this project had failed and that instead the perpetuation of uneven power relations sits at the core of development (Rahnema \& Bawtree, 1997; Sachs, 1992). Some even suggest the abandonment of development as a concept due to its discursive and applied violence and the dangers it brings to people and the environment (Nandy, 1995; Peet \& Hartwick, 1999). Two post-development streams can be identified: one referred to as 'anti-development'; the other 'beyond development'. The first is a radical response to mainstream development theory and practice that also suggests a disillusionment with alternative development; and the other explores paths for those in the practice of development for rethinking the positive promise of development in ways that "may make the idea fly again, in new directions" (McKinnon, 2007, p. 772).

Anti-development writers' disappointment is articulated through the rejection of development theories and practices which result in cultural Westernisation or homogenisation; the imposition of science as power, creating 'laboratory states'; and environmental degradation (R. Kothari, 1988; Nandy, 1988; Visvanathan, 1988 in Pieterse, 1998). Anti-development itself is also critiqued on its methodological premise, as its discursive analysis and resistance to development provides little in the way of concrete or constructive solutions (Corbridge, 1998; Pieterse, 2011). Post-development thinkers draw from postcolonial analyses of global power structures and poststructuralist rejections of the modernisation paradigm of progress. The work of post-development thinkers invites the analysis of development discourses (from 'progress', through 'underdevelopment', to 'participation') that may perpetuate notions of neocolonial superiority, and which result in Indigenous knowledges, livelihoods, and economies being "delegitimized, 
devalued, stolen, and subjected to the dominance of the West" (McKinnon, 2007, p. 773) ${ }^{32}$. More recent work by post-development thinkers such as Gibson-Graham $(2006 ; 2008 ; 2005)$ addresses the uncertainty that saturates development scholarship as well as practice, challenging the premises that the emancipatory thinking and action of the 'development project' is built upon. Work by these and other thinkers such as Bulloch (2014), U. Kothari (2005, 2006), Underhill-Sem (2002, 2016; 2017) and Mosse (2005) opens pathways that consider "how to generate new practices of development that take on board the implications of a critical postdevelopment debate" (McKinnon, 2007, p. 774); they encourage epistemic diversity (U. Kothari, 2019) and pose the challenge to "imagine and practice development differently" (Gibson-Graham, 2005, p. 6). They highlight, for instance, that development practitioners and professionals,

"are no longer just the Western "experts", but also the local village leaders, activists, and nongovernmental organisations (NGOs), as well as national and international volunteers, government officials, and advocates, alongside a broad range of more-or-less well-meaning, and sometimes highly paid (and well-connected), international consultants"

(McKinnon, 2007, p. 772).

They reject the perpetuation of deficit theory narratives as explanations for the position that Indigenous peoples occupy within contemporary societies (Escobar, 2001; Mahuika, 2008). They also emphasise that development discourses are not simply assimilated into a locality, but may be reinterpreted, reshaped and renegotiated by local peoples in ways that serve local interests and priorities (Bulloch, 2014; Laurie, Andolina, \& Radcliffe, 2005). Authors such as Kirk Huffman, for instance, pointed out that the failed promises of 'development' across Melanesia mean that the word 'development' is now "often jokingly used to refer to something that goes wrong" (2019, p. 16).

Some aspects of post-development thought echo teachings by Indigenous scholars and elders who remind us that development discourses, like all other local and

32 See also: Escobar (1995); Esteva (1992); Li (1999); McKinnon (2006); Simon (2006). 
introduced knowledge systems and practices, are negotiated; and in a very fundamental way are generated from their own cultural ontologies (Watson-Gegeo \& Gegeo, 2014; Sanga, 2014).

An international collaboration of post-development thinkers has recently published 'Pluriverse: A Post-Development Dictionary'. This is a transcultural compilation of concepts, worldviews and practices, intended not as policy agendas or instruments to exit 'maldevelopment', but rather

\begin{abstract}
“they are about recognizing the diversity of people's views on planetary wellbeing and their skills in protecting it. They seek to ground human activities in the rhythms and frames of nature, respecting the interconnected materiality of all that lives. [...] The visions and practices offered here put buen vivir before material accumulation. They honour cooperation rather than competitiveness as the norm. They seek work in pleasurable livelihoods [...] Again, too often in the name of 'development', human creativity is destroyed by dull, homogenizing education systems"
\end{abstract}

(A. Kothari et al., 2019, p. xix)

This kind of post-development thought and practice influences this study because it is an invitation to explore what the editors see as relational 'ways of being', to recognise the limits of our own cultural reflexivity and to regard all practice as 'an act of care'. It is also of influence because it invites "a deep process of intellectual, emotional, ethical, and spiritual decolonization" (A. Kothari et al., 2019, p. xvii). This process demands commitment to deconstructing the idea of 'development as progress' and to challenging the homogenising constructs of dominant development models which have been imposed across the world. It can open "a way for cultural alternatives that nurture and respect life on Earth" (A. Kothari et al., 2019, p. xvii) and further promote communal ways of being and place-based forms of autonomy. Such post-development approaches can shine an important critical light on dominant development discourses. A post-development analysis of the 2030 Agenda (UN, 2015; UNEP, 2011), for instance, reveals a

"continued emphasis on economic growth as the driver of development, contradicting biophysical limits, with arbitrary adoption of GDP as the 
indicator of progress; continued reliance on economic globalization as the key economic strategy, undermining people's attempts at self-reliance and autonomy; [alongside the] continued subservience to private capital, and unwillingness to democratize the market through worker-producer and community control"

\section{(A. Kothari et al., 2019, pp. xxvi, xxvii).}

The 2030 Agenda also marginalises 'diverse knowledges' in favour of modern science and technologies; and likewise side-lines culture, ethics, and spirituality which are

"made subservient to economic forces. [It facilitates an] unregulated consumerism without strategies to reverse the global North's disproportionate contamination of the globe [and favours] neoliberal architectures of global governance becoming increasingly reliant on technocratic managerial values by state and multi-lateral bureaucracies"

(A. Kothari, 2013; A. Kothari et al., 2019, p. xxvii).

Post-development thought and practice further challenge the predominance of a "secular trend to functionalise work, education and the land in order to boost economic efficiency" (Sachs, 2013, p. 27). For example, participants' stories in this study reveal Indigenous-led education and development initiatives with an underlying understanding that human and environmental wellbeing do not only rely on money. They prioritise people's assets, tangible and intangible, and their ability to withstand resource crises and economic shock; they likewise emphasise self-governance, diverse and community economies (Gibson-Graham, 2005; Huffman, 2019), guardianship of the environment (Bojang, 2008), policies and institutions that reflect social-economic-politically disadvantaged people's priorities, rather than those of the elite (Gibson-Graham, 2008); and prioritise Indigenous practices and ways of learning and knowing (Bulloch, 2014; Walsh, 2010). Participants' stories reflect some of the concepts and practices of post-development: this is a pluriverse of transformative initiatives, where

"worldviews and practices, old and new, local and global, emerging from indigenous, peasant and pastoral communities, urban neighbourhoods, 
environmental, feminist, and spiritual movements [...] reach for justice and sustainability in a multiplicity of ways"

(A. Kothari et al., 2019, p. xix).

Post-development thought and practice influences this study because whilst the multiplicity of "visions and ways of being and doing" can bring "differences, tensions, and even contradictions", when vision and practice are built on the basis of relationality they are also more likely to be engendered under norms of respect, collaboration, dignity, love, and reciprocity (Aguilar, 2013, p. 33). Relationality makes the pluriverse of alternatives visible. This pluriverse can be seen in the many and diverse concepts, initiatives and practices of development and education articulated by this study's participants. Below I focus on Gibson-Graham's concept of 'diverse community economies', in relation to my experiences encountering a diversity of economies, education, and notions of poverty and wealth in ENB.

\subsubsection{Diverse community economies}

I remember sitting at the back of a PMV truck (public motor vehicle) cruising back home to the village, when talking to one of the women she said:

'Susa (sister), sometimes I feel very sad about those very poor people'

'what poor people sister?' I asked

'those poor people that have to buy their food in the supermarket', she replied.

(personal recollection, 2017)

This simple interaction at the back of a PMV reiterated to me a diversity of understandings of 'poverty' and 'wealth'. In that particular cultural setting, concepts of wealth were also linked to land, and the security, protection and sustenance that connection and kin provide. To be obliged to buy food in the supermarket meant not having land or accessibility to subsistence gardens to provide for family and community, as well as the imperative to engage in cash-generating activities for food purchasing. I remembered then that in the whole time I have been in ENB I have never seen a homeless person, nor people begging on the streets. In that bumpy ride back to the village, I reflected on the importance of land, of ples, of community 
economies and of a firmly established wantok system, all of which sustain communal wellbeing by preventing homelessness, loneliness and food scarcity. Since then, my reflections have expanded and deepened thanks to my relationships and time in ENB province.

Community economies are an important illustration of diverse notions of wealth because they present forms of collaborative economic engagement that respect and require the sharing and gifting of output. They challenge "a conventional approach that 'defines poverty as an 'economic' problem that can be corrected through more jobs and higher incomes' (Yapa, 2002)" (Gibson-Graham, 2005; McKinnon, 2007, p. 774). From the UN Economic and Social Council's (UNECOSOC) definition of poverty as a human condition characterised by the deprivation of what is required for the enjoyment of an adequate standard of living and other various rights, through to the definition by the UNDP of 'poverty of opportunity' as 'the inability of people to lead the kinds of lives they aspire to' (this term is often used in the Pacific context), poverty rhetoric refers to resources, choices, security and power, and to civil, political and social rights (Beban-France \& Brooks, 2008). Yet in the global discourse and discussions on poverty a predominantly economic (i.e. less than a dollar a day) definition prevails, even when some social and wellbeing measures are attached. I find myself, like authors such as Escobar (2001) and Gibson-Graham, puzzled about the continued "inability on the part of Eurocentric thinkers to imagine a world without and beyond modernity" (2005, p. 6).

Work by several post-development authors helps widen the knowledge of economy by exploring diverse and place-based ecologies of productivity, creating a discourse of economic difference and contributing to a politics of economic innovation within development thought and practice. In an Oceanic context, for example, McKinnon, Carnegie, Gibson, \& Rowland used a 'floating coconut' as a research template to represent the economy (Figure 1). They invited community members to enumerate diverse economic engagements and practices that contribute to survival and well- 
being across their different localities, constituting "place-based 'ecologies of productivity'" (2016, p. 1380). These authors' efforts were inspired by GibsonGraham's $(2006 ; 2008 ; 2005)$ work countering the capitalocentrism of dominant economic relations and identifying diverse logics of interdependence that inform actions and transactional relationships. They also share much with the pioneering work of the Vanuatu National Statistics Office (2012) and the Vanuatu Cultural Centre in raising national and international awareness of "the value of kastom economy in providing for Pacific people's survival and well-being" (McKinnon et al., 2016, p. 1382). Indicators for wellbeing developed by the MSG, for instance, are place-specific and provide pathways for establishing broader and more culturally appropriate definitions of economic and social wellbeing, including indicators such as access to 'traditional wealth items'. These items have traditional exchange value throughout Melanesian communities, and include pigs, chickens, yams, bananas, mats, kava, buai and shell money or shell wealth. It is also important to note that the movement to emphasise the value of diverse Melanesian community economies is slowly acknowledging place-based forms of gender recognition within development indicators ${ }^{33}$. Promoting a 'Melanesian lifestyle and Kastom economy',

“is seen by economists as 'blocking development'. However, [...] Melanesians tend to see Kastom as protecting them from bad development and the disease that comes with it - Sik blong Mane or money addiction.

[...] The ni-Vanuatu wish to promote Kastom Economi and protect land rights, agriculture, and self-sufficiency is a much more sustainable trajectory than artificial growth models, such as construction proposals, over-reliance on tourism, or 'retirement lifestyles for Australian baby boomers'".

(Huffman, 2019, p. 17)

${ }^{33}$ see chapter 7 , section 7.4 .3 for more on local place-based considerations. 


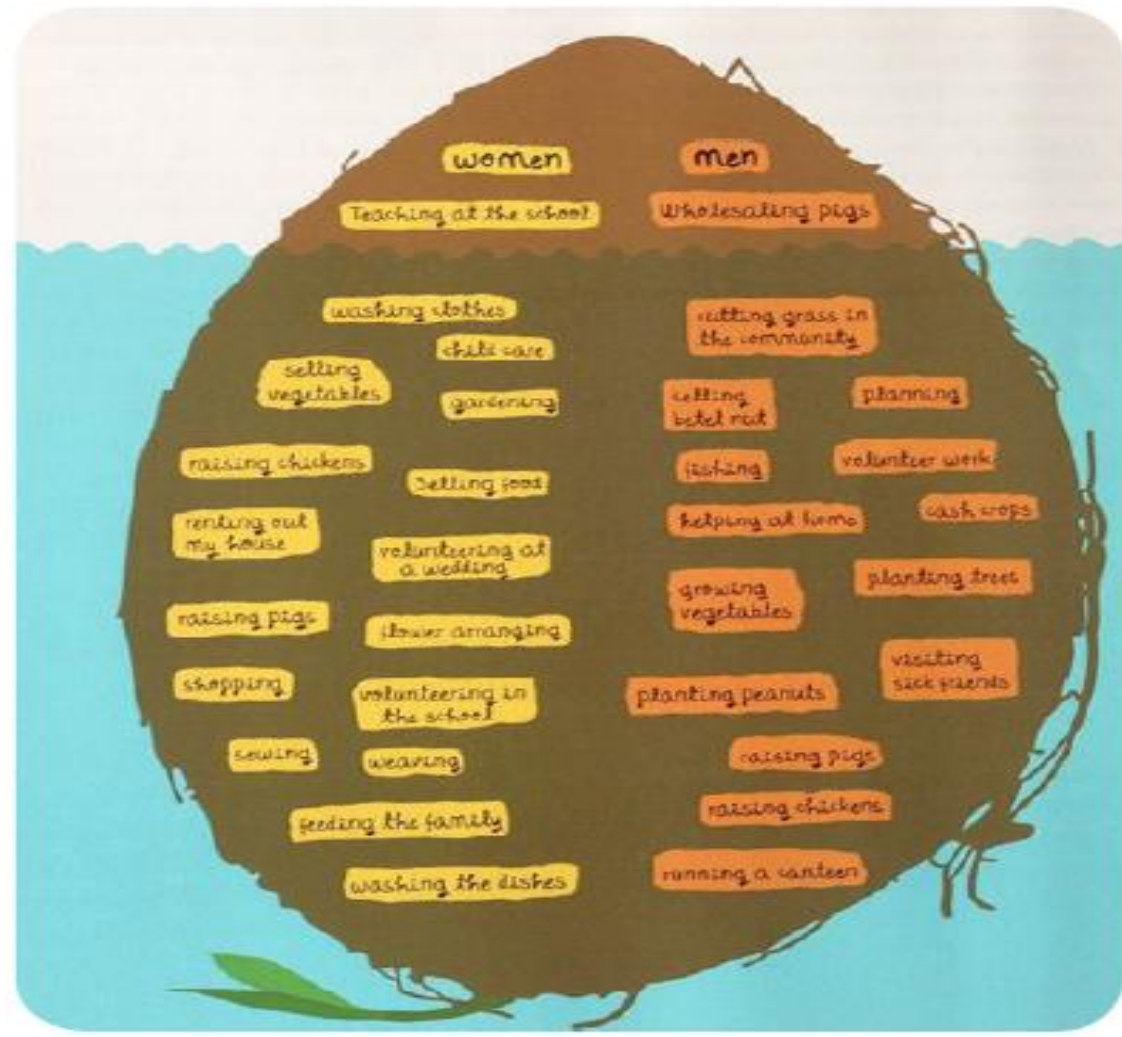

Figure 1. 'Floating coconut' representing diverse labour and leisure practices performed by women and men (Solomon Islands urban community) Source: Mckinnon et al., 2016, p. 1382.

The work of these post-development authors draws from and supports Oceanic

scholars and leaders (K. H. Thaman, 2008) as well as Pacific bodies and organisations

(e.g. PIF Blue Pacific Narrative, MSG development indicators) in reshaping engagement with economic development, without privileging a specific type of knowledge, economic model or development framework; rather they promote a 'sufficient way of life' (Hermkens, 2013). The floating coconut representation ${ }^{34}$ in Figure 1., for instance, shows that Pacific Island livelihoods

"encompass a great volume of activities, many of which do not intersect the formal capitalist economy. Many rely on a range of transactions and interdependencies, informed by the ethics of customary exchange, or household and family sharing, or new forms of reciprocity and social protection appropriate to the squatter lifeworld. This is an ecology of productivity that invites further discussion and research into what a sufficient or desired way of living might be"

(McKinnon et al., 2016, p. 1382).

\footnotetext{
${ }^{34}$ For a broader, detailed description of this resource see Carnegie, M., Rowland, C., Gibson, K., McKinnon, K., Crawford, J., Slatter, C. (2012).
} 
A related passage by Gibson-Graham refers to PNG women who use cash earned in exchanges with capitalist corporations to support noncapitalist household economic activities:

"[These women] participate actively in traditional (noncapitalist) gift exchanges that sustain clan identity, maintain rights to land, redistribute income, and cultivate community. And, rather than taking on a proto-proletarian identity, they are empowered in their traditional gendered identities in both household and community"

(2004, p. 415).

For many Indigenous peoples, complex and diverse community economies exemplify a much more 'sustainable trajectory' than those offered by capitalist economic models. In Melanesia, mining and logging operations facilitated by the alienation of Indigenous lands through sale or lease to outsiders has led to widespread environmental destruction and abuse of human rights. Examples of this can be seen in Indonesia-occupied West Papua, but also in various regions of PNG including Bougainville and ENB. Huffman describes

"the latest chapter of this saga [which] pits landowners on the island of New Britain against Malaysian logging giant Rimbunan Hijau [RH]. The PNG government sides with the company, which also owns a local newspaper and transport company, as well as a massive new hotel complex in the capital"

Participants' storying in this study delves into their own notions and perceptions of global concepts of 'poverty' and 'wealth'. It also reveals the daily reshaping and negotiation involved in their engagement with both capitalist and noncapitalist economic systems. It speaks, for example, of the importance of tabu (shell money or shell wealth) for community wellbeing and autonomy. Complex and diverse community economies are not to be dismissed but rather upheld and sustained, because they have an intrinsic strength and reliability in the face of the uncertainty, periodic downturns and social inequalities that are features of capitalist economies at all scales. This is currently evidenced by the reliability of tabu to provide local 
economies in ENB with an established and robust means to withstand the far reaching social-economic impacts of a global pandemic (Fainu, 2020).

Post-development thinkers ultimately advocate for development discourses that highlight the importance of place-based and diverse economies, for the cultural, spiritual, environmental, social-economic and political wellbeing of local peoples. This wellbeing is built on the collective protection of ples; on the redistribution of wealth and resources; and on culturally specific values of reciprocity and labour that nurture tribe, clan and family identity.

\subsubsection{Diverse education}

Similar to the notion of diverse and place-based economies, there exists a multiplicity of approaches to education built on placed-based knowledges, epistemologies and values, which are directed at addressing locally defined needs and aspirations. In practice, this involves teaching and learning processes across different knowledge systems, traditional skills, understandings and custom, that are held by and articulated through different stories and practices, vernacular languages, as well as local histories and genealogies (Robinson-Pant, 2016). Post-development thinkers have argued for the recognition of notions of multiplicity; of diverse economies and ecologies of production (Gibson-Graham, 2005; 2008; U. Kothari, 2006). This kind of thinking resonates with the work in education by Oceanic scholars, educators and communities addressed throughout this study. By firstly acknowledging the devastating impacts of development interventions on established societies and cultures, authors such as Gibson-Graham $(2005,2008)$ and McKinnon et al. (2016) highlight the many ways that local economies might intersect with, but also go beyond, global capitalism. Diverse worldviews and locally-defined aspirations of development are thus mirrored in diverse forms of place-based education that contain a wide range of locallysanctioned knowledge systems, values and skills, and also incorporate non- 
traditional ways of knowing, learning and doing. Rather than complying to globalising and homogenising processes, these diverse forms of education are grounded in place: they respond to the aspirations of students to live, thrive and work in ways that meaningfully contribute to their communities, within diverse economic configurations and within a pluriverse of development possibilities (Escobar, 2001; A. Kothari et al., 2019).

Place-based ways of knowing and learning are inextricably connected to Indigenous knowledge systems, epistemologies and ontologies (Gegeo, 1998; Gegeo \& WatsonGegeo, 1999). Deeply embedded values, relational beliefs, and understandings are found in long-held Indigenous theoretical frameworks; in observing, listening and talking; in empirical and informal forms of learning; in philosophies, ceremonies, histories and storytelling: all as ways of knowing (Mel, 1995; K. H. Thaman, 2003). Place-based approaches aim to contextualise education (Coxon, 2020) in ways that equip people with skills and knowledge for a changing world. They can also create forms of resistance and the means to reshape development, educational and economic discourses and interventions that are underpinned by colonisation, capitalism and globalisation (Gegeo, 2001a; Gegeo \& Watson-Gegeo, 2002). Such approaches do not advocate absolute resistance to, or seclusion from, the outside world. Rather they help to maintain the integrity of ples by protecting and furthering local stories, skills, relational beliefs, confidence, sovereignty, values, and protocols, as firm foundations for interaction with the wider world. Indeed, as stressed by Bulloch,

"[d]iscourses of development are not simply assimilated by local people but are reinterpreted, reshaped and renegotiated on an ongoing basis, thus creating multiple discourses. In some cases, although local notions of development may articulate with Western notions, they have independent indigenous origins"

(2014, p. 179). 
Place-based and Indigenous systems of education should not be oversimplified as merely conservative or backward-looking. They constantly adapt to environmental conditions and to the dynamic interplay of changing empirical knowledge, based on skills, abilities, and problem-solving techniques, as well as changing social values, norms and power relations (Battiste, 2002).

The multiplicity of place-based forms of education in Oceanic contexts is central to this study. This notion is based on my personal experiences in ENB communities, and on the work by Oceanic scholars and educators, who seek the recognition of a multiplicity of Indigenous languages, epistemologies, knowledge systems, relational values and pedagogies; both in informal teaching and learning settings, and within national curricula. This work also seeks to challenge the continued replication of Western-styled curricula and pedagogies that have largely served to devalue and marginalise the worldviews, relational beliefs and ways of knowing of the cultures and communities that send their young to learn (Nabobo-Baba, 2013; Sanga, 2009; T. K. Teaiwa, 2005a; K. H. Thaman, 1993a, 1999, 2000a).

These place-based diverse forms of education contribute to widening understandings and practices of development, which require culturally and context appropriate collaboration between multiple and hybrid ways of knowing, learning and doing. This is inherently challenging to social structures and power relations. There is a complex interaction between reinforcing and challenging gendered roles and divisions of labour (Paterson, 2016); between current local institutional ways of learning, and the need to prepare students to meet current tensions and possibilities in creative and hybrid ways (Fleming \& Palomino-Schalscha, 2016). There is also tension between fulfilling the requirements of curricula, and the imperative to bring principles of relationality as well as Indigenous values and ways of knowing to the core of teaching and learning practices, as in the case in ENB with the creation of locally-designed and Indigenous-led curricula and teaching materials. 
Properly contextualising diverse educational efforts (Coxon, 2020) can also help address challenges imposed by the involvement of external agencies in the delivery of the educational resources, teacher support and infrastructure required by placedbased educational initiatives. On the one hand, educational-aid donors and national governments often come with specific agendas, goals and indicators, and with the tendency to favour the standardisation of institutions and curricula. Engagement by NGOs and religious agencies, on the other hand, may produce contested scenarios where their agendas and standpoints encourage specific types of economic activity and labour possibilities; or might eclipse or reinforce social-political structures, belief systems and gendered power relations. Decontextualised involvement by these agencies can further marginalise ongoing and emerging place-based educational initiatives. As a result, a strong focus on principles of relationality, including methodologies such as tok stori, is being promoted across Oceania (Sanga, 2020).

Without disregarding the existing and potential perpetuation of local inequalities that privilege social-political elites, post-development thinkers advocate and work towards articulations of local places that reveal them as rich in political, social and educational justice and transformative power (Escobar, 2001). These thinkers encourage approaches to education and learning that resemble our pluriverse of contexts, places, peoples, ways of knowing, and of decolonising and development possibilities (A. Kothari et al., 2019).

\subsection{Gender and Oceanic feminisms}

"In our society, it is about the women, specially our old women... they are the pioneers of education"

(Tok stori with Talatala ToMorton Amos, 2016)

A series of development approaches to gender have evolved alongside educationfor-development thought. Alternative development's recognition of the role and agency of women in processes of social-political change and economic growth stimulated a focus on the gender dimensions of scholarly and applied development 
(Momsen, 2009; Rathgeber, 1990). This drew attention to the exclusion of women and girls in both education and development (Boserup, 1970), highlighted the different nature of work by women and the disproportionate impact of environmental degradation on women, and emphasised the need to critically examine gender (Pala, 1977; Young, 1987). All these considerations inform the conceptualisation and delivery of education strategies at different scales. Some approaches advocate for gender equality, interpreted as equality of opportunities for women and men to lead fulfilling lives within an appreciation of their differing needs, constraints and priorities (Momsen, 2009). Applying these principles within development practice requires a commitment to challenging class and power structures, and gender biases, within development agencies and other organisations.

Various targets within global development agendas have promoted education-fordevelopment strategies by emphasising their benefits for gender equality. These targets emphasise global primary education for girls and women, advocating for women's empowerment and the elimination of gender disparities at all educational levels (MDG2), and promoting inclusive and quality education and lifelong learning for all genders (SDG4). These targets are intended to support sustainable development outcomes such as poverty reduction, improved health, and socialeconomic equity. Current UNDP indicators report improved access to, and participation, in education by women and girls worldwide (UNDP, 2017).

Whilst postcolonial and transnational feminist theorists have contributed valuable insights and critiques of feminist thought (Marchand, 2009), for this study I will focus on work and critique by feminists of colour and anti-colonial thinkers, who have stimulated wider appreciation of non-Western and Indigenous concepts of gender and feminist praxis.

A place-specific intersection between education, development and gender was evident throughout this research process. In order to properly engage with participants' discourses, which often highlighted the place-based gender relations 
underpinning education and development discourses and practices, I emphasise the diversity of feminisms in Oceania with a focus on praxis by Oceanic women, Indigenous feminisms, and related decolonising efforts.

\subsubsection{Decolonising feminisms}

In 'Speaking in Tongues: A Letter to $3^{\text {rd }}$ World Women Writers' (1980) Gloria Anzaldúa powerfully reflected on the diverse lived realities of women of colour in literary and educational spaces:

"My dear hermanas, the dangers we face as women writers of color are not the same as those of white women though we have many in common. [...]

Unlikely to be friends of people in high literary places, the beginning woman of color is invisible both in the white male mainstream world and in the white women's feminist world, though in the latter this is gradually changing. The lesbian of color is not only invisible, she doesn't even exist. Our speech, too, is inaudible $[\ldots]$

Because white eyes do not want to know us, they do not bother to learn our language, the language which reflects us, our culture, our spirit. The schools we attended or didn't attend did not give us the skills for writing nor the confidence that we were correct in using our class and ethnic languages. I, for one, became adept at, and majored in English to spite, to show up, the arrogant racist teachers who thought all Chicano children were dumb and dirty. And Spanish was not taught in grade school. And Spanish was not required in High School. And though now I write my poems in Spanish as well as English I feel the rip-off of my native tongue"

(2015, pp. 165-166).

Anzaldúa also recalled Cherríe Moraga's poetry to depict how the voices, tongues and pens of women of colour often negotiate contexts of educational, literary and lived violence and invisibility:

I lack imagination you say

No. I lack language.

The language to clarify

my resistance to the literate.

Words are a war to me.

They threaten my family.

To gain the word

to describe the loss 
I risk losing everything ${ }^{35}$

Decolonising feminist practices help to demarginalise the praxis of Indigenous feminisms, of work by women of colour, and of some postcolonial and anti-colonial feminist theorists (Crenshaw, 1989). Some of these thinkers have developed critiques of Western feminist discourses, noting that these cannot adequately account for the complexity of non-Western women's experiences, and of the similarities and differences in the lived realities of women worldwide (Mohanty, 1984). They acknowledge that women are not a homogeneous group (by race, class, age, sex, or education) and that their experiences and struggles are not universally shared, nor uniform $^{36}$. They also alert readers to the importance of reflecting about relationality within feminist praxis (Mohanty, 1984, p. 340).

All these critiques highlight the multiplicity and complexity of women's identities and organising, which are created and recreated in response to changes in socialpolitical, economic, and gendered power relations within specific historical contexts (Davis, 1983; Hooks, 2000; Moreton-Robinson, 2000; Yuval-Davis, 2006).

\section{Feminisms from Oceania and learning from Oceanic women}

Yvonne Underhill-Sem described diverse manifestations of "Pacific feminisms from self-declared and socially identified feminists, to those whose practices of social reproduction are aligned with sustaining gender-just livelihoods" (2019, p. 263). Feminisms in Oceania "have been received, rejected, reworked, and, in some cases, reclaimed in order to better the position of women and their societies" (Marsh, 1998, p. 665). Feminist theorising and practice are intrinsic to the lived realities of Oceanic women, girls, and gender non-conforming peoples ${ }^{37}$, embedded in the diversity of

\footnotetext{
${ }^{35}$ From Cherríe Moraga (1983) "It's the Poverty" from Loving In The War Years, an unpublished book of poems in Moraga and Anzaldúa (2015).

${ }^{36}$ For more see: Audre Lorde (1997, 2003); Gloria Anzaldúa, Cherríe Moraga, Naomi Littlebear, Nellie Wong $(1987 ; 2011 ; 2015)$.

${ }^{37}$ When 'women and girls' as well as 'people of gender non-conforming identities' are mentioned, this study refers to diversities as identified by the Pacific Feminist Charter (2016) in reference "to specific identities and needs of women, girls, lesbians, bisexual, trans diverse people, intersex people,
} 
their social-political interactions and cultural expressions (Marsh, 1998; Pacific Feminist Charter, 2016; T. K. Teaiwa, 2015; 2005; Henderson, Mallon, \& Teaiwa, 2011). Feminisms in Oceania embrace a diversity of gendered identities: their socialpolitical relationalities, requirements and practices.

This study aims to uphold the centrality of Oceanic feminisms in acknowledging and actively confronting "the growing influence of conservative, faith-inspired ideologies of traditional egalitarianism" (Underhill-Sem, 2019, p. 264) which weaken the struggles of women and gender non-conforming peoples across Oceania. Such ideologies can ignore the complex politics of indigeneity and of gender identity; can dangerously drive presuppositions of universal equality among women; and can obscure women's authority and agency, alongside ongoing gendered power imbalances in education accessibility, political engagement, reproductive health and rights, and exposure to sexual violence (Duituturaga, 2000; Moreton-Robinson, 2000; Trask, 2003). Oceanic feminisms are also central to recognising and challenging the gendered impacts of colonialism which persist in the region (Donald, Strachan, \& Taleo, 2002; Griffen, 1992, 1994; IWDA, 2013; Kelly, 2009; Meyer, 2008; K. Teaiwa, 2015a, 2015b, 2017); as well as the "often violent, increasingly militarized and deeply dogmatic devotion to global capitalist processes of exploitative accumulation that deepens gender inequality" and negatively impact development outcomes across Oceania (Underhill-Sem, 2019, p. 263; see also: Siwatibau, 1997; Claire Slatter \& Underhill-Sem, 2009; T. K. Teaiwa \& Slatter, 2013; Pacific Feminist Charter, 2016). Notably, within Oceanic feminisms there is a recognition of the important teachings in sentiments of gender egalitarianism from the past, whilst simultaneously challenging contemporary leadership systems that disproportionally privilege men (Underhill-Sem, 2019).

\footnotetext{
fa'afafine, leiti, and other non-heteronormative Pacific identities, ethnically diverse women and girls, women of indigenous minorities, women with physical disabilities, women with psychosocial disabilities, sex workers, women living with HIV and aids, women living in rural and remote places, young women, the girl child, older women, heterosexual women, women in non-traditional roles, women in the formal and informal sectors and others"' (p. 1).
} 


\section{Indigenous feminisms}

Indigenous feminist theorising and practice are part of the diversity of feminisms in Oceania; they reflect positionality and the complex politics of indigeneity (StewartHarawira, 2007). This study does not attempt to define Indigenous feminisms, but rather respectfully engages with diverse manifestations of Indigenous feminisms whose political ontologies are also part of decolonisation efforts across the region. Not all Oceanic feminisms explicitly self-identify as Indigenous, but all are nonetheless deeply entangled with the politics of decolonisation and indigeneity in Oceania.

Michaela Moura-Kocoglu reflected on how Indigenous societies' gendered power relations are not static, but rather "have continuously changed and adapted to the complex dynamics of sociocultural, economic, and political imperatives" (2017, p. 240; Somerville, 2018). Such observations reject notions of Indigenous women's lived realities as singular stories of powerlessness and voicelessness (R. Evans, 1994; Figiel, 1999; K. H. Thaman, 2003; Trask, 1989). Indigenous women's knowledge systems and their diverse cultural expressions and social-political relationalities continue to guide women's resistance: sustaining and expanding visions of social relationships and place (Altamirano-Jiménez \& Kermoal, 2016, p. 11; Bargh, 2007; Jenkins \& Pihama, 2001; Jones, Herda, \& Sua'ali'i-Sauni, 2000; Samu, 2011).

Many Indigenous feminist discourses convey notions of gender regimes that recognise female agency, as well as female connection to, and authority on, land, spirituality and community, alongside experiences of colonial invasion and oppression (Meyer, 2008; Moreton-Robinson, 2000). These reflect

“Indigenous women's complexity, as well as authority, [thus] positioning Indigenous Pacific women as active agents in confronting sexist patriarchal hegemony, and instrumental for creating balance in gender relations, family, community, and nation, amid complex processes of decolonization"

(Moura-Kocoglu, 2017, p. 239). 
Makere Stewart-Harawira emphasises that Indigenous feminist praxis stands "firmly in the intersection of the politics of local and global" (2007, p. 11), and considers that much decolonisation of the local, and transformation of the global, can occur from this intersection.

\section{Learning from Oceanic women}

Learning from the teachings and actions of Oceanic women is central to this study. Oceanic women's scholarly contributions and social-political engagement have been essential to the Pacific-wide revitalisation of Indigenous knowledge systems, languages, and ancestral practices, such as the voyaging renaissance that sustains regional genealogical connections as a legacy for future generations (Drollett, 2018; Siope, 2020; L. T. Smith, 1993; 'A M Taufe'ulungaki, 2002; K. Teaiwa, 2015a; T. K. Teaiwa, 2006b; Teamotuaitau, 2012; Teavai-Murphy, 2002, 2016; K. H. Thaman, 2009a). Oceanic women have safeguarded and advocated for Indigenous peoples' environmental knowledge and rights (Fitzgerald \& Teaiwa, 2017; Hutchings et al., 2007; Mead, 1994, 1996; Rongo et al., 2013; Ruru, 2004; 2010; 2010; K. Teaiwa, 2015a). They have helped debunk Orientalism (Figiel, 1999, 2016), and discredited the notion that Indigenous women's literature serves only as a space for deconstructing the 'othering' of Indigenous women's lives (Grace, 1986, 2006; Moura-Kocoglu, 2017; Te Awekotuku, 1991). They have supported the development of understandings of femininities (Avia, 2004) and of masculinities (Sai, 2007), articulating these complex social-political and spiritual identities and interactions. They have fought for equality of gender and sexuality across Oceania and beyond (T. K. Teaiwa, 1994, 2005b, 2015, 2008a).

Oceanic women have shed light on the work of Pacific Island women poets, including Konai Helu Thaman (1974, 1981, 1987, 1993b), whom Selina Tusitala Marsh credits with establishing poetry as a political platform for empowering Pacific women and children (2004). They have illustrated Pacific women's authority in movements for sovereignty in colonised and militourist contexts (Souder, 1992; 
Trask, 1989), providing feminist insights into militarism and "the grotesque commodification of native cultures typical of the tourist industry" (T. K. Teaiwa, 1999, pp. 257-258; 2001, 2011; Trask, 1993). They have exposed the disproportionate effects on, and activism by, the Indigenous women of West Papua under Indonesian colonial occupation (T. K. Teaiwa, 2016). They have shed light on contemporary articulations and negotiations of women in the Pacific diaspora (Henderson, 1999; Hermes, 2018; Marsh et al., 2006; Somerville, 2012; G. T. Taylor, 2013; T. K. Teaiwa, 2006a). They have tackled the issues around Pacific women crossing epistemological borders in academia, (T. K Teaiwa, 1995 in Hermes, 2018) and much more.

\subsubsection{On the intersection of gender, place, education and development in Oceania}

Yvonne Underhill-Sem argued that from a Pacific Islands, place-based perspective, "as we think more about place, so too we must think more about bodies" (2002, p. 54). Her scholarship highlights ways in which the introduction of Western education, religion and medical care, for instance in PNG, have had discursive and material impacts on women's bodies. It illustrates

"remarkable constellations of powers that constitute the wider issues of bodily politics facing women in [PNG]: demands for equitable conditions of employment, the futility of judicial systems to protect women from domestic violence, and the divergent yet complicit nationalist and religious discourses that place hope for change in higher powers"

(2002, p. 55).

Within these constellations of power and from this place-based perspective, Underhill-Sem stresses the transformative power of women's agency (2002).

Storytelling and oral traditions across Oceania contain insights of ancient cultures viewed through, and guarded by, the perspectives, words, relationalities and authority of women (Fairbairn-Dunlop, 1998; Figiel, 1996; Mila, 2005, 2008; K. H. Thaman, 1987). Further insights are found in the multiplicity and sovereignty of gendered identities in these cultures (Barker, 2017; F. Martin, Jackson, McLelland, \& 
Yue, 2010). In this study, participants' storying engages with complex and diverse gendered power relations, at the intersection of place, education and development. This storying reflects peoples who actively challenge contemporary gender relations, drawing from the principles of societal structures where "often both women and men held separate but critical roles for the survival of their communities, land, and custom" (Moura-Kocoglu, 2017, p. 242).

Some Indigenous societal relations, several thinkers suggest, are characterised more by gender complementarity than absolute male or female power, and cannot be adequately conveyed by Western concepts such as 'matriarchal', 'patriarchal', 'matrilineal', 'patrilineal', 'matrilocal', and so on (Sokoloff, Pratt, \& Rosenberg, 2006).

In development discourse and practice in Melanesia there has historically been a tendency to centre outside perceptions of women's 'liberation', which assume 'maledomination/female-oppression' as the core dynamic of existing (traditional) social relations (Jolly, 1997). Whilst there might be similarities in the roles and challenges faced by women and men globally, these exist within different cultural notions of gender relationalities. Many thinkers therefore stress that development efforts towards gender equality in the Pacific, including those focused on education, must be locally meaningful and locally led, and constructed on women's, men's, and gender non-conforming people's lived realities of place, culture and religion (Jolly, 2005; McKinnon et al., 2016; Sai, 2007).

More broadly, analyses by Oceanic women also emphasise the need to critically examine the impacts that development and education discourses and practices have on gender equality and on women's and girls' wellbeing across the region (Espino \& Underhill-Sem, 2012; Griffen, 1992; Sipolo, 1986; T. K. Teaiwa, 2008b; Underhill-Sem, 2016). These examine gendered and local perspectives of aid and development in Oceania (Bryant-Tokalau, 1995; Coxon \& Tolley, 2005; Nabobo-Baba, 2003; Stupples \& Teaiwa, 2017); advocate for the reconceptualisation of learning and education (Nabobo-Baba, 2007, 2013; L. T. Smith, 1993; K. H. Thaman, 2020) as an essential 
dimension in promoting gender equality and preventing violence against women in Oceania (Fairbairn-Dunlop, 2011); and enact processes of decolonisation of Pacific research and of education (Nabobo-Baba, 2008; Ormond, 2018; L. T. Smith, 2012; K. H. Thaman, 2003; Tuck \& Yang, 2012).

Together, these emphasise that Indigenous and Oceanic leadership in education and development is essential to upholding culturally appropriate and Indigenous models of education across the region (Meyer, 2016; Slatter, 2014; D. M. Taylor, 2015; T. K. Teaiwa, 2005a; K. H. Thaman, 1995). This leadership supports knowledge, epistemologies, language, and cultural revitalisation movements and decolonisation processes in education and research (Case, 2013, 2014, 2019; Chu, Rimoni, \& Sanga, 2011; Chu \& Sanga, 2009; Kidman \& Chu, 2017, 2019; Naepi, 2019; T. K. Teaiwa \& Henderson, 2009), as well as Indigenous-designed and led frameworks for development (Brearley, 2015; Davidson-Hunt et al., 2012). Such leadership in action can tackle issues of social justice and gender equality at their intersections with political representation, education, community and international development, rural economic empowerment, peace, and security.

Oceanic women have led the way as educators, planners and advisers in teaching, learning and curriculum development, as well as in educational-aid relationalities and delivery; whilst simultaneously occupying leadership positions in higher education, national parliaments and ministries (Fairbairn-Dunlop, 2005; Laban, 2020; Taufe'ulungaki, 2003; 2002; K. H. Thaman, 1999, 2008). Their work and example, alongside that of many others, champions Oceanic and Indigenous knowledge and leadership in shaping education and development across the region.

\subsection{Conclusion}

Notions of development around the world have been, are, and will continue to be contested, contradictory, and in constant motion. The same is true of education, the purpose and practice of which is closely bound up with development. 
In Oceania, the praxis of Indigenous thinkers and practitioners constitutes a continual challenge to, and negotiation with, imposed notions of development as a linear path of progress. This notion of modernisation has dominated the global theory and practice of development for several centuries, including by shaping formal education into a mechanism for human capital development and the spread of liberal Western values. Modernisation and its current economic, political and educational incarnation, neoliberalism, have been challenged with various alternative theories, practices and approaches, including dependency and underdevelopment theories, alternative development, and sustainable development. Whilst relevant and influential, none of these critiques and approaches pay substantial or sufficient attention to the relational nature of the intersections between development and education.

This study aligns with and draws inspiration from post-development theories and thinkers, in particular the idea of a 'pluriverse of alternatives' to mainstream development that reflect and respond to local and Indigenous peoples, places, ontologies, and epistemologies (A. Kothari et al., 2019). At the educationdevelopment nexus these alternatives can be expressed as diverse community economies and place-based models of education, which require culturally and contextually attuned negotiation between multiple knowledge systems and locally defined needs and aspirations. These approaches help to maintain the ecological and cultural integrity of ples; the transmission of knowledge, skills and identity; and the continuation of truly sustainable and relevant livelihood strategies.

The intersection of gender and development is likewise highly relevant to education. This study prioritises Indigenous, and especially Oceanic, feminisms as part of its decolonising agenda; the authors of these feminisms embrace the vastness and the depths of Oceania (T. K. Teaiwa, 2005b), and centre gender diversities in discourse and action towards a culturally grounded understanding of both gender equality and decolonisation. 


\section{Education discourses and global strategies}

\subsection{Introduction}

In this chapter I focus on theories as well as global discourses and strategies of education. I reflect on the human-capital-creation/conscientisation divide that persists in the related literature and policy outcomes; signalling in turn approaches to education that go beyond conscientisation. Later I focus on global education-fordevelopment strategies and on their influence on countries' policy and budget priorities.

\subsection{Global discourses of education}

Global discourses on education focus on its value as a tool to combat poverty and to promote socio-economic equity. They highlight the importance of access to basic education as a means to equip people with the fundamental skills required to effectively participate in their society and economy. Education is considered to have a direct effect on overcoming gender bias, improving health, alleviating poverty and contributing towards economic growth. In some global discourses it is maintained that "education at all levels is critical for the overall economic growth needed to appreciably lift a nation's standard of living" (Sullivan in Thomas \& Bessell, 1999, p. 1). Further, they argue that in an increasingly globalising world, 'competition, knowledge and technology' are the drivers of the expansion of, and change in, economies, industries, mobility patterns and labour markets. They suggest that in a world where wealth is significantly created by knowledge, education is crucial for progressive engagement in a dynamic global marketplace. The resulting growing demand for highly skilled, flexible and innovative workers places "good education 
and skills development, by both the public and public sectors" $(1999$, p. 1) as cornerstones of national prosperity.

As pointed out by Kanbur, "education is almost universally recognised as providing the critical foundation for any meaningful long-term development" (1984, p. 1). It is broadly agreed that education is a vital prerequisite for sustainable development (Colclough, 2012; Thomas \& Bessell, 1999). For instance, primary education has been said to be the largest single contributor to social and economic growth. There is also an emphasis on the education of girls and women as underpinning many positive development outcomes around the world, including breaking the cycle of poverty, the successful improvement of reproductive and family health, reducing the likelihood of early or enforced marriage, as well as reducing infant mortality and increasing the likelihood of children attending school (Chaudhry, Malik, Hassan, \& Faridi, 2010; Colclough, 2012; Nussbaum, 2000; P. Schultz, 2002; UNICEF, 2015).

UNICEF maintains that a ripple and intergenerational effect can be created when all children have access to a quality education which is firmly grounded in human rights and gender equality (2015). Furthermore, education is regarded as fundamental to equipping people with the skills necessary for employment-related mobility, this is argued to enhance capabilities and freedoms, including the freedom of exit (Gribble, 2008; McKenzie \& Rapoport, 2010; Sjaastad, 1962; Todaro, 1969). Education's vital role in meaningful long-term development has been inscribed into global education goals, from the confirmation of education as a basic human right during the World Conference on Education for All (EFA) in 1990, through the launching an implementation of the MDGs in the 2000s, to the launch of SDGs in 2015, there has been a palpable global push by multinational organisations, individual governments and aid providers pledging support and implementing relevant policies towards achieving the globally agreed education goals contained in those frameworks (Kiddle, 2005; UN, 2017; UNDP, 2017). 
But what do some of those global discourses referenced above mean by 'national prosperity', 'good or quality education' and 'knowledge and skills development'? And importantly, what concepts and praxis of development or 'sustainable development' are conveyed through those globally agreed goals? Is promoting education as the human-capital service provider for expanding economies, industries and labour markets justified on the quest for global relevance and competitiveness in a globalising economy? But, what about those that following Freire's teachings $(1970,1973)$ promote education as encompassing an consciousness-raising and liberating value, which can teach peoples about the causes behind their oppression and poverty, and thus provide them with the means necessary for their own emancipation and empowerment? (Gamlen et al., 2017). Below I discuss these two approaches, inquire into their divide and signal approaches that learn from, yet surpass said divide.

\subsubsection{The human-capital/conscientisation inquiry}

Whilst these two lines of inquiry - one admittedly neoliberal and economic and the other striving towards liberation and social justice - may profoundly differ in their core tenets and approach, both agree on the value of education in providing a range of economic or political means for individual or collective development. As observed by Gamlen et al. (2017), this consensus makes a strong case for investment in education, one which has further become embedded in global development theory and rhetoric: from the modernisation ideas of Parsons \& Smelser (1956), Rostow (1960) and Lerner (1964), through to the social opportunity, capability and 'development as freedom' assertions of Sen (1999). Nonetheless, alongside this unresolved conflict of ideas between neoliberal and radical approaches, there are also other considerations that require to be highlighted such as that throughout Oceania, the balance of representation between the various functions and values of education continues to be skewed against indigenous values, concerns, practices and philosophies (Sanga, 2000). 


\section{Human capital approaches to education}

The first line of inquiry refers to an instrumental view of education that sees it contributing to the development of human capital. National prosperity has been argued to be largely dependent on the investment on 'good education' and 'skills development' by governments (Sullivan, 1999 in Thomas \& Bessell, 1999). The move against colonial domination that followed the post-WWII era and paved the way for global economic interdependence and national self-determination, preceded decades of a new kind of imperialism that promoted and implemented economic growthcentred policies and development plans. Interventions in the education, health and food sectors of the Global South formed part of the post-WWII World Bank driven and implemented global relaunching of the whole economy. Since then, government policies as well as budget provisions and contributions by civil society (e.g. churches, NGOs, private sector), and international aid allocations to the education sector, have been largely directed towards increased economic output by investing in building human capital, this is, in the creation of a highly skilled, flexible and innovative workforce that could contribute to the economic development of the nation (Sachs, 1992). Behind the many decades of interventions by countless international agencies and administrations into the education systems of countries of the Global South, remain latent and sometimes overt ideas that these countries face scarcity of a skilled workforce to compete in a globalising economy and in general lack the leadership to manage and run their own economies. Furthermore, the education policies that are influenced by these interventions are often founded on tenets of either combating inequality, or promoting growth, urban employment, rural development, rural-urban migration and so forth (Kanbur \& Hau'ofa, 1984).

The influence of Human Capital theory on Western education is evidenced through its role in the shaping of government sanctioned education policies throughout the world that are driven by economic theories of development and of education (Tan, 2014). Historically, the greatest support to both human capital and the application of 
free market economics to public education came from the Chicago School of Economics (Van Overtveldt, 2007). As part of the Chicago School and in the forefront of applying economics to education were Gary Becker, Milton Friedman, Theodore Schultz, and James Heckman, who alongside sociologist James Coleman developed "theoretical frameworks on social capital and rational choice to the economization of education" (Spring, 2015, p. 1). The economisation of education involved the increased involvement of economists in measuring how family life as well as schools contribute to economic growth and productivity. The application of market principles to education largely attributed to the work of Becker and Friedman had a lasting impact on the language of education with the introduction of "terms such as competition, investment, consumer choice, for-profit schools, vouchers, economic progress, and global free trade in educational services" (Spring, 2015, p. 2). Spring (2015) refers to the presence and expansion of this language through these authors advocacy for school choice and for-profit education, by referencing some of their economic phrases which invoke the increase of economic productivity through vocational training, the role of schools in raising the economic value of students, as well as references to students as consumers, teachers as producers, and colleges as engaged in the business of selling schooling. He further referenced the use of terms such as the 'education industry', whose vocational and professional branches are considered an investment in human capital, which was equated to investing in either infrastructure or machinery (Becker, 1964; Friedman, 1962).

The work of economist Theodore Schultz especially from the 1960s, is foundational to theoretical and applied principles of human-capital theory. The Economic Value of Education (1963) one of Schultz's classic works, carried forward the economic language applied to education, as he refers to schools as firms specialising in producing schooling, and to the education establishment as an industry making production decisions. In the meantime, the public view of education as an economic enterprise was effectively influenced by Becker's 1964 book Human Capital. 
Through this and other works by Becker, schooling becomes regarded as 'investment in human capital', and thus education becomes in itself an investment with returns related to a rise in productivity and incomes with direct positive effects on economic growth, and it reaches as far as contributing to ending poverty and increased economic equity (1964; Spring, 2015). Schultz's advocacy for the importance of human capital is built upon what he believes is the economic importance of individuals for the wealth of nations. These beliefs grow in a time in the US, when the post-WWII era was characterised by anti-communist sentiments and the Cold War and saw rising concerns about poverty and a simultaneous ascendency of the Chicago School's ideas of the central role of education in terms of human capital and free market.

Regarding education as of primarily economic importance to national prosperity has influenced education policy throughout the world. At the global level, organisations such as the OECD ${ }^{38}$, the World Economic Forum and the World Bank, supported policies and provided monetary assistance to nations that adopted human capital economics into education policy-making and curriculum development as a direct contributor to economic growth (Spring, 2015). As pointed out by Gamlen et al., "this leads to policies which promote vocational training in ways which provide particular skills to match the labour demands of capital enterprises", [further influencing and sometimes shaping a skills-based curriculum that can span from] “basic numerical skills, through training in industry-specific skills to high-level professional education" (2017, p. 5). Building human capital to supply a skilled labour force to support national prosperity has for decades been at the core of education policies as well as interventions worldwide. As argued by Kanbur and Hau'ofa, Western-styled educational systems worldwide including those in Oceania,

${ }^{38}$ The OECD defines human capital as "productive wealth embodied in labor, skills and knowledge" (2001). 
have been also powerfully shaped by their functions as the suppliers of a skilled, socialised and hierchised workforce (1984, p. 1).

Human capital economics adopted by nations worldwide point at some of the goals of investing on education such as increasing individual income of educated employees, productivity and economic growth, lowering unemployment and resulting in greater social mobility and decrease in income inequalities (Pritchett, 2001). Human capital ideas see the stock of knowledge, as well as inherent and acquired qualities of a person as being of importance to the person's economic productivity (Garibaldi, 2006), thus arguing that investment in education can increase both the productivity and income of people. This became a central argument for the economic development of so-called 'developing' nations and its peoples.

\section{Education as instrument for building human-capital}

Becker (1994) and other authors, conversely, present examples suggesting that in line with human-capital theoretical principles, investment in education has contributed to elevating the earning power of educated peoples, with congruently higher economic gains particularly for so-called 'developing' countries. Surveys conducted by Blundell at al. (1999), present a series of cross-country examples by various authors on individual, corporation/firm and national returns to investment on education, including the relationship between education and earnings. They report that for instance, individual returns in the UK have historically varied over time depending on an evolving interaction between demand for and supply of workers at each qualification level (Moghadam, 1990; Schmitt, 1993). Studies on private returns to individual workers' earnings from employer-provided education and vocational training, suggest being consistently significant, reporting above 5 percent higher real earnings than individuals who do not undertake such training (Blundell, Dearden, \& Meghir, 1996). Other cross-country household surveys and international comparative studies conducted in the US, Ecuador, Venezuela and Argentina 
suggest that the returns are largest for investments in primary education, as well as showing that the rate of return to education tends to be higher in low-income countries (Psacharopoulos, 1981, 1994). More recent studies by Adom and AsareYeboa (2016) provide a picture of a strong complementarity between key components of human capital and a resulting influence in the success of women entrepreneurs and women working in the service, manufacturing and trading industries in parts of sub-Sahara Africa. The authors report that critical to their success were qualifications and knowledge acquired through formal education, as well as skills, competencies and expertise acquired through training.

Studies on the expansion of formal education (primary and secondary schooling) in Nigeria and its long-term political effects across local governmental areas and gender have found large increases in civic and political engagement (Larreguy \& Marshall, 2017). However, the authors argue that education's participatory effects in nonconsolidated democracies still suffer from unequal political representation and limited elite competition; as such the projected benefits of educational reforms and formal education expansion still do not reach the politically disadvantaged (Casey, Glennerster, \& Miguel, 2012; Gugerty \& Kremer, 2008). Yet another recent comparative study in colonial Benin, West Africa found that education had a positive impact on increasing the living standards and political engagement of educated peoples as opposed to those without the same level of education. Further, they report a direct benefit from an individual's education by contributing to their extended family's economic well-being ${ }^{39}$ (Wantchekon, Klašnja, \& Novta, 2014). Following this line of reasoning, various authors have claimed a positive correlation between education and earnings, presenting examples where investment in human capital through formal education and training is an important factor in individual, corporation/firm and national economic growth. These examples present positive

\footnotetext{
${ }^{39}$ This is common place in other parts of the world where the decision-making process on investment on formal education or training of an individual highlights the role of the extended family, the wider community and family diaspora remittances (Gibson-Graham, 2005).
} 
economic returns for individuals, including further individual benefits from training in terms of adaptability, mobility, higher employment stability and job portability ${ }^{40}$, which incentivises the individual to invest in human capital (private return). Those individual benefits have been argued to also spill over to others and provide gains to the economy as a whole (social return).

The accuracy of this line of reasoning however is discussed below, particularly when public investment on education and training has to be justified against a distinction between private and social returns (Blundell et al., 1999). This is because a considerable number of studies corroborate that education and training provide individual private economic returns; however, this is argued to be true to a lesser extent when evaluating the contributions to national economic growth. Moreover, the strong theoretical and applied (e.g. policy, curricula) alignment of these approaches to economic theories of development such as modernisation, means that this line of reasoning has permeated international aid and development's rhetoric and practices worldwide, particularly in education policy interventions and monetary assistance justified on the grounds of supporting the development of nations.

\section{Criticisms and limitations to human-capital approaches to education}

A range of criticisms to approaching education as a means for economic development, point at historical evidence from around the world of workers becoming overeducated and overqualified in relation to available job positions. According to these critics, the mismatch between market demand of workers and education pairing job availability increases the chances of unemployment, underemployment ${ }^{41}$, as well as occupational and political dissatisfaction (Burris, 1983; R. B. Freeman, 1976; Hultin, Lundberg, Lundin, \& Magnusson, 2016; Yamada,

\footnotetext{
${ }^{40}$ A depreciation of skills over time is however, also reported (Blundell et al., 1999).

${ }^{41}$ Underemployment is the condition in which people in a labour force are employed at less than fulltime or at jobs inadequate with respect to their training or economic needs.
} 
2015). Moreover, research by Emrullah Tan (2014) gathers documented examples that suggest that education can increase private returns but not necessarily social returns. Tan notes that human capital economists acknowledge nonmonetary (e.g. social, cultural, intellectual and aesthetic) benefits of education to the individual and society, yet he highlights that these are regarded as mere positive externalities. A micro-macro paradox (Pritchett, 2001) arises where the evidence points at the impacts of education greatly differing from the individual to the national level. Tan cites different studies around the world where authors: do not find strong evidence for the claim that investing in human capital necessarily produces economic growth (Caselli, Esquivel, \& Lefort, 1996); point to cross-country surveys that reveal that "human capital accumulation fails to enter significantly in the determination of economic growth, and even enters with a negative point estimate" (Benhabib \& Spiegel, 1994, p. 166); and present evidence of a negative correlation between schooling and growth in some countries (Islam, 1995);

"[f]or example, even though schooling rates substantially increased in several countries such as Mexico, El Salvador, Bolivia, Jamaica, Peru, and Jordan from 1965 to 2000, only a slight improvement or even negative growth took place in the aggregate production levels of these countries" (L Pritchett, 2009 in Tan, 2014, p. 425).

Nonetheless, Tan also acknowledges that a slow or negative growth, despite investment and increased schooling in a country, is not sufficient evidence to dismiss the claim that building human capital can contribute to economic growth.

Supported by Pritchett's (2001) work, Tan maintains that it can be argued that "social, political, institutional, and cultural factors need to be considered when the impacts of education is predicted" (Tan, 2014, p. 426). Some factors highlighted by other authors' research are:

“an individual's ability measured in early childhood, family background (family income, parental education and number of siblings) and local environment (the opportunities in the local unskilled labour market, the 
quality of schools in the local region and the proximity to a college) in affecting educational attainment"

(Dearden, 1998; Blackburn \& Neumark, 1993; Butcher \& Case, 1994; Card \& Krueger, 1992; Card, 1993 in Blundell et al., 1999, p. 6).

It is argued that a human-capital approach to education has centered education around the requirements of businesses and thus relegated it "to a mere supplementary component of business and industry" (Stuart, 2005 in Tan, 2014, p. 428). Economy-driven education policies are argued to shape education into no more than a survival tool to withstand economic uncertainties (Coffield, 1999; Field, 2000). Ben Fine (2002) suggested that a limited and decontextualised view of the world occurs when education for human-capital building uses contemporary mainstream economics as lenses alone. Thinkers thus stress the social importance of education (Cunningham, 2004). Further expressing their concerns in these approaches' ability to deal with issues of history, identity, gender, culture, cultural expressions such as the creative arts and emotions (Folbre, 1994; Robeyns, 2006).

McGrath (2012) argued that the orthodox dominant account of TVET (technical vocational education and training) ${ }^{42}$ fits squarely in Gidden's (1994) description of productivism. This account enshrines economic development as the ultimate goal of society and sees late modernity being underpinned by the separation of paid employment from other aspects of life. Several thinkers argue that the dominant model of TVET came along with the push for Western models of development that permeated the world since the 1960s. Here, VET assisted "the spread of a monolithic account of industrialisation, modernisation and paid work" (McGrath, 2012, p. 4; see also: Fischer, 2009; Watson, 1994), and has been largely influenced by the ethos of

\footnotetext{
42 Technical vocational education and training (TVET) can carry different meanings to different peoples in regard to formal, non-formal and informal modes of learning and skills formation; formal and informal sector workplaces; as well as its overall objectives (McGrath, 2012, pp. 2-3). This study does not attempt at a definition, rather views it as a changing and context-grounded set of practices and technologies.
} 
productivity, and the ideological framework of neoliberalism (Anderson, 2009). In Anderson's view, within these models of development:

"the institution of TVET [can be] based on a restricted and instrumental view of lifeworlds which reduces people and the environment to the status of human and natural resources for economic exploitation. Such a perspective overlooks the complex and interdependent nature of human existence, the source and meanings of which are inextricably linked to the social relations, cultural practices and natural material conditions. TVET students are not only already, or aiming to become, workers. They are also human beings and citizens with a wide range of needs, relationships, duties, aspirations and interests beyond work; in the family, the local community, in civil society and the global environment. [...] Yet in TVET they learn only to labour and produce commodities"

(2009, pp. 44-45).

Whilst an outright rejection of the orthodox model of TVET would diminish some of its successes (Russo, Bainbridge, \& Dunkel, 2013), and would reveal an outdated view on the general reputation of conventional TVET (McGrath, 2011) in different places of the world. Nonetheless, McGrath argues that individualistic assumptions and short-term focus regarding employability as ultimate goal, and the focus on a particular model of work as paid employment, with serious gender implications: are limitations to this orthodox model, both in terms of its theoretical faculty and its practical efficiency (2012, p. 5).

Whilst TVET has increasingly become a popular policy tool at the national level (Coles \& Werquin, 2009) with multilateral official development assistance (K King \& Palmer, 2011; UNESCO, 2012a), critics argue that it remained a largely evaded topic in terms of human development (Brockmann, Clarke, \& Winch, 2011; Strathdee, 2011; Unwin, 2004). In the theory this began to shift alongside human rights and social inclusion perspectives on education and TVET becoming of import to the development of the MDGs (Tomasevski, 2001; Unterhalter, 2012) and the SDGs (UNDP, 2019). Thinkers argue that in the beginning this human rights approach leaned generally towards legalism and universalistic notions of justice (Rawls, 1971), this was later countered with broader and more flexible notions to reflect social 
complexities (Alston \& Robinson, 2005; Nussbaum, 2003; Sen, 1999). Nonetheless, in practice less than sufficient evidence back TVET reforms having substantial positive impacts on either economic competitiveness or social inclusion (Colley, James, Diment, \& Tedder, 2003), particularly in the Global South (McGrath, 2012; Watson, 1994).

As McGrath, Anderson (2009) and Watson (1994) highlight, it is not about having an incomplete understanding of the way TVET works. The orthodox TVET model is not inherently impoverished, rather its impoverishment "lies in its implicit grounding within an outmoded and inadequate development paradigm" (McGrath, 2012, p. 5). This is a paradigm that is narrowly economic and productivist, and which does not reflect the meanings and diversities of what it is to learn, and ultimately, what it is to be human. This is a paradigm that has also ignored the wealth of literature on and practice of informal learning and place-based learning structures (Fleming \& Palomino-Schalscha, 2016; Folaumahina, 2018; Magaga, 2018; Sanga et al., 2018; K. H. Thaman, 1997).

Nussbaum (2010) and Ball (2010) have lamented that education under human-capital approaches is increasingly conceived as a profit-making business and a market commodity that aids the formulation of labour as a form of capitalist enterprise. The authors further lament that education is no longer viewed as a strategy to promote human development and freedom. Spring explains how global businesses and organisations guarding their interests, support the idea of a human capital approach to permeate education because of its role in emphasising teaching skills required in the workplace. In this context, the author argues:

"human capital goals for education trump other educational goals, such as education for social justice, environmental improvement, political participation, and citizenship training"

(2015, p. 5). 
This approach also dismisses and neglects diverse and long-standing non-capitalist economic models around the world that are founded on values of reciprocity, are accountable to bonds of kin and cultural protocol, and are responsible for the wellbeing of the community by practicing gifting, sharing and the reciprocal exchange of knowledge, goods and services to sustain the young, aged and disadvantaged (Gibson-Graham, 2005).

\subsubsection{Education for critical consciousness beyond conscientisation}

An approach to education that is geared towards critical consciousness, conscientisation and social justice, has been advocated and championed by thinkers throughout the world said to derive from 1970s Freirean approaches. Paulo Freire advocated for the participation of local peoples in identifying their own requirements of development (Freire, 1970; 1973; Chambers, 1997). This, he believed had to be supported by a kind of education that would raise consciousness, teaching people the reasons behind their oppression and poverty, and in turn empowering them with the knowledge and agency to change their lived realities and liberate themselves (1970).

Linda Tuhiwai Smith points out that according to Freire's model of change, when people learn to read the words and worlds of injustice, conscientisation will lead to action or struggle, and they will thus act against injustice. However, she argues referring to the work by Graham Smith-, that in some Indigenous contexts such as the Māori context, "participation in struggle can and often does come before a raised consciousness" (2012, pp. 199-200). Their research shows that participation in struggles in many cases is in the form of solidarity with friends and family, or pragmatically motivated, thus, presenting a form of struggle that can be seen as "group or collective agency rather than individual consciousness" (2012, p. 200). Collective and individual agency are very much at the core of this analysis when 
issues around the differing concepts of poverty ${ }^{43}$, freedom and social justice are central to these discourses.

Education models that strive to contribute to upholding human rights values and societal egalitarian principles, are regarded foundational to achieving social justice, and are thus endorsed in some rhetorical streams and policies by country governments (P. Schultz, 2002) and international organisations such as the UNDP (2018; 2019), UNICEF (2015) and UNESCO $(2015,2018)$. Education is believed to provide skills and the freedom of access to knowledge and information that can transform the decision-making processes of people, providing them with more options in areas of their lives such as reproductive health, employment opportunities, use of technologies, mobility, and so on (Chaudhry et al., 2010; Colclough, 2012; Gribble, 2008; McKenzie \& Rapoport, 2010; Nussbaum, 2000). Freedom within these approaches, however, does not refer solely to increased abilities for economic prosperity, but rather to efforts towards achieving social justice that reflects the social complexities of our world (Nussbaum, 2003; Sen, 1999). Therefore, education can contribute to a kind of social justice that is enacted through promoting and sustaining peoples and Indigenous peoples' freedom to participate in and advance their own community diverse economies (e.g. shell-money and community non-capitalist economic structures) (J K Gibson-Graham, 2008; 2005); the freedom to define and enact their own concepts and ontologies of life structures and development (e.g. Sumak Kawsay/good living, tok stori relational and dialogical methodologies of interaction (Sanga \& Reynolds, 2019)); the freedom to pose, conduct and control their own lines of inquiry and research (L. T. Smith, 2012); the freedom to practice and safeguard the secret and sacred nature of learning processes and knowledge systems (e.g. Indigenous knowledge domains (Sanga, 2018)).

${ }^{43}$ Diverse notions of poverty and wealth are discussed in chapter 5 and throughout the next chapters. 
Moreover, these approaches to education, freedom and social justice can contribute to the decolonising efforts of many peoples throughout the world.

Historical turns in development theory show a reluctant, yet growing, recognition of the importance of centering humans, the Earth, relationality and diversity at the core of development praxis, rather than individualistic economic competitiveness (A. Kothari et al., 2019). They also highlight the need to go beyond economistic notions of the relationship between development and education (McGrath, 1999; UNDP, 2010; UNESCO, 2018). This broader vision of development which includes some older philosophical notions of the good life (Dávalos, 2009) and human flourishing, whilst others invest terms such as human rights (Tomasevski, 2001), capabilities (Nussbaum, 2000, 2003), freedom, agency, well-being and security (Sen, 1999) with radically shifted meanings (McGrath, 2012, p. 6), is important in understanding the current relationship between development and education.

Oceanic thinkers, scholars and peoples have challenged views of education as merely a base for economic prosperity based on modernisation theories of development, and as a route to success in the global market economy. They thus work towards an approach to education that aided by the principles of conscientisation and social justice, can go yet many steps further. What is advocated for, is an approach to education that supports locally appropriate concepts of cultural development. That is a relational approach to education, an approach that sees learning, the people involved and their relationships between each other and their environment, as sacred spaces and processes of cultural renewal (Gegeo, 2001a; Hau'ofa, 1993; Sanga, 2014, 2016; 'A M Taufe'ulungaki, 2000; K. H. Thaman, 1997, 2009c). These kind of approaches to education have been characteristic of Oceania cultures for millennia and continue to be enacted and championed by many Pacific leaders in education and development at the regional and local levels (I elaborate on this throughout this thesis). 


\subsection{Global education-for-development strategies}

Both sides of the philosophical and applied divide between neoliberal and more consciousness raising approaches to education inform international development policies and are reflected in countries' budgets and policies destined to achieve internationally agreed goals and targets.

Education is considered vital for the development of a country, yet, the choice of kind of education, as well as education budget allocation, policy solutions and implementations largely "depend on the kind of 'development' that the country's political leadership seeks to promote" (Kanbur \& Hau'ofa, 1984, p. 4). At the global level Tolley points out that "since the early 1990s, education has emerged in a central role within the current development paradigm [and] it is close to be regarded as a panacea for development and one that is hard to contend and hard to question" (2005, p. 417). The current development paradigm comprises tenets of the divide of approaches to education explained above, nevertheless several thinkers point at an unbalance skewed in favour of national economic growth as central to ideas of development in many countries worldwide and also driving much of international policy on education-for-development formulations. Whatever the case, countries around the world, including those in Oceania, have been urged to adopt and be accountable to internationally agreed education targets such as:

the EFA set of goals of 1990 and its later reviewed and ratified six-goal version under the Dakar Framework of Action of 2000, whose overall goal was to 'provide universal basic education for all by $2015^{\prime}{ }^{44}$;

\footnotetext{
${ }^{44}$ Education for All (EFA): was first launched during the World Conference on Education for all in 1990, aiming to provide universal primary education for all by 2000. EFA was later adopted by The Dakar Framework in 2000 at the World Education Forum, developing six EFA goals to be achieved by 2015. UNESCO was mandated to lead and coordinate the international efforts to achieve those goals, by engaging with all relevant governments, development agencies, civil society, non-government organization, etc. (Kiddle, 2005; UNESCO, 2003a). However, by 2015 the EFA Global Monitoring Report found that just one third of all countries have achieved all the measurable EFA goals.
} 
the UN Millennium Development Goals (MDGs) of 2000 - Goal 2: 'Achieve universal primary education for boys and girls by $2015^{\prime 45}$; and

the UN Sustainable Development Goals (SDGs) ${ }^{46}$ of 2015 - Goal 4: 'Ensure inclusive and equitable quality education and promote lifelong learning opportunities for all by 2030' (UNDP, 2017).

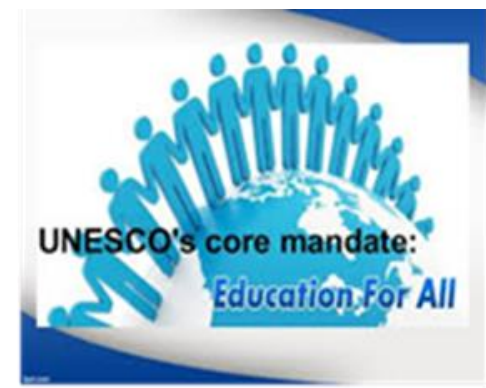

UNESCO's mandate of 2000:

"Universal basic education for all"

Set first in 1990 and revised in 2000, to be achieved by 2015

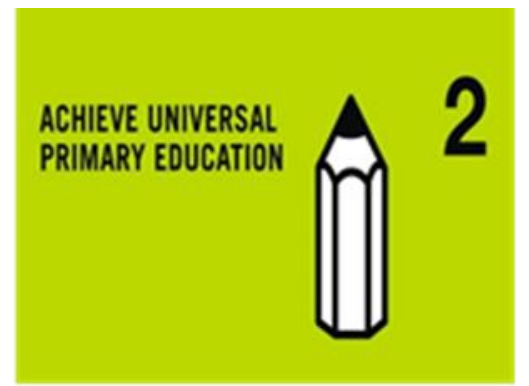

Millennium Development Goal 2:

"Achieve universal primary education for boys and girls"

Set in 2000, to be achieved by 2015

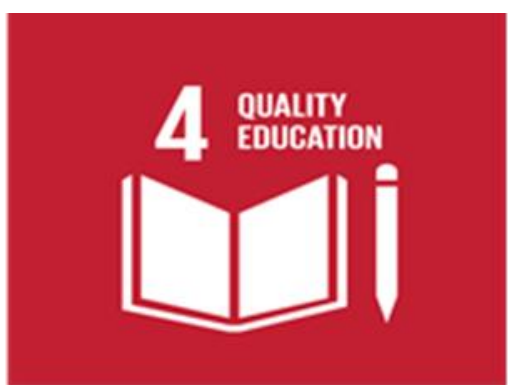

Sustainable Development Goal 4: "Ensure inclusive and equitable quality education and promote lifelong learning opportunities for all"

Set in 2015 to be achieved by 2030

Figure 2. adapted from UNESCO (2003a) and UNDP (2017)

International development policies inscribed into these global agendas, reflect a positive theoretical perspective on education, one capable of attracting significant aid funding to carry out various education initiatives prescribed in said agendas (Bonal, 2004; Gamlen et al., 2017; UNESCO, 2012b; Unterhalter, 2012). For instance, throughout the 1990s and 2000s, plans based on an EFA criterion were installed into individual countries' national frameworks of poverty reduction, budget priority

\footnotetext{
${ }^{45}$ The Millennium Development Goals (MDGs): are the eight international development goals for the year 2015, established during the Millennium Summit of the United Nations in 2000, following the adoption of the UN Millennium Declaration. All $191 \mathrm{UN}$ member states at that time, and at least 22 international organisations, committed themselves to help achieve these goals by 2015. The eight MDGs - which range from halving extreme poverty rates to halting the spread of HIV/AIDS and providing universal primary education, all by the target date of 2015 - formed a blueprint agreed to by all the world's countries and leading development institutions (UN, 2017).

${ }^{46}$ The Sustainable Development Goals (SDGs): are a universal call to action to end poverty, protect the planet and ensure that all people enjoy peace and prosperity. The 17 goals pledge to work in the spirit of partnership and pragmatism to make the right choices now to improve life, in a sustainable way, for future generations. Dignity, peace and prosperity for people and the planet, now and in the future at the heart of the 2030 Agenda, the UNDP operates as its coordinator (UNDP, 2017).
} 
allocation and gender equity strategies. UNESCO supported these action plans "often through consultants attached to education ministries, to a requesting country in developing these action plans" (Kiddle, 2005, p. 189). This however, creates question marks on the purpose, philosophy and cultural appropriateness of such education strategies when designed and implemented by external consultants. Although EFA did not meet its goals by 2015, it did position access to basic education as the most important element of education-for-development, it follows that its partial success and partial failure points to the need to address education more broadly (Kenneth King, McGrath, \& Rose, 2007; McGrath, 2012).

Some authors describe how education-for-development strategies thus became an international focus, and in the struggle to meet their obligations to both global and regional targets, nation-states increasingly allowed external influence in an area previously considered to be the sole responsibility of the state. Tolley for instance explains how:

"the myriad of meanings and understandings surrounding the nature and role of basic education, and the ever-increasing pressure to improve the quality' of basic education, leaves some countries vulnerable to policy decisions that may never achieve this intention" (2005, p. 417).

By the time that the global development paradigm shifted towards poverty reduction in the early 2000s, MDG2 focused on the achievement of universal primary education ${ }^{47}$, whilst also promoting gender equity and the empowerment of women, through the elimination of gender disparity at all levels of education in all UN member states by 2015. The 'pro-poor' agenda of international development and aid agencies had gathered momentum since 1999 through the World Bank's launching of the Poverty Reduction Strategy alongside the International Monetary Fund (IMF), which advocated that: it was more important than ever to the

\footnotetext{
47 The Millennium Development Goal 2: 'Achieve universal primary education', refers to children everywhere, all boys and girls of UN Member countries completing a full course of primary schooling by 2015.
} 
eradication of poverty to bring the marginalised into the mainstream economy (McDonnell, Lecomte, \& Wegimont, 2003; World Bank, 2019). Education thus played a central role in delivering the aims of this agenda amidst "donor policies of debt reduction and good governance, together with the promotion of 'partnership', 'ownership', 'participation', etc.” (Tolley, 2005, p. 412). The World Bank's 1999 Education Sector Strategy paper identified investment in education as the crucial driver towards economic growth and development worldwide. Alongside political reforms and economic adjustment, the improvement of the quality of formal educational systems in countries of the Global South, was thus prescribed as one significant and practical means of delivering the aims of this 'pro-poor', economic growth-centred agenda (1999). However, the adoption and applicability of these poverty-focus agendas as defined by the World Bank in certain contexts such as the Pacific Region, have revealed limitations in the aim of using an all-encompassing policy that remained muddled and contradictory; exposing also a limited understanding of "the nature of poverty in the immediate region and its underlying causes" (Storey et al., 2005, p. 30), which could assist in the consolidation of effective partnerships.

Some considerable lessons learned, and improvements are worth noting regarding the substitution of MDGs by the 2030 Sustainable Development agenda inscribed into the 17 SDGs in 2015, which looks forward to a future where dignity, peace and prosperity for people and planet can be achieved throughout the world (UNDP, 2019). SGD4 the education goal, is to 'ensure inclusive and equitable quality education and promote lifelong learning opportunities for all by 2030'. Considerable progress is noted in terms of access and participation in education, with significant achievement of universal primary education, consistently higher enrolment rates for so-called developing regions, including higher literacy rates for girls and women (UNDP, 2017). This supports the UNDP's and UNESCO's view that sees the achievement of inclusive and quality education for all boys and girls, women and 
men as a vital means towards sustainable development (UNESCO, 2018). SDG4 includes targets to eliminate disparities and access to all levels of education related to gender, rich-poor, rural-urban, vulnerable peoples and peoples with disabilities. It also strives to be sensitive to Indigenous peoples' situations. However, as reported by the review at the High-level Political Forum on Sustainable Development of 2019, there are a still large areas that require of improvement. It is reported that there is a need to keep pace with rapid technological changes, as well as refocussing "efforts to improve learning outcomes for the full life cycle, especially for women, girls and marginalized people in vulnerable settings" (UNDP, 2019).

Historically, global agendas have shown little interest in TVET's role in educationfor-development, particularly in the Global South. TVET has been largely ignored by the EFA goals and by several policy papers and donor agency work, mostly from the World Bank (Heyneman, 1985; Lauglo \& Lillis, 1988; Psacharopoulos, 1981, 1985), that appeared to perpetuate an account of public VET as inefficient and ineffective (Foster, 1965). This meant the paucity of TVET research as well as minimum theoretical and policy developments for over twenty years in the Global South (McGrath, 2012). The view of TVET as unimportant was furthered in the MDGs. Nonetheless, each of these agendas have drawn lessons from its predecessor (Kenneth King et al., 2007) and subsequently provided additional and more TVETspecific targets. Goal 4 of the SDGs agenda makes references to increased, affordable and equal access to quality technical and vocational education, relevant skills and decent employment, further placing import on eliminating disparities that affect Indigenous peoples engaging with TVET (UN, 2017; UNDP, 2019). Nevertheless, TVET targets are not given much prominence (UIS, 2018) or are completely overlooked (UN, 2019) within recent global reviews on progress towards SDGs.

The development-TVET relationship is reflected on global education-fordevelopment targets as well as on localised experiences. In this, some localised TVET experiences built alongside broader understandings of development have opened up 
possibilities for new approaches to thinking and doing vocational education that look at knowledge and capabilities to be developed by learners, institutions and communities in ways that are culturally grounded and which affirm their agency in this process (McLean \& Walker, 2010; M. Walker, 2012; M. Walker, McLean, Dison, \& Peppin-Vaughan, 2009). Such approaches can have significant curricular and pedagogic implications and promote socially empowering TVET models. As TVET is about humans learning, living and working, thinkers such as McGrath have argued that not only the theory, but crucially the practice of development should assist TVET models that promote culturally grounded, relational and equitable ways of learning as well as dignifying forms of work that support the survival of Earth (2012).

An analysis into globally agreed and prescribed education-for-development discourses, targets and policies throughout time, highlights the need for a more indepth understanding of the cultural, socio-economic and political implications at all local, national and regional levels of the development agendas and frameworks they are designed to promote and advance. This analysis further emphasises the importance of reflecting on the philosophical and applied effects of the divide between human-capital-building imperatives connected to a drive towards the economic development and growth of nations; and the advocacy for education for conscientisation as a source of liberation, emancipation and empowerment. When education is considered both a target and a means for development, this analysis furthers our understanding of the direction of educational aid funding provisions, as well as the impacts of development interventions on education policy, that emerge from the cyclically changing nature of paradigms, discourses, strategies and goals of development. For more in-depth analysis, Chapter 3 presented examples of Oceanic regional context educational frameworks and initiatives and their responses to global education-for-development strategies. 


\subsection{Conclusion}

This chapter analysed global discourses and theories of education, reflecting on the continued debate between human capital creation and the conscientisation value of education; and in turn its perceived value for development. Philosophies and practices of education which surpass this debate, such as relationality-based approaches, can help challenge taken-for-granted views about which types of education are good for development. These dominant views are reflected in global education-for-development strategies, and in the continued prioritisation of investment by national governments and aid donors in mainstream educational strategies: from formal schooling to higher education, and from teacher to technical vocational education and training.

Chapter 7 contextualises these global discourses and strategies into place by exploring place-specific and relationality-based manifestations of education and development in ENB. 
CHAPTER SEVEN

\section{Storying place through relationalities in education and development in ENB}

\subsection{Chapter Introduction}

This chapter draws from the reflections of participants, on a number of notions and strategies of education and development conceived and pursued in ENB province. The chapter strings together participants' storying about their motivations for involvement in education and development. Their work and engagement in formal, informal and non-formal education, as well as community development, economic, spiritual and political leadership are explored.

The chapter goes on to addressing education topics through participants' storying, presenting their contributions towards asserting Indigenous epistemological and ontological traditions in education, so as to realise local ideas and requirements of development. It addresses development matters through the lens of relationality, ultimately focusing on the centrality of ples, relationality and culturally appropriate methodologies as essential to education and development in ENB.

\section{About tok stori in this chapter}

Tok stori invokes reflection, because in the core of its process is the imperative of reflecting on each other, through stori. This chapter uses tok-stori-appropriate values and essential relational requisites to address research questions that emerged throughout this study. It then presents the knowledge generated from storying with participants through exploration of several themes.

When we engage in tok stori, the purpose is not simply to reach a specific or predetermined conclusion or to answer a specific question, but to create a collective experience where people simultaneously generate knowledge and develop relationships, through a culturally and interpersonally respectful process of 
interchanging and exchanging (Sanga \& Reynolds, 2019). When storying with friends, colleagues, family and elders in ENB, I have come to observe that there are seldom simple 'yes' or 'no' answers to questions, but rather the sharing of stories that give an insight into each other's worldview. Stories are laden with pieces of knowledge that can be tapped into depending on how much of that knowledge you are granted access to, and of the closeness to those you are storying with.

This chapter therefore focuses on generating knowledge by reflecting on each other's stories without a pre-established conclusion or destination; but rather with the purpose of bringing their relationality to light and strengthening the knowledge that is engendered by those relationships.

\subsection{Motivations}

This section discusses the sources of inspiration, wisdom and encouragement for participants' involvement in, and contributions to, education and development.

Together with this study's participants we stori the historical and genealogical underpinnings of education and learning in ENB province. We stori their experiences of learning, some under a colonial schooling system, and others as a colonial legacy. We stori the chronological waves of political and educational leadership that came alongside successive colonial 'administrations', and those that followed the country's independence. We stori the effect on their localities of the postindependence introduction and implementation of globally-agreed development and education-for-development goals-, as well as government sanctioned national development frameworks and education policies. We also revisit the effect that decentralisation policies, changing educational modalities and curricula, have had on their work, on the ENB education system, and on their communities' wellbeing. Participants share their experiences as teachers and leaders in education, provincial administration and community development; and how these experiences have influenced their own education and employment-related mobility patterns. 
Moreover, they share stories about the challenges to education and development stemming from the dispossession of land and displacement of people caused by environmental disasters, the rampant expansion of extractive industries, increasing land scarcity and a burgeoning population. They also reflect on their participation in the ensuing recovery and resistance efforts.

Their stories convey the constant negotiations between myriad ontological worlds and of local and outsider knowledge systems that are present in their interaction with education and development. Further revealing their active work towards the decolonisation of education and development discourse and praxis in ENB.

\subsubsection{Learning and achievement are intergenerational, relational and collective matters}

Participants in this study, whom are Gunantuna/Tolai elders and peoples, draw heavily from the teachings of their ancestors, elders and relations in framing their participation in education. They draw from the values they learnt and the knowledge that originated from sitting and listening to their elders sharing stories that speak of their ancestors and the connections of kin that they must observe. Societal values of love, trust, respect and obedience, as well as of honouring koko (societal do-nots and taboos of interaction) are central. Knowledge originates through listening and observing members of their extended family and communities engaging in exchange of knowledge, resources and tabu, developed through millennia of exchanges, trade and negotiations with people and communities from outside their kin, territory, province and country.

IaEleonora Varmari Vigil tells us through her storying how the advisory position she occupies in her village, is grounded in the learnings about traditional knowledge and cultural pride imparted by her father: 
"I will give advice, the type of advice that I learnt from my father.

The stories that I heard from my father helped me to fit into the society.

I am always proud, that every time I sit beside the fire telling stories, I ask questions and I say: "how are you related to this person? how are you related to that person?" And then I think where do I fit in here?

Those types of questions can be 'baby questions' but they are very important. So, I treasure those".

(Tok stori with IaEleonora Vigil, 2016)

These important questions speak of the relationship-based exchange not only of knowledge, but also of resources and tabu in Gunantuna/Tolai societies. Knowledge is wealth, and wealth depends on belonging, on connection and on the contributions to your community, as IaEleonora Vigil emphasises:

"you can be a big man, like a prime minister, but back in your community you must have 'that' wealth: the knowledge. And 'that' wealth is our shell money, our tabu, you must have that. Because if you come back, you can't be a big man if you don't have that wealth, nobody will recognise you in the community because you are a 'prime minister'. [...]

You can be a Tolai, but you are not a full Tolai if you don't have what we have".

Recognition in the community depends on other things:

"your contribution to the society, your contribution is your presence in the community, your contribution to the community is what counts, not your money".

(Tok stori with IaEleonora Varmari Vigil, 2016).

IaIva Magaga's storying takes us through diverse meanings of learning and education in her land. She revisits her experiences as a learner, from the time she 
attended the village lukbuk with her sister IaMadik (auntie Jackie) to learn her tok ples Kuanua alphabet, and later as part of the formal schooling system, from elementary to tertiary. Her education and work ventures brought to her life learning from local and foreign peoples, practices and worldviews. Still, she remarks on her gratitude for the teachings passed down by her elders and extended kinship connections. She learnt about happiness from her aunts, about love and nurturing from her three grandmothers, particularly "IaKail, who was 97\% blind, she taught [her] to appreciate life". Behind 'thinking' and 'behaving' was the mentorship from her father and uncle:

\begin{abstract}
"[T]he ones I learnt from to think and behave were my uncle ToMalmal Waisea and my father ToPeter Teu whom I spent most times with, thinking and talking, he was my coach and mentor. I picked up some fine behaviours and attitudes in my village and school, very early in life. I looked up to adults and tried to follow accepted rules, I was a good listener. Today I am thankful for the way my father trained me".
\end{abstract}

(Tok stori with mum IaIva Magaga, 2015 - 2018)

The teachings by her elders installed in her that learning is a sacred pursuit and a relational matter. This sentiment is echoed by Narsimulu through his writings on education in Oceania; where he stated that learning, as it pertains to a person's growth as a Pacific Islander, is "in fact, a sacred ingredient of Pacific Island life" (2007, p. 27). Thus, armed with her long genealogy of knowledge IaIva Magaga has dedicated over four decades to a type of education that seeks the survival and renewal of her people and ples.

The importance of secret places and culturally significant structures of learning abounds in the stories shared by ToGideon Turpat. Places where older men continue to guide young men through important stages of cultural and personal development. One of them - the taraiu (the secret house for the men) - he described as "a classroom with a house, a classroom while talking" (Storying with ToGideon Turpat, 
2017) when in reference to learning. While acknowledging gains from grappling with Western knowledge systems, ToGideon Turpat also points out, that many learning structures of cultural importance were opposed, eroded and even demonised, yet could never be dismantled by colonial powers:

"Everything was done out there in a secret place in the bush, until the Europeans came here. It was hard for our old people to control this, they didn't realise that things will change: the education of what is right and what is wrong, the law and order that came with Tubuan - they were changed.

But even in those times when the missionaries were here, the law and order was administrated through the secret place, through the Tubuan. The Tubuan has still lots of power now".

(Tok stori with ToGideon Turpat, 2017)

Moreover, participants' stories about their own processes of learning and achievements tell us that they are of intergenerational significance; they are relationship-based, dependent on and aimed at collective wellbeing. Talatala ToMorton Amos' stories emanate that holistic and relational approach to education and learning.

"We need to teach children the respect for life, [...] because without respect, without relationships, 'one plus one' is useless", Talatala ToMorton Amos said while storying about the meaning and value of education for his people. In his intellectual tradition: knowledge, wisdom and learning are not only interwoven with, but composed of relationships and cultural values. These yield a sense of belonging and strengthen kinship connections:

"When you think about us all, it's about our relationships ah.

How we relate to each other, the way we have certain names to call each other.

Life [and] everything we do is for strengthening our relationships".

(Tok stori with Talatala ToMorton Amos, 2016) 
Whilst storying with Talatala about the motivating factors, inspiration and wisdom behind the many decades of work and spiritual guidance he has dedicated to his community, I observed a profound reverence and respect to his kinship connections and the emphasis on the vital role of the wider community on his upbringing and achievements. He highlighted the unconditional love and spiritual guidance from his mother (all of his mothers) and said:

"In our society, it is about the women, especially our old women.

Education is through our mothers, they teach us how to share, how to give.

Wherever I go people show me respect, but they forget I am here because of those women, our mothers.

The pioneers of education in the community are those that brought us up, and in my case, it was the old women".

(Tok stori with Talatala ToMorton Amos, 2016)

Talatala ToMorton Amos explained the importance of understanding the concept of 'mother' and 'motherhood' in his society and said:

"Maduk's children all call her mother, because you don't only have one mother. My wife, she has four other sisters, so our children don't differentiate between them, they call all of them mothers, mother, not aunty. The only way we can tell that they are talking about the eldest is because they will call her big mummy, another one is called mother Morobe, because she is married to a Morobean, but nothing will separate that real sense of 'mother' of 'motherhood' ah. We treat them as the same, with the same respect, this is very unique and very good"

(Tok stori with Talatala ToMorton Amos, 2016).

The achievement of a person when it is relational and rooted in a sense of belonging, can be a route to development according to Talatala ToMorton Amos, as he told me:

"When someone in our family graduates, we will thank them for collecting our degree on our behalf. 
We Tolai are educated people. Some go out and get big jobs after their studies, but you are to share the knowledge that you've gained.

That is development, it is sharing what you have acquired, and sharing is not only about money, you also have to share your experiences, your knowledge".

(Tok stori with Talatala ToMorton Amos, 2016)

This reminded me of ToGideon Turpat who said:

"I wonder how I am like this? I'm 83 years old now, you live longer when you do good things for other people. The more you give, the more life you get".

(Tok stori with ToGideon Turpat, 2017)

Indeed, the participants whose stories fill these pages, from the elders to the young, give much of their lives to support their people, to learn and achieve, with an intergenerational and collective purpose: to provide the means to long and fulfilling lives for those today and those to come.

\subsubsection{Looking back towards the future}

"Much as it was for the Pacific Islanders of old, who sailed back and forth, cutting through the mighty waves, the ocean is a powerful symbol of both success and obstacles in the twenty-first century. Pacific Islanders face challenges whose outcomes depend on our confidence in our own framework for success. It is empowering for our children to know that their ancestors were equipped with survival skills that rivalled the Vikings, that they navigated across the largest body of water skilfully and confidently, knowing both where they were and where they were going.

Thus, it is pertinent that we teach our children skills to navigate through the twentyfirst century like their ancestors of old".

(Narsimulu, 2007, p. 32) 
In 'Island Time', Salesa pointed out that "those best positioned for this Pacific future are Pacific communities and people themselves" (2017, p. 223). Oceanic peoples possess the knowledge and skills to confidently navigate the present into their own notions of future, success and development.

Participants storying reflect the practice of engaging ancient knowledge and practices for contemporary complexities and challenges in education and development. In ToHenry Tavul's storying of his involvement with education and social-economic development efforts in ENB and PNG, he emphasises a sense of collective responsibility to prevent poverty and social-economic hardship. This is learned from what he referred to as the historical wisdom of Melanesian people. ToHenry Tavul's view corresponds with Narokobi's (1980) emphasis on the right and indeed the "duty to call on the wisdom of our ancestors" [for Melanesians are] "an ancient people, born to liberty, born to ancient culture and civilisation" (p. 66). Through this wisdom, they collectively possess "the treasures of time tested and proven strengths" (Narokobi, 1980, p. 66) to face contemporary challenges. The importance of ensuring that the ancestral wisdom of collective responsibility for people and ples is not marginalised or regarded as 'alternative' within locallyappropriate practices of education and development in ENB today, continues to encourage participants' work.

In ENB province peoples including Gunantuna/Tolai societies, educational strategies and policies, either in the hands of local people and organisations, or in cooperation with international development and aid partners, must appreciate and respect Indigenous knowledge systems and practices. In order to face contemporary complexities and challenges in a sustainable and culturally appropriate way, it is important not to presume the adequacy of foreign-inspired concepts and practices related to education and development. Reframing the relationship between knowledge systems and approaches to community wellbeing so that they can effectively engage Indigenous knowledge and practices, contributes to establishing 
relational equity. This ensures Gunantuna/Tolai, and other Indigenous peoples across ENB are not reduced to learners/recipients in these relationships.

Community-centred approaches which are ples and context-specific have been encouraged for decades through teachings on development by David Gegeo and other Oceanic thinkers (Nabobo-Baba, 2013; Sanga, 2005; L. T. Smith, 2012; K. H. Thaman, 1997).

Examples of effective ways to engage Indigenous knowledge and practices for contemporary complexities come from storying with ToHenry Tavul. His storying spoke of the ethical Indigenous leadership and vision, in education and in the economic development sector, that prevail and are continually renewed in ENB. Highlighting that there is no room for poverty in his communities, ToHenry Tavul explained:

"poverty was something that was brought in, I don't know, to attract the funding, but you see it [the funding] come in and quickly gone".

(Tok stori with ToHenry Tavul, 2016)

ToHenry Tavul explained how this only promotes reliance on others, as well as the erosion of communal knowledge systems of reciprocal care that characterise Melanesian societies. His work in education and in economic development revolves thus around finding ways to recall the "wisdom [...] the wise knowledge" to get people out of this "so-called 'poverty syndrome'", by asking:

"how we, the people of ENB, should be driving this, so that we don't continue to rely on others to do it, to make it happen for us"

(Tok stori with ToHenry Tavul, 2016)

Reconceptualising and reshaping the approach to poverty issues is a priority for ToHenry Tavul's work as ENB Provincial Advisor of the Division of Commerce and Primary Industries, and throughout his time heading education initiatives in the province. He, alongside his colleagues and their communities are reframing the 
drive towards economic development in this province, as well as the relationship with relevant international development partners. He explained:

"we don't have the gold, we don't have the mines, but yes, we have cocoa and copra,

and we also have the wisdom, the power to make decisions based on changing situations, we look at realities, and we talk realities"

(Tok stori with ToHenry Tavul, 2016)

According to Salesa,

"There has long been a sense that there are core tensions between business imperatives or practices and Pacific cultures. But any entrepreneurial or economic development that is successful and enduring will begin where people are, and build from their knowledge, position and strengths."

Throughout colonial expansion, ToHenry Tavul explained how their land was alienated to give way to cocoa and copra plantation development. Yet today he can see that ENB has the wisdom and capacity to sustainably develop their land by tapping into the current global "export potential" and demand for these and other local commodities. Engaging in partnerships with international development partners for economic development is no longer about depending on them to make it happen, but rather about creating partnerships that can contribute to autonomy and Indigenous leadership in the local economic sector. Moreover, it is about partnerships that can match the ethical leadership of officials and elders such as ToHenry Tavul, who has for decades been an active and powerful voice for environmental protection against the current unregulated and devastating spread of extractive industries in his land.

In the education sector in ENB, Indigenous educators, elders and leaders have engaged Indigenous knowledge as well as teaching and learning practices, to face contemporary challenges, through the creation of a tourism and hospitality homegrown curriculum for the province. These educational materials aim to put a 
stop to the perpetuation of colonial legacies in vocational education which have seen their young trained to serve within a tourism and hospitality industry that has historically devalued and commodified their peoples and cultures. Storying with a few of the curriculum writers they shared their vision for this new teaching materials:

I can't wait for the day the trainees can have the book in their hands and say, "this is talking about this place, I know that place, I've been there". That will make us feel very proud seeing them looking at the book and for the first time knowing everything in this book and saying "this is talking about us, this is talking about our culture, this is talking about our place".

We want them to hold that book and feel and see that it is their own, that is what we want to see.

(Tok stori with Carrie-Anne Karela, 2016)

This initiative draws from the local wisdom of looking back towards the future of their province. A culturally and geographically appropriate vocational education and training programme can thus support Indigenous youth continuing to value their ancestral knowledge, practices and beliefs, respecting kinship networks, protecting customary land and places, whilst engaging with a rapidly burgeoning industry.

The skills and knowledge needed to navigate through the challenges of this century are diverse and complex, yet when teachers and educators across villages, classrooms, at sea and on land, share culturally-enhancing stories and practices, the stories of the way their ancestors have skilfully and confidently (Narsimulu, 2007) survived and thrived for thousands of years: the world of today is but a mighty wave in an ocean that Oceanic and ENB people are incomparably skilled at and equipped to navigate. 


\subsection{Storying education}

Stories shared by this study's participants convey a rethinking and re-enacting of education to foster locally appropriate concepts of wellbeing and development in ENB. Participants storying reveals not only their challenges and aspirations of education and development in their province, but also their ongoing involvement in rethinking and re-enacting in areas of education design and delivery through curricula and teaching and learning strategies.

Through the knowledge generated through storying with participants, this section addresses some key complexities and challenges in education. Further, it draws attention to participants' involvement in contributing towards the appropriate articulation of the needs of students, educators and communities in ENB, such that they can foster wellbeing and better livelihoods at this time and towards the future.

\subsubsection{The purpose and process of education in ENB}

In ENB the global human capital/consciousness-raising educational divide persists and impacts educational and development discourses and approaches.

The relationship between the way education is currently conceptualised and delivered in ENB, to locally recognised concepts of learning, knowledge and wisdom is being questioned through this study's participants' work in the education and development spheres. Participants are questioning whether the current educational system, curricula and teaching and learning strategies in the province are enacting a type of education as a means for cultural renewal and survival: one that is synonymous of Oceanic and Melanesian societies. Amid the push to generate human capital to compete in a 'modernising' economy and a globalising world, participants are also asking if the type of education currently enacted in ENB is truly 'the great equaliser'? This is because they are observing: the prevalence of culturally irrelevant content and teaching strategies in classrooms; undifferentiated education with a bias towards formal (namely narrowly academic) education; and vocational education 
strategies primarily focused on the mere provision of human capital for expanding (often environmental and culturally eroding) industries. These all result in thousands of their young leaving schools with skills that do not match the employment demands or development needs of their province, their village and their ples.

\section{Cultural relevancy of content and practices in education in ENB}

Both academic and vocational curricula contain different units based on Papua New Guinean content such as "traditional ways of dying fabric, making tapa cloth, printing methods, traditional cooking and history" (Tok stori with Roselyn Onesu, 2017). Teachers use creative ways to deliver this content to a culturally diverse population of students. And an increasing number of educators and thinkers across the country are advocating for Indigenous learning systems to be centred in education delivery (Matang \& Owens, 2004).

In classrooms across PNG and in ENB many educators are working with culturally irrelevant content that prioritises foreign knowledge systems and pedagogical practices. This poses limitations on educators to fully engage with the content they are delivering and often afflicts them with 'a fear of getting it wrong', a phrase I often heard in when storying and working with many of these participants:

"We see that there is more to what we have been teaching. We still need to have more skills and knowledge about what we are teaching.

Yet, there are only limited ways we have been allowed to teach and allowed to deliver skills and knowledge to trainees"

(Tok stori sessions with ENB educators, 2016)

This fear, in turn, produces a divide between teacher and learner that results from a commonly seen practice in classrooms: lessons are delivered by teachers giving their backs to students, writing extensively on chalkboards, students diligently copying on their notebooks, with very limited engagement in conversation, questioning or 
activities between students, and between students and teachers. These practices stand in stark contrast to the purpose, content and processes of learning that are commonplace among Indigenous cultures in ENB and across Melanesia, where different types of learning took and, in some localities, still take place on the ocean ${ }^{48}$, on land and at various secret places ${ }^{49}$, and where learning generally occurs through a relational and dialogical process. Such process of learning is foundational to the domains of knowledge in Melanesian intellectual traditions which encompass millennia of constant cultural renewal in the realms of knowledge, land and peoples' welfare, trade, warfare, hospitality, voyaging, family planning and so on; including the vast ontological negotiations between local and outside influences.

Schooling structures that operate as colonial legacies and which prioritise globally sanctioned practices of education, are generally unable to identify and accommodate different educational epistemologies (Narsimulu, 2007, p. 28), further serving to diminish and neglect the values, knowledge domains and practices characteristic of ples-specific learning structures. Symptomatic of this, teachers and students are facing the conflicting learning and cultural expectations of foreign-inspired curricula, and those of their home cultures. This is added to excessive numbers of students in classrooms ${ }^{50}$, a resulting heavy workload for teachers and the predominance of assessment of learning through written tests and exams, even for non-academic or technical/vocational learning. Globally-dictated educational content and goals, which are at odds with Indigenous traditional values and ways of creating meaning, can have significant influence on teacher professional and student learning underachievement in schools in ENB. Addressing these challenges is one of

\footnotetext{
48 i.e. traditional navigation methods called 'way finding', use learning indicators such as swells, wave and wind patterns, cloud formations, location of islands, birds' flight paths and stars.

49 i.e. the taraiu or house for the men, where young men learn from the older men (Tok stori with ToGideon Turpat, 2017). Also described as the secret Tubuan's place (Kakabin, 2017b).

${ }^{50}$ This has been exacerbated since the 2012 implementation of the TFF Policy, which focused on making education universally available to all Papua New Guineans by increasing access and retention, yet the system faces limited capacity regarding infrastructure, resources, number and training of teachers, and appropriate curricula.
} 
the central aims of the creation of a home-grown vocational curriculum for ENB, where the content was gathered through years of tok stori. This primarily dialogical labour, led by Indigenous educators and elders, is producing a series of educational materials with content that prioritises Indigenous values, practices and knowledge. While it is in constant conversation with useful strings of outside knowledge systems and practices, it prioritises culturally relevant content and relational educational practices, articulating the vocational learning needs of students, educators and communities in order to meet locally recognised concepts and requirements of development.

\section{Addressing the human-capital/consciousness-raising educational divide with reference to current social-economic and development complexities in ENB}

Human capital development through education has been historically regarded as a way for alleviating poverty by engaging in cash-generating employment inside and outside localities; suggesting upskilling, increased flow of migration-generated remittances and the return of skilled and educated people (Becker, 1994; Wantchekon et al., 2014). Nevertheless, this study's participants observe that the promises of cash-income generating employment and higher education possibilities that characterise the formal education process in ENB, are no longer being realised for most school leavers. They are, thus, re-thinking the persistent humancapital/consciousness-raising global divide, reclaiming culturally appropriate learning processes and spaces, that aim to see their young being educated, accessing employment, migrating and returning home - all with dignity.

IaIva Magaga's reflections after decades of experience and leadership in formal, informal and non-formal, as well as academic and vocational education in the province covey that:

"In our communities we desire to have our children gain a good education so that they can then work and earn a living or simply do things at home. 
Today, this is no longer a dream come true.

There are just too many students with no space to further their education, no work for employment and no business opportunities"

(Tok stori with mum IaIva Magaga, 2018)

Participants who are teachers in ENB echoed such observations:

So far we see that from those who graduate, only a few go into getting jobs. Most go back to the village. Yet those that go back to the villages do their best to use their knowledge and skills to do something, to create their own living. But a lot of them also engage in things that don't earn them a proper living. Some wander the streets.

(Tok stori sessions with ENB educators, 2016)

This is exacerbated by rapid population growth with almost 40 percent under the age of 15, alongside:

"inadequate school placements, limited job training opportunities, and high levels of unemployment faced by young people, [which] can result in disengaged adolescents and youth feeling unable to participate in the development of their communities. This disengagement can lead to participation in opportunistic crimes and violence, and fuel feelings of rejection, low self-esteem, and cause mental health issues."

(UN-PNG, 2018, p. 37)

Limited post-schooling options added to desperation to access cash-income generating jobs, can, thus, push their young to engage in culturally demeaning and/or dangerous employment. Some flood the urban centres where finding limited employment options, find themselves doing very low-skill jobs at predominantly foreign-owned retailing businesses ${ }^{51}$, oftentimes with little to no upward economic

${ }^{51}$ Foreign ownership is extensive among medium-sized and large private firms, and is fairly widespread across all economic sectors. Most minerals, logging, manufacturing, wholesale, transport and distribution activities, and many plantations are managed by foreign-owned enterprises. Largescale retailing is also dominated by foreign enterprises. Traditionally, Australia has been the dominant source of foreign direct investment, but investment from East Asian countries is well established in logging, canneries, and retail activities (ADB, 2008, p. 8; Longgar, 2006, p. 25). 
mobility or professional development. Others become part of service industries, where they can be exposed to poor and culturally demeaning treatment, unfair remuneration and gendered safety issues; whilst others move away to work in dangerous conditions within extractive industries such as mining, logging and palm oil forestry (Longgar, 2006; Tok stori with Talatala ToMorton Amos, 2016). Reflecting on the dangerous and unequal working and living conditions of some of his people employed by foreign owned oil palm plantations in West New Britain, where he once provided spiritual guidance, Talatala ToMorton Amos said:

"What are my people doing as part of the stock [market] exchange?

What have you done for my poor people, I ask these multibillion companies?"

"Oil palm is all about slavery, modern-time type of slavery, where a company owns you"

(Tok stori with Talatala ToMorton Amos, 2016).

In regard to the tourism industry, the ENB homegrown curriculum initiative which is endorsed and supported by the provincial government and DoE; echoes the words by Hon. Cosmas Bauk, who can see the current potential as well as the possible downfalls of this burgeoning industry:

"yes, tourism is coming here, and yes we want people to come and visit [but it does not mean that] we can allow our culture to be sold for a few dollars, it doesn't mean that we have to sell ourselves".

(Public speech by Hon. Cosmas Bauk, Deputy Governor and Chairman for the Education Parliamentary Commission2017)

The role of ENB educators, who "are on the front lines of tourism and hospitality in this province", is to support efforts towards "making sure that our people [are not] begging for a few tourists' dollars, [this] cannot happen in our province" (Public speech by Hon. Cosmas Bauk, 2017).

Talatala ToMorton Amos observed how nowadays within the tourism sector, the 'promotion' and the 'sale' of his culture have become somehow interchangeable 
concepts; where sacred cultural symbols and practices can be purchased for entertainment. This is highlighted also by ToGideon Kakabin writings on the meaning of Tubuan's masks, performed only by initiates, warning that they "should not be part of any Mask Festival" (2017c). Referring to the $d u k d u k$, a sacred Gunantuna/Tolai cultural symbol Talatala ToMorton Amos explained:

"I see especially how our dukduk are being abused. Originally in our society when they perform, they wouldn't do it for people who come to see it as a form of entertainment. Dukduks don't perform to entertain somebody. No! They have certain roles and responsibilities in our society.

They are not to perform for tourists that come to spend their money. But nowadays they don't care about the fact that this is very wrong. Those that do this have been blinded by money, and they have abused the role of the dukduk in our society. I wonder if our elders realise this?"

(Tok stori with Talatala ToMorton Amos, 2016)

Amidst constant social-economic pressures, of concern for this study's participants and their communities is how the education system that trains their young to become part of the province's workforce, is contributing to their physical, cultural, intellectual and spiritual wellbeing. They can see a strong disconnect between the retailing, service and extractive industries that employ their young, and the traditional social-economic structures which have their roots in village life and in community economies. Within these structures, semi-subsistence and/or subsistence economies are important; and peoples' customary responsibilities and strong bonds of kinship, mean their obligations extend beyond the immediate family group and often can supersede perceived duties to employers.

Sevi Kaue, a research participant who manages a locally owned-operated tourism and hospitality company in ENB, envisions an industry that can overcome this disconnect in the future (Tok stori and interview with Sevi Kaue, 2016). Under the Pidi family's ownership, they have established a company that is culturally 
enhancing, since it encourages respect for village life and relational societal structures within the company's structure. Furthermore, supporting their employees to tend to customary responsibilities is regarded as an important component, rather than an impediment to the company's growth. This knowledge has contributed significantly to the home-grown curriculum for tourism and hospitality training.

Safe accommodation and appropriate nutrition provided by employers, as well as safe means of transportation (at appropriate times of the day) between villages and their place of employment, are major concerns observed through my work in the vocational education sector and have also been raised by many participants. This is an issue that some vocational educators, industry as well as church representatives, are currently trying to address through the collective coordination of an On the Job Training programme (OJT) in ENB. This programme gives vocational education trainees the opportunity to train within industry establishments, whilst providing them with appropriate accommodation, food and transport, and opening future employment opportunities (Tok stori with Jeddah Violet Gigi, 2016; Interview with Archbishop Francesco Panfilo, 2016; personal communication with Mario Pangalos, 2015).

Participants' stories unearth the need to question the extent to which the educational content, pedagogical practices and cash-income generating promises of the schooling system in ENB can be contributing to further subordination of the people, environment, land and cultures, to global demands for natural resources and human capital for the urban industrial sector and foreign extractive industries. Provincial leaders in education and economic development such as ToHenry Tavul and Hon. Cosmas Bauk emphasise the need for ethical Indigenous leadership to match education delivery, create employment opportunities and contribute to socioeconomic development. This kind of leadership encourages a kind of education that when geared towards human-capital-development is focused on establishing a healthy workforce through harnessing the ples-specific 'wise knowledge'. ToHenry 
Tavul referred to this 'wise knowledge' as Indigenous wisdom that goes beyond cash-generating ventures alone; wisdom that prioritises locally-relevant concepts and practices of wealth creation which respect village life, customary responsibilities and kinship bonds, and is culturally and environmentally strengthening.

Relevant education "with empowerment for community living", is what communities in ENB are working towards:

"education should support our people to be able to progress from where they are physically, mentally, psychologically, financially, spiritually and be elevated to another level.

When we are able to re-create our lives and become successful in all areas of our lives, then we are developing into a healthy and happy community".

(Tok stori with Ia Iva Magaga, 2018)

Similarly, Talatala ToMorton Amos explained that one of the roles of education is to contribute to the holistic development of people, this is:

"developing a person intellectually, culturally and spiritually. We are not just talking about getting things like degrees, this is a very small piece of development.

When a person is properly developed it creates a good person who knows how to recognise the positive and the negative types of 'development'.

To me Lorena, personally, I am not against having 'big buildings', it might be a sign of 'development', but again for me: 'development is a person'.

We can rationalise things Lorena, you and me, can go around and around; but it is through education, I think again the key is education. I'm not saying there will not be more problems, no ... they will still come, but when you are a holistically developed person, even when you migrate, you know where to go and you know where you are going". 
In ENB, I regard that Indigenous knowledge systems, ples-specific learning structures, and the Indigenous leadership behind the continued renewal of approaches to education and development, go beyond the humancapital/consciousness-raising divide that permeate education-for-development strategies across Oceania. This divide "one avowedly neoliberal and economic and the other concerned with social justice and transformation $[\ldots]$ both agree that education is critical, providing variously the economic or political means for individual or collective development" (Gamlen et al., 2017, p. 5). Yet within the unresolved conflict between neoliberal and radical sides, education-for-development strategies still follow a linear continuum '-for-development', a 'means-to-an-end' philosophy (of both education and development) that often can neglect ples-specific learning structures (and the genealogy of people); whose concepts and practices of 'development' are not linear, and their rich genealogical ontology has been fundamental and effective at upholding knowledge domains and beneficial practices that support life, and the renewal and survival of their cultures.

\subsubsection{Politics of knowledge: 'the prioritisation of stories and practices in education'}

"Not seeing the knowledge that you want to impart, is teaching for the sake of teaching. Teaching is about trying to help someone to get somewhere [...] that's my responsibility. It is a joy to see them learn properly."

(Tok stori sessions with ENB educators, 2016)

Of importance to this study is the question whether stories told and prioritised in classrooms across ENB sound, look and feel like the young people that sit behind those desks and the educators that share them?

Educational strategies and pedagogies are "often shaped by the cultural values and ideologies of the society in which it originates and teachers transmit and reinforce the cultural values that are embedded in the various teaching approaches that they use" (Aikman, 1995; Barrow, 1990 in K. H. Thaman, 2009c). ToHenry Tavul noted 
that in classrooms, local "teachers [are who] tell us what we want to produce for our people" (Tok stori with ToHenry Tavul, 2016). The diverse ontological, political and professional demands that ENB teachers negotiate every day in the classroom, mean that cultural understanding and sensitivity to contribute to a holistic kind of learnersuccess can become a daily struggle. This is because they are expected to manage the cultural expectations of the communities that send their children to school, as well as the preparation and delivery of lessons that are predominantly done through foreign-inspired educational resources, in addition to managing large or excessive numbers of students. There is likewise a continuous country-wide struggle to access professional development and further education opportunities.

Participants shared what have been historically some of their experiences:

"We collect resources from many sources just to deliver one lesson. We start in the night, go next day all day and afternoon, then at night again, next day wake up early and try to complete it before we come to class.

Books and resources are mostly irrelevant to us. Some of the things mentioned in those books, we do not see them here, seriously.

How are you going to ask the trainees to stand in a train station for practicing: 'how are you going to welcome a tourist in the train station?' We don't have a train station here. Students get confused. Ingredients for cookery classes too. I've tried growing parsley, chives and dill.

So, students not following instructions only goes back to how we communicate with them. And in this, language is important. Trying to deliver knowledge in English to trainees is really hard, especially to Grade 8s. Language then becomes the main barrier. So, what I do is I explain the sub-module in English, then I try Pidgin, then I try tok ples; and if they don't understand I sit down and look into a different strategy to teach them. It's a long process to get trainees to fully understand."

(Tok stori sessions with ENB educators, 2016) 
For one of the educators that contributed to this study, to be a good teacher means both: "commitment and background knowledge". Her stories about students asking for her help outside the classroom reflect their aim to fill gaps left by chalkboardteaching styles that can be pervasive in schools, even within vocational education which often requires practical and activity-based learning:

"[many] trainees come in and say: "Miss, my teacher sent me to ask you to explain this to me" or, "Miss, could you tell us the history on this site?", but I'm not the only one from here [ENB], so I tell them: "there are other teachers from here too, go ask them."

(Tok stori with Jeddah Violet Gigi, 2016).

The background knowledge that Jeddah Violet Gigi refers to spans across what is locally specific and relevant, through to the technical and theoretical knowledge required for teaching a vocational trade as sanctioned by the current schooling system. Yet, without the appropriate educational resources, professional development, nor the space for cultural sensitivity: this is arduous and demanding labour for teachers.

My experience working alongside teachers in the creation of a homegrown curriculum in ENB, is that they possess vast knowledge of the domains of their intellectual traditions and are capable and agile storytellers and educators. These teachers are also deeply involved with the communities around their schools (Tok stori with Jeddah Violet Gigi, 2016; Tok stori with Roselyn Onesu, 2017). However, what is also tangible is that the schooling system continues to marginalise the articulation of their own Indigenous stories inside the classroom, in order to accommodate for foreign-inspired content and practices. This limits teachers' ability to prioritise locally relevant and culturally enhancing stories and pedagogical practices in the classroom.

Indigenous educators in ENB are equipped with an intergenerational and longstanding history of ontological negotiations with foreign knowledge systems. So 
perhaps, when they are given the opportunity to shape their own teaching and learning practices and tell their own stories from the start of the educational strategising process, it could result in something more meaningful than a mere attempt at 'blending' Indigenous knowledge with namely Eurocentric knowledge. This is because this 'blending', as argued by Battiste, "raises the continuing issue of whose knowledge is validated in educational enterprises" (2002, p. 22). The binary thinking that creates a sort of knowledge wars (Hoskins, 2019) between 'Eurocentric and local' knowledges, ignores the reality that a Melanesian locality hauls millennialong and ongoing influences and negotiations with knowledge systems and peoples from across 'native seas' (Salesa, 2018) and beyond, long before those seas were named Pacific Ocean and some of its people Melanesians, and also prior to European expansion (Narokobi, 1980).

The stories shared by participants align with Battiste's observations that "the politics of knowledge production and dissemination are at the heart of the matter" $(2002, \mathrm{p}$. 22), when the legitimisation, production, packaging, dissemination and sanctioning of curricula and school policies have been generally skewed against Indigenous values, epistemologies and languages (Skutnabb-Kangas, 2003).

\section{Challenging politics of knowledge through the reclaiming and reprioritisation of Indigenous stories and practices in education in ENB}

"I can't wait for the day the trainees can have the book in their hands and say: 'this is talking about this place oh I know that place I've been there'. That will make us feel very proud.

Seeing them looking at the book and for the first time knowing everything in this book and saying: 'this is talking about us, this is talking about our culture, this is talking about our place, talking about a place that is here", saying "I've been there I've seen this'. We want them to hold that book and feel and see that it is their own, that is what we want to see." 
Working through the creation of a homegrown teaching resources for vocational education in ENB was a valuable exercise at challenging politics of knowledge by questioning what and whose stories are told, written and taught in classrooms. Whilst engaging in storying sessions to define the content of each teaching module, there was an initial - though short lived - sense of perplexity by our educators when it was made clear that their own Indigenous stories and locally-relevant educational practices were to form the core of the content of these educational resources. This revealed to me the long-standing history of teachers feeling that their Indigenous knowledge of place, environment or ples-based teaching and learning practices were not meant to enter the classroom (Giraure, 1974). Teaching materials for the trade of tourism and hospitality have historically disregarded the fact that Melanesians, including Indigenous cultures in ENB such as Gunantuna/Tolai, possess longestablished hospitality practices, developed through thousands of years of welcoming and accommodating visitors and also being themselves visitors to other places across these native seas (ENB Curriculum Development Project Collective, 2015; Tok Stori with mum IaIva Magaga, 2018; Simet, 1991; Tok Stori with ToHenry Tavul, 2016).

These curriculum materials utilising research and storying revealed that across Melanesia and in ENB, the training of people in this occupation has prioritised mostly Eurocentric content, topics and stories, as well as teaching and learning practices. Students, for instance, were expected to learn things such as: how to welcome guests at a train station, when there are no train stations in a single Melanesian locality; or how to make hollandaise sauce, when it is nearly impossible to find, transport or refrigerate butter at most localities, and where butter is not common in the local diet. Other troublesome topics within foreign-inspired resources were: hierarchical structures in hospitality businesses and work modus operandi which have little to no regard for village-based societal structures, or respect for kinship and customary responsibilities such as presence at funerals, bride-prices, 
initiations, all important village-based activities that people are required to participate in and which contribute significantly to community economies and strengthening of kinship networks (McKinnon et al., 2016).

There were other topics such as: steps detailing how to welcome, converse and interact with tourists and guests, which largely disregard gendered, age, and taboo restrictions of interaction within specific localities. For instance, Gunantuna/Tolai culture has gendered rules of interaction between siblings, or in regard to the proximity to and interaction between women and sacred Tubuan; therefore for a tourist to consider appropriate to ask for siblings to pose closely together for a picture, or for a woman to stand near, look directly at, speak to or take a photograph with a member of the sacred Tubuan society: is a violation of cultural protocols. It is important to note that I do not presume knowing all Gunantuna/Tolai cultural protocols and regulations, nor how they are exercised by different individuals, families and clans; this is only an example that was referred to during the collective creation of these teaching materials.

Furthermore, I am not suggesting that learning topics and information about practices elsewhere is completely irrelevant, as these can generate further knowledge, provide perspective of the local alongside forming understandings of an increasingly globalising world, be informative and interesting, and also important to support students who aim at pursuing further education and employment opportunities overseas. What I am implying is that these have been disproportionally privileged over any locally relevant knowledge systems, stories, languages and practices. There is no balance, it is culturally undemocratic, it marginalises and oftentimes disrespects the knowledge systems and cultural practices of the students and the teachers involved in the learning process (NaboboBaba et al., 2012). 
Many importantly, local stories are generally not given priority in classrooms, such as the stories of Gunantuna/Tolai resistance against the alienation of their land ${ }^{52}$ through the imposition of 'European law' on land ownership during colonial times (Longgar, 2006; Mackenzie, 1934). As well, the subsequent history of selling and reselling ${ }^{53}$ these lands to various (predominantly foreign) organisations, multinational companies and private businesses ${ }^{54}$, are central to understanding the current ownership, use and restrictions on local peoples' access to some of their ancestral lands along the foreshore of urban areas and those used for plantation logging (Longgar, 2006). Many of these may be stories of loss and dispossession, yet they were not passively experienced, for they are also stories of the agency of local people, related power struggles and a multiplicity of ontological considerations.

Similarly, in classrooms teaching tourism and hospitality as a trade, important stories are missing. These include stories about Gunantuna/Tolai political activists, intellectuals, leaders and elders that have fought for decades to protect their sacred symbols and cultural practices to ensure they are regarded as inalienable (Kakabin, 2017a; Tok Stori with mum IaIva Magaga, 2018; Simet, 2000; Tok Stori with Talatala ToMorton Amos, 2016). Stories that are omitted range from the inspiring writings by Jacob Simet (2000), Nelson Giraure (1974) and Gideon Kakabin (2017a) on education and culture, to stories about ples and Indigenous concepts of hospitality articulated by local storytellers, healers, cooks, gardeners, spiritual leaders, mothers, fathers and elders. Moreover, it is crucial to accommodate contemporary stories about local action against the violation of the collective intellectual property rights of the

\footnotetext{
${ }^{52}$ Examples include the violent confrontations that ensued following Queen Emma's 1890's plan to build a road that went through a taraiu (secret Tubuan place) and men's fishing grounds (Kakabin, 2017b; Tateyama, 2006).

${ }^{53}$ This includes the rush to relocate business from Rabaul after the 1994 volcanic eruptions, which resulted in private land sales while the government was concerned with the resettlement of local people that were displaced (Puipui, 2011).

${ }^{54}$ An example of this is the "illegal logging [that is] carried out on the land by Indonesian and Malaysian logging companies under false promises of developing rural infrastructures to benefit local populations in the village" (Huffman, 2019; Longgar, 2006, p. 25).
} 
Indigenous people of ENB, and the desecration of Indigenous traditions and cultural laws by foreign businesses and visitors ${ }^{55}$.

Locally relevant stories are invaluable sources for ENB students and teachers, including those in tourism and hospitality vocational education and training, to learn from the vastness of past and current negotiations, resistance, action and agency exercised by their people and communities. These stories can contribute to safeguarding their natural and cultural heritage, their rituals and traditions from exploitation that can be part of a booming tourism industry if left unregulated. Yet many of these culturally enhancing and safeguarding stories continue to be marginalised by the prioritisation of foreign-inspired stories and practices in classrooms.

In some cases, it goes beyond the disproportionate prioritisation of foreign-inspired stories and practices in education. Through my work and later through this study, I came to observe a persistent level of dismissal and even demonisation of local knowledge systems and cultural values and practices, by foreign people working in private businesses, others engaged in 'charitable' causes or even by foreign religious leaders that have access to classrooms and other training and learning spaces. Of prevalence were stories about a newly arrived foreign religious leader who told Gunantuna/Tolai people that what keeps them 'poor' is their continued practice of using tabu (shell money or shell wealth), inferring that the only way to overcome what this person regarded as 'poverty', was to cut links with this millennia-long and sacred practice and subscribe to a capitalist mindset that will make them rich. This shows disregard for the long-practiced dual engagement with traditional and capitalist economic systems by Gunantuna/Tolai people. It disregards the deep

\footnotetext{
${ }^{55}$ For example, Chinese fashion group ICICLE took pictures at a local tourism festival of secret men's society sacred symbols and then portrayed female models in proximity to a Tubuan. This was met with a petition by Pauline Vetuna to stop ICICLE fashion group from desecrating Indigenous cultures, followed by letters by local people (2019) and by a notice to the brand issued by ENB Tourism Authority $\mathrm{Mr}$ Douglas Pidi and Hon. Jelta Wong (current PNG Minister of Health) (Loop Author, 2019).
} 
historical and contemporary significance of products of the sea especially the muchvalued shells in places across PNG, which are vital to "shaping their ceremonial and political systems" (Hau'ofa, 2000, p. 37). Tabu is regarded as fundamental to Gunatuna/Tolai autonomy (Tok Stori with IaIva Magaga, 2018) particularly when facing the pressures of fluctuating global markets, the social-economic consequences of corruption, and challenges to sustainable livelihoods brought about by climate change and pandemics (Fainu, 2020). In reference to community economies for instance (McKinnon et al., 2016), tabu represents one of the most comprehensive, advanced and robust socio-economic and political systems (and safety nets) in existence today. This is because it has to do with Indigenous concepts of wealth, where 'tabu is Gunantuna/Tolai wealth' (Tok Stori with IaEleanoraVigil, 2016).

Encouraging and inspiring the protection of their knowledge systems, sacred cultural symbols, places and practices, such as tabu, is possible through education, when educators can engage with context-specific stories and practices, and tell their own stories at lotu, in the village and in classrooms. Indigenous elders, educators and leaders in ENB are thus working towards the continued and increasing prioritisation and articulation of their own stories, not only within the schooling system across the province, but also within development, as well as religious and business spheres. They challenge thus, decades of foreign or foreign-trained peoples attempts at commodifying knowledge and practices within these different spheres, with little to no understanding of pre-existing cultural systems that centre "the relationship of Indigenous knowledge [in] the establishment and maintenance of individual and community wholeness" (Battiste, 2002, p. 30; Mel, 1995). As pointed out by Narokobi, Melanesians do not derive their civilisation, laws, and values from others, and it is precisely because of what they are, possess and know, that they can embrace the twentieth century and the future (1980). 


\subsubsection{Educators: Storying change in education}

"There is no need for us to believe that we are poor, that we need programmes to come in from the outside.

For them to come and tell me: 'Henry you are poor', I can tell them to go and jump.

And here is when education comes in, for teachers are supposed to be the influencers, the agents of change.

They tell us what we want to produce for our people"

(Tok stori with ToHenry Tavul, 2016)

The telling of culturally enhancing stories in schools that are populated by Indigenous youth from Gunatuna/Tolai, Qiakit, Pomio, Sulka, Butam, Taulil, Duke of York communities and Indigenous diaspora from other provinces in ENB, raises a few points: creating safe spaces to revive their Indigenous stories by also being articulated in their own Indigenous languages; prioritising and celebrating their own Indigenous stories and practices; respecting their sacred knowledge and practices; and not privileging stories that have historically meant the dispossession of their land and the demining of their traditional institutions and cultural values.

Throughout ENB, I have encountered educators that are skilful and knowledgeable storytellers, and who through different types of education represent powerful agents of social, political and cultural change and renewal. Many of them engage plesspecific tok stori methodologies in teaching and learning strategies, as powerful ways of making meaning, of conveying, communicating and retaining knowledge. These methodologies' cultural importance resides in the fostering of connection between the people engaged in the learning process, connection between people and their ples, as well as the connection of people's present status to both their future and their past. They challenge narrowly capitalist concepts of education and their purpose, for they regard teaching and learning processes as so much more than a preparation for a linear and predominantly economic version of future. 
I have observed the power of ples-specific pedagogies in the running of an elementary school by auntie IaJackie and uncle Ezekia, where using a combination of languages to cater specific student needs, is also done under the protocols and values of the village. Also, in the mentoring mum IaIva Magaga provides to youth in the village, where she celebrates their brilliance, upholding their dignity and encouraging them to create their own stories, their own realities. Storying as mentoring tool is rooted in values of love, it encourages connectedness to ples and respect to genealogical histories. The village is also a teacher. It provides a "vocation and the basic skills to live nowadays [...] when everything costs money, even education" (Tok stori with ToGideon Turpat, 2017). As illustrated by Narokobi (1980), the village is the "ancient, timeless, eternal University of Melanesia [...] where courses are offered in living" (p. 1). It is important thus to note that teachers are also the elders, storytellers, gardeners, artists, healers, mothers and fathers in the village; for they shape history in ples (Narokobi, 1980) with stories and processes of learning that support cultural renewal and survival.

Teachers who became writers for the ENB homegrown curriculum engaged in storying context-appropriate pedagogies alongside elders, storytellers, community members and students, throughout module and content creation, as well as during school trials. Jeddah Violet Gigi, a curriculum writer emphasised that in addition to "commitment and background knowledge", teachers need to have "passion to teach their students", these are all "important things that should motivate a teacher to teach". Adding that what is needed today in education is:

"teachers thinking outside the box, like we did with the lessons and the activities inside the curriculum. I think it will be more fun. I think the trainees will be happy to come to school and learn because of the way the activities are done." 
The power of storying in education is also in its active nature, which "mitigates against stagnation and dependence, and works in favour of productive and deep conversations" (Sanga et al., 2018, p. 8). It focuses on cooperative activity and calls upon inclusiveness, further validating ontological traditions that are dialogically mediated and constructed. Ples-specific tok stori methodologies in pedagogical strategies further encourage the power of innovation through the contextual reshaping and "construction of new, fluid realities" (Sanga et al., 2018, p. 8).

\subsection{Storying development}

This section looks at several development related matters through the stories shared by the participants of this study. It discusses education as integral element and touches on the topic of mobility for this analysis. Understanding relationalities between education and development in ENB is central to this analysis.

Following the establishment of Western educational structures during the colonial period in ENB, leaders and their communities recognised the importance of education. Many aimed to ensure their young continued to rise up to assume leadership positions, thus ensuring they retained a level of autonomy in governance, leadership and decision making. This was particularly important for the country's independence and post-independence efforts. In more recent decades and across PNG, schools have experienced pressures generated from globally sanctioned education and development rhetoric, policies, practices and goals. The oftentimes limited practical applicability of those goals is exacerbated by the generally tight development delivery timeframes they come attached to. Those timeframes are furthermore often at odds with local goals and practices that are built on Indigenous notions of time, as well as with the construction of ontological realities that are dialogically and relationally mediated (Aperahama, 2017; Tok Stori with IaIva Magaga, 2016; Narokobi, 1980; Sanga \& Reynolds, 2019). 
In ENB at present there are several Indigenous people, their diaspora and other people from outside the province and country involved in prioritising Indigenous knowledge and practices to inform education and development efforts in ENB. They are engaging the ancestral knowledge and ples-specific know-how that we have touched on throughout the stories in this thesis and the first section of this chapter. This study's participants are some of the people negotiating a diversity of presentday gendered, generational and socio-political stances. These are the different stances among the young technological knowledgeable and the older more traditional groups in their societies. Between people educated inside and outside the country, who hold political and educational leadership positions at different levels (K. H. Thaman, 1997). As well as those involved in local and international development and aid relationships.

Storying with participants produced a number of themes relevant to contemporary development matters and their implication for education in ENB. These are: the reframing and re-establishing development and aid relationships; autonomy, tabu and place; and decolonising the gender/development intersection.

\subsubsection{Reframing and re-establishing development and aid relationships}

Reframing the way that development and importantly educational-aid relationships are established and conducted at both discursive and practical levels is important to the participants of this study. Participants' stories reveal the imperative for placing people, environment and ples-specific values in the forefront of efforts aimed at strengthening community wellbeing and economic growth; particularly within those related to educational strategies. Commonly, Indigenous Pacific bodies of knowledge, worldviews, understandings and skills, as well as ideas and thought have not been part of the discourse or practice of educational aid. Even when clearly articulated by Pacific thinkers, researchers and practitioners. Nor have they been 
included in policy formulation by international development partners and governments (Huffer \& Qalo, 2004; Sanga, 2005).

Storying with participants reveals the work towards re-conceptualising the notion of what resources are of value under current development and aid relationships. They challenge the idea that resources commonly offered by international development partners such as funding, technical expertise, delivery at the shortest time possible and certain working practices (e.g. task/objective oriented rather than relationshipbuilding and sustaining oriented working practices), are more valuable than those held by Pacific partners. Foundational resources in Pacific relationships are as described by Sanga: "goodwill, hospitality, humility, listening, respect, [...] reciprocity, [as well as] local knowledge, which is essential for aid activities" (2005, p. 20; Nabobo-Baba, 2003). Values of love, respect, obedience and trust, are central to any relationship, including to those related to development and educational aid for many Gunantuna/Tolai people in ENB (Tok stori with IaIva Magaga, 2016). Participant's storying further reveals a clear need for longer-term aid-partner relationships and goals; and for welcoming local leadership and Indigenous beliefs and practices, as the means to navigate that relational space.

Long-term relationships demand the building of trust, sharing time and gaining mutual understanding; it ultimately necessitates of accountability, resource-sharing, and co-constructing the agenda, priorities, activities and the goals of said relationships. It necessitates of educational-aid relationships to embrace, prioritise and support the addressing of Pacific partners' concerns, which in the case of ENB are related to their efforts towards sustaining their autonomy on aspects such as: social-economic and political decision-making; their traditional practices and protocols. This coincides with remarks made by Sanga (2005) regarding strategies for rethinking educational-aid relationships in Oceania, where he points out the need to prioritise Pacific partners' desires to strengthen their educational leadership at the national, organisational, provincial and village levels. 
A number of participants have experienced relationships with development and aid partners through their own work or as part of the communities where programmes and/or projects have taken or are currently taking place. Of priority to the participants is that international development partnerships and educational-aid strategies support the local cultural survival, leadership and autonomy they have devotedly worked for inside and outside the classroom, as well as inside and outside development and aid partners' meeting rooms. ToHenry Tavul pointed out that since independence, he observed his communities experiencing unequal relationships with development partners:

"development partners come in a package, and they will come, and they will tell you: 'we have all the chocolates that you would like to have'.

They will not tell you though, that in the chocolate box, they also have some ginger. By the time you've realised that there is ginger and chilli and whatever else they want to put inside - they will be gone!"

At present, ToHenry Tavul's leadership in the economic and education sectors in the province means that negotiations with development partners are conducted in a way that places people, ples, environment and their values in the forefront of the efforts towards a 'wise, healthy and wealthy' province. In ENB, he explained:

"we have the national PNG Vision for 2050, [with its] broader issues. [...] we have the SDGs targets, and the ENB provincial targets which are set up to be achieved before 2030.

For my division [Commerce and Primary Industries], we are working to ensure we are part and parcel of facing these challenges and achieving these targets.

We are connecting people to financial institutions, [by] creating the micro-finance institution of Kokopo. I wrote that particular document, using my experience in education and finance. We 
started with PGK 250,000 and today we are talking about almost

13 million kina, serving up to 30,000 members. Not only from

ENB, but from New Ireland, Bougainville, we [also] have

automatic tailing machines."

(Tok stori with ToHenry Tavul, 2016)

When both the bottom line and the challenge of education and development is the benefit of local people, he believes that nowadays the leadership, projected outcomes, and the way of establishing and conducting partnerships: must be in local hands.

"If the big players can make it happen, there is no reason why the smaller players can't. We can make it happen for us, this is the message that I want to put forward, to challenge development: 'Whatever the elephant can do, the ants can make it happen better!'

(Tok stori with ToHenry Tavul, 2016)

Development partners that come to these localities can support "making things happen", but "the way we want them to happen", ToHenry Tavul asserted.

The effectiveness of international development and aid programmes in PNG is dependent on a few foundational points according to Rela Wawaneya:

"I can see that the only way that anybody from overseas can tap into those really important things is to understand and to always liaise and always communicate with local people. There is no way we can bring an idea and impose it, because it will again be repeating the mistake of the past.

But instead it is about listening, and understanding first, and knowing exactly where you are. You know, understanding that you are in Papua New Guinea and you have to behave in that way. You know, you have to see in that way, you have to view those beautiful Papua New Guinea glasses and you have to view through them"

(Tok stori with Rela Wawaneya, 2017) 
In educational aid relationships the imperative is to look into supporting the development of locally existent, context-specific and robust Indigenous pedagogical leadership. The "availability, ubiquity and cultural value” (Sanga \& Reynolds, 2019) of tok stori as a mode of learning, for instance, can also be beneficial to levelling the relational inequity that exists in educational-aid relationships. Tok stori is practiced, owned and can be confidently developed by people in ENB to guide the relational, discursive and practical interplay between development partners engaged in educational-aid relationships. This is because in Melanesia, tok stori is not a borrowed or learnt practice, but a ples-specific one. As such it can support placing "the power in the hands of Melanesian leaders as experts. This, in turn, can influence the level of pedagogical effectiveness" (Sanga \& Reynolds, 2019).

The stories presented in this thesis testify to the power of tok stori as a means for establishing Indigenous pedagogical leadership, as in the creation of the homegrown curriculum for ENB, which was dialogically and relationally constructed. Tok stori is however, also strongly advocated as a culturally appropriate means of navigating development and aid relationships, programme strategies and delivery in Melanesian settings:

"The cultural relevance of tok stori for leadership development programmes in Melanesia diverges from often-used donor leadership development programme strategy, practice and research. Perhaps this mismatch is a crucial element in the recurring failure experienced in the post-training implementation of donordevised approaches as lamented by Sanga (2009).

It may well be that international donors and Pacific Islands stakeholders involved in leadership development programmes would benefit by extending their own boundaries to embrace tok stori leadership and pedagogy. Operationally, because tok stori is not yet commonly used in donor-funded leadership development programmes, the activity of donors and other stakeholders in adopting tok stori may support its theoretical and practical development in international development settings."

(Sanga \& Reynolds, 2019, p. 22)

Indigenous peoples with their own ontological intellectual traditions and the genealogy of stories, hold the key to their autonomy, to their own cultural and 
environmental survival and renewal. Reframing and re-establishing development and aid relationships through prioritising Indigenous leadership at the discursive and practical levels, can foster relational equity amongst those involved, and render better development outcomes. In this reframing, Indigenous leadership can guide development and aid partner interaction by aptly conducting courageous conversations and consolidating enduring relationships, as foundational for development practice. For this to happen: silence, humility, time and reciprocity, are some of the principal gifts that are to be placed on the mat.

\subsubsection{Autonomy, tabu and place}

"The land is our mother and before it was stolen, we were very rich [...] We had everything we needed. Our land provided us food and water, protein, building materials, medicines, beauty, warmth and everything else. We were promised developments, were promised jobs, service, money [but] we were never asked.

Money cannot buy any of the things our land provided for us. Money won't buy my heart to give my land away [...] Please don't understand this wrong. I'm not saying that I don't want developmentroads, bridges, schools, etc. [...] We all want development, but no one wants to be landless.

I only want a better future... I want everyone to be free. I only want people to realize that their god given rights-like tradition, culture, and custom-need to be protected"

(Paul Palosualrea Pavol, 2016, 2018)

Communities across New Britain are being severely impacted by the illegal and aggressive operations extractive industries (Huffman, 2019). Many local human rights and environmental advocates such as Elizabeth Tongne and Rodney Simai in West New Britain (WideBay Conservation Association, 2015), as well as Paul Palosualrea Pavol in ENB, have worked for years to stop the logging which is rapidly transforming their lands into oil palm plantations. Roads and other 
infrastructure built for logging activities have short-lived or non-existent benefits to customary landowners, and devastating environmental impacts.

Many research participants are committed to protect and promote their ability to exercise their autonomy in political, educational, economic, cultural, knowledge systems, land rights, environmental protection and other areas of their social realities.

Decentralisation reforms established nation-wide between 1970-90s, have contributed to provincial-level autonomy on planning and implementation of policies and strategies, including those related to education (Walton, 2019). This for instance enabled the ENB Provincial Executive Council in 2017 to sanction the introduction and implementation of a homegrown curriculum for the province (ENB Curriculum Development Project Collective, 2015). By storying with Gunantuna/Tolai people (predominantly elders) about locally recognised and exercised concepts of autonomy, it was revealed that it has much do to with the protection of their customary rights over their land and their perpetual possession, practice and use of tabu. As pointed out by IaIva Magaga:

"one of the most important roles of tabu is that it gives us a basis to have autonomy in and over our province, [as well as] the ability to govern, rule and [..] run our own affairs. [...]

No foreign country or government can stop or take that away from the people. We don't have to ask for it, we already have autonomy"

(Tok stori with mum IaIva Magaga, 2018).

According to ToHenry Tavul, for Indigenous people in ENB to exercise autonomous power nowadays they require to call on that 'Melanesian wise knowledge'. This requires to cement the understanding that Gunantuna/Tolai are people with knowledge on how to look after themselves, their relatives and also "fellow travelling men" in this "society [there is no] room for poverty", and a society with their own customary land, resources and practices (Tok stori with ToHenry Tavul, 2016). 
ToHenry Tavul observed that many peoples in Oceania, including ENB are pushing for "autonomy, for autonomous powers". However, he says, autonomy at all levels from provincial, to LLGs, to village, to family, to the individual: necessitates primarily of the 'wise knowledge' to support people getting out of "the so-called 'poverty syndrome'". Autonomy is also about strengthening their own concepts of wisdom, health and wealth that are intrinsically linked to kinship connections, land and tabu. their kinships connections:

"We want our people to have the wisdom, to think right. We want them to be healthy, because we need a healthy workforce, and then when these two are working hand in hand, you will develop a lot of wealthy people."

(Tok stori with ToHenry Tavul, 2016)

ToGideon Turpat and IaEleonora Varmari Vigil's stories shed a light on the importance of safeguarding their peoples' autonomy and wellbeing, among the contemporary complexities and challenges faced by Gunantuna/Tolai societies. I stori with ToGideon Turpat about the fact that much of the world's population are not born into a system that grants them customary land rights ${ }^{56}$, and upon reflection he says:

"We are lucky here, because we have tribes, we have land, and each tribe has land. My land starts from the beach up to the mountains, and it belongs to my clan, not to everybody. This is big land, and this is our land. [...]

(Tok stori with ToGideon Turpat, 2017).

I have observed how the village, the clan and the extended family look after their people when circumstances change or demand it, such as loss of employment,

\footnotetext{
${ }^{56}$ I have storied extensively with several people and elders in ENB about how for many people around the world, renting a house or borrowing money through mortgages is the only way to access land and/or housing, as we are not born into customary land ownership systems. Many of those I storied with in ENB, specially the elders, find it a bizarre and saddening concept, one that is rather synonymic of poverty.
} 
illness, or caring for children and the elderly. IaEleonora Vigil emphasises that " $a$ very strong-hold Tolai must always have 'something' to sit back on in the community". That 'something' is dependent on the person's presence in and contribution to the community. Participating in important occasions, sharing wealth which is manifested not only through cash-money, but through the sharing of knowledge with kin and the amount of tabu a person possesses: "That [something] is what we are proud of" she asserted (Tok stori with IaEleanora Vigil, 2016).

When faced with present-day land scarcity challenges, education can contribute to a sense of autonomy, and give people something to sit back on, as described to me by ToGideon Turpat. He encourages his people to have an education because he can see the burgeoning population and land shortage issues in Gelegele-Matalau village. Education can provide a future,

"if you've got no land that you can cultivate, [education] is your living, if you've got no land, your education is your land"

(Tok stori with ToGideon Turpat, 2017).

Participants storying tells us about the ability for many Gunantuna/Tolai people to continue exercising autonomy over their own affairs. This ability is intrinsically linked with the protection and promotion of their customary land rights and kinship-strengthening and wealth-sharing practices. They understand that presentday socio-economic, political and environmental challenges can and do affect their ability to exercise their autonomy. As such they are engaging in pedagogical and development leadership processes that address those complexities, furthering the work towards sustaining their autonomy. Ultimately, they are safeguarding their ples for generations to come. 


\subsubsection{Decolonising the gender/development intersection}

Whilst storying with participants with knowledge of their customary land systems, it became evident that it speaks of a society that has historically valued and respected female connection and authority related to ples. ToGideon Turpat told me:

"My wife, as a woman, has her own land and that land belongs to her, not to me.

Everybody is like this here; the women have their own land"

(Tok stori with ToGideon Turpat, 2017)

Customary ownership related to ples, comes with immense responsibility to nurture, protect, and uphold the sacredness of land and of the genealogy of people that belong to it. This was evident to me by the immeasurable amount of time and care mum IaIva Magaga provides her ancestral land Matalau, the relocation land Gelegele-Matalau, and all other important places to her clan and extended family. When speaking with Archbishop Francesco Panfilo about gender and customary land systems in ENB he pointed out that it is apparent how "women are more respected here, they have to" he emphasised (Interview with Archbishop Francesco Panfilo, 2016).

I have observed that female connection to every aspect of life such as the genealogical transfer of land, spirituality, as well as village and community wellbeing, is respected in Gunantuna/Tolai cultural contexts. I have also seen that gender complementarity rather than absolute power is present in a lot of these contexts. Nevertheless, it is important to clarify that by no means do I presuppose for example, the universal gender equality among Gunantuna/Tolai women. I further do not presume to know the inherent diversity of complex kinship affiliations to different clans, vunatarai and extended families. The meaning of vunatarai, for example, is argued to be difficult to accurately define in other epistemologies and languages: 
"several writers have incorrectly defined the 'vunatarai' as a clan that can attribute their origin to a single mother. Whilst this is generally true, this definition ignores the incidence of adoptions which were conducted principally to strengthen the clan's fighting capabilities and to preserve land tenure where there are no females members in a family"

(Kakabin, 2017d).

Any such presuppositions would result in the homogenisation of women's lives, obfuscating women's agency and existing power imbalances. They would have a similar homogenising effect on other gendered identities, as well as on the agency of clans, families and other kinships networks.

In PNG it is reported for instance, that "other than nutrition, where there are consistently more stunted boys, on most human development indicators (health, education, literacy and numeracy) women's status lags behind that of men" (UNPNG, 2018, p. 20). Women across the country also face power imbalances in political engagement and representation, and face high levels of physical, psychological and sexual violence (Degerman, 2014; Underhill-Sem, 2019). These include several women in ENB who, while they hold power through customary land ownership and other Indigenous customary structures, they still experience lived socio-economic inequalities. This is of particular concern for the formulation and implementation of educational strategies, given that violence and oppression of girls endangers their freedom to pursue education and can sometimes disadvantage them in terms of accessibility, participation and retention in PNG schools (Underhill-Sem, 2002; Wilson, 2019).

At present in ENB, village-level women societies and civil society groups such as the ENB Council of Women promote gender equality at diverse levels. Grassroots NGOs such as Wide Bay Conservation Association (WBCA) led by Elizabeth Tongne (2015), an ex-teacher and world-renowned leader in conservation from East Pomio, are tackling issues of contemporary commercial development of customary land usually passed down through generations of women. WBCA works on related issues such as 
increased domestic violence, decreased food security and lack of social security for women and children; and on building relationships with local government and relevant organisations to promote gender participation in decision-making processes (IWDA, 2013).

Throughout the country, as well as in ENB and within Gunantuna/Tolai Indigenous customary structures, it is also common to find that the education and entrepreneurship of women is valued and respected. An example of this is the way that 'bride-price' or 'bride-wealth' (K. Martin, 2018), practiced through sacred ceremonial proceedings would increase in a way that shows respect to women's educational and entrepreneurial achievements (Wilson, 2019). Furthermore, there also exist customary-based structures that deal with instances of violence against women and domestic violence (Tok Stori with mum IaIva Magaga, 2016; Tok stori with ToGideon Turpat, 2017). It is thus important to highlight that a web of relations that negotiate domination and subordination, privilege, and agency, as well as a multitude of layers of inequality: are all part of women's experiences in ENB (Collins, 2002; Crenshaw, 1989; Moura-Kocoglu, 2017).

An active part of the decolonising agenda of this study is challenging what Talpade Mohanty (1984) calls the "othering" of Pacific women's social reality, which constructs them as "victimized, voiceless, homogenous objects without agency" (Moura-Kocoglu, 2017, p. 240). Therefore, it is crucial to address potential damaging consequences of the continued institution of foreign-inspired language and practices to tackle gender equality. Historically, it is argued, that the tendency has been to impose Western biases and assumptions (Rathgeber, 1990) into the establishment of development strategies destined to tackling issues of violence against women, and gender economic inequality in ENB) (Jolly, 1997, 2005). These assumptions prevail despite decades of global shifts in development that claim learning lessons from wrongly presupposing that existing (traditional) social relations are characterised by a dynamic of male domination and women oppression (Jolly, 2005; McKinnon et al., 
2016). Although well-meaning, at times international development and other outside interventions may "remain limited in comprehending Indigenous women's agency as much as multiple and interconnected forms of inequality and oppression" (Moura-Kocoglu, 2017, p. 242). When approaching gender relationalities in Oceania, and due to my outsider/insider positionality, I am always reminded of a question posed in an encounter with Teresia Teaiwa, where she asked us: "as outsiders, can we develop a feminist analysis that is not colonizing?" (2016). Therefore, respectfully learning from Indigenous feminist perspectives ${ }^{57}$ "allow us to examine critically the positionality of Indigenous women in negotiating agency and authority against the background of colonial histories and Eurocentric hierarchies"' (p. 242).

Limitations can also come from approaching gender equality with a singular focus on one gender identity or solely on women and men power relations (Moser, 2012). Throughout the years, I have heard from many Gunantuna/Tolai women and men that I work and live with, that both women and men knew they were powerful. Yet, over many decades, polarising gendered ideas and structures have impacted on younger generations' understanding of underlying forms of gender complementarity, diversity and equality. A key to gender equality, as highlighted by Avataeao Junior Ulu is to recognise that:

"men and women often have different needs and priorities, face different constraints and have different aspirations. Above all, the absence of gender equality means a huge loss of human potential and has costs for both men and women, and also for development"

Ples-specific knowledge and practices sustain and negotiate gendered power relations. For example, relationships in Gunantuna/Tolai society are largely constructed on kinship, and on "the need of social support and access to resources such as land" (Simet, 1991, p. 182). Gender roles have been defined by

\footnotetext{
${ }^{57}$ See chapter 5, section 5.3. for more on gender and decolonising feminist thought.
} 
responsibilities and privileges contained within such relationship dynamics; it "entails certain modes of behaviour and responsibilities for the people who are involved in them" (Tok Stori with mum IaIva Magaga, 2016; Simet, 1991, p. 170; Tok Stori with Talatala ToMorton Amos, 2016; Tok stori with ToGideon Turpat, 2017). They serve to guide the way women and men for example, interact and support each other: within socio-political and economic matters; with the safeguarding and distribution of land and tabu; in ceremonies and rituals; with labour; with sustenance and care (including care of children, elders and 'burying' ${ }^{58}$ ); with protection from others; with general moral support in any venture undertaken; with the transfer of intellectual property, "such as dance songs of the clan, healing knowledge, magic and ritual design" (Simet, 1991, p. 178); within the clan, between clans, with outsiders, as well as intergenerationally.

A requirement remains for development and aid representatives working towards gender equality to gain culturally respectfulunderstandings of traditional knowledge and practices concerning the law, order and justice exercised at the tribe, clan and village level by different Indigenous governing bodies. For example, Tubuan has historically prevented, judged and punished violence against women and children (Tok stori with ToGideon Turpat, 2017). There also needs to be recognition and respect to the long-standing role that elders, and in more recent times lotu and its village level representatives, as well as women and men councils at the village level, and civil society bodies, play in spiritual and ethical leadership regarding gendered power relations (Talatala ToMorton Amos, 2016). It is fundamental to respect the leadership of elders and their communities in holding spaces where they use their own Indigenous language and work within their own

\footnotetext{
${ }^{58}$ Burying the dead is an important traditional means of establishing rights of ownership over land, it is an important ceremonial event, that requires the coming together of many people for a ceremony to appropriately 'bury' the person where a Tubuan will conduct the mortuary rituals and where there is distribution of tabu (Simet, 1991; Tateyama, 2006).
} 
structures in gender related matters (J K Gibson-Graham, 2005; Jolly, 2005;

McKinnon et al., 2016).

In ENB, and also across Oceania, it is essential that education and development work contributing to economic and social-political gender equality, is built into existing cultural and social structures and institutions. It requires to appropriately address the areas of engagement, agency, leadership positions, entrepreneurship, decision making, contribution to social-economic development, and participation of women and men in professional, political and social-economic spaces, at the provincial, clan, village and household levels, and in both cash-generating and non-capitalist senses (McKinnon et al., 2016; Rathgeber, 1990; Vunisea, 2019). For example, within community economies and networks engaged in the harvesting, transportation, distribution and sale of produce (e.g. vegetables, cocoa, copra, peanuts), as well as processing (e.g. coconut oil products), prepared foods, the making of art crafts (e.g. bilums bags, earrings) and clothing (e.g. meri blouses) at markets and other retailing channels inside and outside ENB (Tok stori with Jeddah Violet Gigi, 2016).

Guided by the stories and wisdom of elders, the way these community economies, networks and systems support each other and negotiate underlying gendered roles, powers and responsibilities attached to land, governance, kinship, knowledge and centrally education, have been key to shaping this study and to my work within the education sector in ENB.

\subsection{The purpose of education in relation to ples: mobility, education and development}

The history of mobility in PNG reflects intricate trade links that spanned across the most distant islands at sea and remote mountains inland (Narokobi, 1980). Mobility is an central aspect of Melanesian life and identity. Millennia-long traditions of movement across sea and land for a myriad of reasons including the trading of shells 
and goods, precede a more recent type of mobility related to formal education, labour and trade opportunities.

Important to this study is the way that education-driven mobility patterns are related to the achievement of locally sanctioned educational and development objectives in ENB. Education can shape diverse and empowering mobility patterns in Melanesian localities as shown by some participants' own education and/or labour related mobility. Formal education-driven mobility patterns are common in ENB, with many young people migrating to Port Moresby, Goroka and other urban centres for higher education at different universities, teacher colleges, and so on.

This section reflects on this study's participants' insights into the purpose of their mobilities. Into how these mobilities relate to education strategies and development outcomes, and into the links to and impact on their ples.

\subsubsection{Migrating with dignity}

Participants' stories have revealed that, contrary to pessimist viewpoints on moving away from ENB, the reasoning and purpose behind many Gunantuna/Tolai people's mobility for education (and also labour) highlight the role of family and wider community in the related decision-making process. Decisions to either migrate or stay home are made collectively by considering the benefit to family, village and province. This was evident to me one day whilst storying with a respected provincial political leader, who told me how when he had the opportunity to move to Port Moresby and make a lot of money, his father invited him to stay in the province, telling him that his skills and efforts would be better suited to leading the province; 'it is not all about money', he remembered his father telling him.

The five elders who storeyed with me, as well as MP for Rabaul ToAllan Marat, all migrated for education and/or labour opportunities across PNG and to other countries. Before becoming a respected spiritual leader for his church, Talatala ToMorton Amos studied at university outside the province. His work later took him 
to many localities across the country, one of them Kimbe, where he witnessed the large-scale devastation on people and land brought about by oil palm companies. Storying about the relationship between mobility, education and development, he put it simply and powerfully:

"beetles are beetles, they come back to where they belong"

"we are educated people, some [...] go out and get big jobs after

their studies, but you are to share the knowledge that you gained.

That is development".

(Tok stori with Talatala ToMorton Amos, 2016)

Migrating for education and/or labour for many Gunantuna/Tolai elders and leaders, thus "is about coming back and showing up" (Tok stori with ToHenry Tavul, 2016). These stories refer to a reciprocal purpose of migration which holds an intrinsic sense of dignity:

"Ok, you can go back [to the outside], but the home is still waiting for you. [...] You will come back again.

I'm going to still hold my cigarette in here, until the time they will come back and ask me for this butt".

(Tok stori with Talatala ToMorton Amos, 2016)

Because there is no dignity in people coming back to the community "after spending 30-35 years working [and] go drink and drink and show off, [...] they spend all their money, [and] when the money is finished, they will become beggars" (Tok stori with Talatala ToMorton Amos, 2016). A sense of belonging and dignity are all essential parts of migration:

"especially Tolai people, when they come back for holidays, they contribute something towards the community church, they buy a packet of rice for their auntie, their uncle, they give 2 kina to their nephew; people value that".

(Tok stori with Talatala ToMorton Amos, 2016) 
Studying or working outside their homeland has a lot to do with what benefit it can bring back home. IaEleonora Vigil for instance, remembered vividly telling her father: "I want to go study and help my people", and letting nothing stop her (Tok stori with IaEleonora Vigil, 2016). Later, when she went to study at university, she drew inspiration from IaIva Magaga who was studying at the same institution:

"Mrs Magaga graduated before me, but when she graduated from college, she came back to ENB. She was, and she is, the precedent.

We are so patriotic about our province. Is that the right word?"

(Tok stori with IaEleonora Vigil, 2016) This devotion to education and ENB was exemplified by one of IaEleonora Vigil's stories about a newspaper article that was written during her time training as a teacher outside the province and alongside other Gunantuna/Tolai student teachers. The harsh criticisms in this article about the ENB education system, their peoples and the way the province was doing education in comparison to other provinces, became a force that changed the future of education in ENB. She explained:

"some of us decided that when we graduate we must go back and develop our province. [...] So, we just pulled ourselves together and that group of students, we all came back to ENB and we are still here; some of them have recently resigned.

But [...] we just came back, some went to Kokopo and others to all the schools in ENB, and we spent all of our years, teaching in our province [...] for over 36 years now."

(Tok stori with IaEleonora Vigil, 2016)

I recall Dr ToAllan Marat saying how Gunantuna/Tolai people always return home, always listening to their elders when they ask them to come back and look after their people. The positive impacts on the educational, political and community development spheres of the province that currently are, and will be felt for many generations, are consequential to the return home of skilled and committed people such as these elders. 
ToHenry Tavul told me about his experiences outside the province before coming back to lead the ENB Division of Commerce and Industry, where he has managed to weave cultural values and environmental protection with ethical ways of connecting people to financial institutions that service thousands of people today. He worked for over a decade outside the province as a freelancer in diverse educational fields, traveling to many corners of the world "to bring back what [he] has seen". He wanted to tackle the challenge on "how can we make it happen on the local context and based on the local environment? Solutions are not about "replicat[ing] exactly what is [out] there" but creating culturally appropriate strategies such as "[d]eveloping the right curriculum with the right principles" (Tok stori with ToHenry Tavul, 2016). Storying about the relationship between education, development and mobility, he said:

"go to the end of the universe!

[Because] when we are talking about education, we have policies, directives and principles that are established in the name of 'development', but a lot of times they imprison us, they catch us, so that people don't become enterprising, about how they, how we should see life!

Get out there, enjoy it, and see what we can get out of the world".

(Tok stori with ToHenry Tavul, 2016)

Doing so means also 'carrying your basket with you', remembering where you come from:

"when you go to another province and you see them holding that basket you know what it means: 'I am my origins!'

'I'll be here for a while, but I need to go back to where this basket came from, [...] we are not saying it out directly, but seemly, a basket on a hand is saying: 'I am from ENB and I want to go back to $E N B^{\prime}$.

As the story goes, there is no better place than home!"

(Tok stori with ToHenry Tavul, 2016) 


\subsubsection{Returning to the village as empowerment}

In ENB there is another mobility pattern, however this is one of concern for some elders, educators and communities. In recent decades they have observed that the systemic devaluing of the importance of village life by formal education institutions, strategies and policies, has impacted the return migration of school leavers back to the village.

Those that return to the village with no cash-generating jobs or higher education prospective pathways following several years of formal education are alienated, chastised, ridiculed and labelled 'drop-outs' or 'failures'. This stigma has pushed youth to regard going back to the village as 'a fate worse than death' (Giraure, 1974). Thousands of children who are dissatisfied with and alienated from village life, then flood the towns looking for the jobs they feel entitled to. The result still is levels of social unrest, unemployment or youth engaged in culturally demeaning or dangerous labour.

To address these challenge, this study's participants have been involved for decades in strategising and implementing a kind of education that promotes mobility patterns that also consider the return to the village as encompassing dignity, possibilities and future, one that is synonym of empowerment.

For instance, some of our ENB curriculum writers and many of the vocational teachers I have worked with in the province, are involved in the training of early school-leavers and "young mothers who have been at the village for quite some time" (Tok stori with Jeddah Violet Gigi, 2016). They offer them village-relevant six-month-long courses such as cooking (including nutrition, hygiene, and commercial cooking for catering purposes), sewing, poultry management training, and more, through the vocational centres they teach at. Although this adds pressures to teachers already heavy workloads, this kind of initiatives support young mothers, men and women early school-levers and even the elderly at the village level (Tok stori with Roselyn Onesu, 2017). 
Though most people at the village level are engaged in labour and responsibilities related to their place-based community economies (McKinnon et al., 2016), the stigma and alienation attached to not being part of cash-income generating employment following years of schooling is strongly felt at the village level. There are other initiatives such as the community college programmes conceptualised and implemented by IaIva Magaga while heading Malaguna Technical Secondary School. With the support of Dr ToAllan Marat in the early 2000s, this initiative accommodated, trained and issued TVET certificates to hundreds of young people who through the eruptions of 1994 were displaced from their place of origin and also lost any evidence of them exiting their final grades. The community college supported students gaining a form of recognition of learning to access formal employment elsewhere or start their own businesses at home (Tok Stori with mum IaIva Magaga, 2018). A participant also shared a story about a local company that is promoting local youth returning to contribute to the village throughout supporting their whole journey of education and employment:

"currently back at home there is this local construction company where the owner of the company collects young boys from the village, he puts them into school, and when they come out, they go straight into his construction company. He recruits the boys back to the village".

(Tok stori with Jeddah Violet Gigi, 2016)

This study's participants and their communities in ENB have voiced their concerns about a type of schooling system that continues to funnel through countless students out schools, to face a reality where there is "no space to further their education, no work for employment and no business opportunities" on the exiting side of their schooling years:

"So far, we see that from those who graduate, only a few go into getting jobs. Most go back to the village. 
Yet those that go back to the villages do their best to use their knowledge and skills to do something, to create their own living.

But a lot of them also engage in things that don't earn them a proper living. Some wander the streets"

(Tok stori sessions with ENB educators, 2016)

ToGideon Turpat also reflects on the fact that "parents are expecting the kids to just find a job when they leave school" (Tok stori with ToGideon Turpat, 2017) something that he can however understand, given the major financial investment done by families to put their young through school. Yet, the reality is that with no further education nor employment or business creation opportunities to match the skills they have learned at school, they end up with

"too many students in [the] villages who have graduated from

Grade 8, 10 and 12, even those that graduated from the universities around the country, who are not fully developed to use their potential and talents to advance in life"

(Tok Stori with mum IaIva Magaga, 2018)

Returning to contribute to village life requires of certain skills that a great proportion of youth coming out of the schooling system are not equipped with:

"[A]fter all those years of education, [many] are still not able to carry out simple instructions or work".

But also, [many] don't have the skills for building a small house, toilets, small kitchen, to beautify their homes, drain water, make good sustainable gardens.

Skills to plant trees, fruits and vegetables"

(Tok Stori with mum IaIva Magaga, 2018)

IaIva Magaga, thus emphasised the need in communities for relevant education "with empowerment for community living" (Tok Stori with mum IaIva Magaga, 2018). She reiterated that the role of education should have a holistic focus on supporting people to develop "physically, mentally, psychologically, financially, spiritually", this can in turn develop healthy and happy communities. Education's failure to do so she 
said, will see a depressing future for the whole country, because what PNG needs is "an education with a focus on survival, not on getting jobs" (Tok Stori with mum IaIva Magaga, 2018).

A balanced combination between cash-income generating, academic, technical and village-grounded skills, was a part of the lives of many of this study's participants growing up in ENB. Yet, in recent years this balance has been eroded due to diverse social-cultural and environmental reasons (Tok stori with Talatala ToMorton Amos, 2016). Yet, among the contemporary complexities of employment scarcity; limited access to higher education opportunities; a burgeoning population; climate-change related threats to livelihoods; displacement and relocation of people following natural disasters; to the encroachment on customary land ownership by multinational extractive industries: the youth that returns to their villages following their schooling years, should not, cannot be alienated nor labelled 'failures'. They are the present-day learners of the knowledge to care for their people and protect their ples for generations to come.

Bringing dignity back into the return of young school-leavers to the village, is something that participants in this study are working towards in their own places, institutions and villages. They recognise that 'failure' is not in their young coming back to the village with no job or money, but in a type of education that is unable to connect the sanctioned curricula and educational policies to the needs and development objectives of their young and of the village.

Educational strategising and delivery in ENB requires of a growing appreciation for the village as also a teacher (Tok stori with ToGideon Turpat, 2017). An appreciation for the important place that people who 'keep the fire going' occupy in the village's social-economic, cultural and spiritual domains (Doherty, 2017). Contributing thus, to the development of skills and ples-appropriate knowledge that ensures their young's ability to 'survive and thrive in their communities' (Magaga, 2018), in the 
face of contemporary challenges that exist, and thanks to the advantages of the village.

One of the objectives of the ENB homegrown curriculum is to support 'returning to the village as empowerment' to encourage community development. It draws from the wisdom of the village, its people and their ples. Yet it has also a firm and curious gaze over the horizon. It focuses on providing skills for community living, as much as learning skills that could serve students wanting to work and/or study elsewhere in the country or overseas:

"[this initiative] could help them balance things out back in the village. They could use those traditional activities, or traditional skills, not as something to lure tourists in, but to sustain the livelihood in the village.

But they have to [also] balance it with school. They could use their skills in tourism and hospitality maybe to improve their homes. They do not have to have very big homes and live luxuriously to cement those skills. They can use the skills they've learnt at school back at home. So, I think maybe there could be a balance"

(Tok stori with Jeddah Violet Gigi, 2016).

Led, conceptualised and developed locally, this curriculum materials draw principally from and take proud in what is local, in the stories passed down for generations, in respectfully sharing the stories that are culturally-enhancing, and in line with their cultural values, can protect sacred traditional knowledge and practices of ples (Talatala ToMorton Amos, 2016).

Ples-relevant and -reverent education can contribute to enhancing and celebrating, instead of diminishing the genealogy and culture of the communities that send their young to school.

So, whatever their mobility patterns end up being, either choosing to return to the village, going to university in the big cities, working in other countries, or as ToHenry Tavul would say 'going to the end of the universe': they can proudly carry 
their basket and be comfortable and confident with the knowledge and skills needed to succeed in all those spaces. This success is founded in a strong sense of belonging and pride connected to ples, to their village and to their community.

\subsection{Conclusion}

The conceptualisation, emergence and implementation of processes of change that render education strategies and policies for Pacific Island schools, have historically been skewed against Indigenous concerns. This has pushed their stories past and present, knowledge systems, languages and social practices into spaces of marginalisation (Giraure, 1974; Mel, 1995; Nabobo-Baba, 2013; Nagai, 2001; Narokobi, 1980; Sanga, 2000; L. T. Smith, 2012; K. H. Thaman, 1995).

Years into storying with colleagues in the education sector, community leaders and friends from across the province, I came to realise that these practices and associated concerns were also commonplace in ENB. Nevertheless, through the continued rethinking and re-enacting of education and development by visionary Indigenous people, they have also consistently remained open spaces of hope and resistance.

Some of them are the people that became the participants of this study. Together we delved into a tok stori exploration of the motivating, as well as the mitigating factors of processes of change that aim at generating education and development strategies that foster locally recognised notions of wellbeing. Working within education and development spheres, participants contribute to education strategies for formal, nonformal and informal educational institutions; to curricula development; to infrastructure and resources; to employment generation, entrepreneurship and ethical economic endeavours; to gender equality; to environmental and customary land protection; to educational response following natural disasters, displacement and relocation; to reframing development and aid relationships; to the prioritisation of Indigenous cultural values, stories and practices in education, as well as mobility and development strategies. 
The four themes that emerged from our shared process of storying presented in this chapter - motivations, education, development and the purpose of education in relation to ples - ultimately reveal that participants' concerns and effective contributions to education and development possess similar characteristics. They are rooted in cultural, social, economic and environmental continuity, renewal and survival. Their vision and action in education and development are inherently relational; that is, they are made of, tied to, and woven into people and ples.

The following final chapter draws conclusions and major insights from this study. 


\section{CHAPTER EIGHT}

\section{Conclusion}

I say mujer magica (magical woman), empty yourself. Shock

yourself into new ways of perceiving the world, shock your readers

into the same. [...] Write of what most links us with life, the

sensation of the body, the images seen by the eye, the expansion of

the psyche in tranquility: moments of high intensity, its movement,

sounds, thoughts. Even though we go hungry we are not

impoverished of experiences.

(Anzaldua, 1983, p. 172)

\subsection{Overview of conclusions}

This study centres on the ways that relationalities in Oceania contextualise the intersection of education and development. In following this branching and multifaceted line of inquiry, the study considers the following core research questions:

1. How are notions of education and development recognised and articulated at the local scale in ENB?

2. What type of education and development notions and strategies are currently being conceived and pursued in ENB?

3. How do these strategies contribute to asserting Indigenous epistemological and ontological traditions that meet locally appropriate and recognised ideas and needs of development?

4. How are place-based relationalities between education and development articulated in the design, development and implementation of education strategies in ENB? 
Research on these questions was guided at every step by Gunantuna/Tolai elders. This study thus aims to honour and uphold their relational space of learning, their intellectual traditions, their kindship networks, and their ples, which they generously share with me. They are the ones calling for a decolonisation of the mind from imposed concepts that pay little or no attention to Indigenous knowledge, values, places, practices, or relationalities. They want to contribute to education and development that fosters a better living at this time, when humanity requires the wisdom to face the existential cultural and environmental challenges of the twentyfirst century, and to find a pathway to renewal and revival.

This concluding chapter responds to the core research questions above by tracing key thematic and methodological insights, which emerged primarily through storying with participants. These insights relate to: rethinking and reclaiming education and development in Oceania; the role of tok stori as a decolonising methodology; and relationality and place in education and development. I finish with a final note for readers and participants.

\subsection{Thematic and methodological insights}

\section{Rethinking and reclaiming education and development in Oceania}

Education and development are negotiated processes, where Oceanic peoples negotiate privilege, marginalisation, and responsibility, and where they exist in several worlds simultaneously. A narrowly economic view of education as the foundation for modern development and neoliberal economic prosperity across Oceania has meant that non-formal, informal and traditional community models of education can be, and have been, neglected and marginalised. Educators and leaders in ENB find themselves confronted with competing global narratives of education, whether education for human capital focused on generating skills for employment and economic growth; or education for conscientisation focused on awarenessraising and offering alternative livelihoods. Faced with such different models and 
conceptions, these educators, leaders and their communities are actively asking: 'What relationship do our current educational systems, curricula and teaching and learning strategies have to our locally recognised concepts of knowledge and wisdom?' Their work as educators and leaders thus consists of daily epistemological and ontological negotiations, as they continuously bridge local and external knowledge systems in classrooms, offices, meeting rooms and villages.

Some of the elders and leaders whose stories can be found in this study inspired and guided the process of rethinking and re-enacting education in ENB through the creation of a home-grown vocational education curriculum. For many decades, these educators, elders and leaders have experienced the culturally undemocratic environment where learning, teaching and assessment take place. They understand the persistent bias that prioritises a type of formal education which is dominated by the use of foreign, culturally irrelevant content and languages in schools. They also recognise where the schooling structure can devalue and diminish the values and knowledge of the communities that send their children to school.

Yet the impositions and impacts of colonisation have not been passively embraced and internalised. Oceania abounds with visionary Indigenous women and men that have worked for generations towards notions and enactments of education and development as a means for cultural survival and renewal. They have engaged in careful strategising and their daily negotiations, characteristic of an active, constructive and caring resistance, places their stories, values, knowledge systems and social practices at the core of educational strategies, rather than at the margins. These educators, elders and leaders do not reject all external educational media or content, but rather recognise the desirability of some of these in order to engage with the outside world and to bring other carefully mediated benefits to their communities. They continually stress that this must be delivered in accordance with an education programme capable of cultivating cultural, social and economic 
wellbeing, a sense of identity and belonging, and the skills for thriving as part of their ples.

To say this another way, locally generated notions of education and development can and do overlap with outside knowledges, questioning the grey spaces, rather than focusing on black and white. This reminds me of the words of Talatala ToMorton Amos, who said to me while storying that "when a person is properly developed it creates a good person who knows how to recognise the positive and the negative types of 'development'" (Tok stori with Talatala ToMorton Amos, 2016). It is important to question, to criticise, but also to know when to accept things from the outside.

Numerous examples of rethinking and reclaiming the intersection of education and development emerged while storying with elders as part of this research and are presented in the tok stori interactive texts. Mum IaIva Magaga spoke about the conceptualisation and creation of an affordable community college within the prestigious Malaguna Technical Secondary School in Rabaul, for people with good working skills but no formal qualifications. Combining political and educational leadership, and industrial expertise from the community, it provided youth with useful skills to build and rebuild their villages, to encourage reconnection with ples following environmental disasters and displacement, encouraging entrepreneurship and preventing unemployment and youth vulnerability (Tok stori with IaIva Peteva Magaga, 2016). IaEleonora Varmari Vigil told me about the making of Our Lady of the Sacred Heart Secondary School in Kokopo through the dedication and passion of its leader who supported by kinship connections transformed this institution from a small high school into an exemplary secondary school that provides high quality, culturally relevant and identity-raising education to women in ENB (Tok stori with IaEleonora Varmari Vigil, 2016). ToHenry Tavul spoke about the conceptualisation and creation of educational curricula to develop the entrepreneurial capacity of school children and connect adults to micro-finance institutions, drawing on Indigenous leadership in the economic sector that prioritises local people, ples, 
environmental protection and values when working towards a "wise, healthy and wealthy" province (Tok stori with ToHenry Tavul, 2016). Talatala ToMorton Amos and ToGuideon Turpat both spoke with me about education that focuses on protecting the sacredness of ples which generates a sense of belonging and responsibility for personal and collective wellbeing (Tok stori with Talatala ToMorton Amos, 2016; Tok stori with ToGuideon Turpat, 2017).

Such rethinking and reclaiming has a central role for spiritual guidance from elders who have dedicated much of their lives to inspire a holistic kind of education that teaches 'respect to life' and the importance of cultural values, identity and relationality. This is the legacy of these Gunantuna/Tolai educators and leaders, who have consistently returned to their province following education or employmentrelated outer migration, with the purpose of strengthening the education system and supporting development efforts. Their stories are the fabric of their intellectual tradition and the means for continuity, survival and renewal of people and ples.

I have had the honour of narrating a story about a grassroots curriculum development initiative in ENB undertaken by Indigenous educators, with the guidance and support of local leaders, elders and the wider community (Tok stori about curriculum development project). As a collective we decided to create a safe and culturally enhancing space, and worked to actively challenge the practice of prioritising foreign stories, including foreign-created stories 'about' ENB and its peoples. We worked to bring culturally sustaining stories and practices to the forefront of vocational teaching, with a particular focus on relationships between educators, and on respecting the cultures of students. These stories and educational practices aim at much more than the schooling system; they have a political and spiritual momentum, and aim at creating opportunities for transformation with every interaction. As pointed out by Hoskins (2019), the Indigenous reclamation of spaces and stories of education and development is a matter of acknowledging and supporting a lifelong process of learning. 
The kinds of rethinking and reclaiming described in these stories could be called emancipatory Indigenous education. Many of these local-level projects are radical in their proposed scope of pedagogical change and contribution to practices of selfdetermination. They actively challenge the presumption that Oceanic educators and communities are unable to produce materials suitable for teaching their own people, in their own localities, a presumption that aligns with broader implicit and explicit representations of Indigenous peoples in development theory and practice. They are reclaiming educational spaces that were historically aimed at shaping children to fit the standards of 'developed' nations (Nagai, 2001). They are thus also reclaiming the stories that are needed to weave the life patterns of their people into education and development policy and practice in ENB.

\section{Tok stori as decolonising methodology}

This study contributes to the case for tok stori as a legitimate and effective decolonial methodology for education and development research and practice in Oceania. Tok stori is a powerful decolonial practice because it validates those whose ontological tradition is generally mediated through storying, and whom in many cases are relegated to the margins of knowledge generation and decision making. As a collective practice, one that is inherently relational and must be done together, storying manifests a "commitment to togetherness" that nurtures the emergence of collective action for community wellbeing (Sanga et al., 2018, p. 8). This runs counter to the individualist values and practices that are a feature of so many Westernderived education and development discourses and interventions in Oceania.

The five tok stori interactive texts with Gunantuna/Tolai elders that emerged from this research, alongside the one narrated story about the curriculum development project, are attached as an appendix rather than the main body of this text in order to comply with academic requirements. These texts are the primary outcome of this research process, as the stories they contain are expressions of Indigenous transformational action in education and development in ENB. They are the words 
of Gunantuna/Tolai elders who see education as a sacred pursuit, and community wellbeing as a mandate inseparable from this pedagogy. These are stories of active and highly ethical leaders in education and community development; stories of devoted educators, their extended families and communities; stories of friendships, mutual support, and respect; stories of inspirational and enduring relationships. Some of these are stories of hope and resistance, that speak of vision, strategies and relational work towards education that means will not only see their people surviving but truly thriving. These stories do not move linearly: they swell and recede like the ocean tides, they tighten and stretch like the strings of a woven mat, they are strung together and then broken to be shared like the tabu (shell money) of Gunantuna/Tolai people; for they are made of reciprocal relationships, of kinship networks and of reverence for ples. These stories also offer wisdom to the wider world by "giving a window on what is possible when re-thinking occurs" (Sanga \& Reynolds, 2019, p. 12).

I wish to emphasise here my conviction, which has emerged from my participation in tok stori and my wider relationships in ENB and Aotearoa, that educational storying is itself an expression of development. The global theories, practices, programmes and goals of both education and development, when applied to intercultural contexts such as the many different kinds of donor-funded projects implemented in Oceania, can result in "issues which have ontological origin [...] provoked by relational inequity between programme funders and programme recipients" (Sanga \& Reynolds, 2019, p. 12; Coxon \& Tolley, 2005). Relational methodologies such as tok stori are a means of upholding Indigenous values and ontologies in the often fraught negotiations which surround education and development projects, in the context of power imbalances and the legacies of colonial history. Storying provides an alternative relational space for the nourishing, strengthening, and re-emergence of Indigenous narratives and counternarratives grounded in Oceanic practices and systems of knowledge. 
In an academic context, I hope that the use of tok stori in this study will contribute to the increasing, but unfortunately still marginal, understanding that Indigenous methodology, ontology and metaphor are legitimate and robust elements of scholarship. As a relational research methodology, tok stori counteracts the decontextualised and dehumanised processes of knowledge generation that still characterise so much academic work in both education and development. Storywork is labour, that requires time and effort. It demonstrates that those involved value other people and respect other ways of being within the processes of knowledge creation.

Finally, tok stori is effective as a methodology for the practice of both education and development, and especially at their intersection. Every story and every silence is purposeful and requires conscious work. Sharing a relational space is about mutual responsibility, and holding this relational space with respect is not something you can simply opt out of. Believing in the intrinsic dignity of others is one of the core values from where we can together create new stories: stories that can enhance their world and their lives, stories that weave the life patterns of our learners and teachers into education by respecting their dignity and celebrating their brilliance (Sanga, 2016). This weaving of storywork into methodological practice is related to the insights that follow about the significance of relationality and place in education and development.

\section{Relationality and place in education and development}

This study makes the case for the centrality of relationality and place in the theory and practice of education and development in Oceania. This case is made through the storying of ENB ontologies, approaches, notions and practices that come directly from the words of participants, and from my own relationships and observations.

It is a long-standing trope among development practitioners that we should be 'doing ourselves out of a job'. Based on this study and my wider experiences and 
relationships in ENB, I argue instead that a respectful engagement in education and development initiatives in Oceania means that practitioners should rather be willing to engage in committed, long-held and enduring relationships with people and place. In this way my storying, observations and relationships in ENB demonstrate unequivocally to me that education and development are inherently relational practices; in these final paragraphs I reflect on some of the insights that have emerged from this study relating to the nature of relationality in place, in the context of education and development.

A non-idealised approach to relationality means I must note that there is not a single ENB perspective, approach, worldview or value system. Although my relationships and storying have been largely with Gunantuna/Tolai people, there are a number of Indigenous peoples in ENB, all with unique languages, histories and ontologies. As with any people group, Gunantuna/Tolai people have a range of personal views and ways of interacting with the world. By presenting the stories of elders that I have relationships with, I do not intend to essentialise Gunantuna/Tolai people, but to pay full respect to these relationships by taking their ontologies, values, and experiences seriously.

Individual and collective agency are sometimes overlooked as aspects of relationality. I have learnt, however, that ENB people do not behave like victims. They are aware of their own agency, and despite the ongoing marginalising impact of colonisation they negotiate their engagement with outside people, organisations, values and discourses on their own terms. This practical and ontological negotiation is based on the values of ordinary life in ENB: love, respect, trust, obedience, and reciprocity. It is enacted through Indigenous ways of being, thinking, doing, organising and behaving, and through the engagement of differences that acknowledges the life force and agency of others.

For a relational 'pathway' to exist in education and development, we must address the ontological difference between individuals, agencies, and cultures. There has 
been relatively little critical engagement in development policy circles with deeper questions concerning the type and nature of development that is sought through different educational strategies and policies, and still less work that questions the ontological basis of education-for-development in a way that suggests a practical pathway for practitioners, educators, community members and other actors. This study demonstrates that it is critical to acknowledge different worlds, realities, logics, and pedagogical practices, and that doing so can only be done through open engagement that respects Indigenous relational practices and notions of time. It is possible to progress relationships through significant ontological differences, but often only by being in a place (and in a ples) for everyday face-to-face interactions that build trust and reciprocity. These interactions are deliberately decolonising, because they challenge the multiple and sometimes hidden ways that the politics, values, discourses and priorities of dominant actors shape funding, design, and assessment decisions about education-for-development initiatives.

I am very aware that knowledge itself is relational: some knowledge can only be given, and no knowledge should be considered to be universally available (Smith, 2012). I have been careful in this study to only present knowledge that pertains to me, and that I am permitted to share, and to represent this knowledge as belonging to others, who have been generous enough to share parts of their stories with me. People from outside the Pacific who wish to engage in these relational spaces and practices must be prepared to respect these boundaries and to understand the expectation of reciprocity to both people and place.

\subsection{Final note}

There were many beginnings to this study, and I cannot write them all here. One beginning, however, was as a study about education and development. Over time and after much storying, however, I realised that it was really about storying as education, and storying as development. I am honoured to participate in this 
storying, and to present these stories and their insights on behalf of my elders, community and adopted family in ENB.

The stories included in this study are, of course, not complete. They are contiguous with the past and future, and intimately intertwined with each other. Like the evercontested notions and practices of education and development, they represent brief moments in the transition of one thing into another, whilst also remaining the same. Their nature is that of emergence, of coming forth.

In a 2016 lecture, Teresia Teaiwa noted that there will never be a conclusion to the things that Oceanic people do. They endure and fight for the same things as 30 years ago, just in different ways and through different lenses (Teaiwa, 2016). This is why storying is important, because it is a place-based, grounded, but continually evolving practice of engaging with the passage of time.

The stories presented in this study are an open roaring flame for emancipation and self-determination through education and development. This fire is made of many times and many imaginations. It is a slow-burning fire that demands time, patience, space and silence; a fire made by wise, patient minds and strong, gentle hands; a fire that has been constantly and consciously tended for generations and seasons unknown; a fire that requires the building and sustaining of relationships for its upkeep; a fire that knows when it is time to rage, and thus to bring new life, and when it is time to wait safely in the nurturing belly of its imagination.

Thank you for your attention. In reading this study you also have become part of its story. Ngalana boina tuna. 


\section{Bibliography}

Adamson, J. W. (2013). A short history of education. Cambridge: Cambridge University Press.

ADB. (2008). Foundation for the Future: A Private Sector Assessment for Papua New Guinea. Mandaluyong City, Phil: Retrieved from Asian Development Bank: https://www.adb.org/sites/default/files/institutional-document/32218/psa-png2008.pdf

Adom, K., \& Asare-Yeboa, I. T. (2016). An evaluation of human capital theory and female entrepreneurship in sub-Sahara Africa: Some evidence from Ghana. International Journal of Gender Entrepreneurship, 8(4), 402-423.

Aguilar, R. G. (2013). Conocer las luchas y desde las luchas. Reflexiones sobre el despliegue polimorfo del antagonismo: entramados comunitarios y horizontes políticos. Acta sociológica, 62 (1), 11-30.

Aikman, S. (1995). Territory, indigenous education and cultural maintenance: The case of the Arakmbut of South-Eastern Peru. Prospects, 25(4), 593-608.

Almond, G. (1964). Comparative Political Systems. [rev edn]. Comparative Politics, 5064.

Almond, G., \& Coleman, J. (1960). The Politics of the Developing Areas. Princeton: Princeton University Press.

Alston, P., \& Robinson, M. (2005). Human rights and development: Towards mutual reinforcement. Oxford: Oxford University Press.

Altamirano-Jiménez, I., \& Kermoal, N. (2016). Living on the land: Indigenous women's understanding of place. Edmonton, Canada: Athabasca University Press.

Altbach, P. G., \& Kelly, G. P. (1978). Education and colonialism. New York: Routledge.

Amin, S. (1972). Underdevelopment and dependence in Black Africa-origins and contemporary forms. The Journal of Modern African Studies, 10(4), 503-524.

Anderson, D. (2009). Productivism and ecologism: changing dis/courses in TVET. In J. Fien, R. Maclean, \& M-G. Park (Eds.) Work, learning and sustainable development (pp. 35-57). Dordrecht, The Netherlands: Springer. 
Anzaldúa, G. (1980). Speaking in Tongues: A Letter to 3rd World Women Writers. In. Anzaldúa, G. (1987). Borderlands/La frontera: The New Mestiza (1 ${ }^{\text {st }}$ ed.). San Francisco: Spinsters/Aunt Lute.

Aperahama, H. ( 2017). Whao Tangiata, Rākau Ōpurepure: Harmonic Chisel, Rainbow Wood. Paper presented at the Kimihia te mea ngaro: Pūrākau and Indigenous Storywork Research Symposium, Waikato-Tainui College for Research and Development, Hopuhopu, Ngāruawāhia.

Atkinson, J. (September, 2001). 'Privileging Indigenous research methodologies'. Paper presented at the National Indigenous Researchers Forum, University of Melbourne, Melbourne.

AusAID. (2002). Curriculum Reform Implementation Project: Second Annual Plan July 2002 - June 2003. Retrieved from Pacific Archive of Digital Data for Learning and Education:

http://www.paddle.usp.ac.fj/cgi-bin/paddle?e=d-010off-paddle--00-1--0---0-10TX--4-------0-111--11-en-50---20-home---00-3-1-000--0-0-11-0utfZz-8$\underline{00 \& a}=$ file\&d=png037

Avia, T. (2004). Wild dogs under my skirt. Wellington, Victoria University Press.

Ayala Mora, E. (2002). Ecuador: Patria de Todos. La nación ecuatoriana, unidad en la diversidad. (Master's Thesis). Universidad Andina Simón Bolívar, Quito, Ecuador. Retrieved from http://www.uasb.edu.ec/UserFiles/File/ecuador\%20patria\%20enrique\%20ayala. pdf

Baba, T. (1989). The Business of Australian Aid: Education, Training and Development. St Hilda's College, University of Melbourne: Melbourne.

Ball, S. J. (2010). New Voices, New Knowledges and the New Politics of Education Research: the gathering of a perfect storm? European Educational Research Journal, 9(2), 124-137.

Baran, P. (1952). On the political economy of backwardness. The Manchester School, 20(1), 66-84.

Baran, P. (1957). The Political Economy of Growth. New York: Monthly Review Press.

Barclay-Kerr, H. (2006). Waka - canoes. Retrieved from Te Ara The Encyclopaedia of New Zealand https://teara.govt.nz/en/waka-canoes 
Barclay-Kerr, H. (2016). From Myth and Legend to Reality. In emerald, e., Rinehart R.E., Garcia A. (Eds.) Global South Ethnographies (pp. 87-91). Rotterdam: SensePublishers.

Barford, C. (2006). Our Stories Are Within Us. In S. T. Marsh (Ed.), Niu Voices: Contemporary Pacific Fiction (Vol. 1) (pp. 55-58). Wellington: Huia Publishers.

Bargh, M. (2007). Resistance: An indigenous response to neoliberalism. Wellington: Huia Publishers.

Barker, J. (2017). Critically sovereign: Indigenous gender, sexuality, and feminist studies. Durham, NC: Duke University Press.

Barrow, R. (1990). Culture, values and the language classroom. In B. Harrison (Ed.), Culture and Language Classroom (pp. 3-10). Hong Kong: Modern English Publications and the British Council.

Batibasaqa, K., Overton, J., \& Horsley, P. (1999). Vanua: Land, people and culture in Fiji. In J. Overton and R. Schewens (Eds.), Strategies for sustainable development: experiences from the Pacific, (pp. 100-106.). London: Zed Books.

Battiste, M. (2002). Indigenous knowledge and pedagogy in First Nations education: A literature review with recommendations. Ottawa: National Working Group on Education.

Bauk, C. (April 2017). Deputy Governor and Education Chairman's Speech during ENB Tourism and Hospitality Curriculum Launch Day [Unpublished Speech].

Beban-France, A., \& Brooks, J. (2008). Guide to International Development Terms and Acronyms: Pacific Focus. Te Whanga-nui-a-Tara, Aotearoa: Development Resource Centre.

Becker, G. S. (1964). Human Capital. A Theorical and Empirical Analysis with Special Reference to Education ( $1^{\text {st }}$ ed.). Chicago: The University of Chicago Press.

Becker, G. S. (1994). Human Capital. A Theorical and Empirical Analysis with Special Reference to Education ( $3^{\text {rd }}$ ed.). Chicago: The University of Chicago Press.

Bedford, R. (1981). Melanesian internal migration: recent evidence from Eastern Fiji. New Zealand Journal of Geography (Vol. 71). 
Bedford, R. (1988). Population movement in post-colonial Fiji: Review and speculation. GeoJournal, 16(2), 179-192.

Benhabib, J., \& Spiegel, M. (1994). The role of human capital in economic development evidence from aggregate cross-country data. Journal of Monetary economics, 34(2), 143-173.

Bermeo, S. B. (September, 2009). The curse of aid? Re-examining the impact of aid on regime change. Paper presented at the Re-Examining the Impact of Aid on Regime Change, Toronto. Retrieved from ResearchGate https://www.researchgate.net/publication/228124064 The Curse of Aid ReExamining the Impact of Aid on Regime Change

Black, C. E. (1966). The dynamics of modernization: A study in comparative history. New York: Harper \& Row.

Blackburn, M. L., \& Neumark, D. (1993). Omitted-ability bias and the increase in the return to schooling. Journal of Labor Economics, 11(3), 521-544.

Blundell, R., Dearden, L., \& Meghir, C. (1996). The determinants and effects of workrelated training in Britain. London: Institute for Fiscal Studies.

Blundell, R., Dearden, L., Meghir, C., \& Sianesi, B. (1999). Human capital investment: the returns from education and training to the individual, the firm and the economy. Fiscal Studies, 20(1), 1-23.

Bodley, J. H. (2014). Victims of Progress (6 $6^{\text {th }}$ Ed.). London: Rowman \& Littlefield.

Bojang, A. B. (2008). Aid and Development. London: Evans Brothers.

Bonal, X. (2004). Is the World Bank education policy adequate for fighting poverty? Some evidence from Latin America. International Journal of Educational Development, 24(6), 649-666.

Bonnemaison, J. (1984). The tree and the canoe: roots and mobility in Vanuatu societies. Pacific Viewpoint, 25(2), 117-152.

Boserup, E. (1970). Women's Role in Economic Development. London: Earthscan.

Brady, W. (1997). Indigenous Australian Education and Globalisation. Traditions, Modernity and Post-modernity in Comparative Education, 43(5-6), 413-422. 
Brand, U., \& Lang, M. (2019). Green economy. In A. Kothari, A. Salleh, A. Escobar, F. Demaria, \& A. Acosta (Eds.), Pluriverse: A Post-Development Dictionary (pp. 5659). New Delhi: Tulika.

Bray, M. (1996). Decentralization of education: Community financing. Washington D.C.: The World Bank.

Bray, M., \& Packer, S. (1993). Education in small states: Concepts, challenges, and strategies. New York: Pergamon Press.

Brearley, L. (2015). Deep Listening and Leadership: An Indigenous Model of Leadership and Community Development in Australia. In Voyageur, C., Brearley, L., and Calliou, B. (Eds.). Restorying Indigenous Leadership: Wise Practices in Community Development (2 ${ }^{\text {nd }}$ Ed.) (pp. 91-127). Alberta: Banff Centre Press.

Breheny, M. J., Gent, T., \& Lock, D. (1993). Alternative development patterns: new settlements. London: H.M. Stationery Office.

Brock, C., \& Crossley, M. (2013). Revisiting scale, comparative research and education in small states. Comparative Education, 49(3), 388-403.

Brock, K., Cornwall, A., \& Gaventa, J. (2001). Power, knowledge and political spaces in the framing of poverty policy. (Working Paper No. 143). Retrieved from Department for International Development (UK) https://www.gov.uk/research-for-development-outputs/power-knowledgeand-political-spaces-in-the-framing-of-poverty-policy

Brockington, D., \& Sullivan, S. (2003). Development Fieldwork. London: SAGE Publications Ltd.

Brockmann, M., Clarke, L., \& Winch, C. (2011). Knowledge, skills and competence in the European labour market: What's in a vocational qualification? London: Routledge.

Brohman, J. (1996). Popular development: Rethinking the theory and practice of development. Oxford: Blackwell

Bryant-Tokalau, J. (1995). The myth exploded: urban poverty in the Pacific. Environment Urbanization, 7(2), 109-130.

Bulloch, H. (2014). Contending Developments: Local notions of development on Siquijor Island, Philippines. Journal of International Development, 26(2), 177-186. 
Bulloch, H. (2017). In pursuit of progress: Narratives of development on a Philippine island. Honolulu: University of Hawai'i Press.

Burris, V. (1983). The social and political consequences of overeducation. American Sociological Review, 18 (4), 454-467.

Butcher, K. F., \& Case, A. (1994). The effect of sibling sex composition on women's education and earnings. The Quarterly Journal of Economics, 109(3), 531-563.

Butz, D., \& Besio, K. (2009). Autoethnography. Geography Compass, 3(5), 1660-1674.

Cameron, J., \& Gibson, K. (2005). Participatory action research in a poststructuralist vein. Geoforum, 36(3), 315-331.

Card, D. (1993). Using geographic variation in college proximity to estimate the return to schooling. (NBER Working Paper No. 4483). Retrieved from the National Bureau of Economic Research

https://www.nber.org/papers/w4483

Card, D., \& Krueger, A. B. (1992). Does school quality matter? Returns to education and the characteristics of public schools in the United States. Journal of Political Economy, 100(1), 1-40.

Cardoso, F. (1972). Dependency and development in Latin America. New Left Review, $74(1), 83-95$.

https://newleftreview.org/issues/I74/articles/fernando-henrique-cardosodependent-capitalist-development-in-latin-america.pdf

Carling, J., Erdal, M. B., \& Ezzati, R. (2014). Beyond the insider-outsider divide in migration research. Migration Studies, 2(1), 36-54.

Carmen, R. (1996). Autonomous development: Humanizing the landscape: An excursion into radical thinking and practice. London: Zed Books.

Carnegie, M., Rowland, C., Gibson, K., McKinnon, K., Crawford, J., \& Slatter, C. (2012). Monitoring gender and economy in Melanesian communities: Resources for NGOs, government and researchers in Melanesia. Melbourne: International Women's Development Agency.

Carrier, J. (1982). Taming the school: understanding schooling on Ponam Island. Papua New Guinea Journal of Education, 18(1), 22-37. 
Case, E. (2013). Mai ka mole mai: From the source towards an analysis of Hawaiian language literature. Retrieved from ResearchGate https://www.researchgate.net/publication/257132826 Mai Ka Mole Mai From the source towards an analysis of Hawaiian language literature

Case, E. (2014). Review of One of 'Ray's Babies': Hula, history and Hawaiian rooms By Imada, A.L. Asia Pacific Viewpoint, 55(3), 401-402.

Case, E. (2019). Caught (and Brought) in the Currents: Narratives of Convergence, Destruction, and Creation at Kamilo Beach. Journal of Transnational American Studies, 10(1), 73-92. https://escholarship.org/uc/item/0kg0m6kn

Case, E. [emalani] (2020, February 26). A future Built by Stories. He Wahī Pa'akai: A Package of Salt - adding flavor and texture to your world through story [Blog Post]. Retrieved from https://hewahipaakai.wordpress.com/2020/02/26/a-future-built-by-stories/

Caselli, F., Esquivel, G., \& Lefort, F. (1996). Reopening the convergence debate: a new look at cross-country growth empirics. Journal of Economic Growth, 1(3), 363-389. https://personal.1se.ac.uk/casellif/papers/reopeni4.pdf

Casey, K., Glennerster, R., \& Miguel, E. (2012). Reshaping institutions: Evidence on aid impacts using a preanalysis plan. The Quarterly Journal of Economics, 127(4), 1755-1812.

Chambers, R. (1994). The origins and practice of participatory rural appraisal. World Development, 22(7), 953-969.

Chambers, R. (1997). Whose Reality Counts? Putting the First Last. London: Intermediate Technology Publications.

Chapman, M. (1991). Pacific Island movement and socioeconomic change: metaphors of misunderstanding. Population Development Review, 17(2), 263-292.

Chappell, D. A. (2005). Oceanian diaspora. Encyclopaedia of Diasporas: Immigrant Refugee Cultures Around the World, 224-232. New York: Springer.

Chappell, D. A. (2016). Double Ghosts: Oceanian Voyagers on Euroamerican Ships. London: Routledge. 
Charmaz, K. (2000). Grounded Theory: Objectivist and Constructivist Methods. Thousand Oaks: Sage.

Charmaz, K. (2014). Constructing Grounded Theory (2nd Ed.). London: SAGE Publications Ltd.

Chaudhry, I. S., Malik, S., Hassan, A., \& Faridi, M. Z. (2010). Does education alleviate poverty? Empirical evidence from Pakistan. International Research Journal of Finance and Economics, 52, 134-141.

Chu, C. (2009). Mentoring for Leadership in Pacific Education. (Doctoral Thesis, Victoria University of Wellington). Retrieved from http://researcharchive.vuw.ac.nz/xmlui/bitstream/handle/10063/1103/thesis.pdf ?sequence $=1$

Chu, C., Rimoni, F., \& Sanga, K. (2011). Tok piksa of Leadership Pacific: as seen through students' eyes. Wellington: He Pärekereke, VUW.

Chu, C., \& Sanga, K. (2009). Living and leaving a legacy of hope: stories by new generation Pacific leaders. Wellington: He Pärekereke, VUW.

Coffield, F. (1999). Breaking the consensus: Lifelong learning as social control. British Education Research Journal, 25(4), 479-499.

Colclough, C. (2012). Education, poverty and development - mapping their interconnections. Comparative Education, 48(2), 135-148.

Coles, M., \& Werquin, P. (2009). The influence of qualifications frameworks on the infrastructure of VET. In Maclean, R. and Wislon, D. (Eds.). International Handbook of Education for the Changing World of Work (pp. 439-452): Rotterdam, The Netherlands: Springer Netherlands.

Colley, H., James, D., Diment, K., \& Tedder, M. (2003). Learning as becoming in vocational education and training: class, gender and the role of vocational habitus. Journal of Vocational Education and Training, 55(4), 471-498.

Collins, P. H. (2002). Black feminist thought: Knowledge, consciousness, and the politics of empowerment. London: Routledge.

Connell, R. (2007). Southern Theory: The Global Dynamics of Knowledge in the Social Sciences. Crows Nest, N.S.W: Allen \& Unwin. 
Conrad, A. (1969). Hawai'ian Registered Vessels. Hawai'ian Journal of History, 3, 3141.

\section{http://hdl.handle.net/10524/146}

Conway, D., \& Heynen, N. (2014). The Companion to Development Studies (3 ${ }^{\text {rd }}$ Ed.). Oxfordshire: Routledge.

Cooke, B., \& Kothari, U. (2001). Participation: The New Tyranny? London: Zed Books.

Corbin, J., \& Strauss, A. (2014). Basics of Qualitative Research: Techniques and Procedures for Developing Grounded Theory. Thousand Oaks: SAGE Publications Ltd.

Corbridge, S. (1998). 'Beneath the pavement only soil': The poverty of postdevelopment. The Journal of Development Studies, 34(6), 138-148.

Corris, P. (1968). 'Blackbirding' in New Guinea Waters, 1883-84: An episode in the Queensland labour trade. The Journal of Pacific History, 3(1), 85-105.

Cowen, M., \& Shenton, R. W. (1996). Doctrines of Development. London: Routledge.

Coxon, E. (2020). Introduction: Education for 'Development' in Oceania. In Johansson-Fua, S., Jesson, R., Spratt, R. and Coxon, E. (Eds.) Relationality and Learning in Oceania: Contextualizing Education for Development. Koninklijke Brill NV: Leiden, The Netherlands.

Coxon, E., \& Cassity, E. (2011). Editorial - Education in the Pacific: Rethinking Partnerships. International Education Journal: Comparative Perspectives, 10(2).

Coxon, E., \& Munce, K. (2008). The global education agenda and the delivery of aid to Pacific education. Comparative Education, 44(2), 147-165.

Coxon, E., \& Tolley, H. (2005). Aid to Pacific education: An overview. In Sanga, K. (Ed.) Re-thinking aid relationships in Pacific education, 28-82. Wellington: He Pārekereke, Institute for Research and Development in Māori and Pacific Education.

Craig, D., Bedford, R., Gegeo, D., Rodi, P., Miller, R., \& Friesen, W. (2014). Labour mobility and diaspora: An overview of Solomon Islands' historical regulatory experience, 1850s-2013. (NIDEA Working Paper No. 6). Retrieved from National Institute of Demographic and Economic Analysis https://hdl.handle.net/10289/8586 
Craig, D., \& Porter, D. (2003). Poverty Reduction Strategy Papers: A New Convergence. World Development, 31(1), 53-69.

Crenshaw, K. (1989). Demarginalizing the Intersection of Race and Sex: A Black Feminist Critique of Antidiscrimination Doctrine, Feminist Theory and Antiracist Politics. University of Chicago Legal Forum, (Article 8), 139-67

Creswell, J. W., \& Miller, D. L. (2000). Determining Validity in Qualitative Inquiry. Theory into Practice, 39(3), 124-130.

Crocombe, R. (1976). The Pacific Way: An Emerging Identity. Suva, Fiji: Lotu Pasifika.

Crocombe, R. (2001). The South Pacific. Suva: USP Press.

Crossa, V. (2012). Relational positionality: Conceptualizing research, power, and the everyday politics of neoliberalization in Mexico City. ACME: An International Journal for Critical Geographies, 11(1), 110-132.

Crossley, M. (1984). Strategies for Curriculum Change and the Question of International Transfer. Curriculum Studies, 16(1), 75-88.

Crossley, M., Bray, M., \& Packer, S. (2009). Education in the Small States of the Commonwealth: Towards and Beyond Global Goals and Targets. The Round Table, 98(405), 731-751.

Crush, J. (1995). Power of Development. London: Routledge.

Cummins, H. G. (1977). School and Society in Tonga. (Unpublished M.A. thesis. Australian National University). Canberra.

Cunningham, P. M. (2004). Critical pedagogy and implications for human resource development. Advances in Developing Human Resources, 6(2), 226-240.

DAC. (2001). The DAC guidelines: poverty reduction. Paris: OECD.

Dattaray, D., \& Keegan, P. (November, 2016). The spirit that is one's own: A conversation in two tongues, Ko te wairua nō te tangata ake: He whakawhitiwhiti kōrerorero ki roto ingā reo e rua. Paper presented at The $7^{\text {th }}$ Biennial International Indigenous Research Conference, Auckland.

Dávalos, P. (2009, 11 October). Reflections on Sumak Kawsay (good living) and theories of development [Opinion Piece]. Retrieved from Latin America in Movement https://www.alainet.org/es/node/136929 
Davidson-Hunt, I. J., Turner, K. L., Mead, A. T. P., Cabrera-Lopez, J., Bolton, R., Idrobo, C. J., . . Robson, J. P. (2012). Biocultural design: a new conceptual framework for sustainable development in rural indigenous and local communities. Surveys and Perspectives Integrating Environment Society 5(2), 1-51.

Davierwalla, S. (1996). Equity, efficiency and "empowerment": The construction of gender and the environment in development discourse. (Doctoral Thesis, University of Massachusetts Amherst). Retrieved from ProQuest Dissertations Publishing https://scholarworks.umass.edu/dissertations/AAI9638951

Davis, A. (1983). Women, Race and Class. New York: Vintage

De Santolo, J. (2017). Yanyba Jarngkurr, Kingkalli: song tradition renewal \& story-world enactments of sustainable autonomy. Paper presented at the Kimihia te mea ngaro: Pūrākau and Indigenous Storywork Research Symposium, Waikato-Tainui College for Research and Development, Hopuhopu, Ngāruawāhia.

Dearden, L. (1998). Ability, families, education and earnings in Britain. (IFS Working Papers W98/14). Retrieved from Institute for Fiscal Studies https://ideas.repec.org/p/ifs/ifsewp/98-14.html

Degerman, V. (2014). Gender-based violence in Bougainville: Stories of change. Wellington: VUW Press.

Della Porta, D., \& Keating, M. (2008). Approaches and methodologies in the social sciences: A pluralist perspective. Cambridge: Cambridge University Press.

Department of National Planning and Monitoring. (2010). Papua New Guinea Development Strategic Plan, 2010-2030. Port Moresby Retrieved from http://www.asialeds.org/sites/default/files/resource/file/Publications DSP20102030.pdf

Diaz, V. M., \& Kauanui, J. K. (2001). Native Pacific cultural studies on the edge. The Contemporary Pacific, 13(2), 315-342.

Doherty, W. (2017). Ngā-here: Exploring the Landscape of Pürākau. Paper presented at the Kimihia te mea ngaro: Pūrākau and Indigenous Storywork Research Symposium, Waikato-Tainui College for Research and Development, Hopuhopu, Ngāruawāhia.

Donald, I., Strachan, J., \& Taleo, H. (2002). Slo slo: Increasing Women's Representation in Parliament in Vanuatu. Development Bulletin, 59, 54-57. 
Dore, R. (1980). The Diploma Disease Revisited. The IDS Bulletin, 11(2), 55-61.

Dos Santos, T. (1970). The Structure of Dependence. The American Economic Review, 60(2), 231-236.

Drollett, A. H. (2018). As Cited In O. Simmonds \& K. Tanikawa (Eds.). A Specific Period when Māori Arrived in Aotearoa-New Zealand (2018). Retrieved from https://www2.nao.ac.jp/ mitsurusoma/gendai5/10 simmonds.pdf

Duituturaga, E. (2000). New Caledonia: Fatal Intimacy: Gender Dynamics of STD and HIV/AIDS. Pacific AIDS Alert Bulletin (19), 14-15.

Eberlei, W. (2000). Taking a Lead in the Fight against Poverty? World Bank and IMF Speed Implementation of Their New Strategy. Development Cooperation (3), 2324.

Eisenstadt, S. (1970). Breakdowns of modernization. In Eisenstadt, S. (Ed.) Readings in social evolution and development (pp. 421-452). Oxford: Pergamon Press.

El-Gack, E. N. (2007). Participatory Approaches to Development: an Analysis of the Experiences of Development Projects in Sudan. (Doctoral Thesis, Massey University). Palmerston North. Retrieved from https://mro.massey.ac.nz/bitstream/handle/10179/1455/02 whole.pdf

ENB Curriculum Development Project Collective, C. (2015). Curriculum Development Project Reports. L. d. l. Torre \& I. Magaga (Eds.) [Unpublished Division of Education (PNG) Project Reports].

ENB Curriculum Writers (2016). [Unpublished Tok stori sessions].

England, K. V. L. (1994). Getting Personal: Reflexivity, Positionality, and Feminist Research. The Professional Geographer, 46(1), 80-89.

Escobar, A. (1995). Encountering Development: The Making and Unmaking of the Third World (STU - Student edition ed.) Princeton: Princeton University Press.

Escobar, A. (2001). Culture sits in places: reflections on globalism and subaltern strategies of localization. Political geography, 20(2), 139-174.

Escobar, A. (2010). Latin America At A Crossroads: Alternative modernizations, post-liberalism, or post-development? Cultural Studies, 24(1), 1-65. 
Espino, A., \& Underhill-Sem, Y. (2012). Gender, Social Equity and Regional Economic Processes: Latin America and the Pacific perspectives. Development, 55(3), 358.

Esteva, G. (1992). Development in The Development Dictionary-A Guide to Knowledge as Power. London: Zed Books.

Evans, J. (2015). Hekenukumai Busby: Not Here by Chance. Wellington: Huia

Evans, R. (1994). The Negation of Powerlessness: Maori Feminism, a Perspective [Paper delivered on 10 August 1993 in the Auckland University Winter Lecture Series.]. Hecate, 20(2), 53.

Evans, V. (2003). The structure of time: Language, meaning and temporal cognition: Amsterdam: John Benjamins Publishing.

Fainu, K. (August 22, 2020). The return of shell money: PNG revives old ways after Covid's blow to economy. The Guardian. Retrieved from https://www.theguardian.com/world/2020/aug/22/the-return-of-shell-moneypng-revives-old-ways-after-covids-blow-to-economy

Fairbairn-Dunlop, P. (1998). Tamaitai Samoa: Their Stories. Suva, Fiji: Institute of Pacific Studies, USP.

Fairbairn-Dunlop, P. (2005). Gender, Culture and Sustainable Development - the Pacific Way. In Hooper, A. (Ed.) Culture Sustainable Development in the Pacific, 62-75. Canberra: Asia Pacific Press, ANU.

Fairbairn-Dunlop, P. (2008). Reconnecting to our Sea of Islands: Pacific Studies in the Next Decade. AlterNative: An International Journal of Indigenous Peoples, 4(1), 4556.

Fairbairn-Dunlop, P. (2011). Community Education: An Essential Dimension in the Prevention of Violence Against Women. International Education Journal: Comparative Perspectives, 10(2), 140-153.

Fasavalu, T. I., \& Reynolds, M. (2019). Relational Positionality and a Learning Disposition: Shifting the Conversation. International Education Journal: Comparative Perspectives, 18(2), 11-25.

Field, J. (2000). Governing the Ungovernable: Why Lifelong Learning Policies Promise so Much Yet Deliver so Little. Educational Management Administration, 28(3), 249-261. 
Figiel, S. (1996). Where We Once Belonged. Auckland: Pasifika Press.

Figiel, S. (1999). They Who Do Not Grieve. Auckland: Vintage.

Figiel, S. (2016). Free Love. Honolulu: Loihi Press.

Finau, A. S. P. U. (2016). Storying as a Method. Paper presented at the DevNet Conference 2016-Pacific Currents, Global Tides, Wellington, New Zealand.

Fine, B. (2002). "Economic Imperialism": A View from the Periphery. Review of Radical Political Economics, 34(2), 187-201.

Finney, B. (1993). Rediscovering Polynesian Navigation through Experimental Voyaging. The Journal of Navigation, 46(3), 383-394.

Finney, B., Rhodes, R., Frost, P., \& Thompson, N. (1989). Wait for the West Wind. The Journal of the Polynesian Society, 98(3), 261-302.

Firth, S. (2003). Future Directions for Pacific Studies. The Contemporary Pacific, 15(1), 139-148.

Fischer, A. M. (2009). Putting aid in its place: Insights from early structuralists on aid and balance of payments and lessons for contemporary aid debates. Journal of International Development, 21(6), 856-867.

Fitzgerald, M., \& Teaiwa, K. (2017). Remaking culture in 'Project Banaba': Katerina Teaiwa in conversation with Michael Fitzgerald. Art Monthly Australasia (304), 48-51.

Fleming, K., \& Palomino-Schalscha, M. (2016). Re-envisaging Education from a Diverse Economies Perspective: The Role of Rural Training Centers in the Solomon Islands. (Development, Education and Migration in Oceania Working Paper No. 2). Wellington: School of Geography, Environment and Earth Sciences, VUW.

Folaumahina, A. (2018). 2018 Vaka Pasifiki Education Conference. Address given at Vaka Pasifiki Education Conference, Suva, Fiji.

Folbre, N. (1994). Who Pays for the Kids?: Gender and the Structures of Constraint. London: Routledge.

Foster, P. J. (1965). The Vocational School Fallacy in Development Planning. Education and Economic Development, 32, 142-166. 
Frank, A. G. (1966). The Development of Underdevelopment. Monthly Review, Sept. issue, $17-31$.

Frank, A. G. (1967). Sociology of Development and Underdevelopment of Sociology. Cahiers Internationaux de Sociologie, 42(JAN-J), 103-131.

Frank, A. G. (1969). Latin America: Underdevelopment or Revolution. New York: Monthly Review Press.

Frank, A. G. (1975). On Capitalist Underdevelopment. Oxford: Oxford University Press.

Freeman, D. (1983). Margaret Mead and Samoa : the making and unmaking of an anthropological myth. Cambridge, Mass.: Harvard University Press.

Freeman, R. B. (1976). The Overeducated American: New York: Academic Press.

Freire, P. (1970). Pedagogy of the Oppressed. New York: Continuum International Publishing Group.

Freire, P. (1973). Education for Critical Consciousness. New York: Seabury Press.

Freire, P. (1976). Education, the practice of freedom. London: Writers and Readers Publishing Cooperative.

Friedman, M. (1962). Capitalism and Freedom. Chicago: University of Chicago Press.

Friedmann, J. (1992). Empowerment: The Politics of Alternative Development: Hoboken, N.J.: Blackwell.

Gamble, B. (2006). Darkest Hour: The True Story of Lark Force at Rabaul-Australia's Worst Military Disaster of World War II: St. Paul, MN: Zenith Press.

Gamlen, A., Murray, W., \& Overton, J. (2016). A Review and Research Agenda for Linking Education, Migration and Development in Oceania. [Unpublished Working Paper] Wellington: School of Geography, Environment and Earth Sciences.

Gamlen, A., Murray, W., \& Overton, J. (2017). Investigating education, migration and development - Moving triangles in the Pacific. New Zealand Geographer, 73(1), 3-14. 
Gannicott, K. G. (1990). Education for Economic Development in the South Pacific: Caberra: Asia Pacific Press at ANU.

Garibaldi, P. (2006). Personnel economics in imperfect labour markets. Oxford: Oxford University Press.

Gegeo, D. W. (1998). Indigenous knowledge and empowerment: Rural development examined from within. Contemporary Pacific, 10(2), 289.

Gegeo, D. W. (2001a). Cultural rupture and indigeneity: the challenge of (re)visioning 'place' in the Pacific. Contemporary Pacific, 13(2), 491-507.

Gegeo, D. W. (2001b). (Re)visioning Knowledge Transformation in the Pacific: A Response to Subramani's "The Oceanic Imaginary ". The Contemporary Pacific, 13(1), 178-183.

Gegeo, D. W., \& Watson-Gegeo, K. A. (2001). "How we know": Kwara'ae rural villagers doing indigenous epistemology. Contemporary Pacific, 13(1), 55.

Gegeo, D. W., \& Watson-Gegeo, K. A. (2002). Whose knowledge?: Epistemological collisions in Solomon Islands community development. The Contemporary Pacific, 14(2), 377-409.

Gegeo, D. W., \& Watson-Gegeo, K. A. (1999). Adult education, language change, and issues of identity and authenticity in Kwara'ae (Solomon Islands). Anthropology E Education Quarterly, 30(1), 22-36.

Gibson-Graham, J. K. (2004). Area studies after poststructuralism. Environment Planning, 36(3), 405-419.

Gibson-Graham, J. K. (2005). Building community economies: women and the politics of place. In W. Harcourt \& A. Escobar (Eds.), Women and the Politics of Place (pp. 130-157). Bloomfield: Kumarian Press.

Gibson-Graham, J. K. (2006). A Postcapitalist Politics. Minneapolis: University of Minnesota Press.

Gibson-Graham, J. K. (2008). Diverse economies: performative practices for 'other worlds'. Progress in Human Geography, 32, 613-632.

Gibson-Graham, J. K. (2005). Surplus Possibilities: Postdevelopment and Community Economies. Singapore Journal of Tropical Geography, 26(1), 4-26. 
Giddens, A. (1994). Beyond left and right: The future of radical politics. Redwood City, CA: Stanford University Press.

Gigi, J. (2016). [Unpublished Tok stori with Jeddah Violet Gigi, ENB Curriculum Writer].

Giraure, N. (1974). The need for a cultural programme: personal reflections. In T. Verave (Ed.), Diploma Education and Training Program, Foundations Studies, Curriculum Studies (pp. 13-17). Port Moresby: PNGEI.

Goeman, M. (2008). From place to territories and back again: Centering storied land in the discussion of Indigenous nation-building. International Journal of Critical Indigenous Studies, 1, 23-34.

Goldsmith, E. (1993). The way: An ecological world-view. Boston: Shambhala.

Gómez-Baggethun, E., \& Naredo, J. M. (2015). In search of lost time: the rise and fall of limits to growth in international sustainability policy. Sustainability Science, 10(3), 385-395.

Goodman, R., Lepani, L., \& Morawetz, D. (1985). The Economy of Papua New Guinea. An Independent Review. Development Studies Centre. Canberra: ANU Press.

Grace, P. (1986). Potiki. Auckland: Penguin Random House NZ Ltd.

Grace, P. (2006). Small Holes in the Silence. Auckland: Penguin Books.

Greenwald, B. C., \& Stiglitz, J. E. (1987). Keynesian, new Keynesian, and new classical economics. Cambridge, Mass.: National Bureau of Economic Research.

Gribble, C. (2008). Policy options for managing international student migration: the sending country's perspective. Journal of Higher Education Policy and Management, 30(1), 25-39.

Griffen, V. (1992). White Ashes. In S. George \& V. Griffen (Eds.), Asian and Pacific Women's Resource and Action Series: Environment (Vol. 155). Kuala Lumpur: Asian and Pacific Development Centre.

Griffen, V. (1994). Marama. In A. Emberson-Bain (Ed.), Sustainable Development or Malignant Growth? Perspectives of Pacific Island Women (pp. 173-174 ). Suva, Fiji: Marama Publications. 
Griffin, K. (1977). Increasing poverty and changing ideas about development strategies. Development and Change, 8(4), 491-508.

Gugerty, M. K., \& Kremer, M. (2008). Outside funding and the dynamics of participation in community associations. American Journal of Political Science, 52(3), 585-602.

Gutek, G. L. (1972). History of Western educational experience. New York: Random House.

Gutiérrez, K. D., \& Rogoff, B. (2003). Cultural ways of learning: Individual traits or repertoires of practice. Educational researcher, 32(5), 19-25.

Hart, J. A. (1983). The New International Economic Order: Conflict and Cooperation in North-South Economic Relations, 1974-77. London: Palgrave Macmillan.

Hau'ofa, E. (1993). A new Oceania: rediscovering our sea of islands. Suva, Fiji: USP, Beake House.

Hau'ofa, E. (1994). Our sea of islands. Contemporary Pacific, 6(1), 147-162.

Hau'ofa, E. (2008). Pasts to Remember. In E. Hau'ofa (Ed.), We Are the Ocean (pp. 6079): University of Hawai'i Press.

Hau'ofa, E. (2000). The ocean in us. Canberra: Asia Pacific Press at ANU.

Henderson, A. (1999). Gifted flows: netting the imagery of hip hop across the Samoan diaspora. (M.A. Thesis, University of Hawai'i). Retrieved from http://hdl.handle.net/10125/21103

Henderson, A., Mallon, S., \& Teaiwa, K. (2011). Dancing Gender, Culture and Identity: The Art and Politics of Moving Bodies in Oceania. Intersections: Gender and Sexuality in Asia and the Pacific, Issue 27, November 2011. Retrieved from http://intersections.anu.edu.au/issue27/introduction.htm

Hereniko, V. (2000). Indigenous Knowledge and Academic Imperialism. In E. Said, J. Clifford, A. Wendt, M. Sahlins, G. Dening, P. Grace, Hau' ofa, E., W. S. Merwin, G. Prakash, R. White, \& others (Eds.), Remembrance of Pacific Pasts (pp. 78-91). Honululu: University of Hawai'i Press.

Hermes, K. L. (2018). The female voice in Pasifika poetry: An exploration of "hybrid" identities in the Pacific diaspora. Journal of Postcolonial Writing, 54(5), 655-669. 
Hermkens, A.-K. (2013). 'Raits blong mere'? Framing Human Rights and Gender Relations in Solomon Islands. Intersections: Gender and Sexuality in Asia and the Pacific, Issue 33, December 2013. Retrieved from http://intersections.anu.edu.au/issue33/hermkens.htm

Heyneman, S. (1985). Diversifying secondary school curricula in developing countries: An implementation history and some policy options. International Journal of Educational Development, 5(4), 283-288.

Hibler, R. W. (1984). Escape from the Stone Age: Education in Papua New Guinea. The Clearing House, 57(9), 420-421.

Hickling-Hudson, A. (2002). Re-visioning from the inside: Getting under the skin of the World Bank's Education Sector Strategy. International Journal of Educational Development, 22(6), 565-577.

Hooks, B. (2000). Feminist theory: From margin to center. London: Pluto Press.

Hopkins, T. K., \& Wallerstein, I. M. (1982). World-systems analysis: Theory and methodology (Vol. 1). Thousand Oaks: SAGE Publishing Ltd.

Hoskins, T. K. (2019). The relation is everything. Paper presented at the Educating for Critical Consciousness Symposium, Te Herenga Waka Marae, Wellington.

Huffer, E., \& Qalo, R. (2004). Have We Been Thinking Upside-Down? The Contemporary Emergence of Pacific Theoretical Thought. Contemporary Pacific, 16(1), 87-116.

Huffman, K. (2019). Oceania's Kastom Ekonomi. New Delhi: Tulika Books and Authorsupfront.

Hultin, H., Lundberg, M., Lundin, A., \& Magnusson, C. (2016). Do overeducated individuals have increased risks of ill health?: a Swedish population-based cohort study. Sociology of health $\mathcal{E}$ illness, 38(6), 980-995.

Hutchings, J., Mead, A., Reynolds, P., Smith, L. T., Reid, T. T. M. D., Ratuva, S., . . Kanehe, L. a. M. (2007). Pacific Genes and Life Patents, Pacific Experiences $\mathcal{E}$ Analysis of the Commodification $\mathcal{E}$ Ownership of Life. Tokyo: Call of the Earth Llamado de la Tierra, UN University-Institute of Advance Studies.

Hviding, E. (2003). Between Knowledges: Pacific Studies and Academic Disciplines. The Contemporary Pacific, 15(1), 43-73. 
Illich, I. (1976). An Alternative to Schooling. In E. B. Thomas (Ed.), Papua New Guinea Education (pp. 257-266). Melbourne: Oxford University Press.

Inkeles, A., \& Smith, D. (1974). Becoming Modern: Individual Change in Six Developing Countries. Cambridge, Mass.: Harvard University Press.

Islam, N. (1995). Growth empirics: a panel data approach. The Quarterly Journal of Economics, 110(4), 1127-1170.

IWDA. (2013). Her Story: Elizabeth Tongne. Retrieved from International Women's Development Agency https://iwda.org.au/her-story-elizabeth-tongne/

Jackson, M. (1992). The Treaty and the Word: The Colonization of Māori Philosophy In Oddie, G., and Perrett, R. W. (Eds.) Justice, Ethics and New Zealand Society (pp.1-10). Auckland: Oxford University Press.

Jenkins, K., \& Pihama, L. (2001). Matauranga Wahine: Teaching Maori Women's Knowledge Alongside Feminism. Feminism \& Psychology, 11(3), 293-303.

Johansson-Fua, S. U., Jesson, R., Spratt, R., \& Coxon, E. (2020). Education for Development in Context: Solomon Islands and Tonga. In Coxon, E. (Ed.) (2020). In Johansson-Fua, S., Jesson, R., Spratt, R. and Coxon, E. (Eds.) Relationality and Learning in Oceania: Contextualizing Education for Development (pp. 17-41). Koninklijke Brill NV: Leiden, The Netherlands.

Jolly, M. (1997). Woman-nation-state in Vanuatu: women as signs and subjects in the discourses of kastom, modernity and Christianity. In Thomas, T. O. A. N. (Ed.), Narratives of nation in the South Pacific (pp. 133-162). Amsterdam: Hardwood Academic.

Jolly, M. (2005). Beyond the horizon? Nationalisms, feminisms, and globalization in the Pacific. Ethnohistory, 52(1), 137-166.

Jones, A., Herda, P., \& Sua'ali'i-Sauni, T. (2000). Bitter sweet: indigenous women in the Pacific. Dunedin: University of Otago Press.

Joskin, A. (2013). Investigating the Implementation Process of a Curriculum: A Case Study from Papua New Guinea. Victoria University of Wellington

Kaitani, M. M., Mohanty, M., Muliaina, T. A., Buadromo, V. T., Kumar, R. R., Kumar, S., \& Naidu, V. (2011). Development on the move: measuring and optimising 
migration's economic and social impacts in Fiji. Suva, Fiji: Oceania Development Network.

Kakabin, G. (2017a). Sacred Objects - A personal Viewpoint. [Blog Post]. Retrieved from

https://gkakabin.net/

Kakabin, G. (2017b). To Inia and the acceptance of German control. [Blog Post]. Retrieved from

https://gkakabin.net/

Kakabin, G. (2017c). Totokoi. [Blog Post]. Retrieved from https://gkakabin.net/

Kakabin, G. (2017d). Vunatarai / Apiktarai / Tauntarai. [Blog Post]. Retrieved from https://gkakabin.net/

Kakabin, G. (2018). Some definitions for debate. [Blog Post]. Retrieved from https://gkakabin.net/

Kallis, G. (2015). The degrowth alternative. Great Transition Initiative, 1-6. Retrieved from https://greattransition.org/publication/the-degrowth-alternative

Ka'ili, T. (2017). “Indigenous Time and Space." Marking Indigeneity: The Tongan art of sociospatial relations. Tucson: University of Arizona Press. 23-33

Kanbur, M. G., \& Hau'ofa, E. (1984). Education for development in the South Pacific. Suva, Fiji: USP.

Kaplan, R. (2018). Participatory Approaches to Educator Learning: Toward Equity and Allyship in Education. (Doctoral Thesis, University of Colorado at Boulder). Retrieved from https://www.proquest.com/docview/2048235380

Kapoor, I. (2005). Participatory development, complicity and desire. Third world quarterly, 26(8), 1203-1220.

Kapur, D., Lewis, J. P., \& Webb, R. (1997). The World Bank: Its First Half Century. Washington, D.C.: Brookings Institution.

Karela, C.-A. (2016). [Unpublished Tok stori with Carrie-Anne Karela, ENB Curriculum Writer]. 
Kaue, S. (2016). [Unpublished Tok stori and Interview with Sevi Kaue from Kokopo Village Resort].

Kava, L. K. (2015). In Our Own Verse: Tongan Music and Poetry-Writing as Decolonial Praxis. (M.A. Thesis, University of Hawai'i). Retrieved from http://hdl.handle.net/10125/36871

Kawagley, A. O. (2010). Alaska Native education: Views from within. University of Alaska Fairbanks: Alaska Native Knowledge Network.

Kawulich, B. B. (2005). Participant observation as a data collection method. Forum Qualitative Sozialforschung, 6(2), Article 43. Retrieved from

https://www.qualitative-research.net/index.php/fqs/article/view/466/996

Kelly, A. K. (Writer). (2009). Noho hewa: The wrongful occupation of Hawai'i [Documentary film]. In K. W. Productions (Producer). Kailua, HI.

Kesby, M. (2007). Spatialising Participatory Approaches: The Contribution of Geography to a Mature Debate. Environment and Planning A, 39(12), 2813-2831.

Kiddle, L. (2005). The Education For All Agenda in Vanuatu: Exploring Process and Issues. In K. Sanga, C. Hall, C. Chu, \& L. Crowl (Eds.), Re-thinking aid relationships in Pacific education (pp. 187-203). Suva, Fiji: USP.

Kidman, J., \& Chu, C. (2017). Scholar Outsiders in the Neoliberal University: Transgressive Academic Labour in the Whitestream. New Zealand Journal of Educational Studies, 52(1), 7-19.

Kidman, J., \& Chu, C. (2019). 'We're not the hottest ethnicity': Pacific scholars and the cultural politics of New Zealand universities. Globalisation, Societies and Education, 17(4), 489-499.

Kim, B. (2001). Social constructivism. Emerging perspectives on learning, teaching, and technology, 1(1), 16.

Kindon, S. (2007). Participatory action research approaches and methods connecting people, participation, and place. Milton Park, Abingdon, Oxon: Routledge.

King, K., McGrath, S., \& Rose, P. (2007). Beyond the basics: Educating and training out of poverty. International Journal of Educational Development, 4(27), 349-357. 
King, K., \& Palmer, R. (2011). New trends in international cooperation. (Background paper for the World Report on Technical and Vocational Education Training). Paris: UNESCO

King, T. (2005). The Truth About Stories: A Native Narrative (Vol. 1). Minneapolis: University of Minnesota Press.

Kothari, A. (2013). Missed Opportunity? Comments on two global reports for the post-2015 goals process. Retrieved from Kalpavriksh and ICCA Consortium https://www.academia.edu/4017916/Missed Opportunity Comments on two global reports for the post 2015 goals process

Kothari, A., Salleh, A., Escobar, A., Demaria, F., \& Acosta, A. (Eds.) (2019). Pluriverse: A post-development dictionary. Alwarpet, Chennai, India: Tulika Books and Authorsupfront.

Kothari, R. (1988). Rethinking development: In search of humane alternatives. Dehli, India: Ajanta Publications.

Kothari, R. (1993). The yawning vacuum: A world without alternatives. Alternatives, $18(2), 119-139$.

Kothari, U. (2005). Authority and expertise: the professionalisation of international development and the ordering of dissent. Antipode, 37(3), 425-446.

Kothari, U. (2006). Spatial practices and imaginaries: Experiences of colonial officers and development professionals. Singapore Journal of Tropical Geography, 27(3), 235-253.

Kothari, U. (2019). A radical history of development studies: Individuals, institutions and ideologies. London: Zed Books.

Kumar, R. R., Naidu, V., \& Kumar, R. (2011). Exploring the nexus between trade, visitor arrivals, remittances and income in the Pacific: a study of Vanuatu. Acta Universitatis Danubius. OEconomica, 7(4).

Lange, M., Mahoney, J., \& Vom Hau, M. (2006). Colonialism and development: a comparative analysis of Spanish and British colonies. American Journal of Sociology, 111(5), 1412-1462.

Larreguy, H., \& Marshall, J. (2017). The Effect of Education on Civic and Political Engagement in Nonconsolidated Democracies: Evidence from Nigeria. Review of Economics and Statistics, 99(3), 387-401. 
Lauglo, J., \& Lillis, K. (1988). Vocationalising education. Oxford: Pergamon Press.

Laurie, N., Andolina, R., \& Radcliffe, S. (2005). Ethnodevelopment: social movements, creating experts and professionalising indigenous knowledge in Ecuador. Antipode, 37(3), 470-496.

Le Fanu, G. (2013). The inclusion of inclusive education in international development: Lessons from Papua New Guinea. International Journal of Educational Development, 33(2), 139-148.

Lee-Morgan, J. (2017). Pūrākau: From the inside out. Paper presented at the Kimihia te mea ngaro: Pūrākau and Indigenous Storywork Research Symposium, Waikato-Tainui College for Research and Development, Hopuhopu, Ngāruawāhia.

Lee, H., \& Francis, S. T. (2009). Migration and transnationalism: Pacific perspectives. Canberra. ANU Press.

Lerner, D. (1964). The Passing of Traditional Society: Modernizing the Middle East. Glencoe, IL: Free Press.

Lessa, W. A. (1950). Ulithi and the outer native world. American anthropologist, 52(1), 27-52.

Lewis, D. (1994). We, the navigators: The ancient art of landfinding in the Pacific: Honululu: University of Hawaii Press.

Li, T. M. (1999). Compromising power: Development, culture, and rule in Indonesia. Cultural Anthropology, 14(3), 295-322.

Lichtman, M. (2012). Qualitative research in education: A user's guide. Thousand Oaks: SAGE Publishing Ltd.

Lichtman, M. (2013). Qualitative research for the social sciences: Thousand Oaks: SAGE Publishing Ltd.

Little, A. (2000). Development studies and comparative education: context, content, comparison and contributors. Comparative Education, 36(3), 279-296.

Little, A., \& Lewin, K. (1984). Examination reform and educational change in Sri Lanka, 1972-82: Modernisation or Dependent Underdevelopment? (IDS Discussion Paper 180). Retrieved from https://www.ids.ac.uk/download.php?file=files/dmfile/discussionpaper180.pdf 
Longgar, W. (2006). Towards a theology of land for the New Guinea islands.

(Doctoral Thesis, E Stanley Jones School of World Mission and Evangelism

Asbury Theological Seminary). Wilmore, Kentucky. Retrieved from ProQuest

Dissertations Publishing

https://search.proquest.com/docview/304923625?pq-

origsite $=$ gscholar\&fromopenview $=$ true

Loop Author. (2019). Authority issues notice to Chinese clothing brand. Loop PNG.

Retrieved from

http://www.looppng.com/png-news/authority-issues-notice-chinese-clothingbrand-82217

Lorde, A. (1997). Age, race, class, and sex: Women redefining difference. Cultural Politics, 11, (pp. 374-380)

Lorde, A. (2003). The Master's Tools Will Never Dismantle the Master's House. In Lewis, R., and Mills, S. (Eds.) Feminist Postcolonial Theory: A Reader, (pp. 25-28). New York: Routledge.

Lutunatabua, F. (2016). A Talanoa-style Session on Climate Change. Paper presented at the DevNet Conference 2016-Pacific Currents, Global Tides, Wellington, Aotearoa New Zealand.

Mackenzie, S. S. (1934). The Australians at Rabaul: The capture and administration of the German Possessions in the Southern Pacific, 10. Sydney: Angus \& Robertson.

Macpherson, C. (2004). From Pacific Islanders to Pacific people and beyond. In Spoonley, P., Macpherson, C., and Pearson, D. (Eds.) Tangata tangata: The changing ethnic contours of New Zealand. Southbank, Victoria: Dunmore Press. $135-155$

Macpherson, C. (2008). Migration and social transformation in the contemporary Pacific. New Zealand Sociology, 23 (1), ii-xiii.

Macpherson, C., Bedford, R., \& Spoonley, P. (2000). Fact or Fable?: The Consequences of Migration for Educational Achievement and Labor Market Participation. The Contemporary Pacific, 12(1), 57-82.

Magaga, I. (2016). [Unpublished Tok Stori with a Gunantuna/Tolai elder, education leader and my adoptive mother: IaIva Peteva Magaga]. 
Magaga, I. (2018). [Unpublished Tok Stori with a Gunantuna/Tolai elder, education leader and my adoptive mother IaIva Peteva Magaga].

Māhina, ‘O. (2004). “Art as Tā-Vā 'Time-Space' Transformation”. Research the Pacific and Indigenous Peoples: Issues and Perspectives. Tupeni Baba, 'Okusitino Māhina, Nuhisifa Williams, and Unaisi Nabobo-Baba (Eds). Auckland: Centre for Pacific Studies, University of Auckland. 86-93

Māhina, 'O. (2010). “Tā, Vā, and Moana: Temporality, Spatiality, and Indigeneity.” Pacific Studies 33(2/3), 168-202

Mahuika, R. (2008). Kaupapa Māori theory is critical and anti-colonial. Mai Review, $3(4), 1-16$.

Marbrook, A. (Writer). (2020). Loimata: The Sweetest of Tears. In J. M. Tamasailau Suaalii-Sauni, Anna Marbrook, Gaylene Preston (Producer). Samoa/Aotearoa.

Marchand, M. H. J. (2009). The Future of Gender and Development after 9/11: insights from postcolonial feminism and transnationalism. Third World Quarterly, 30(5), 921-935.

Marsh, S. T. (1998). Migrating feminisms: Maligned overstayer or model citizen? Women's Studies International Forum, 21(6), 665-680.

Marsh, S. T. (2004). Ancient banyans, flying foxes and white ginger: the poetry of Pacific Island Women. (Doctoral Thesis, University of Auckland). Auckland. Retrieved from Proquest https://search.proquest.com/docview/1306161639?pqorigsite $=$ gscholar\&fromopenview $=$ true\&imgSeq $=1$

Marsh, S. T. (2013). Fast Talking PI. Auckland: Auckland University Press.

Marsh, S. T., Wendt, A., Whaitiri, R., \& Sullivan, R. (2006). Afakasi Is. Auckland: Blackmail Press

Martin, F., Jackson, P., McLelland, M., \& Yue, A. (2010). AsiaPacifiQueer: Rethinking genders and sexualities. Chicago, IL: University of Illinois Press.

Martin, K. (2018). Tolai tabu as wealth and money: A shifting and unstable distinction. History and Anthropology, 29(3), 392-406.

Martínez-Echazábal, L. (1998). Mestizaje and the Discourse of National/Cultural Identity in Latin America, 1845-1959. Latin American Perspectives, 25(3), 21-42. 
Matane, P. (1986). A Philosophy of Education for Papua New Guinea. Port Moresby: Ministerial Review Committee on the Philosophy of Education, Department of Education.

Matang, R., \& Owens, K. (2004). Rich transitions from Indigenous counting systems to English arithmetic strategies: Implications for mathematics education in Papua New Guinea. In F. Favilli (Ed.), Proceedings of the 10th International Congress on Mathematical Education, Copenhagen, Denmark, Discussion Group 15, Ethnomathematics: Ethnomathematics and mathematics education (pp. 107-117). Pisa, Italy: ICME.

Mathur, H. M. (1995). The role of social actors in promoting participatory development at local level: A view from India in H. Schneider and M. Libercier (Eds). Participatory development from advocacy to action. (pp. 153-170). Paris: OECD.

Maude, H. E. (1981). Slavers in paradise: the Peruvian labour trade in Polynesia, 18621864. Canberra: ANU Press.

Maxwell, J. (1992). Understanding and validity in qualitative research. Harvard Educational Review, 62(3), 279-301.

Maxwell, J. (2012). Qualitative research design: An interactive approach (Vol. 41). Thousand Oaks: SAGE Publishing Ltd.

Mazrui, A. (1975). The African university as a multinational corporation: Problems of penetration and dependency. Harvard Educational Review, 45(2), 191-210.

McClelland, D. (1961). The Achieving Society. Princeton: D. Van Nostrand Co.

McDonnell, I., Lecomte, H.-B. S., \& Wegimont, L. (2003). Public Opinion Research, Global Education and Development Co-operation Reform: In Search of a Virtuous Circle. (Plenary Session 4). Retrieved from http://www.oecd.org/development/pgd/1840009.pdf

McGrath, S. (1999). Education, development and assistance: the challenge of the new millennium. In K. King \& L. Buchert (Eds.), Changing International Aid to Education (pp. 68-90). Paris, Geneva: UNESCO/Norrag.

McGrath, S. (2011). Where to now for vocational education and training in Africa? International Journal of Training Research, 9(1-2), 35-48. 
McGrath, S. (2012). Vocational education and training for development: A policy in need of a theory? International Journal of Educational Development, 32(5), 623-631.

McIntyre, A. (2008). Participatory Action Research. Retrieved from http://methods.sagepub.com/book/participatory-action-research-qrm

McKenzie, D., \& Rapoport, H. (2010). Can migration reduce educational attainment? Evidence from Mexico. Journal of Population Economics, 24(4), 1331-1358.

McKinnon, K. (2006). An orthodoxy of 'the local': post-colonialism, participation and professionalism in northern Thailand. Geographical Journal, 172(1), 22-34.

McKinnon, K. (2007). Postdevelopment, Professionalism, and the Politics of Participation. Annals of the Association of American Geographers, 97(4), 772-785.

McKinnon, K., Carnegie, M., Gibson, K., \& Rowland, C. (2016). Gender equality and economic empowerment in the Solomon Islands and Fiji: a place-based approach. Gender, Place, Culture and Sustainable Development in the Pacific, 23(10), 1376-1391.

McLaughlin, D. (1994). Through whose eyes do our children see the world now? Traditional education in Papua New Guinea. Papua New Guinea Journal of Education, 30(2), 63-79.

McLean, M., \& Walker, M. (2010). Making lives go better: University education and'professional capabilities'. South African Journal of Higher Education, 24(5), 847-869.

McLeod, A. (2008). Leadership models in the Pacific. Retrieved from https://openresearch-repository.anu.edu.au/handle/1885/10082

McManus, P. (1996). Contested terrains: politics, stories and discourses of sustainability. Environmental Politics, 5(1), 48-73.

Mead, A. T. P. (1994). Misappropriation of indigenous knowledge: The next wave of colonisation. Otago Bioethics Report, 3(1), 4-7.

Mead, A. T. P. (1996). Genealogy, sacredness, and the commodities market. Cultural Survival Quarterly, 20(2), 46-51.

Mel, M. A. (1995). Mbu: a culturally meaningful framework for education in Papua New Guinea. Prospects, 25(4), 683-694. 
Merriam, S. B. (1998). Qualitative Research and Case Study Applications in Education. San Francisco: Jossey-Bass.

Merriam, S. B., Johnson-Bailey, J., Lee, M.-Y., Kee, Y., Ntseane, G., \& Muhamad, M. (2001). Power and positionality: Negotiating insider/outsider status within and across cultures. International Journal of Lifelong Education, 20(5), 405-416.

Meyer, M. A. (2008). Indigenous and authentic: Hawaiian epistemology and the triangulation of meaning. In. Denzin, N. K., Lincoln, Y. S., \& Tuhiwai Smith, L. (Eds.) Handbook of critical and Indigenous methodologies, 217-232. Thousand Oaks: SAGE Publishing Ltd.

Meyer, M. A. (2016). Ho'oulu : our time of becoming: collected early writings of Manulani Meyer. Honolulu, Hawai'i: Short Stack.

Mikaere, A. (2011). Colonising myths: Maori realities he rukuruku whakaaro. Wellington: Huia, Te Wañanga o Raukawa.

Mila, K. (2005). Dream fish floating. Wellington: Huia Publishers.

Mila, K. (2008). A well written body. Wellington: Huia Publishers.

Moghadam, R. (1990). Wage determination: an assessment of returns to education, occupation, region and industry in Great Britain. (CEP Discussion Papers dp0008). Retrieved from Centre for Economic Performance, LSE https://ideas.repec.org/p/cep/cepdps/dp0008.html

Mohan, G. (2002). Participatory Development. In Desai, V., and Potter, R. The companion to development studies (3rd Ed.) (pp.131-36). New York: Routledge

Mohanty, C. T. (1984). Under Western eyes: Feminist scholarship and colonial discourses. On Humanism and the University I: The Discourse of Humanism, 12(3), 333-358.

Momsen, J. (2009). Gender and Development. London: Routledge.

Moore, W. (1963). Social Change. Englewood Cliffs, NJ: Prentice Hall.

Moorfield, J. C. (2011) Te Aka (3 ${ }^{\text {rd }}$ ed.). Wellington: Longman/Pearson Education New Zealand.

Moraga, C. (2011). A Xicana codex of changing consciousness: Writings, 2000-2010. Durham: Duke University Press. 
Moraga, C. (1983). Loving In The War Years: Lo que nunca pasó por sus labios. London: South End Press.

Moraga, C., \& Anzaldúa, G. (2015). This bridge called my back: Writings by radical women of color: New York: SUNY Press.

Moreton-Robinson, A. (2000). Talkin'up to the white woman: Aboriginal women and feminism. Brisbane: University of Queensland Press.

Morton, H. (1982). The whale's wake. Honululu: University of Hawaii Press.

Moser, C. (1991). Gender planning in the Third World: meeting practical and strategic needs. In R. Grant \& K. Newland (Eds.), Gender and International Relations (pp. 83-121). Milton Keynes: Open University Press.

Moser, C. (2012). Gender Planning and Development: Theory, Practice and Training. London: Routledge.

Mosse, D. (2005). Cultivating development: An ethnography of aid policy and practice. London: Pluto Press.

Moura-Kocoglu, M. (2017). Decolonizing Gender Roles in Pacific Women's Writing: Indigenous Feminist Theories and the Reconceptualization of Women's Authority. Contemporary Women's Writing, 11(2), 239-258.

Munro, D. (1990). The Peruvian slavers in Tuvalu, 1863: how many did they kidnap? Journal de la Société des Océanistes, 90(1), 43-46.

Murray, W., \& Overton, J. (2011a). The inverse sovereignty effect: Aid, scale and neostructuralism in Oceania. Asia Pacific Viewpoint, 52(3), 272-284.

Murray, W., \& Overton, J. (2011b). Neoliberalism is dead, long live neoliberalism? Neostructuralism and the international aid regime of the 2000s. Progress in Development Studies, 11(4), 307-319.

Nabobo-Baba, U. (2000). Teacher education in an aid project: The case of the FijiAustralian teacher education project. Paper presented at the Research Unit in Pacific Education symposium, Auckland.

Nabobo-Baba, U. (2003). The human dimension of project aid. Some local counterpart perspectives with regards to 'expertise exchange and relationships': a Fijian case. 
Global/Local Intersections: Researching the delivery of aid to Pacific education. Auckland: The University of Auckland Press.

Nabobo-Baba, U. (2006). Knowing and learning: An indigenous Fijian approach. Suva, Fiji: USP Press.

Nabobo-Baba, U. (2007). Teacher education for new times: reconceptualising pedagogy and learning in the Pacific. In Puamau, P. (Ed.) Pacific Voices: Teacher Education on the Move. (pp. 201-33). Suva, Fiji: USP Press.

Nabobo-Baba, U. (2008). Decolonising framings in Pacific research: Indigenous Fijian Vanua research framework as an organic response. AlterNative: An International Journal of Indigenous Peoples, 4(2), 140-154.

Nabobo-Baba, U. (2013). Transformations from within: Rethinking Pacific Education Initiative. The Development of a Movement for Social Justice and Equity. International Education Journal: Comparative Perspectives, 12(1), 82-97.

Nabobo-Baba, U. (November, 2018). Keynote address at the 44th Annual Conference of the Oceania Comparative \& International Education Society, University of Sydney.

Nabobo-Baba, U., Naisilisili, S., Bogitini, S., Baba, T. L., \& Lingam, G. I. (2012). Rural and remote schools in Udu, Fiji: Vanua, indigenous knowledge, development and professional support for teachers and education. Suva, Fiji: USP Press.

Naepi, S. (2019). Why Isn't My Professor Pasifika? A snapshot of the academic workforce in New Zealand universities. MAI Journal, 8(2), 220-34.

Nagai, Y. (2001). Vernacular Education and Development: Dilemmas, Struggles and Innovations in Papua New Guinea. Convergence, 34(1), 67-82.

Naidu, V. (1991). Development, State and Class Theories: An introductory survey. Suva, Fiji: Fiji Institute of Applied Studies.

Naidu, V. (2006). Development assistance challenges. In Powles, M. (Ed.) Pacific Futures. (pp.142-157). Canberra: Pandanus Books, ANU.

Nanau, G. L. (2011). The Wantok System as a Socio-economic and Political Network in Melanesia. OMNES: The Journal of Multicultural Society, 2(1), 31-55.

Nandy, A. (Ed.) (1988). Science, hegemony and violence: A requiem for modernity. Oxford: Oxford University Press. 
Nandy, A. (1995). Development and violence. Retrieved from http://edoc.vifapol.de/opus/volltexte/2012/3833/pdf/019.pdf

Narokobi, B. (1980). The Melanesian way: total cosmic vision of life. Port Moresby: Institute of Papua New Guinea Studies.

Narsimulu, V. P. (2007). Hia ou ra ta ma hia la fá: Owning Rotuman Education. Pacific Rim Studies: Understanding the Pacific Islander, 1, 25-35.

Nazareth Rehabilitation Centre (2013). IWDA on Nazareth Rehabilitation Centre and Sister Lorraine Garasu. Retrieved from https://iwda.org.au/nazareth-centre-for-rehabilitation/

NDoE. (2003). Education Reform in Papua New Guinea. PNG Retrieved from https://www.education.gov.pg/TISER/documents/in-service/in-serviceelementary-unit1-education-reform-in-papua-new-guinea.pdf

NDoE. (2004). Achieving a better future - a National Plan for Education 2005-2014. PNG: Department of Education

NDoE. (2014). The State of Education in Papua New Guinea (1st Draft). (Unpublished Draft). PNG: Department of Education

NDoE. (2015). National Education Plan 2015-2019: 'Quality learning for all' PNG: Department of Education

NDoE. (2018a). PNG Reformed Education Structure. Retrieved from https://www.education.gov.pg/quicklinks/parents.html

NDoE. (2018b). Technical, Vocational Education \& Training (TVET). Retrieved from http://www.education.gov.pg/quicklinks/tvet.html

NDoE. (2020). PNG COVID-19 Education Emergency Response and Recovery Plan. Retrieved from

https://www.education.gov.pg/documents/PNG-COVID-19-EducationResponse-and-Recovery-Plan-(Final-Draft-04-05-2020).pdf

NSTF. (2011). Papua New Guinea Vision 2050. Port Moresby: National Strategic Task Force

Nussbaum, M. (2000). Women and Human Development: The Capabilities Approach. Cambridge: Cambridge University Press. 
Nussbaum, M. (2003). Capabilities as fundamental entitlements: Sen and social justice. Feminist Economics, 9(2-3), 33-59.

Nussbaum, M. (2010). Not for profit: Why democracy needs the humanities (Vol. 2): Princeton, N.J.: Princeton University Press.

Obed, R. (2004). Education: An investment for Vanuatu. Re-thinking Vanuatu education together, 124-135. Suva, Fiji: USP.

OECD. (2001). Glossary of statistical terms. Retrieved from http://stats.oecd.org/glossary/detail.asp?ID=1264

O'Leary, M. (2017). Collected Poems 1981-2016. Wellington: HeadworX.

Onesu, R. (2017). [Unpublished Tok stori with Roselyn Onesu, ENB teacher].

Ormond, A. (Ed.) (2018). Decolonisation in Aotearoa: Education, Research and Practice (Vol. 53). Singapore: Springer Singapore.

Overton, J., \& De la Torre, L. (2016). [Unpublished Notes from Supervisory Sessions].

Overton, J., Prinsen, G., Murray, W., \& Wrighton, N. (2012). Reversing the tide of aid: Investigating development policy sovereignty in the Pacific. Le Journal de la Société des Océanistes 135 (2012-2), 229-242.

Pacific Feminist Charter. (2016). Retrieved from http://www.fwrm.org.fj/images/PFF/PFF-Charter-Final-2Dec2016.pdf

Pacific Islands Forum Secretariat. (2013). Pacific Plan 2013: Annual Progress Report. Retrieved from https://www.iucn.org/sites/dev/files/import/downloads/2013 0819 pif annual report circ 141.pdf

Pacific Islands Forum Secretariat. (2019). Pacific Regionalism \& The Blue Pacific. Suva, Fiji: Pacific Islands Forum Secretariat

Pacific Islands Forum Secretariat, \& USP. (2018). Pacific Regional Education Framework (PacREF) 2018 - 2030: Moving Towards Education 2030. Suva, Fiji: PIF \& USP.

Pala, A. O. (1977). Definitions of women and development: An African perspective. Signs: Journal of Women in Culture Society, 3(1), 9-13. 
Panfilo, A. F. (2016). [Unpublished Interview with Archbishop Francesco Panfilo in Vunapope].

Pangalos, M.(n.d.). [Unpublished Telling stories with Mario Pangalos from Gazelle International Hotel Kokopo].

Parkyn, G. W. (1977). Comparative Education Research and Development Education. Comparative Education, 13(2), 87-93.

Parsons, T., \& Smelser, N. (1956). Economy and Society: A Study in the Integration of Economic and Social Theory. London: Routledge and Kegan Paul.

Paterson, R. (2016). Instrumental and Gendered Discourses in Vocational Education: A Case Study in Rural Papua New Guinea. (Development, Education and Migration in Oceania Working Paper Series No.5). Wellington: VUW Press.

Pavol, P. P. (2 Dec 2016) Papua New Guinea villager takes six-year logging fight to the world stage/Interviewer: E. Tlozek. [Radio Interview]. ABC News.

Pavol, P. P. (2018) Money Will Not Buy My Heart to Give My Land Away/Interviewer: P. Langer $\mathcal{E}$ J. Robinette. [Radio Interview]. Oakland Institute.

Peet, R., \& Hartwick, E. (1999). Theories of development. New York: Guilford Press.

Pieterse, J. N. (1998). My paradigm or yours? Alternative development, postdevelopment, reflexive development. Development Change, 29(2), 343-373.

Pieterse, J. N. (2011). Discourse analysis in international development studies. Journal of Multicultural Discourses, 6(3), 237-240.

Pohatu, T. W. (2005). Ata: Growing respectful relationships. (Unpublished Manuscript). Manukau: Te Wānanga o Aotearoa.

Pollard, A. A. e. (2003). Women's Organizations, Voluntarism, and Self-Financing in Solomon Islands: a Participant Perspective. Oceania, 74(1-2), 44-60.

Prebisch, R. (1950). The Economic Development of Latin America and Its Principal Problems by the United Nations. Economic Commission for Latin America. Geneva: United Nations Department of Economic Affairs.

Pretty, J., \& Chambers, R. (1993). Towards a Learning Paradigm: New Professionalism and Institutions for Agriculture. (IDS Discussion Paper No. 334). Brighton: Institute of Development Studies, University of Sussex. 
Pritchett, L. (2001). Where Has All the Education Gone? World Bank Economic Review, 15(3), 367-392.

Pritchett, L. (2009). Does schooling help explain any of the big facts about growth. Revised version of presentation given to the Growth Commission on October, 19, 2007.

Psacharopoulos, G. (1981). Returns to education: an updated international comparison. Comparative Education, 17(3), 321-341.

Psacharopoulos, G. (1985). Returns to education: a further international update and implications. Journal of Human resources, 583-604.

Psacharopoulos, G. (1994). Returns to investment in education: A global update. World Development, 22(9), 1325-1343.

Puipui, I. (2011). Kokopo Urban Local Level Government Report. Retrieved from Kokopo, ENB https://www.lgma.org.au/downloads/File/KOKOPO.pdf

Radmehr, F., Laban, H. L. W., Overton, J., \& Bakker, L. (2020). Student perceptions of effective lecturers: the need to recognise the role of ethnicity and choice of discipline. Higher Education Research \& Development, 39(2), 302-317.

Rahnema, M., \& Bawtree, V. (1997). The post-development reader. London: Zed Books.

Ramalho, R., Adams, P., Huggard, P., \& Hoare, K. (2015). Literature review and constructivist grounded theory methodology. Paper presented at the Forum: Qualitative Social Research.

Ramasamy, S., Krishnan, V., Bedford, R., \& Bedford, C. (2008). The Recognised Seasonal Employer policy: seeking the elusive triple wins for development through international migration. Pacific Economic Bulletin, 23(3), 171-186.

Randell, S. (2003). Teacher regarding strategy working paper 1. [Unpublished working paper].

Rathgeber, E. M. (1990). WID, WAD, GAD: Trends in research and practice. The Journal of Developing Areas, 24, 489-502.

Ravuvu, A. (1983). Vaka i Taukei: The Fijian way of life. Suva: Institute of the Pacific Studies, USP. 
Rawls, J. (1971). A Theory of Justice. Cambridge: Belknap.

Reddy, M., Mohanty, M., \& Naidu, V. (2004). Economic Cost of Human Capital Loss from Fiji: Implications for Sustainable Development. International Migration Review, 38(4), 1447-1461.

Riesenberg, S. H. (1965). Table of voyages affecting Micronesian islands. Oceania, $36(2), 155-170$.

Rist, G., \& Camiller, P. (2014). The History of Development: From Western Origins to Global Faith. London: Zed Books.

Ritzer, G., Zhao, S., \& Murphy, J. (2001). Metatheorizing in sociology: The basic parameters and the potential contributions of postmodernism. In Handbook of sociological theory (pp. 113-131). Boston: Springer.

Robeyns, I. (2006). Three models of education: Rights, capabilities and human capital. Theory and research in education, 4(1), 69-84.

Robinson-Pant, A. (2016). Education and rural development: Proposing an alternative paradigm. London \& New York: Routledge.

Rongo, T., Evans, J., Passfield, K., Cramp, J., Sudek, M., Tautu, B., . . Hanchard, B. (2013). Cook Islands Marine Park: Coral reef survey of Aitutaki, Manuae, Mitiaro, Takutea, and Atiu in the southern Cook Islands. Retrieved from http://clarewormaldsteele.cikeys.com/wp-content/uploads/2015/07/CIMPFINAL1.pdf

Rostow, W. W. (1960). The stages of growth: A non-communist manifesto: Cambridge University Press.

Ruru, J. (2004). Indigenous peoples' ownership and management of mountains: The Aotearoa/New Zealand experience. Indigenous LJ, 3, 111.

Ruru, J. (2010). Discovering indigenous lands: The doctrine of discovery in the English colonies. Oxford: Oxford University Press.

Ruru, J. (2010). Undefined and unresolved: exploring indigenous rights in Aotearoa New Zealand's freshwater legal regime. The Journal of Water Law (2010) 20, 236242. 
Russo, G., Bainbridge, S., \& Dunkel, T. (2013). Benefits of Vocational Education and Training in Europe for People, Organisations and Countries. Cedefop - European Centre for the Development of Vocational Training: ERIC.

Sachs, W. (1992). Development: a guide to the ruins. New Internationalist. Retrieved from https://newint.org/features/1992/06/05/keynote

Sachs, W. (2013). Liberating the World from Development. New Internationalist (460), 22-27.

Sack, P. G., \& Clark, D. (1979). German New Guinea: The Annual Reports. Canberra: ANU Press.

Sai, A. (2007). Tamot: Masculinities in Transition in Papua New Guinea. (Doctoral Thesis, Victoria University). Melbourne. Retrieved from http://vuir.vu.edu.au/1494/

Sakaida, H. (1996). The Siege of Rabaul. Saint Paul, MN: Phalanx Press.

Salesa, D. (2003). 'Travel-happy' Samoa: Colonialism, Samoan migration and a 'Brown Pacific'. New Zealand Journal of History, 37(2), 171-188.

Salesa, D. (2017). Island Time: New Zealand's Pacific Futures (Vol. 64). Wellington: Bridget Williams Books.

Salesa, D. (2018). Native seas and native seaways: The Pacific Ocean and New Zealand. In F. Steel (Ed.), New Zealand and the Sea Historical Perspectives. Wellington: Bridget Williams Books.

Salesa, D. (2019). 'Into Native Seas, Europeans Encounter an Indigenous Ocean' [Turnbull Founder Lecture 2019]. Wellington: Turnbull Endowment Trust.

Salleh, A. (2016). Climate, water, and livelihood skills: A post-development reading of the SDGs. Globalizations, 13(6), 952-959.

Samu, T. W. (2011). Tala Mai Fafo : (re)learning from the voices of pacific women. Pacific-Asian Education, 23(2), 11-22.

Sanga, K. (2000). Learning from indigenous leadership. In Pacific cultures in the teacher education curriculum series. Suva, Fiji: Suva Institute of Education, USP/UNESCO. 
Sanga, K. (2002). Beyond access and participation: Challenges facing Pacific education. Tree of opportunity: rethinking Pacific Education, 51-57.

Sanga, K. (2005). A Strategy for Rethinking Aid Relationships. In K. Sanga, C. Chu, C. Hall, \& L. Crowl (Eds.), Rethinking aid relationships in Pacific education. Wellington, Suva: He Parekereke, Institute for Research and Development in Maori and Pacific Education, Victoria University of Wellington; Institute of Education, USP.

Sanga, K. (2009). The Pacific public servant: Serving three masters. Canada: Graduate School of Public Policy, University of Saskatchewan.

Sanga, K. (2014). Indigenous Pacific Emerging Educational Metaphors. The International Journal of Diversity in Education, 12(4), 39-52.

Sanga, K. (2016). Split-worlds, side-questions and weaving: Storying the politics of Pacific Learning. Paper presented at the The Politics of Learning Noku ano te Takapau Wharanui, Victoria University of Wellington.

Sanga, K. (2017). Leadership development through friendship and storytelling. In U. Vaai \& A. Casamira (Eds.), Relational Hermeneutics: Decolonising the Mindset and the Pacific Itulagi (pp. 101-113). Suva, Fiji: USP Press \& Pacific Theological College.

Sanga, K. (2018). Tok Stori 101: An ontological exploration of Melanesian knowledge domains. Paper presented at the 46th Oceania Comparative and International Education Society Conference, Wellington.

Sanga, K. (2020). Forward. In Johansson-Fua, S., Jesson, R., Spratt, R. and Coxon, E. (Eds.) Relationality and Learning in Oceania: Contextualizing Education for Development (pp. vii-viii). Koninklijke Brill NV: Leiden, The Netherlands.

Sanga, K., Chu, C., Hall, C., \& Crowl, L. (2005). Re-thinking aid relationships in Pacific education. Suva, Fiji: Institute of Education, USP.

Sanga, K., \& Reynolds, M. (2019). Melanesian tok stori in leadership development: Ontological and relational implications for donor-funded programmes in the Western Pacific. International Education Journal: Comparative Perspectives, 17(4), 11-26.

Sanga, K., Reynolds, M., Paulsen, I., Spratt, R., \& Maneipuri, J. (2018). A tok stori about tok stori: Melanesian relationality in action as research, leadership and scholarship. Global Comparative Education: Journal of the WCCES, 2, 3-19. 
Sanga, K., \& Taufe'ulungaki, A. M. (2003). Re-thinking educational aid in the Pacific: Report on the Pacific regional conference on educational aid, Wellington: He Parekereke.

Sanga, K., \& Taylor, L. (2001). Partnership in an aid project: Is it a teacher-learner relationship. Directions: Journal of Educational Studies, 23(1), 42-55.

Sanga, K., \& Thaman, K. H. (2009). Re-thinking education curricula in the Pacific: challenges and prospects. Wellington: He Parekereke.

Sasaoka, Y., \& Nishimura, M. (2010). Does universal primary education policy weaken decentralisation? Participation and accountability frameworks in East Africa. Compare, 40(1), 79-95.

Schensul, S. L., Schensul, J. J., \& LeCompte, M. D. (1999). Essential ethnographic methods: Observations, interviews, and questionnaires (Vol. 2). Lanham MD: Rowman Altamira.

Schmitt, J. (1993). The changing structure of male earnings in Britain, 1974-88. London: Centre for Economic Performance, LSE.

Schultz, P. (2002). Why governments should invest more to educate girls. World Development, 30(2), 207-225.

Schultz, T. (1961). Investment in Human Capital. The american economic review, 51(1), $1-17$.

Schultz, T. (1963). The economic value of education. New York: Columbia University Press.

Scoones, I., \& Thompson, J. (1993). Challenging the populist perspective: rural people's knowledge, agricultural research and extension practice. Institute of Development Studies, University of Sussex.

Sen, A. (1999). Development as Freedom. Oxford: Oxford University Press.

Sillitoe, P., Bicker, A., \& Pottier, J. (2002). Participating in development: approaches to indigenous knowledge (Vol. 39). Hove, East Sussex: Psychology Press.

Simet, J. (1991). Tabu: Analysis of a Tolai Ritual Object. (Doctoral Thesis, Australian National University). Canberra. Retrieved from https://openresearch-repository.anu.edu.au/handle/1885/110381? mode=full 
Simet, J. (2000). Copyrighting traditional Tolai knowledge? In K. Whimp \& M. Busse (Eds.), Protection of Intellectual, Biological and Cultural Property in Papua New Guinea (pp. 62-80). Canberra: ANU Press.

Simon, D. (2006). Separated by common ground? Bringing (post) development and (post) colonialism together. Geographical Journal, 172(1), 10-21.

Sipolo, J. (1986). Praying parents: a second collection of poems. Honiara, Solomon Islands: Aruligo Book Centre.

Siwatibau, S. (1997). Pacific islands economic management: challenges for the 21st century. Paper presented at the Islands in the Pacific century. VIII Pacific Science InterCongress.

Sjaastad, L. A. (1962). The costs and returns of human migration. Journal of political Economy, 70(5, Part 2), 80-93.

Skutnabb-Kangas, T. (2003). Revitalisation of indigenous languages in education: Contextualising the Papua New Guinea experience. Language and Education, 17(2), 81-86.

Slatter, C. (2010). Gender and custom in the South Pacific (Tuhonohono: Custom and State). Yearbook of New Zealand Jurisprudence, 13E14. Retrieved from https://www.waikato.ac.nz/ data/assets/pdf file/0015/106620/NZYJ-Vols-13and-14-2010-11.pdf

Slatter, C. (2014). Building 'Shared Societies' in Pacific Island States: Prospects and challenges. Development, 57(1), 104-111.

Slatter, C., \& Underhill-Sem, Y. (2009). Reclaiming Pacific Island Regionalism: Does Neo-Liberalism Have to Reign? . In B. D'Costa \& K. Lee-Koo (Eds.), Gender and Global Politics in the Asia-Pacific. New York: Palgrave McMillan.

Smelser, N. J. (1967). Mechanisms of change and adjustment to change. Indianapolis: Bobbs-Merrill

Smith, G. H. (1997). The development of kaupapa Māori theory and praxis. (Unpublished Doctoral Thesis). University of Auckland, Auckland.

Smith, G. H. (2000). Maori education: Revolution and transformative action. Canadian Journal of Native Education, 24(1), 57. 
Smith, L. T. (1993). Getting out from down under: Maori women, education and the struggles for mana wahine. In Arnot, M. and Weiler, K. (Eds.) Feminism and social justice in education: International perspectives, (pp. 58-78). London: The Farmer Press.

Smith, L. T. (1999). Decolonizing Methodologies. In. Cambridge: Cambridge University Press.

Smith, L. T. (2012). Decolonizing methodologies: research and indigenous peoples (2nd ed.) London: New York: Zed Books.

Sokoloff, N., Pratt, C., \& Rosenberg, K. (Eds.). (2006). Domestic violence at the margins: readings on race, class, gender, and culture. London: Rutgers University Press.

Somerville, A. T. P. (2012). Once Were Pacific: Māori Connections to Oceania. Minneapolis: University of Minnesota Press.

Somerville, A. T. P. (2018). Searching for the Trans-Indigenous. Verge: Studies in Global Asias, 4(2), 96.

Souder, L. (1992). Daughters of the island: Contemporary Chamorro women organizers on Guam. MARC Monograph Series No. 1: Lanham MD: University Press of America.

Spoonley, P., \& Bedford, R. (2003). Blurring the boundaries: The impact of contemporary migration flows and transnational linkages on Aotearoa/New Zealand. In Iredale, R. R., Hawksley, C., and Castles, S. Migration in the Asia Pacific, (pp.305-319). Northampton: Edward Elgar.

Spoonley, P., \& Bedford, R. (2012). Welcome to our world?: Immigration and the reshaping of New Zealand. Auckland: Dunmore Publishing.

Spratt, R. (2011). Aided Professionals: Professional Subjectivity and Development in the Solomon Islands. (Unpublished Master's Thesis). University of Auckland.

Spring, J. (2015). Economization of education: Human capital, global corporations, skillsbased schooling. New York: Routledge.

Steel, F. (2011). Oceania Under Steam: Sea Transport and the Cultures of Colonialism, c.1870-1914. Manchester: Manchester University Press. 
Stewart-Harawira, M. (2007). Practising Indigenous Feminism: Resistance to Imperialism. In J. A. Green (Ed.), Making space for Indigenous feminism (pp. 124139). Black Point: Fernwood Pub.

Stone, K. (2011). Decolonised destinies: Oceanic critical regionalism as a protest against the foreign definition of Pacific identities. In J. G. T. Shaw, \& S. Cornellisen (Ed.), The Ashgate research companion to regionalisms (pp. 306-309). Burlington: VT: Ashgate.

Storey, D., Bulloch, H., \& Overton, J. (2005). The poverty consensus: some limitations of the 'popular agenda'. Progress in Development Studies, 5(1), 30-44.

Strand, K. J., Cutforth, N., Stoecker, R., Marullo, S., \& Donohue, P. (2003). Community-based research and higher education: Principles and practices: Hoboken, N.J.: Wiley

Strathdee, R. (2011). The implementation, evolution and impact of New Zealand's national qualifications framework. Journal of Education and Work, 24(3-4), 303321.

Stuart, M. (2005). Learning in Partnership: Responding to the Restructuring of the European steel and metal sector. Final Report for Fifth Framework Socio-Economic Key Action Award, European Commission DG Research. Retrieved from https://cordis.europa.eu/project/id/HPSE-CT-2001-00049

Stupples, P., \& Teaiwa, K. (2017). Contemporary perspectives in art and international development. New York: Routledge.

Talatala ToMorton Amos (2016). [Unpublished Tok Stori with Talatala ToMorton Amos: Education, Community Development, Migration, Industrialisation and Poverty in New Britain].

Tan, E. (2014). Human Capital Theory: A Holistic Criticism. Review of Educational Research, 84(3), 411-445.

Tarte, S. (2014). Regionalism and changing regional order in the Pacific Islands. Asia $\mathcal{E}$ the Pacific Policy Studies, 1(2), 312-324.

Tateyama, H. (2006). Tubuan: History, Tradition, and identity among the Tolai of Papua New Guinea (Doctoral Thesis, The University of British Columbia). Vancouver, BC Canada. Retrieved from https://open.library.ubc.ca/cIRcle/collections/ubctheses/831/items/1.0092976 
Taufe'ulungaki, A. M. (2000). Pacific cultures in the teacher education curriculum: Vernacular languages and classroom interactions in the Pacific. Suva, Fiji: USP, UNESCO.

Taufe'ulungaki, A. M. (2002). Introduction. In A. M. Taufe'ulungaki, F. Pene, \& C. Benson (Eds.), Tree of opportunity: Re-thinking Pacific education. Suva, Fiji: Institute of Education, USP.

Taufe'ulungaki, A. M. (2003). The role of research: A Pacific perspective. In Coxon, E. and Taufe'ulungaki A. M. (Eds), Global/Local Intersections Researching the Delivery of Aid to Pacific Education, (pp. 19-40). Auckalnd: Auckland University Press.

Taylor, D. M. (2015). The future of the Pacific Islands forum and the framework for Pacific regionalism. In Fry, G. and Tarte, S., The New Pacific Diplomacy (pp. 3947). Canberra: ANU Press.

Taylor, G. T. (2013). Afakasi Speaks. Honolulu: Ala Press.

Te Awekotuku, N. (1991). Mana Wahine Maori: Selected Writings on Maori Women's Art, Culture, and Politics. Wellington: New Women's Press.

Teaiwa, K. (2014). Reframing Oceania: Lessons from Pacific Studies. In Framing the global: entry points for research. Bloomington: Indiana University Press.

Teaiwa, K. (2015a). Consuming Ocean Island: Stories of People and Phosphate from Banaba. Bloomington: Indiana University Press.

Teaiwa, K. (2015b). Ruining Pacific islands: Australia's phosphate imperialism. Australian Historical Studies, 46(3), 374-391.

Teaiwa, K. (2017). Our sea of phosphate: The diaspora of Ocean Island. In Harvey, G. and Thompson Jr., C. (Eds.) Indigenous diasporas and dislocations (pp. 169-192). New York: Routledge.

Teaiwa, T. K. (1993). A New Oceania: Rediscovering Our Sea of Islands. Suva, Fiji: USP.

Teaiwa, T. K. (1994). Bikinis and other s/pacific n/oceans. The Contemporary Pacific, 87-109.

Teaiwa, T. K. (1995). Searching for Nei Nim'anoa. Suva, Fiji: USP 
Teaiwa, T. K. (1999). Reading Gauguin's Noa Noa with Hau'ofa's Kissess in the Nederends. Lanham, MD: Rowman \& Littlefield.

Teaiwa, T. K. (2001). Militarism, Tourism and the Native: Articulations in Oceania. Santa Cruz: University of California, Santa Cruz.

Teaiwa, T. K. (2005a). The classroom as a metaphorical canoe: Cooperative learning in Pacific studies. WINHEC: International Journal of Indigenous Education Scholarship(1), 38-48.

Teaiwa, T. K. (2005b). Solidarity and Fluidarity: Feminism as Product and Productive Force for Regionalism in the Pacific. Paper presented at the Colloquium presentation, University of Hawai'i.

Teaiwa, T. K. (2006a). I am, Amnesia I-IV. Suva, Fiji: USP.

Teaiwa, T. K. (2006b). On analogies: Rethinking the Pacific in a global context. Contemporary Pacific, 18(1), 71-87.

Teaiwa, T. K. (2011). Bleeding boundaries: Gendered analyses of militarism in the Western Pacific. Asia Pacific Viewpoint, 52(1), 1-4.

Teaiwa, T. K. (2015). What makes Fiji women soldiers? Context, context, context. Intersections: Gender and Sexuality in Asia and the Pacific, 37.

Teaiwa, T. K. (2016). Women, Double Colonization and National Liberation: A presentation on West Papuan women. Suva, Fiji: USP.

Teaiwa, T. K. (2017). Charting Pacific (Studies) Waters: Evidence of Teaching and Learning. The Contemporary Pacific, 29(2), 265-282.

Teaiwa, T. K. (Ed.) (2008a). Globalizing and Gendered Forces: The Contemporary Militarization of Pacific/Oceania. Honolulu: University of Hawai'i Press.

Teaiwa, T. K. (Ed.) (2008b). On women and 'Indians': The politics of inclusion and exclusion in militarized Fiji. New Brunswick: Rutgers University Press.

Teaiwa, T. K., \& Henderson, A. (2009). Humanities and Communities: A Dialogue in Pacific Studies. Pacific Studies, 32(4), 421-438.

Teaiwa, T. K., \& Slatter, C. (2013). Samting Nating: Pacific Waves at the Margins of Feminist Security Studies. International Studies Perspectives, 14(4), 447-450. 
Teamotuaitau, J. (2012). L'altérité à la presqu'île de tahiti. de samuel wallis à frederick o'brien (1767-1921). (Doctoral Thesis, University of French Polynesia) Puna'auia. Retrieved from theses.fr https://www.theses.fr/s32482

Teavai-Murphy, H. (2002). Director of Te Pu Atiti'a Association. Gump Station: University of California.

Teavai-Murphy, H. (2016). Resisting the present, reclaiming the past and reshaping the future. Can data sciences help Polynesian Islands become more resilient to climate change adverse effects? In C. Cabasse-Mazel (Ed.): University of California Berkeley.

Thaman, K., \& Thaman, R. (2009). Pacific Island principles: learning to live wise and sustainable lives. In Corcoran, P.B. and Osano, P. M. (Eds.) Young people, education, and sustainable development (pp.63-75). Wageningen: Wageningen Academic Publishers.

Thaman, K. H. (1974). You, the choice of my parents: poems. Suva, Fiji: Suva, Fiji : Mana Publications:available from South Pacific Creative Arts Society.

Thaman, K. H. (1981). Langakali: poems. Auckland: Mana Publications.

Thaman, K. H. (1985). The defining distance: people places and worldview. Pacific Viewpoint, 26(1), 106-115.

Thaman, K. H. (1987). Hingano: Selected Poems, 1966-1986. Suva, Fiji: USP.

Thaman, K. H. (1992). Towards a culture-sensitive model of curriculum development for Pacific Island Countries. Directions, 13, 1-11.

Thaman, K. H. (1993a). Culture and the Curriculum in the South Pacific. Comparative Education, 29(3), 249-260.

Thaman, K. H. (1993b). Kakala. Suva, Fiji: USP.

Thaman, K. H. (1995). Concepts of learning, knowledge and wisdom in Tonga, and their relevance to modern education. Prospects, 25(4), 723-733.

Thaman, K. H. (1997). Reclaiming a place: Towards a pacific concept of education for cultural development. The Journal of the Polynesian society, 106(2), 119-130. 
Thaman, K. H. (1999). The forgotten context: Culture and teacher education in Oceania. Directions: Journal of Educational Studies, 21(1), 13-30.

Thaman, K. H. (2000a). Pacific cultures in the teacher education curriculum. Module one, towards culturally democratic teacher education. Suva, Fiji: USP, UNESCO.

Thaman, K. H. (2000b). Towards a new pedagogy: Pacific cultures in higher education. Local knowledge and wisdom in higher education, 43-50.

Thaman, K. H. (2003). Decolonizing Pacific studies: Indigenous perspectives, knowledge, and wisdom in higher education. The Contemporary Pacific, 15(1), 117.

Thaman, K. H. (2008). Nurturing relationships and honouring responsibilities: A Pacific perspective. In Living Together (pp. 173-187) New York: Springer.

Thaman, K. H. (2009a). Educational ideas from Oceania : selected readings ( $2^{\text {nd }}$ ed.). Suva, Fiji : Institute of Education in association with the UNESCO Chair in Teacher Education and Culture, USP.

Thaman, K. H. (2009b). Introduction: The need to re-think Pacific curriculum. Rethinking education curricula in the Pacific: Challenges prospects, 13-27.

Thaman, K. H. (2009c). Towards cultural democracy in teaching and learning with specific references to Pacific Island Nations (PINs). International Journal for the Scholarship of Teaching and Learning, 3(2), 6.

Thaman, K. H. (2018). Keynote. Paper presented at the 2018 Vaka Pasifiki Education Conference, Suva.

Thaman, K. H. (2020). Afterword. In Johansson-Fua, S., Jesson, R., Spratt, R. and Coxon, E. (Eds.) Relationality and Learning in Oceania: Contextualizing Education for Development (pp. 167-8). Koninklijke Brill NV: Leiden, The Netherlands.

Thaman, R. (1993). Moana Nui, Vanua and Wantoks. In E. Wadell, V. Naidoo, \& E. Hau'ofa (Eds.), A new Oceania: Rediscovering our sea of islands (pp. 38-48). Suva: University of the South Pacific.

Thomas, P., \& Bessell, S. (1999). Education for sustainable development : getting it right / edited by Sharon Bessell , Pamela Thomas. Canberra: Australian National University, Development Studies Network.

Thompson, N. (2010). On Wayfinding. Honolulu: Polynesian Voyaging Society 
Thornberg, R. (2012). Informed grounded theory. Scandinavian journal of educational research, 56(3), 243-259.

Todaro, M. P. (1969). A model of labor migration and urban unemployment in less developed countries. The american economic review, 59(1), 138-148.

ToHenry Tavul (2016). [Unpublished Tok stori with a Gunantuna/Tolai elder and leader: ToHenry Tavul].

Tollefson, J. W. (1991). Planning language, planning inequality: language policy in the community. London: Longman.

Tolley, H. (2005). Basic Education: Where did it come from and where is it going. Rethinking Education Curricula in the Pacific: Challenges and Prospects. Wellington: He Parekereke.

Tomasevski, K. (2001). Human rights obligations: making education available, accessible, acceptable and adaptable. In Right to Education Primers, Primer No. 3, 13-16.

Torre, M. E. (2009). Participatory action research and critical race theory: Fueling spaces for nos-otras to research. The Urban Review, 41(1), 106-120.

Trask, H.-K. (1989). Fighting the battle of double colonization: The view of a Hawaiian feminist (Vol. 4).

Trask, H.-K. (1993). From a Native Daughter: Colonialism and Sovereignty in Hawai'i. In. Monroe, Maine: Common Courage Press.

Trask, H.-K. (2003). Talkin'up to the White woman: Indigenous women and feminism. The Contemporary Pacific, 15(2), 474-475.

Truman, H. (1949). Truman Inaugural Address, January 20, 1949. Speech presented at President Truman's Inaugural Address, Washington, D.C. [Speech]. Retrieved from

https://www.trumanlibrary.org/whistlestop/50yr archive/inagural20jan1949.ht $\underline{\mathrm{m}}$

Tuck, E., \& Yang, K. W. (2012). Decolonization is not a metaphor. Decolonization: Indigeneity, education \& society, 1(1). 
Turpat, T. (2017). [Unpublished Tok stori with a Gunantuna/Tolai elder and education leader: ToGuideon Turpat].

UIS. (2018, 5 December). Global review of progress towards SDG 4-Education 2030 targets and commitments: Main monitoring issues and recommendations. Paper presented at the Education in an interconnected world: Ensuring inclusive and equitable development, Brussels.

Ulu, A. J. (2018). Folauga mo A'oa'oaga: Migration for education and its impact on Samoa's development as a nation. Wellington: Victoria University of Wellington.

UN-PNG. (2018). The United Nations Development Assistance Framework 2018-2022. Port Moresby: United Nations Papua New Guinea.

UN. (2015). Transforming Our World: The 2030 Agenda for Sustainable Development. New York: UN.

UN. (2017). Millennium Development Goals. Retrieved from http://www.un.org/millenniumgoals/

UN. (2019). Special edition: progress towards the Sustainable Development Goals. Retrieved from https://undocs.org/E/2019/68

Underhill-Sem, Y. (2002). Embodying Post-Development: Bodies in places, places in bodies. Development, 45(1), 54-59.

Underhill-Sem, Y. (2016). Critical gender studies and international development studies: interdisciplinarity, intellectual agility and inclusion. Palgrave Communications, 2(1), 1-5.

Underhill-Sem, Y. (2019). Pacific Feminisms. In A. Kothari, A. Salleh, A. Escobar, F. Demaria, \& A. Acosta (Eds.), Pluriverse: A Post-Development Dictionary. New Delhi: Tulika Books, Authorsupfront.

Underhill-Sem, Y. (2017). Academic work as radical practice: getting in, creating a space, not giving up. Geographical Research, 55(3), 332-337.

UNDP. (2010). Human Development Report 2010: The Real Wealth of Nations: Pathways to Human Development. Retrieved from http://hdr.undp.org/en/content/human-development-report-2010 
UNDP. (2014). 2014 National Human Development Report: Papua New Guinea. Retrieved from

http://hdr.undp.org/sites/default/files/2014 png national human development report.pdf

UNDP. (2017). Sustainable Development Goals. Retrieved from

http://www.undp.org/content/undp/en/home/sustainable-developmentgoals.html

UNDP. (2019a). Human Development Report 2019. Retrieved from

http://hdr.undp.org/sites/default/files/hdr2019.pdf

UNDP. (2019b). Sustainable Development Goals Knowledge Platform. Retrieved from https://sustainabledevelopment.un.org/sdg4 \& https://sustainabledevelopment.un.org/hlpf/2019

UNEP. (2011). Towards a Green Economy: Pathways to Sustainable Development and Poverty Eradication: A Synthesis for Policy Makers. Retrieved from https://sustainabledevelopment.un.org/index.php?page $=$ view \&type $=400 \& n r=12$ $\underline{6 \& m e n u=35}$

UNESCO. (2003a). Education for all: Frequently Asked Questions. Retrieved from http://www.unesco.org/education/efa/ed for all/faq.shtml

UNESCO. (2012a). Eight proposals for a strengthened focus on technical and vocational education and training (TVET) in the education for all (EFA) agenda. Retrieved from https://www.eldis.org/document/A74404

UNESCO. (2012b). Youth and skills: putting education to work. New York: UNESCO

UNESCO. (2015). Education 2030 Incheon Declaration and Framework for Action. Paris: UNESCO.

UNESCO. (2018). Issues and trends in Education for Sustainable Development (Vol. 5): Paris: UNESCO.

UNICEF. (2015). Girls' Education and Gender Equality. Retrieved from http://www.unicef.org/education/bege 70640.html

Unterhalter, E. (2005). Global inequality, capabilities, social justice: The millennium development goal for gender equality in education. International Journal of Educational Development, 25(2), 111-122. 
Unterhalter, E. (2012). Poverty, education, gender and the Millennium Development Goals: Reflections on boundaries and intersectionality. School Field, 10(3), 253274.

Unwin, L. (2004). Growing beans with Thoreau: rescuing skills and vocational education from the UK's deficit approach. Oxford Review of Education, 30(1), 147160.

Uphoff, N. (2005). Analytical issues in measuring empowerment at the community and local levels. In Measuring Empowerment: Cross-Disciplinary Perspectives (pp. 219-246). Washington D.C.: The World Bank.

Va'ai, U., \& Nabobo-Baba, U. (2017). The Relational Self: decolonizing personhood in Pacific colonized spaces. Suva: University of the South Pacific Press.

Van Overtveldt, J. (2007). The Chicago School: how the University of Chicago assembled the thinkers who revolutionized economics and business. Chicago: Agate Publishing.

Van Peer, L. (2006). Catching the vision: rethinking Pacific education initiative - An exemplar for future development practice? Report on RPEI participants' critical reflections. Retrieved from https://files.eric.ed.gov/fulltext/EJ1017700.pdf

Vanuatu National Statistics Office. (2012). Alternative Indicators of Wellbeing for Melanesia, Vanuatu Pilot Study Report. Retrieved from http://www.christensenfund.org/wp-content/uploads/2012/11/AlternativeIndicators-Vanuatu.pdf

Vetuna, P. (2019). ICICLE fashion group: Stop desecrating indigenous cultures! [Online Petition]. Retrieved from https://www.change.org/p/isabelle-capron-vice-president-of-icicle-shanghaifashion-group-icicle-fashion-group-stop-desecrating-indigenouscultures?recruiter $=75675020 \& u t m$ campaign=signature receipt\&utm medium $=$ twitter\&utm source $=$ share petition

Vigil, I. W. (2016). [Unpublished Tok stori with an elder and education sector leader IaEleonora Warmari Vigil].

Visvanathan, S. (1988). On the Annals of the Laboratory State. In Nandy, A. (Ed.) Science, Hegemony and Violence: A Requiem for Modernity, (pp. 257-288). Tokyo: UNU Press. 
Vunisea, A. (2019, 9 July 2019). Working with culture to achieve women's economic empowerment. Paper presented at the Regional Learning Forum on Women's Economic Empowerment, University of the South Pacific, Suva, Fiji.

Vygotsky, L. (1967). Play and its role in the mental development of the child. Soviet psychology, 5(3), 6-18.

Walker, I., \& Zhu, Y. (2008). The college wage premium and the expansion of higher education in the UK. Scandinavian Journal of Economics, 110(4), 695-709.

Walker, M. (2012). A capital or capabilities education narrative in a world of staggering inequalities? International Journal of Educational Development, 32(3), 384-393.

Walker, M., McLean, M., Dison, A., \& Peppin-Vaughan, R. (2009). South African universities and human development: Towards a theorisation and operationalisation of professional capabilities for poverty reduction. International Journal of Educational Development, 29(6), 565-572.

Walsh, C. (2010). Development as Buen Vivir: Institutional arrangements and (de)colonial entanglements. Development, 53(1), 15-21.

Walton, G. W. (2019). Fee-free education, decentralisation and the politics of scale in Papua New Guinea. Journal of Education Policy, 34(2), 174-194.

Wang, H. (2006). Globalization and curriculum studies: Tensions, challenges, and possibilities. Journal of the American Association for the Advancement of Curriculum Studies, 2(2006), 1-17.

Wantchekon, L., Klašnja, M., \& Novta, N. (2014). Education and human capital externalities: evidence from colonial Benin. The quarterly journal of economics, 130(2), 703-757.

Watson-Gegeo, K. A., \& Gegeo, D. W. (2014). "Heavy Words and Important Silences": Kwara'ae Children Learning the Indigenous Epistemology of Willingness and Rank. Pacific Studies, 37(3), 172-201.

Watson, K. (1984). Dependence and interdependence in education: international perspectives. London: Croom Helm.

Watson, K. (1994). Technical and vocational education in developing countries: Western paradigms and comparative methodology. Comparative Education, 30(2), 85-97. 
Wawaneya, R. (2017). [Unpublished Tok stori with Rela Wawaneya].

Weeks, S. G. (1993). Education in Papua New Guinea 1973-1993: the latedevelopment effect? Comparative Education, 29(3), 261-273.

Wendt, A. (1982). Towards a new Oceania. In Amirthanayagam, G. (Ed.) Writers in East-West Encounter (pp. 202-215). London: The Macmillan Press Ltd.

Wendt, A. (1987). Novelists and Historians and the Art of Remembering. Class and culture in the South Pacific, (Suva, 1987), 78-91.

Wesley-Smith, T. (1995). Rethinking Pacific Islands Studies. Pacific Studies, 18(2), 11537.

Wesley-Smith, T. (2016). Rethinking Pacific Studies twenty years on. The Contemporary Pacific, 28(1), 153-169.

Whimp, G. (2008). Interdisciplinarity and Pacific studies: roots and routes. The Contemporary Pacific, 20(2), 397-421.

WideBay Conservation Association (2015). [Unpublished Tok Story with Elizabeth Tongne: Ward Development Plans and teh effects of oil palm plantations in East Pomio District].

Williams, L. R. T., \& Ormond, A. (2010). What is research? Mai Review(3), 1-6.

Wilson, P. (October 2, 2019). Gender based violence and basic education in PNG. [DevPolicy Blog Post]. Retrieved from https://devpolicy.org/gender-based-violence-and-basic-education-in-png$\underline{20191002 /}$

Wood, H. (2003). Cultural Studies for Oceania. The Contemporary Pacific, 15(2), 340374.

Wood, R. E. (1986). From Marshall Plan to debt crisis: Foreign aid and development choices in the world economy (Vol. 355). Los Angeles, London: University of California Press.

World Bank. (1999). Education sector strategy: Washington D.C.: World Bank Publications. 
World Bank. (2007). What do we know about school-based management? Washington D.C.: World Bank Publications.

World Bank. (2016). Implementation, completion and results report. Retrieved from http://documents1.worldbank.org/curated/en/554711467263195339/pdf/ICR363 7-P105897-Box396255B-PUBLIC-disclosed-6-28-16.pdf

World Bank. (2019). James David Wolfensohn: 9th President of the World Bank Group, 1995 - 2005. Retrieved from https://www.worldbank.org/en/about/archives/history/past-presidents/jamesdavid-wolfensohn

Yamada, G. (2015). The boom in university graduates and the risk of underemployment. IZA World of Labor(165), 1-10.

Yapa, L. (2002). How the discipline of geography exacerbates poverty in the Third World. Futures, 34(1), 33-46.

Yapita Moya, J., \& Miracle, A. (1981). Time and Space in Aymara. In Hardman, M.J. (Ed.) The Aymara Language in the Social and Cultural Context, (pp. 33-56). Gainesville: University of Florida.

Yates, D. (2018). The UN Declaration on the Rights of Indigenous Peoples: Education in Aotearoa New Zealand. Retrieved from https://www.linkedin.com/pulse/un-declaration-rights-indigenous-peopleseducation-aotearoa-yates/

Young, K. (1987). Gender and Development: Notes for a Training Course on Gender and Development. Toronto: AgaKhan Foundation.

Yuval-Davis, N. (2006). Intersectionality and feminist politics. European Journal of Women's Studies, 13(3), 193-209. 


\section{Appendices}

Appendix 1 - Consent Form

Appendix 2 - Information Sheet for research Participants

Appendix 3 - Semi-Structured Interviews Schedules

Appendix 4-Poem by Author: original version in Spanish

Appendix 5 - Tok stori interactive texts 


\title{
Appendix 1 - Consent Form
}

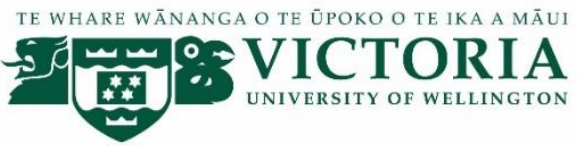 \\ Development and Education: \\ Pacific Islands Case Study - East New Britain Province, \\ Papua New Guinea. \\ CONSENT TO PARTCIPATE IN RESEARCH
}

This consent form will be held for 5 years.

Researcher: Lorena de la Torre, School of Geography, Environment and Earth Sciences, Victoria University of Wellington, New Zealand

- I have had the research explained to me clearly and understand the project. I have had the opportunity to ask questions, and any questions I had were answered to my satisfaction.

- I agree to take part in an audio recorded interview.

I understand that:

- I have the ability to withdrawal any information I give as long as it is prior to the completion of data collection and analysis (30/05/17).

- $\quad$ The information I have provided will be destroyed 5 years after the research is finished.

- I understand that during those 5 years all information will be kept securely stored by the researcher and accessible only by her should she require it for future studies on the same topic.

- I have the ability to refuse to the information given by me to be used for further studies on the topic after the completion of this research and ask for that information to be destroyed upon the completion of the current research.

- I understand that the information I give will be kept confidential to the researcher and their supervisor, and I will remain completely anonymous and my responses will not be attributed to me in any way.

- I understand that the only way my name will be used is if I give explicit permission for this.

- I understand that the results will be used for a PhD thesis and a summary of the results may be used in academic articles and/or presented at conferences.

- I understand that this data will remain completely confidential and will be stored in a secure manner.

- $\quad$ My name will not be used in reports, nor will any information that would identify me.

- $\quad$ I consent to my organisation being identify in reports (if you answer yes, you will be referred to as a "representative from [your organisation]", if answer no, your Yes $\square$ No organisation will not be mentioned).

- I would like to receive a copy of the final report and have added my email address Yes $\square$ No on the following page.

Signature of participant:

Name of participant:

Date:

Contact details: 


\title{
Appendix 2 - Information Sheet for research participants
}

\author{
TE WHARE WĀNANGA O TE ŪPOKO O TE IKA A MĀUI \\ 59: VICTORIA \\ Development and Education: \\ Pacific Islands Case Study - East New Britain Province, \\ Papua New Guinea
}

\section{INFORMATION SHEET FOR PARTICIPANTS}

Thank you for your interest in this project. Please read this information before deciding whether or not to take part. If you decide to participate, thank you. If you decide not to take part, thank you for considering my request.

\section{Who am I?}

My name is Lorena De la Torre and I am a Doctoral student in Development Studies at Victoria University of Wellington, New Zealand. This research project is work towards my thesis.

\section{What is the aim of the project?}

This project will study place-based notions of education and development, by aiming to answer questions on some of the types of education and the types of development being articulated and enacted in East New Britain Province.

The work will study how different types of education are driving, and are being driven by, different development processes in East New Britain Province, Papua New Guinea. It will investigate the development objectives and visions for East New Britain, Papua New Guinea governments, communities and individuals. It will explore the way education strategies are currently being articulated and pursued in East New Britain Province (ENB), Papua New Guinea. It will help our understanding on whether or not education strategies currently taking place in ENB see people, families and communities achieving various development goals.

This research has been approved by the Victoria University of Wellington Human Ethics Committee.

\section{How can you help?}

If you agree to take part, I will interview/stori with you in a public place or somewhere you feel most comfortable. I will ask you questions about the relationship between education and development and the effects this relationship has in your community. I will record this and write it up later. You can stop the session at any time, without giving a reason. You can also skip any questions you do not want to answer. You can withdraw from the study prior to the completion of data collection and analysis (01/10/18). If you withdraw, the information you provided will be destroyed.

\section{What will happen to the information you give?}

This research is confidential. I will not name you in any reports, and I will not include any information that would identify you if you express it is not appropriate. The transcripts, 
summaries and any recordings will be kept securely and destroyed 5 years after the research ends. During those 5 years all information will be kept securely stored by me, and will only be used should I require it for future studies on the same topic. Please let me know if you do not want the information you give to be used by me for further studies on the topic after the completion of this research; I will then destroy all information upon the completion of the current research.

\section{What will the project produce?}

The information from my research will be used in my PhD thesis. You will not be identified in my report unless you explicitly state you want to be identified. I may also use the results of my research for conference presentations, and academic reports and articles. You will not be identified in any presentation or report.

\section{If you accept this invitation, what are your rights as a research participant?}

You do not have to accept this invitation if you don't want to. If you do decide to participate, you have the right to:

- $\quad$ choose not to answer any question;

- $\quad$ ask for the recorder to be turned off at any time during the interview;

- withdraw from the study prior to the completion of data collection and analysis (30/05/17);

- $\quad$ ask any questions about the study at any time;

- $\quad$ read over and comment on a written summary of your interview;

- $\quad$ agree on another name for me to use rather than your real name;

- be able to read any reports of this research by emailing the researcher to request a copy.

If you have any questions or problems, who can you contact?

If you have any questions, either now or in the future, please feel free to contact either:

\section{Student:}

Lorena De la Torre

lorena.delatorreparra@vuw.ac.nz

\section{Supervisor:}

Professor John Overton

Professor

School of Geography, Environment and Earth

Sciences

Phone: +64-4 4635281

john.overton@vuw.ac.nz

\section{Human Ethics Committee information}

If you have any concerns about the ethical conduct of the research you may contact the Victoria University HEC Convener: Associate Professor Susan Corbett. Email susan.corbett@vuw.ac.nz or telephone +64-4-463 5480. 


\title{
Appendix 3 - Semi-structured interview schedules
}

\author{
Development and Education: \\ Pacific Islands Case Study - East New Britain Province, \\ Papua New Guinea
}

INTERVIEW SCHEDULE: Industry Representatives

State: If you do not want to answer any of the questions please feel free to say "pass" and we will move on to the following question.

\section{Section 1: Personal Information}

1. Where are you from? What is the name of your village?

2. What are your Wantok connections (i.e. tribal connections)?

3. How long have you lived in East New Britain? Can you tell me more about your move to this area? For example; reasons for moving, experiences and any challenges encountered [If participant is not from the studied area].

Section 2: Industry Information and Area of Expertise

4. Where in the industry sector do you work? For example, tourism sector, business sector, etc.

5. How long have you worked in this industry?

6. What does your organisation/company does?

7. What is your position (area of expertise) and responsibilities in this industry?

Section 3: Knowledge about education sector and the sector's development objectives

8. Are you aware of any national government development objectives in relation to the education sector? If so, what do these development objectives mean to you/your industry and organisation?

9. Are you aware of any development objectives (and/or goals) pursued by your industry sector in relation to the education sector? If so, what do these development objectives (and/or goals) mean to your organisation, to you and to the work you do in your position? 
10. If you answered yes to the previous question: Are you able to comment on whether or not the different types of education strategies supported and pursued by your industry sector and organisation are helping achieving the development objectives/goals for the education sector in your province?

11. If you answered yes to question 9: Can you comment on whether or not the different types of education strategies supported and pursued by your industry sector and organisation are helping achieving the development objectives/goals for the education sector at the national level?

12. If you answered no to question 9: Are you able to provide any comments on why there is no connection between your industry/organisation and the education sector (including this sector's development objectives)?

13. If you answered yes to question 9: Are you able to provide any comments on whether or not the different types of education strategies supported and pursued by your industry sector/organisation are helping local communities and individuals achieving their community/village level development objectives/goals? For example, community well-being, mobility, income generation, etc.

14. Do you have any further comments?

Thank you very much your kind contributions - interview over 


\section{Appendix 4 - Poem by Author: original version in Spanish}

\section{Los colibríes de tu jardín}

The Hummingbirds of Your Garden

Lying in the shade of your rose garden, between sleep and wakefulness, the sun filtering through, red, yellow and deep, deep orange I was woken by the hummingbirds of your garden. Around me the hummingbirds floated effortlessly, flitting from flower to flower, wrapped in all the colours of your roses, like a sunset although it was just midday. Flying, their wings imperceptible, rapid, their small colourful bodies, almost inaudible.

So much grace and delicacy.

But when they woke me, for less than a second I heard wings beating, I could see their wings.

So much movement, so much effort disguised as inertia.

I, your granddaughter, the one that mi abuelita used to call colorada such a tiny girl lying under your roses

thinking only that red was red, yellow was yellow, orange was orange, and that those colours together fused into a sunset.

There, as a small child, in your garden, was the last place in which I remember existing without struggle.

You, abuelito, with your skilled hands gave me the sunset at midday, and with each note of your charango you painted my soul.

But the hummingbirds of your garden offered me something else:

a vision that goes beyond that delicate, colourful, inaudible, almost still image,

a reality made of thousands of beats per second

a new way to understand our existence.

And I, always asking things that no one wanted to hear, or could answer, asked of your roses if they would take away the sunset in exchange for time passing more slowly.

Because mi abuelito, I wanted to see the wings of the hummingbirds.

And from that day on I haven't lain in the shade of your rose garden,

I lost the sunset at midday,

and no more could I live without struggle, without questions.

And I asked, I asked everything to everyone.

I asked of red because it was behind the scabs that I shouldn't scratch, but was also in the flags of the plazas.

I asked of yellow because it was high in the sky and also was covering 
cathedrals and bearded men turned into monuments.

And I asked of orange because it was in the oil of achiote and was in papaya,

but slowly disappearing from our table.

And hence curious I grew more and more confused,

because the question marks were growing like kikuyo in my veins,

and the answers hurt like the point of a scythe.

Because the hummingbirds in slow motion were now not so delicate:

the hummingbirds were noisy, rushed and tireless,

full of contradictions and uncertainties,

implacable.

And so, curious, I left your garden and followed the hummingbirds to the highlands.

There, tired, I rested in the long grass,

when I opened my eyes there were rose gardens no more, but intense blue skies

and the sun burned just like it should at midday.

There, in that ancestral silence, the wingbeats of the hummingbirds sounded like lightning,

each beat reverberating like my questions

until I could no longer find sleep.

And thus I understood that there is no silence without lightning

there is no delicacy without movement

no grace without questions

no roses without sky

no sunset without midday

no rest without struggle.

When I had to leave the garden of your house on the slopes of Ruku Pichincha

I lost the refuge of your rose garden, I lost calmness, I lost effortless childhood.

But between your house and the highlands

I learned that I am full of questions

and that I cannot find calm without answers.

Between your house and the highlands

I learned that I am made of blood and of sun.

Between your house and the highlands

I learned that inside of me are nestled the colours of hummingbirds and of roses.

And here today, with my feet covered in sand at the other side of our ocean,

After going from canoe to canoe following currents

to places where kumara also grow under the glitter of the same nine stars,

places where there are also stories about big sails and about panpipes;

here, with wings tired from so much beating,

my skin burnt around the scabs,

my soul even more colorada, my vision still in slow motion,

and fundamentally with many more questions than answers:

I suspect and feel that something in me has the flavor of the sea,

that in me grows the grass of the high plains, as grows the kikuyu,

but also in me dwells the scythe.

(Translation by author and Geoff Whittle, my dear friend) 


\section{Appendix 5 - Tok stori interactive texts Tok stori interactive texts}

\section{Preface}

The following five tok stori interactive texts with Gunantuna/Tolai elders and leaders in education and development are presented alongside a narrated story about a grassroots curriculum development initiative in ENB. These tok stori interactive texts are a fundamental element of this research process. The words of participants are presented as said by them, with the final text being reviewed by a Gunantuna/Tolai elder. Its final destination is the hands of participants themselves.

These tok stori interactive texts are presented here as an appendix to comply with academic convention. However, these texts are an important outcome and the central source of inspiration to this study. 


\section{Tok tok stori tasol}

\section{Tok stori with lalva Magaga}

Mum IaIva looks at me, smiles and says:

"When I talk, sometimes when I say things, they don't come from me

I don't know where these ideas or words come from

Most of the time, if you ask me... I won't remember what I just

said to you...

Know that those words are for you, and only you."

(Tok Stori with mum IaIva Magaga)

I have shared countless stories with mum, some told, some created together, most of the knowledge shared remains private. The personal stories and knowledge that mum IaIva Magaga has chosen to share here, aims at providing us all with some of the wisdom that assisted her in her life journey as a visionary woman in education and community development in East New Britain, in other localities in Papua New Guinea and now across Oceania.

This is but a small window into the stories of IaIva Magaga and her carefully woven network of relationships -past, present and future-. These are some of the strands that when firmly and lovingly tightened together weave the gentle and strong woman, the visionary, the educator, the leader, the elder, the $b u b u$, the mother.

\section{Growing up: The village, family, learning from elders and early understandings of education}

My name is Iva Peteva and my parents' names are To Peter Teu

Puang and Ia Pirida Palum. I was born in 1957 in Matalau village

and I got married to Blasius Magaga in 1977. When I was able to

go to school I remember vividly going to lukbuk with my sister Ia 
Madik (Jackie) and learning the Kuanua alphabet in class, later going to preschool and being taught by a white young woman who loved us and taught us well.

I also remember vividly being nurtured by three grandmothers, Ia Rakila, Ia Niumai and Ia Kail who was 97\% blind she taught me to appreciate life. They all made me happy in the village. My aunts, Ia Dada, Ia Doris and Ia Kivung.

But the ones I learnt from to think and behave were my uncle To Malmal Waisea and my father To Peter Teu whom I spent most times with thinking and talking, he was my coach and mentor. My father warned me time and time again of the consequences of speaking out loud. So, I learnt to be silent and to speak only when spoken to. I picked up some fine behaviours and attitudes in my village and school very early in life. I looked up to adults and tried to follow accepted rules, I was a good listener. Today I am thankful for the way my father trained me.

Education to me meant [when young] that you are able to think and behave rationally or wisely. Smart in your maths and English. Being able to think out problems and solve them, that is having an analytical mind. Able to make wise and smart choices.

\section{The educator and her mission}

Walking around villages, towns and cities in East New Britain and around Papua New Guinea with mum IaIva Magaga, has a rhythm, a kind of pace capable of rocking you gently, it is almost spellbinding. From one exalted encounter to the next, person after person, story after story, reveal a lifetime of dedication to every single 
one of those encounters by IaIva Magaga, the educator. There by her side, this being under the shade of enormous trees, inside classrooms, on the street in the midday sun, or treating ourselves to coffee and cake after a big day of work; I am transported to the world of every person IaIva Magaga's life has touched. Gentle and proud the stories approach, stories of the inspiration, encouragement and protection IaIva Magaga provides to countless students, colleagues, women and men, young and old, local and foreign. IaIva Magaga honours every encounter, retelling these stories by carefully bounding them with pride, respect and love. Upon the farewell and as if closing a precious sacred treasure, she simply carries on with her day. Her dignified, humble, unassuming ways are a big part of the spell.

I had been teaching for almost 40 years when I retired, mum tells me. When I started teaching I saw it as a mission, I went out to train youths to be leaders.

Is this why you devoted your life to education mum?

Yes, I started teaching in 1977, in my third year of teaching I was given a senior subject masters position. After that in 1983 I left to teach in New Ireland for two years where I became the Head of the English Department at Mangai High School. I returned to George Brown in 1985 and became the Deputy Head of School under an Australian, Mr Boyle who headed the school. After four years of deputing at George Brown I transferred to Rabaul High School and became the Head of the English Department in 1988. In 1989 I was given the Deputy Head of School position under Mr Savage an Irish man. I was the Deputy there until the Mt Tavurvur eruption in 1994. After the eruption, in 1995 I got transferred to Malaguna Technical, where I was Deputy Head of School under Mr Brain Lock, an Australian up till 1998. 
In 1999 I got transferred to Malabunga Secondary when it became the first secondary school in East New Britain. I was Head of the Language $\mathcal{E}$ Literature Department for two years then left to teach at Kerevat National High School in 2001 and 2002. When Kokopo High School became a secondary school, I was offered the Deputy Principal Academic position. I was in this position up until 2006. In 2007 I was offered to head Malaguna Technical Secondary School, so I took that up and for 8 years I was Principal of Malaguna Technical Secondary School. I retired in 2015. I had been teaching for 38 years.

\section{The creation of a Community College}

"The old people knew we needed to leave, no one died, they knew, they observed the birds, the animals and the water"

This is what I always hear when telling stories with people in ENB about the Mt Tavurvur eruptions in 1994. The collective experience of devastation and loss during the eruptions, was by and large mitigated by Indigenous peoples' wisdom of their land in the villages and towns surrounding. What followed were countless stories of community resilience built upon kinship networks of support.

One of them was in the education space through the creation of a community college in Malaguna Technical Secondary School (Maltech), by IaIva Magaga with the support of Dr Allan Marat (MP for Rabaul District) in the early 2000s. Whom together with their communities, institutions, staff and kinship networks, created a safe, purposely affordable and encouraging space to support people who were displaced from their villages during the eruptions, and have since suffered the associated flow-on environmental and socio-economic effects. Vocational training under the guidance and patronage of two leaders and respected elders, became thus 
an avenue to provide youth with options: with useful skills to rebuild their villages; to access formal and informal employment within and outside the province; to encourage reconnection with land following displacement. Ultimately preventing youth unemployment and vulnerability.

What do you know about community colleges daughter?

I think you know a lot more about them than I do mum, you created one at the school a few years ago.

Yes, we got some good people involved. It helped many of our students and village people. It helped the school too. So many came together to work with us.

I need to learn a lot more about them in practice, mum. I've learnt of different places in the world that have them, and they have often been good for their communities.

It would be good if we had more of them in the villages, daughter. You know a safe and good place to support our young people to learn good skills, using their hands and minds, helping in the village. They can create jobs too, they can be decently paid when these skills get the respect they deserve. They can build houses, toilets, systems to collect and drain water, repair their houses, fix their trucks and machinery, create good sustainable gardens. Their skills are so needed in the village.

"Yes mum, it would be good for the villages in the origin Matalau and for those people that were relocated to Gelegele-Matalau after the eruptions. They already have some people with those skills in the village, but they need to also be supported, recognised for their 
work, paid accordingly. Then they can share their skills, teach the young while helping to build and rebuild. Create spaces that make sense in the village, where those learning and those teaching know each other, and they can feel safe. A space that builds their skills with dignity, with wantoks and family and their elders around, just as when you all worked to create the community college at Maltech."

Yes, I remember well how the initiative of the community college in Maltech came about. It happened when I realised that there was need for people to get some form of recognition to get formal employment away from home.

Rabaul District students missed out a lot in the eruption of 1994. Those in Grade 8, 10 and 12 never got their certificates. There was no evidence of them exiting their final grades. So, we opened opportunities for them to get a TVET certificate, and also for those that had lost their certificates during the eruption or were working without a certificate but had good experience through working. We graduated 300 plus students through that initiative. Dr Marat our MP for Rabaul District, the Rabaul District Administration and the Rabaul Urban Department, were behind the success of this initiative. Maltech and its staff and students were also very supportive of this programme.

The experts were called in, and so the community college had both, vocational educators and community members working in technical industry jobs, teaching and learning side by side. Hundreds of students benefited from this programme, gaining skills that are relevant and needed in the village setting, increasing their 
employability, and even venturing into starting their own businesses. Further, those that graduated left behind a great legacy in the shape of a newly completed science building for the school. It was a remarkable achievement that benefited both, vocational and academic branches at the school, reinforcing connections and mutual respect between the these two oftentimes divided educational paths.

\section{Learning is a sacred pursuit, a relational matter}

Working together with mum IaIva Magaga for a few years within the education space in ENB province, has meant that our daily interactions are filled with stories about education and about learning. Many are stories about the meaning and practice of education. We explore together the history of past and current policies and practices in educational spaces, from the village to the provincial level; from PNG, through my land of origin Ecuador, to my current home Aotearoa New Zealand and across the world.

Every story and every silence are purposeful, they require of conscious labour, yet they never feel exhausting. They are about mutual responsibility when sharing a relational space. Holding this relational space with respect is not something you can simply opt out of, particularly when you are an educator. Believing in the intrinsic dignity of our learners and teachers is one of the core values from where we can together create new stories. Stories that can enhance their world and their lives, stories that weave the life patterns of our learners and teachers into education by respecting their dignity and celebrating their brilliance (Sanga, 2016).

IaIva Magaga sometimes revisits her experiences as a learner, from the time she used to go to the village lukbuk with her sister Ia Madik (aunty Jackie) to learn her tok ples Kuanua alphabet, and later as part of the formal education system from elementary school up to her time at University of Goroka. She found several people along the path, both local and foreign from whom she observed the diversity of thought and of doing that surrounded her. Yet, the teachings she is deeply grateful for, those that 
have carried her throughout all aspects and stages of her life, came from her kinship connections and elders, from the nurturing of her three grandmothers IaRakila, IaNiumai and particularly IaKail, who as she retells earlier in this story, was almost entirely blind, -from her she learnt to appreciate life-. She learnt about happiness through her aunts Ia Dada, Ia Doris and Ia Kivung. She learnt to think and behave from her uncle To Malmal and specially from her father To Peter Teu, who she spent most of her time thinking and talking. She explored the realms of secret and sacred knowledge through the mentoring and love of her father. Mum IaIva Magaga learnt from them all that learning is a sacred pursuit, a relational matter.

There have been many changes in educational policies lately mum, they come with good intentions and aspirations, yet in the ground I see that the pressure is huge for many schools, for many educators and students, there is not a lot of support for them to adjust to the changes.

Yes daughter, I have seen that in the last couple of years, the government reforms have brought about a mixture of successes and failures. We have experienced standards dropping in Grade 10 and 12. Lagging two years back. The introduction of $O B E / C^{59}$ into secondary and introducing the $\mathrm{NC} 1^{60}$ and 2 to vocational centres and schools, where students come in straight from Grade 8, this was a big mistake. These courses were given to students who exited Grade 10 and were chosen to do NC1 in technical colleges. This was a huge step and a big drop for the TVET sector. It brought confusion and duplication of courses in all levels when technical courses got introduced into the vocational centres and schools.

\footnotetext{
${ }^{59} \mathrm{OBE} / \mathrm{C}$ : Outcome Based Education Curriculum.

${ }^{60} \mathrm{NC}$ : National Certificate.
} 
Now with the education policy to use Standard Base Education in place of the most criticised $O B E / C$. This again I feel it may be another set-back for the secondary schools. The initiative that the province had about developing their own tourism and hospitality curriculum is the result of this push to support vocational education throughout these reforms. We were looking for answers on how to accommodate NC1 into the vocational education sector, seeing the difficulty for vocational teachers and students to understand the NC1 curriculum and using it. It is an excellent local initiative that works as a bridge for our teachers and students before they use the NC1, by first looking into skilling and empowering them for community living, for well-being.

I see how this happened in the community college at Maltech too mum. Everyone that worked alongside you and Dr Marat running this initiative had that same goal, the focus was to empower educators and students for community living through vocational training. But this was intentional and planned vocational training, it was relevant for your local communities, for your students. You taught them skills that were needed in the village, and that could also help them to find a job outside, if that is what they wanted.

\section{"Papua New Guinea needs an education with a focus on survival"}

What I have learnt daughter throughout these decades, is that the community needs relevant education. Education that will skill and empower the youths to successfully live anywhere, be it in the village or town or city and they can survive and be successful. The education system today is still failing our school children because 
after Grade 8, Grade 10 and Grade 12, after all those years of education, they are still not able to carry out simple instructions or work. They don't have the skills for building a small house, toilets, small kitchen, to beautify their homes, drain water, make good sustainable gardens. Skills to plant trees, fruits and vegetables.

What the community needs is relevant education with empowerment for community living. In our communities we desire to have our children gain a good education so that they can then work and earn a living or simply do things at home. Today, this is no longer a dream come true. There are just too many students with no space to further their education, no work for employment and no business opportunities. So today we have too many students in our villages who have graduated from Grade 8, 10 and 12, even those that graduated from the universities around the country, who are not fully developed to use their potential and talents to advance in life.

Education should support our people to be able to progress from where they are physically, mentally, psychologically, financially, spiritually and be elevated to another level. When we are able to recreate our lives and become successful in all areas of our lives, then we are developing into a healthy and happy community. Our future in education looks depressing. PNG needs an education with a focus on survival not on getting jobs. Our children need to survive in our communities. 


\section{Tok stori with laEleonora Varmari Vigil}

Our pawpaw plant can heal everything, from the bark to the fruit, from the seeds to the leaves, every part of our plant has a medicinal purpose.

IaEleonora Vigil says, while we sit in her office telling stories and sharing some cut pawpaw.

You see Lorena if you have an open wound, you put this part, the fleshy part of the pawpaw skin on the wound, it will heal.

\section{"My name makes me who I am"}

I am Eleonora Varmari Gile, that is my maiden's name, Gile is my father's name. Varmari in our language means 'to make something beautiful'. I'm always proud of explaining my name because, it makes me 'who' I am. Varmari means 'to make something beautiful', and some people call me Warmari which means 'to have mercy on people', so that's my name. Eleonora is a German name given to me by a nursing nun when I was born here in in St Mary's hospital in Vunapope, it is unique and I'm also proud that I was given that German name. I am from Ulaulatava village, in the Kokopo District, in the Kokopo-Vanamame LLG, which is within the town area. My village is about $7 \mathrm{kms}$ inland from the Toma-Kerevat Road.

\section{Early schooling years - the love to science and music}

I attended Kokopo Secondary School when I was of young age, from grade seven to grade ten, and then I went straight to the University of Goroka, straight from grade 10. Lorena, I was just 
lucky I made it through, because at this time we had to go to grade 11 and 12 before we can go up to university (IaEleonora Vigil proudly laughs). The specialist subjects that I studied were Mathematics, Science, Home Economics, but at the same time I was taking music, as one of my extra subjects, because I was always interested in the choir, in learning music. I am not very good with this German, but I am very good with my voice. I am very good with singing.

\section{"We all had broken hearts, [...] and we just told ourselves: "let's go back and develop the education system of our province"" - The newspaper article that changed the future of education in East New Britain}

I graduated in 1980 and then started teaching back in East New

Britain. I always dreamt to go to university, and nothing stopped me on the way; I told my father I wanted to go study and help my people. I tell you a story Lorena, during the time I was at the teachers' college, there was an article that was written about ENB, and the education system in our province. They did a lot of criticisms about our Tolai people and the state of education at home at that time. There were a lot of us Tolai student teachers in the college, so we had a meeting because after reading that article for a whole week they spoke about our people, our education system and the way ENB was doing education. There were a lot of criticisms, they compared us with other provinces, and so from there, some of us decided that when we graduate we must go back and develop our province. There is where I started, so since then which was in 1981 up top today, I have been teaching for over 36 years. 
I had been here in my province, I haven't gone out, I've been here. And that is because of that article that was written about us Tolai. We all had broken hearts, we felt sorry for our province, and so we just told ourselves: "let's go back and develop the education system of our province".

I see this clearly here IaEleonora Vigil, that calling to come back home for Tolai people. Doesn't matter where you go or do, you always want to come back and bring back what you've learnt and know and what you have. But in your case, there was also a mission ah, to prove that what was written in that article was not right.

That's right Lorena, and that's' what I did. Myself and my husband Mr Vigil, we went to college together, there's where we met. My husband was the president of the Students Association, and he called up a meeting, cause of a lot of the information that was written in that article wasn't true about the Tolai people. So, we wanted to prove to the country and to anybody the truth about Tolai people in the classrooms. There were so many things written there that were really degrading. So, we just pulled ourselves together and that group of students, we all came back to ENB and we are still here; some of them have recently resigned. But Lorena, we just came back, some went to Kokopo and others to all the schools in ENB, and we spent all of our years, teaching in our province. But nowadays because the newcomers did not have that experience, - to read through the article-, they would go to another province and teach and spend their fresh time in another province, 
before they come back to ENB. For some of us, we spent all of our time here.

Lorena, we talk about Mrs Magaga ah, she graduated before me, but when she graduated from college, she came back to ENB. She was, and she is, the precedent. We are so patriotic about our province. Is that the right word? (ToVarmari laughs and giggles).

\section{I think it is!}

So, Lorena we love to come back to our province, we love to develop our home, we love to give our best to our people. Even during the time of the volcanic eruptions in 1994, I was a young teacher, but I took a leadership role in OLSH and looked after over 2,000 refugees. I helped with the distribution of food and with the census that followed. There were thousands of refuges everywhere, specially down there were the bank is now. I did a lot of counselling for my people during that time.

\section{The value of giving and role modelling in education}

IaEleonora Vigil, I am so honoured to share time with the men and women like you and mum IaIva (Mrs Magaga), and I can see how much you have all done for the education system in the province. East New Britain, Tolai leaders in education have become an example for the nation; and these are the words I heard in the Department of Education the last time I was there. What about the young teachers and the young people that are coming to take on those leadership positions? Do they have the same love, the same patriotism (laughs), the same everything? 
Not so much, I can say that the committed teachers, and the ones that love to give their best, some of them are already out of the system. But, and this is important Lorena: 'some of us still here!'. So, we have become the role model for the ones coming up, and a lot of these young ones are seeing what we are doing, and they are trying to copy and follow. They have to really sit down and observe, they have to see why is it that I have been in the same school for 28 years, there is a reason. People come and ask: "you don't get tired of staying in one school?", and I say: "no, I don't get tired, because every year is different, and every year I meet different students, and every year I do different things, and that helps me to keep up".

Even now that I am in my 36th year of teaching and 28 years in the same school, I find that I still have the strength to give more. My teaching is only going forward. A lot of the time is the health that does not allow us to continue, otherwise we would like to give more. And we would like to educate our students the way we want them to be, not only in school, not only in the workplace, but also back in the community. They have to be fit to go back into the community, so sometimes we told them: "if you cannot fit back into the community, you're a misfit to society".

It's a hard thing for the young ones that become adjusted to the way of life in the bigger towns, and when they go back to the communities, to the village, it's hard for them sometimes. 


\section{"What we are proud of"}

You can really tell that those that are brought up at the community

level, they are well off and they can fit into the community, they can survive. Those that come from town and try to come back, if they have needs there is no much they can do, they become clumsy, and sometimes they cannot fit back into to the society. So, the education for a Tolai, for a very strong hold Tolai is this: 'the Tolai must always have something to sit back on in the community, and that is what we are proud of' (we both laugh proudly and knowingly of the truth of this statement).

This is something that I have felt and experienced first-hand IaEleonora Vigil, that pride in being Tolai, that sense of love and belonging to your land and to your people, to the village, to the tumbuna.

That's right Lorena, we are proud to be Tolais. And every time I think of it, I'm proud to be a Tolai. I'm proud to be a Tolai not only because I am recognised in the work place, or in the province, but because I am recognised back in my community. So, when there's a death, I am up, I have to reach out with money, I have to participate. That is how I make myself to be part of the community and to be respected in the community.

\section{Gunantuna/Tolai pride and traditional knowledge}

Education for Tolai people then IaEleonora Vigil goes beyond learning your ABCs and 123s. It is a holistic way of looking at the individual maybe? knowing they are able to fit at school, in a job, but also being able to go back to the community and give back, 
knowing that learning every tradition and practice is important for the community.

Oh yes Lorena, you got to know them, you've got to know them!

I can say that I am proud to be Tolai because I can organise a bride price ceremony for my own children and I don't ask for help. If I have to prepare 400 fathoms, 500 fathoms, I will prepare them myself, and take them to my brothers, so that they can help me after, I will prepare everything and pay everything. I know exactly what to do, that I am very proud of as a Tolai.

If I am in the village then they will always include me in any meetings, they will send a message saying: "we will have this big meeting about this piece of land and we would like you to be part of this". I will give some advice, the type of advice that I learnt from my father, every time we tell stories he would say: "you are part of these relationships, this is your father, this is their land, and that belongs to this tribe, and this one to this tribe". So, the stories that I usually would hear from my father helped me to fit in to the society. And Lorena truly, I am always proud, that every time I sit beside the fire telling stories, and I ask questions and I say: "how are you related to this person? how are you related to that person?" And then think where do I fit in here? Those types of questions can be 'baby questions' but they are very important. So, I treasure those. 


\section{Gunantuna/Tolai concepts of wealth and belonging}

Education is seen in many different ways here IaEleonora Vigil, like you said before: those important stories from your father, the traditional knowledge we learn in the village and is then passed down through the generations: 'that is as important as school'. This is something unique in this world, we have lost so much of our Indigenous and ancestral knowledge, but here it remains strong.

Yes, that's right, here it is still strong! A good example Lorena: you can be a big man, like a prime minister, but back in your community you must have 'that' wealth: the knowledge. And you must have 'that' wealth, our shell money, our tabu, you must have that. Because if you come back, you can't be a big man if you don't have that wealth, nobody will recognise you in the community because you are a 'prime minister'. So, say for example, Rabbie Namaliu was once a prime minster, but back in his home he's got round wheels of tabu; he has to have that, otherwise you cannot connect yourself with the community. You can be a Tolai, but you are not a full Tolai if you don't have what we have.

In a few ceremonies I have been invited to, I have observed that it is the tabu that represents everything ah. It is very clear through the amount of tabu you have if you've been there for my father's funeral, or for my sister's bride price. All these different important ceremonies and time shared in life events: they are what gives you wealth, the name, the recognition, the love and the respect of the community; no how much money you have, or the titles you have. 
Yes Lorena, it is your contribution to the society, your contribution is your presence in the community, your contribution to the community is what counts, not your money. Then you have two different types of wealth there: your tabu shell money; and your money. You cannot get anything with your money in any traditional gatherings, shell money is more important there than any money can be.

\section{The making Our Lady of the Sacred Heart Secondary School - a story of love, persistence and trust}

When I came to this school in 1991 it had a very low profile, it was a small school, with eight classes: two grade 7, two grade 8, two grade 9, and two grade 10 . Then all the reforms came in...

Some of the school stuff walk into IaEleonora Vigil's office to pick up some papers, silence- in that moment they realise they have interrupted her halfway telling a story, we all look at each other and brake into uncontrollable giggling while they slowly walk out of there. Mrs. Vigil continues:

So, where was I? Ok, when I came here I was 29 and this school was still a high school. It was the early 2000 s and at that time they started reforming the schools, they started talking about dropping off grade 7 and 8 from the high schools and putting them back into primary schools. They wanted also to take grade 11 and 12 and make them into secondary schools. At the time here at OLSH we went on for a couple of years with grade 9 and 10. And that is when my man started working, I said to him: "we cannot expand with a limited number of facilities, so we have to start thinking of what we can do to expand the school". So, when our grade 8 
became grade 9 we started increasing grade 9 from two to four classrooms, because you remember Lorena -we had eight classrooms in total-. So, four classrooms for grade 9 and then the following year we had four classrooms for grade 10, that's how we started off.

We started renovating the facilities because of the increasing demand, and we said ok: "we had to take in another grade 9 classroom". But after two years, after they went through grade 10, I started seeing my students thrown everywhere, it was not good for them, so I started thinking... All the while we continued increasing the number of grade 9 and grade 10 students, so I was also looking for more -and good-teachers. You know Lorena what it is like in here, we needed more teachers' houses, so we were concentrating on that and then it came to us! (Mrs. Vigil smiles and her eyes are bright, beaming with peaceful delight) 'we were at a stage where a lot of my students from here were being out into schools that their parents didn't want to see their daughters going to, for many reasons, one being that they wanted their daughters to be able to practice their faith'.

That was in 2003 and there was a lot of talk during our PE $C^{61}$ meetings, which made me to start planning, so I wrote my first submission to get this school to secondary status. I put my submission in, in those 23 pages of submission I wrote what my dream for this school was, I was only dreaming, but Lorena there

${ }^{61}$ P\&C: Parents' and Citizens' Associations are an association representing parents of students and other persons interested in the education and welfare of students at the school, this association is to be approved by the education agency and possess a constitution stating its functions (Papua New Guinea Education Act, 1983). 
was really nothing in place, what I had was a dream of getting this school into secondary status. A year later and my submission was not back, they would say: "you are not enough, why don't you just amalgamate with St Mary's Vuvu? -which is a boys' school-, that did not go well with me. I said to them: "they have their own facilities that are fit for the boys, in OLSH we have our facilities, that are fit for the girls, I would like the two schools to remain single sex schools"; no, they cannot dictate that to us. So, I continued, I was lucky I was part of the PEB -the Provincial Education Board-, I would fight, and I would argue, but then people would not listen. I said: "I will not stop, I will continue!", so I started off by putting up the new library, and slowly worked on my plans.

In 2004 we built the new library, it is a big library. I started by looking around for a building plan and I got it from Malabunga, yes, -you know the library in Malabunga Secondary School Lorena-, it is basically the same library, but I tried to modify mine a little bit to fit to OLSH. We were lucky that Gordon Lee -an Australian-, gave me the plan for free, he said: "you can use this plan, go put it through the Building Board, and have your library built". So, I did, I changed everything that was needed for the requirements of the Building Board, I got it through, and the library was built from.

\section{"We built the library with our voices"}

I put a second submission in 2004 but it was knocked off a second time again, so I said to myself: "ok, I will stop here, and I will get all my buildings done". Our library is the result of our voices 
Lorena, we built that library with our voices! We did a lot of fundraising through our school choir; they would invite us to sing the national anthem, so I taught the girls to sing the national anthem well, polishing every part of the song. Every time they asked for our choir to sign at events I would say: "cash on delivery", we will deliver, we'll get the cash! (IaEleonora Vigil and I giggle). Our rate was 300 kina for a group of girls to sing; on top of that we would make leis -frangipani leis, because we had a lot of frangipani trees here-. So, for the frangipani leis I'll charge 10 or 15 kina, that was also on an invoice saying: "cash on delivery" (more giggles), we always received the payment. So, we made over 10,000 kina just from our voices, the girls voices; it was something I had to do, for the sake of our women in this country and this province. People were calling me an 'iron woman' and I said to them: "for the sake of my women in this province I have to do that".

I went on to the next thing and I started the science lab project. It was a double classroom the top floor of that building, but at that time the top part wasn't there, we only had half of that building. So, what we did is: we removed the top of the roof and built so we had two classrooms ready for grade 11 .

Wow IaEleonora Vigil, that simple ah (we both laugh).

And I said: "we need to get two classrooms ready for our grade 11", so when we finished them, I said: "now we're going to prepare our lab, and we did! You know I had a very good carpenter at that time, Mike Roberts, he is an Australian from Tasmania actually. 
Oh, my best friend is from Tasmania, good folks from there ah.

Mike was here, we gave him a house because he did not have any work, that was after the eruption. We accommodated him here in one of the houses and he was doing all of this work for us with a small group of men, he was a good carpenter. So, we went into the library, sit down and put together a plan to submit to the Building Board; when it was approved we started the building. Today Lorena, we have one of the best science labs for a secondary school, and the best library in East New Britain! (IaEleonora Vigil proudly looks out the window across to the library that sits behind an enormous tree, girls and teachers stand or sit there under its shade; we both come to a complete stand still, as if trying to listen to what both building and tree were saying to us).

So, we did put up those two classrooms... (IaEleonora Vigil brings us back to our story) one room for Chemistry and Biology, and the other one for Physics. We had everything, all the chemicals for the junior lab in the one room, but we had to order a few more things for the other room to fulfil the requirements as a secondary school's Biology and Chemistry lab, and so we did. Once the science lab was done we concentrated on the Physics lab; we had to order materials for it. We were lucky, my son is an Applied Physics graduate from Unitech $^{62}$ and an electrical engineer, so he helped us to order all the Physics' equipment. He ordered them through the internet and got all the things we needed according to each of the experiments planned for the lab. He ordered them from Amazon and they came.

\footnotetext{
62 Unitech: PNG University of Technology.
} 
They came? What a feat of your son's IaEleonora Vigil I can never even get a letter through (we both laugh).

I said to my son: "I need the specific tools that my Physics students will be using in their experiments", and my son did it for us, he is part of the lab. Even though he works in Morobe now, he comes every 3 weeks and helps them with the lab and with the teaching too. So, that's how we set up our science lab Lorena, and it is one of the best in the province.

\section{"I will not stop fighting for my women of this province"}

After the science lab, we continued with the other half of the building, to be ready for when our grade 11 came in. That was in 2008, we waited until then to put in another submission, this was my third submission, you remember Lorena: 2003 was the first, 2004 the second, and they knocked them both back-. So, I thought, I might have to stop writing submissions and prepare my buildings instead. Between 2004 and 2007 I prepared those buildings and completed more teachers' houses. In 2007 I wrote another submission, but this time I challenged them! I even rung Mr Mike Pearson in the TSC Commission in Moresby 63, I met him before in one of our meetings. I challenged him, and I said: "Mike if you think my school is going to be a very small school, I would like you to come and see for yourself. Come and see what I have been preparing for my secondary school. I would like my girls to do

\footnotetext{
${ }^{63}$ Mr Michael Pearson, Chairman of the Teaching Service Commission (TSC) which looks after the welfare of teachers in PNG.
} 
grade 11 and 12 here before they go into any tertiary education, so I challenge you Mike, I said, you come and see for yourself".

Then in 2008 he came around to do inspections in other high schools. So, before he arrived I prepared and checked everything. Lorena, at that time I had over 100,000-kina worth of books, I had my science lab, I had my library and I had my two classrooms ready; I was prepared. I needed them to say yes so that I could continue on with this dream. After challenging him, Mike came around and the first thing he did was to come and see what we have done. He started with the library and finished off with the textbooks; he checked all my facilities. My science lab was done and locked, we opened it for the first time for him and I said: "this is my lab, this is my library, these are my classrooms, if you agree Mike, if you say yes, I will continue with the rest". So, after he came and saw all my text books -Maths, Physics, Biology, Chemistry, English, Social Sciences-, he said: "what if I don't give you the status as a secondary school?" I said: "Mike you are going to give it to me". You know Lorena, he asked me that question.

I said to Mike: "If you are concerned about these women in this province, you are going to give it to me". That day he said to me: "I thought OLSH was a very small school, but OLSH is a good and big school". He even went into the classroom and saw the learning of my students, I said: "go and see for yourself Mike, I told you come and see for yourself". At the end he went back to Moresby and after 2 months he wrote us a letter that said: "you can start 
your secondary school" (IaEleonora Vigil's smile lights up the room, a humble and triumphant smile; we both start giggling with pure rejoice).

So, I prepared to go down to Moresby and make the selection for my school, they told me I needed to pay my own way, "yes", I said: "don't worry, I will pay my way, I will find my accommodation". I went down and spent the week after the selection with Marianville Secondary School, -which is a sister school to mine ran by the OLSH sisters in the outskirts of Moresby; it is also a girls' school and it's one of the highest performing schools in the country-. I went through all the syllabus, you know seeing what type of books they are using, gathering advice for grade 11 and 12, they helped me a lot. From there I went into the office, they interviewed me and asked me about my structure for the school, which was already in the submission.

In those times, I even challenged the Provincial Education Board, because every time I presented something they will knock it down, they would see all the negatives, and I said: "I will not stop fighting for my women of this province, to do grade 11 and 12 in my school. I will continue, and I will prove to you, even if I had to stand in my head with my leg up, I will! I will do this!" I challenged them, and they just couldn't believe it.

And so you did IaEleonora Vigil, just look out there under that tree, all those girls, all those teachers and your library. 
I had the support of my board Lorena, my Board of Governors ${ }^{64}$, they were my side all along. Together with the Catholic Education Board we went up to the Provincial Administration in a team with the leadership of Gerard Awe, who was previously here with us. So, we went up as a team and we presented it, we said: "this is our submission, we want our school to become a secondary school", and with that the provincial Administration had to write a sort of endorsement for us.

IaEleonora Vigil, you know that just yesterday I was visiting the Archdiocese ${ }^{65}$ and had a long and great talk with Archbishop Francesco Panfilo. Your name came up and as always there was only smiles and praise for you (IaEleonora Vigil giggles shily) for what you have done for this school and these women. They can see up there in Vunapope how hard you have worked and how much you have given for your community and to the education system. Archbishop has so much respect for you and love for this school.

I was fighting alone for a long time Lorena, but then we involved our Catholic Education Board. We had an Auxiliary Bishop Patrick Taval at the time, he came with us, with one of the inspectors $\mathrm{Mr}$ Thomas, he died already, he was a very good Catholic. Mr Thomas helped me editing my submission; he gave me a template and a sample, I followed that and would try and change it to fit our institution and what we would like to do. And I can say

\footnotetext{
${ }^{64}$ It enables local level community participation in important matters taking responsibility for student discipline and maintaining the welfare of both students and staff.

${ }^{65}$ Catholic Archdiocese of Rabaul in Kokopo, ENB.
} 
(IaEleonora Vigil stops and gives me a small and sincere smile)

that I did it well.

"I think so IaEleonora Vigil" (I point outside to the tree).

It was really an amazing experience for me. I would work tirelessly, even spend the whole night in the computer lab; I would hide myself and sleep there. I would bring a pillow and my little daughter with me, now she is in grade 5, and she will wait for me there. Sometimes I would take my babysitter and my daughter, and the three of us will be there in the computer lab they would go to sleep, and I would sit up working. I'd join them, and we will sleep here until tomorrow morning, that's what I was doing.

My PEC Board was supportive, they would try to rise money and contribute, paying a 20-kina PEC fee or 100-kina. That's how we were managing things here, I never asked the Division or anybody else to raise money for the school or for the buildings. The only organisation that I would ask was the Diocese: I would make a loan to them, it was a 50/50 arrangement, so, if I plan for a building to be 100,000-kina, then I would get a loan of 50,000-kina.

Oh ok, 50/50, good thinking!

Yes, and those 50,000-kina were interest free, they wouldn't ask you to pay anything extra, it was really helpful. I built some of my teachers houses with this, I would ask for 50,000-kina, never anything higher than that. I would agree to pay back that loan at the beginning of the year and then made a new loan in the middle 
of the year for another project. 50,000-kina was enough so that I could manage to pay back.

The story of an amazing school that refused to be called 'small' ah IaEleonora Vigil? (we both giggle).

At the time the population in the school was approximately 350, and now we have over 800 normally, with an average 35 or 32 girls per class, the maximum is 50. And we still manage to get the best out of these girls.

\section{Education doesn't happen in the classroom alone}

Seeing the girls doing so well, and experiencing your leadership, would've been a great incentive for the parents to support the school to grow and say: 'we want our daughters to continue here and not to be sent...

...to other schools (IaEleonora Vigil finishes my sentence). Yes, the parents were very supportive, I never commanded or demanded anything from them, I would only ask: "how can you help getting this project off the ground?" And so, they would organise their own fundraising in their parishes, in their LLGs. That is one of the amazing things they would do to support.

IaEleonora Vigil you ensured that education was not only seen as something that happens in the classroom. Parents, the community, the village are all part of that education too ah.

You know Lorena, before they were introduced into the province and even before there was any talk about 'project fees': the parents 
here already started their own project fees system. Every year they would come up with a project fee of 50-kina or 100-kina, and with that added to the other money we will do our project for the year. I would tell them: "ok, next year we would like to put up two more teachers houses, or another classroom, a science lab; and they will contribute. When we put our people together, the project gets done and the parents see the result. Nowadays, many schools ask them for project fees, but the project doesn't come up off the ground because the money is used elsewhere. But for OLSH, every time, every year, there is something going up. I will always report back to the parents: "this was your project fee, this is what we came up with".

It is all based on trust...

Yes.

...trust in your strong leadership IaEleonora Vigil. Mum, Mrs Magaga, always speaks so highly of you, with such respect and love. We all know here in the province, and nationally, that your leadership of this school is what has made it what it is. OLSH is you... you are OLSH. (IaEleonora Vigil giggles, her eyes glistening with the liquid expression of love). But is not only the contribution to this school, but to the education system, to the province, to these girls. And I know I am only seeing the surface of an ocean of your love and work for them. 


\section{Storying education}

IaEleonora Vigil stops as if going through each and every one of her life choices, every experience, and every face along the way; she begins telling stories of the past.

Lorena, what we used to have in the colonial times, what they educated us for, was a white-collar job. We were educated to get the job, to earn money, and bring it to the community... or something like that. But the education system of today is a dual system, where you are not only educated for a white-collar job, but you're also educated to fit well back into the community. It is sort of a dual form, where you are educated to fit well back into the community if you don't get a white-collar job. If you don't get into an institution, at least you can go back to the community and develop the community. That is the education system of today, that's what the government is aiming at, because there are not enough jobs, not enough places in the institutions and so forth.

\section{Outcome Based (OB) Education System and the important role of in- services for educators}

What the government is trying to do is to educate them well, and

they were on a good path with this Outcome Based system, it is one

of the best; it is the way our teachers are able to really deliver as they try and impart knowledge to the students. When it was introduced I really liked the idea because I am part of the inservices $^{66} . I$ was the in-service coordinator for the province for a long time, a lot of the in-services I organised were through this Outcome Based education system. There are many tasks in

\footnotetext{
66 Teacher in-services are crucial for professional development, training and familiarising educators with new educational materials, policies, etc.
} 
education, they gave me one of the biggest: the provincial in-service coordinator for the province. So, the only time I gave it away was when I got sick in 2014, after 15 years on the role.

"Is there anything you weren't doing IaEleonora Vigil?" (we both laugh).

Yes, on top of everything else (giggles) at the same time I was representing all the secondary schools and high schools in the Provincial Education Board up until 2015 when I resigned.

\section{Generosity at the centre of education}

The vast knowledge I have, and my heart: were for the students and for what our teachers can impart to them. I was even compensating for what the province could not give us; OLSH will always provide.

I know this first-hand IaEleonora Vigil.

OLSH would fund a whole province in-service again and again.

There's where my heart was, I felt so compassionate for education in the province. So, even when I organise something and then no compensation comes through, well... I cannot just say: "forget about the meeting, forget about the in-service"; I would continue, I'd go ahead. I think you saw Lorena what I did with the in-services ah? I don't have to wait for the money from the government to come to provide for others. I had to provide, because I value education. That's the biggest thing for me. Maybe my heart must've been too big for the province. 
Vigil.

I am still funding sports, in-services, any emergency meetings, they will come and find OLSH. You know well about our hospitality here in OLSH.

I know it well IaEleonora Vigil, you believed in us, and supported our curriculum project. With all my heart I can say this: "without you this project would not have happened". Because of you, because of your heart, and your love for education we were able to find a home for our teachers and writers.

It is just how much I value the project Lorena. In my own mentality, if something is going to benefit everybody, why throw it out? it is good that you are part of it, and you try to come up with something, even if you all have to make it from nothing, you can still come up with something. Because the divine providence is always there, that's what I count on, the divine providence: 'once you do something with your heart, he will provide' (IaEleonora Vigil looks at me and without words tells me that everything will be alright).

Do you remember the career expo in 2014? (she continues, after a long held and healing shared silence).

Yes, I remember, it was huge!

I funded it, over 50,000-kina and one year later I am still waiting from my reimbursement, but if it doesn't come, don't worry it is 
for the benefit of everybody in the province. So, I said: "we have to forget it, why do we have to kill ourselves with worry? If God sees that we are doing something good, we will rip more blessings in the future. I tell my bursar: "you don't worry, because if we give it up, em sem blong ol (the shame is on them), we are ok. We do not owe anything to anybody, they owe us". There are times when we need to let go... You will always find support here in OLSH, I do not know what will happen when I leave, but this is something that I will always treasure.

It is a place of refuge, from personal experience writing the curriculum with mum Iva and our teachers from here, it feels like coming home every time. You have fed our heart, our soul, and our bodies; we feel very nurtured here IaEleonora Vigil.

Lorena, I really treasure this school, because it is more than what you can ever imagine.

\section{"What we need is good and strong leadership in education"}

I can see your heart and you can see mine IaEleonora Vigil, what do you see in the future of education?

What we need in education is good leadership. The leader must be strong in order to persuade, in order to convince; at the same time, the leader must be trusted, must be transparent, in order for the people and the government to trust in him. If our leader is not transparent, then a lot of things are going to be difficult in terms of service delivery. We need strong leadership in our services offices too, leaders that are committed and dedicated. Leaders that will see 
our teachers travelling from the remote areas and will help them, making sure they go away happy. Leadership that knows the balance between being strict and tending to the needs of our teachers. We need leadership that is educated at all levels, leadership that is professional and leads by example. Education needs of leadership that would barter well for our schools to give us what we need.

\section{Storying finance and education}

Finance is important in education Lorena, for example: 'if I don't get my subsidy, where can I get help in order for the school to run?'

Yes, IaEleonora Vigil, I remember working out there in a vocational centre and after 10, 11 weeks the subsidy hasn't gone through. It is really hard to run a school, when there's no money to even feed the students. Where do the subsidies stop?

The delay is with the government, this goes back to them, because now we have to live on what the government can give. When they remove the parental contribution -where the parents helped subsidising the students-, it made it very difficult, because you need between 800 and 1,000 kina a year per student to look after them well. Now parents contribute a little bit, what is called the project fee, but it is too small; nowadays, you cannot run a school with 230 kina per student, that's what I'm charging for project fees. 
That was when they introduced the Tuition Fee Free Policy right?

How was it like for you and OLSH at that time?

At the time they started in 2012 it was very good. They were paying 1,600-kina per boarding student and 990-kina for day students, which was sufficient. But as the years go by, we started experiencing difficulties with subsidies coming in and also because they instructed us not to charge the parents. It made it very hard sometimes. I don't know what would happen if they change the government, maybe a new and good policy?

What I have learned from teachers and students here is that when the TFF policy came through, many students flooded into the schools, but the infrastructure wasn't there to cater for them all.

There was not enough Lorena.

So many students in one class, some having to sit on the floor. Is the government supporting the schools for the growth in numbers?

No, not really, they expect the schools to try and look for money to facilitate and accommodate these students. The things politics do to our schools. But in my school, I am controlling this finding ways to look after these women. It is really hard Lorena, because the education system is a good system, it is just that the lack of financial and leadership support is lowering the standards.

You still strong in your leadership despite all of these financial hard times. 
Yes, but we do not have to pretend that we have money. And whenever we have big bills like the one I received last month from the Water Board, we have to look at solutions like inspecting our bore to try and revive it. I had somebody in yesterday to look at it. We have to cut down in a lot of areas, I even lay off my carpenters for the time being, until we have a project for them. The major projects had to be put on hold, we are doing only maintenance.

\title{
"These women are not only trained to get a white-collar job"
}

\author{
I thought about the group of you that read that article at \\ university about the state of education in ENB, and you came back \\ to prove them wrong and to show the way Tolai can run their own \\ education system. And I cannot stop thinking about that 'home \\ calling, going 'bak lo ples' is alright, is a good thing to do for our \\ people. So, you came together and contributed to creating the dual \\ education system that you were telling me about. One that says: \\ "you can get a job, but it also prepares you to go back to the \\ village.
}

Let me tell you stories about the girls in this school Lorena. They are not only trained to get a job, they are trained to be what I could say: good citizens, to be mothers. Most importantly, to accept that they are not failures if they do not continue to grade 11, they can go back and help the community. We have a leadership course, I started taking it yesterday for this year, this course tries to make them know 'who' they are, and their potential. Because these women, they can be leaders in anything, whether they are leaders in their family, or in the workforce, in their communities. We are not only teaching them how to do maths and science. We are 
organising them so that they take responsibility over work parade, every working group has 10-15 girls and a leader looks after them. We don't have to be around to supervise them, they know exactly what they need to do. They have to learn to do things on their own, because in the future they will be responsible for a lot of different things. We train them to be responsible of liturgies in the church, they organise themselves taking turns in leading the liturgy and the singing. They organise their own devotional groups: the boarders and the day students, the non-Catholic, all have their own groups.

There are a few ways we prepare them to go back to the community. I am proud because all these years our OLSH girls are taking the lead. You go to the community and you will find an OLSH girl proud to take the lead in Catholic and non-Catholic communities. They are proud of the students that are coming out of OLSH. We can see that we are not only preparing them for a white-collar job, but we are also preparing them to be good citizens of their community. They also learn cooking, you see the girls chopping fire wood, you know we train them and tell them: "this is how you chop, because one day your husband is not going to be there to chop your fire wood, and you have to do it".

"Having spent all this time trialling the curriculum materials here with your girls, I know exactly what they are capable of, they are such a delight for us all, for our teachers and curriculum writers. We come out of the classroom with a massive smile on our faces, these are great women, great leaders, and their communities will be very proud, I agree IaEleonora Vigil". 
The story of your school, your dream IaEleonora Vigil, is nothing short of exceptional and inspirational. You support so many other schools, initiatives, people, even if they don't share your same faith or institution. Your school has become a strong village in itself, one that supports the wider community. I cannot tell you enough how honoured I've been to listen your dream put into words. To have the blessing of listening to the woman and the leader, and who is a very dear friend in my life. Ngalana boina tuna ToVarmari, your name is so true: you make everything beautiful!

In my husband's place they call me Warmari, and in my village my name is Varmari: 'to make something beautiful'. Warmari is a person with a lot of mercy, I am always proud of both names and I try to live up to them.

You do indeed!

By this time, I am in floods of tears, IaEleonora Vigil, Varmari, Warmari looks at me, there is beauty and mercy in her eyes, she simply says:

I am very proud to share this with you Lorena, tell you stories from my past experience. I only wish that my health could stretch me a little bit more.

IaEleonora Vigil passed away a year later, leaving behind a legacy of love, persistence and strength for education, for women, for her province, and for every single one of us that were blessed by her wisdom, guidance and friendship. The stories of a grieving and heavy heart sometimes cannot be written, so I am leaving this story here, as no words will ever be able to fill the space she occupies. 


\section{Tok stori with Talatala ToMorton Amos}

“We Tolai are educated people. Some go out and get big jobs after their studies, but you are to share the knowledge that you've gained.

That is development Lorena, it is sharing what you have acquired, and sharing is not only about money, you also have to share your experiences, your knowledge".

When I met Talatala ${ }^{67}$ ToMorton Amos and his Marama ${ }^{68}$ in Gelegele-Matalau, we were all sharing lunch on a Sunday after lotu. The invitation to sit down and tell stories with everyone meant that I was blessed enough to sit next to Talatala ToMorton Amos on that day. That Sunday was the beginning of a relational space that has been imbued with deep spiritual exchange and a kind of learning that regards every word and every story as a sacred component of our shared experience. And when I say learning, I indeed mean all of what I have been honoured to learn from this respected elder and spiritual leader whose loving, caring and selfless ways of seeing and being in the world, have become a legacy for his tribal relations and all the communities he has served for over thirty years as a minister for the United Church in Papua New Guinea.

One morning in the village mum IaIva said: "we will go and see Talatala ToMorton Amos today", and walked me to his home, which was not far away from ours. That day Talatala ToMorton Amos kindly sit down with me in the morning sun, surrounded by the sound of the wind rustling through the crowns of enormous tropical trees and those of the village-going-ons. We dedicated that morning to sharing stories about the holistic nature of education, and about the importance of cultural values, identity, relationships and a sense of belonging to ensure personal

\footnotetext{
${ }^{67}$ Talatala ToMorton Amos: Reverend.

${ }^{68}$ Marama: Reverend's wife.
} 
and collective wellbeing. "Because without respect, without relationships, 'one plus one' is useless" Talatala ToMorton Amos tells me, a long while into storying about the meaning and value of education for his people. "When you think about us all, it's about our relationships" he says, before delving into the sacred and relational nature of knowledge, wisdom and learning in Gunantuna/Tolai society. Knowledge, wisdom and learning are not only weaved with, but made of values of love, respect, trust and obedience which yield a sense of belonging and are built on strong kinship connections in this society.

Every story shared by Talatala ToMorton Amos possesses a high level of reverence and respect to those that 'made him', highlighting the intrinsic value of, and respect to kinship networks in Gunantuna/Tolai culture.

\section{Talatala ToMorton Amos}

I'm a minister of the United Church, Reverend Morton Amos, I'm married, I have five grown up children, they are already married also. Most of them are working, I have three boys, and two girls. My girl is looking after me, it is our custom tradition from our ples: one child or two will stay back at home and look after its parents. My daughter stays here, she went out to town today, I think she's coming back soon.

I have been working as a pastor for the United Church for almost thirty years now. I am back here in the village, due to sickness, I took my last posting in Talval Sikut up in the Baining Ranges, the environment there it was too cold for me, so I had to move back here to Gelegele. I'm helping around with the committee and the church activities here now.

It's a pleasure to talk to Lorena today. 
"Talatala ToMorton Amos I am so very honoured to be here today sitting with you, surrounded by these trees, sharing stories in your land, stories of the communities you have supported and guided for many years. We are here today in Gelegele-Matalau, the relocation place after the volcanic eruptions, but you were born in the origin Matalau".

\section{Life and education in Matalau and the impacts of the Mt Tavurvur eruptions}

I was born way back in Matalau, the original Matalau. I wasn't at home during the eruptions, I was working in another place, but I think the eruption was a setback for many people back home, most of us lost our homes, our crop trees, the things that sustain life. Some of the damage was done by the initial eruption, but unfortunately some people took advantage of this and broke into our homes and stole our properties, our belongings, it was very sad to know that our own people did this to us. During the eruption I was teaching at or local pastors' college in the North Coast, and my mother already knew, she already experienced the 1937 eruption, so when the earthquake came up and started shaking the place up, she knew that soon an eruption will take place. So, she moved our whole family, my brothers, sisters, cousins, and aunties out of Matalau and they went, they filled the big truck and went down to where I was teaching. Fortunately, my brother had a big truck, and my sister had a bus, so they put our belongings in the cars and drove to the North Coast thinking that it was safe down there, because the 1937 eruption affected only our Mt Kambiu community, and a few other villages, but this was more devastating than the last one. It really was a setback for my people, 
the shock of the eruption, and especially during the evacuation from home to Kokopo and later from Kokopo to Gelegele.

"Talatala ToMorton Amos, it was devastating I can see the layers of dust that buried the villages and towns, even now over twenty years later. Some of those buildings and places that are buried were schools, high schools".

We were fortunate in the Matalau region before the eruptions, we had the primary and high schools within working distance. We had a good road, it was all sealed down. We were very fortunate to grow up out of that type of environment, education wise, at the time we were privileged. It was also to the effort of our parents to make sure that we had to go to school, sometimes they forced us to go to school. If you went somewhere else instead, then you are in big trouble. We were fortunate, because everything was there, regarding education, and our parents encouraged us, especially in our culture, it was a very holistic type of upbringing, there were church activities, cultural activities and education. Our parents gave us that, they stood behind us and pushed, and said: "you have to have a good education". But unfortunately, today specially after the eruption there was a disruption for education. It took about a year before our children could start going back to school, the eruption disrupted the education system; it was not only those affected areas, everything came to a standstill here. At the time my eldest daughter and many other children were attending school, but after the eruption, education was called off and they stayed back at home for a year. 


\section{"respect to life must be taught to the children"}

"The focus and encouragement on education from your parents in Matalau was very strong Talatala ToMorton Amos, and you told me that it a holistic type of education, beyond formal education. I can see in people of your generation here that the values and respect to others, to the rules of the society, the koko, the wisdom from your elders and ancestors were very much part of your education".

Here in Gelegele, we are in a totally different situation, from my observation specially people from my generation, our point of view is that we see that the values we had, have gone down in most of the parents here now. Because our situation has changed. I tell you this, at home we had cocoa and copra, and at the time when I was young I was the one that according to our custom, while most of our brothers and sisters were working, and I wasn't, so I looked after my old father and mother. But we had cocoa and copra, so sometimes I used to walk around with 500 bucks in my pocket, I was not working, but we had money, during my young days that we were very lucky. Whereas today is not the same here in Gelegele, our style of living has been affected. For example, we had eight children in our family, most of them were working, I was the only one back home, so my mother or father, told me: "you go harvest the cocoa or copra". We also had a block at Tavilo in the government type of settlement, there I harvest cocoa, then back home I harvest copra, I had a lot of money after giving my parents their share. I could take mine and go enjoy myself, I was very fortunate, we were very lucky. I have been to a lot of places and I know my people are hardworking people, because up there at home, 
they grow coconut, cocoa. But today in Gelegele cash earning options are non-existent. This has affected the education of our current children.

Another thing that affects the education of our children is TV. At home we did not have TV, although they say it is a part of development, but without it we concentrated in our studies. But these people today they have TVs, phones, DVDs, movies; sometimes they start watching from 7 at night, until 6 the next morning. That's not good, from my point of view, you are bringing them up in the wrong way, they don't encourage them to study, they just leave them. Development as I see it is not helping our children and our education. For me education must always be holistic, respect to life must be taught to our children when they are young, because when they grow up their minds are blocked already. So, here I believe Lorena, if we want our children to be educated, it has to be from when they're small, not in the classroom, but back at home; teach them little bits and pieces of the basics of life, not to litter, not to make a lot of unnecessary noise, to discipline them not to go about. I have two small bubus, and I teach them to not throw rubbish around, if they see rubbish they take it and throw it in the bag. So that is the type of education we need today, teach them while they're still young.

"Talatala ToMorton Amos I believe that when you and I story about education is not only about what happens in the classrooms, it's about so much more, like the way you teach your bubus to grow up knowing about the respect to life, to environment, to nature, to their ples; that creates strong men and women. 
Knowing how to read and write are good skills but learning the values of your society and how to respect them is a vital part of education. Learning how to look after and work in the land in the way your generation did-you saw that as much as you needed money for your pocket you also needed love and respect in your heart".

There's is a big difference Lorena, as I've told you before, at home we had cocoa and copra blocks, but during the weekend, on Saturday, our father used to take us to the block to cut grass, there was no playing around, that was installed in me, that you have to work hard. That is what we need today, to teach our children in a way that they appreciate working hard, but it is hard nowadays because there is no land. So, they now go to watch DVDs, they just roam around, and they will continue doing so because there is no land to provide them with something to do in those weekends.

Lorena, it came to my mind when we were talking about education down there at lotu, education it's a way through, a doorway to knowledge. What we need is a holistic type of education, not only to know how to add one and one or spell 'b o y', there's more to it than that. We were discussing down there, and it came to my mind: 'education is an entrance, what we might call a doorway to life; because knowledge is there, money is there, everything is there, but you get there through education'. 


\section{The importance of respect, relationships and cultural values in education}

"Living here for a few years Talatala ToMorton Amos, I've seen the strongest kind of learning happens in the relationship between bubu and bubu. I see mum IaIva with her bubus, or you with your bubus, and how much they learn from you both. They're always watching you and they cannot wait for papu to come home to sit down with you, tell stories, do things, they are always following you around" (Talatala ToMorton Amos laughs).

Us Tolai have a unique way of ensuring that our relationships are always maintained. For example, before, if you are my sister, I will not wear your laplap, I will not wear your shirt; if they are cousins and they are sitting here, they will have to face another way, because this is tabu, it is sacred, but nowadays, that respect is not as strong as before. I believe this must also be included in our education, teaching them respect to their relationships is also education. Because without respect, without relationships, 'one plus one' is useless.

To maintain and strengthen those close relationships there are certain thing we can do through our culture. There are certain cultural things that bind us together, we have the sharing and breaking of wealth, of tabu. Our culture Lorena is always for the underdog and there are certain cultural obligations that make those ties strong. Unfortunately, nowadays those things are being abused, it's my personal opinion, I don't know what others will say. 


\section{Storying about migration and the sacred nature of place}

"Talatala ToMorton Amos you have provided guidance, mentorship and support to many people, so I am humbled by and treasure your opinion. Because coming from you it is more than just an opinion, it's a very strong guidance for people. You have seen the transition, the changes in your communities, through the devastation and the aftermath of the eruptions, relocating to this land with no mountains and no ocean".

My last posting was to Talvat which is in the Kombiu LLG, one time in our committee gathering somebody from the government came over and told us that Talvat will no longer be under Rabaul District, that they will transfer the powers to Pomio District. There was a lot of discussion, they were opposing this, because we people from Rabaul have our own very different culture. So, we stood up and said to them: "culture is manmade, so no matter you are from Rabaul or Sikut, your culture is still your culture". There will be certain aspects that will change a bit, but wherever we go, we take our culture with us. So, I encouraged them, and said: "our culture is always the same". Because Lorena you see here, us Talvat people speak a certain dialect, Matupit people, Matalau people, all three have different dialects although we belong to the smallest LLG in PNG. So, I told them: "you will be still speaking the dialect of Talvat, to honour your elders, if you continue to speak Talvat, your children, your bubus will do it too. But if you try to change your dialect, your culture, your dialect will be lost forever". 


\section{Land, relocation and our sacred places}

I studied Anthropology in the college, and I know that during the process of migration there are somethings that will change in cultures, for example back at home we have special places for our sacred meetings. One for Tumbuan, and you will not use your sacred place for initiating a young man, you will not initiate a young woman there either, you use a completely different place, this is tabu. But now that there is no land available here in Gelegele we use the same place for Tumbuan, initiation, for everything. But at home where we had land, our elders set aside these places for our cultural activities. Here I think to myself Lorena, during the relocation of my people the government should also look at these things and take them into consideration. The government should consider our need for land for cultural activities, as they are ought to take place. They set up places aside for community areas, but that's where the primary school is, they did not set aside any place for our cultural activities. That's why all these places are here, there and everywhere.

\footnotetext{
"It's not only giving people a place to live but allowing them to continue practicing culture as they do Talatala ToMorton Amos, I agree, for they are the pillars of your community.
}

One of the most important things are also our cemeteries, if we don't have a cemetery, it is a very expensive exercise to hire out many cars to go and bury the poor guy back at home. You were very lucky today Lorena, because I excused myself, that I won't be in a funeral, that's why I am so well dressed up you see, a guy died, he is married to Kokopo, but his relatives, took his body, that's our 
tradition. When he is alive he can spend his money with you, when he is dead you only want his body to come here and give him a proper burial back at his home. So, this is what has happened, this uncle, spent most of his life in Raburua along Kokopo Road, but when he died, his relatives went there and demanded his children, please release our uncle back to us. We have to bury him properly with his relatives.

"I hear they say that your bones always belong to your mother".

His wealth, his money, his house, they don't matter, when he's dead all you want is his body.

"He needs to be buried in his mother's land".

He needs to be buried with his mother, his maternal uncles, he needs to be buried with his people.

\section{"Beetles are beetles, they come back to where they belong" -}

"Speaking of returning Talatala ToMorton Amos, I have learnt that many Tolai people, specially those in your generation that went for further education outside, in Port Moresby or Goroka, or overseas, you always come back. It feels as if you always know that you will come back. I've heard from a few elders that said: "I come back to serve my people, to bring back to them what I have learnt".

We are educated people, some of them go out, and get big jobs after their studies, but you are to share the knowledge that you gained. That is development Lorena, it is sharing what you have acquired, and sharing is not only money, you also have to share your 
experiences, your knowledge. This is very important, some people, after spending 30-35 years working, they come back to our community, they go drinking they spend all their money, when the money is finished, they become beggars. Our young people have a strange attitude also, when somebody comes back from work, they will be friends to him, until the money is finished, and then they make jokes behind his back. Because when they come for holidays, they hire cars, go and have dinner in town, it is their right but, the local people will be watching and thinking: "ok, you can go back but the home is still waiting for you".

"You will come back".

You will come back again. I'm going to still hold my cigarette in here, until the time they will come back and ask me for this butt. (Talatala ToMorton Amos and I are laughing so hard it hurts).

"I remember you telling me that when they come back they slot right back in to where they belong in the village structure. No matter their degrees or their money".

Beetles are beetles, they come back to where they belong. Some of them are very good, specially Tolai people, when they come back for holidays, they contribute something towards the community church, they buy a packet of rice for their aunty, their uncle, they give 2 kina to their nephew, people value that; but if you just come and drink and drink and show off... 


\section{Knowledge, wisdom and education in Gunantuna/Tolai society}

"Talatala ToMorton Amos you have shared so much of what you know and have with your community throughout your whole life".

I warned you Lorena, you have to speak louder (Talatala

ToMorton Amos looks at me smiling).

How I see this, is that I have contributed a little back to the community. The community has done lots for me, I'm not here on my own, I am here because of the community. So, I think, what I have done sharing my knowledge or my experiences is only a small part of what the community has contributed towards me being up there. Because in our society, it is about the women, specially the old women. When you come back from school, they will have banana here ready for us, they will talk to us and guide us: "don't follow this, don't do that" they would say. The women helped me in many ways. Even our big men in our community when they talk, sometimes they have to be hushed, the women try to mould us, shape us into something. The old women are our home, beyond what we were taught in school or college, they moulded us, so we have to bring something back, contribute to them. The pioneers of education in the community are those that brought us up, and in my case, it was the old women.

I am here because of them, but in the community, they don't appreciate or acknowledge their contribution to us being up there. Sometimes they are degraded, disrespected, made fun of, but we never remember that they pray for us, they cry for us when our 
fathers beat us up. Wherever I go, people show me respect, but they forget I am here because of those women, our mothers. So, for me it is an honour to give something back, because I believe that all of this belongs to them. I share my knowledge with them because they rightly deserve it. It is a big challenge to see it in this way for many people that say to be 'educated' but cannot appreciate this.

Education is through our mothers, they teach us how to share, how to give, our fathers help, but it's mostly through our mothers. So now with through their teachings I encourage our people: 'teach your children how to give, when you prepare something, you tell your children, go give this to him or her'. I used to talk to the Sunday school children: 'if you have a small tied up firewood, give it to someone else'; we need to encourage the concept of sharing in our children, because it all comes straight back to you, when you grow up.

"Sorry Talatala ToMorton Amos for crying... It's an honour to be in front of a man, an elder like you and listening to the stories of your old women, your mothers".

Our mums leave a legacy with us - what they told us-, I am here because of my mother. Ok my father paid for my education, give me that and taught me how to work. But it's still my mother, what I am today is because of what my mother did through her prayers. You know Lorena, when I was small, the first voice I always heard was my mother's and the last voice was my mother's; she will wake up and she'll pray for us, and at night she'll pray for us, first and last. I used to tell my congregation, I'll never forget my mother because she was a unique person. Every time I woke up, early in 
the morning before she went up and prepared breakfast, I will hear her praying, and at night after tidying up, washing up the plates, we were already asleep, we will hear her pray. That was her legacy.

"I can see her legacy here with my own eyes Talatala ToMorton Amos"

I mentioned this before to you Lorena, nowadays I see how being responsible of raising a child is no longer considered as important. Parents treat their children like nobody's business. After school they throw the books down, go to play and nothing else before sleep. Without the women they are losing what we might call their selfesteem. Our children's self-esteem is fading away, waning, going down and down. So, 'education' is available to all, but learning is a matter of choice also: 'you accept education or knowledge', this choice is a person's responsibility now.

\section{Storying about development and education}

\footnotetext{
"Talatala ToMorton Amos, so the way we look after and support the self-esteem of our children now, the way we respect and honour our old women and mothers, will be the bases for a good healthy future. Is this wellbeing, is this development?"
}

Personally, to me development is developing a person holistically, I have to stress this Lorena: 'you have to be developed holistically'. We are not just talking about getting things like degrees, this is a very small piece of development. For me development is a person, and what I mean is that a person must be developed intellectually, culturally and spiritually. Because when the person is developed properly and comes to his youth, he won't be surprised, and won't 
go against things. He will accept positive aspects of development and refuse negative ones - those that destroy your community. It creates a good person who knows how to recognise the positive and the negative types of development.

The real development is about developing the positive areas of a person's life. To me Lorena, personally I am not against having big buildings, it might be a sign of 'development', but again for me 'development is a person'. We can rationalise things Lorena, you and me can go around and around, but it is through education, I think again the key is education. I'm not saying there will not be more problems, no... they will still come, but when you are a holistically developed person, even when you migrate, you know where to go and you know where you are going.

\section{Migration and extractive industries in New Britain}

When I was posted to work in Kimbe in the 60s and 70s, there was large migration done by the government for the oil palm industry. They took Tolais from here, people from Sepik, from Morobe and put them all together down in the settlements. Ok, it was good for the original people, they prepared for the 'pioneers', but what about their children? They did not prepare room for them, and now there are about four generations of settlers down there, and there's nothing for the new generations. For example, a certain portion of land is given to me as an individual, but none for my children, none for my grandchildren, none for places to conduct our sacred practices. This is an aspect of migration that we should also consider within government planning. Nowadays we have a lot of problems in Kimbe, in comparison to people here, they have rascals, 
drugs, holdups, some of which I believe was the government's making, because they only planned for the original settlers but not for their children or grandchildren. We are lucky here, because we haven't yet gone entirely to that stage.

"The thing with those oil palm plantations, I have seen the destruction that they cause to the people and the land. It is similar in Ecuador where I was born, all our land in the coast smells of palm oil kernel, we can't even eat in peace because of the flies that are attracted to the plantations, the land looks sick and our people working for them are in poverty. It looks like this industry doesn't care about the future of our peoples, they just care about making money now, right now. So, they give you a little place to live in exchange for what? Your heavy, dangerous, poorly-paid and arduous work and all the money you can make them.

"What are my people doing as part of the stock exchange? What have you done for my poor people I ask these multibillion companies?

I remember Lorena a place where they introduced oil palm to, when I was there I observed that when you work for the oil palm industry, you are no longer a free man, you are now a slave of the company. Because if they tell you to harvest on this day - you harvest, even Sundays a sacred day for us Christians; but if you don't work you miss out. So, they own your time, your life, many times when we have church meetings down there, the person will have to leave straight away, because today is harvest day. So actually, oil palm is all about slavery, modern-time type of slavery, 
where a company owns you. You get those overalls, spades, and they say that they give it to you freely, but oh no, it's been deducted off you pay. There's nothing free in our days.

"What future do they have?"

This is interesting Lorena, watching those settlers go to work, everything is being cut down. And I remembered when I left my people to go and work down in Kimbe, my people count 10 toia, 20 toia, this is ok, because the difference is that my people here have good homes; down there, they have 500 kina every fortnight.

"What is money if you don't even have a little garden to grow some food? I see in those areas nothing grows but palm oil".

So, I say to them: "you plant cocoa and copra because you can have good houses, buy good cars because of cocoa and copra, not because of palm oil". The different between palm oil and copra, is that around copra you can plant cocoa, you can plant buai, banana, daka, peanuts all in between the palms. Oil palm is greedy, everything is for itself, and now they are using those fertilisers, because the land's own fertilisers are so used up, that they are using these chemicals. We had a meeting down there and a person from the oil palm industry himself told us that the kind of chemical that they are bringing today is very powerful and very dangerous.

"Talatala ToMorton Amos, telling stories with the teachers I work with, and with people from all over the province, some from Pomio district, some from the Bainings, some Tolai, they tell me that these companies will not honour contracts with the customary 
land owners and come with bulldozers to ransack their food gardens, their villages and clear out land for the palm oil plantations. They also destroy sacred places, a teacher from Pomio told me the story of her ples, they had spirits that lived in the forest around some massive trees that grow there, those with endless roots that shoot straight down to the centre of the Earth. These spirits were their protectors, but after the palm oil companies came, the spirits were never seen again. Everything that belongs to the land and people is taken by the greed. As you said, I too see how both the companies and the plant itself are greedy, they take everything and don't allow for the life around to survive or thrive.

When I was down there in Kimbe, one big ship came down, a tank to collect oil palm, they had big tanks at the wharf. So, after the ship left one guy from the company came and told us, that that ship left with forty-four-million-kina worth of oil palm, and he said: "forty million is for the company, four million is for the people here" (Talatala ToMorton Amos laughs in disbelief).

"They told me that they promise them to pay for school fees for their children, roofing iron for their houses"

\section{Palm oil industry's scheme}

There are certain schemes there Lorena, they firstly introduced one for mothers: they pick up the loose fruit, they put them into bags, and when pay day comes the mothers get some money. But now they have also introduced a so-called 'pikinini scheme', so pikinini ${ }^{69}$

${ }^{69}$ Pikinini: (Pidgin) children. 
don't go to school, they will stay back to go and collect those loose fruit also. So, these children don't go to school because they are too busy picking up those loose fruits, they get money, but they do not think about their own future. So, there you see, the main benefactor is the father, then the mother comes in, and now the child also gets involved. (I can see in Talatala ToMorton Amos's face the deep sadness at what he has seen in Kimbe, he shakes his head and makes that unique Gunantuna/Tolai sound with his mouth that expresses disappointment, sorrow, a sound that contains infinite codes of emotion and one that speaks louder and clearer than any words can).

"So, the future for those families is focused on money"

\section{"We Tolai people are peace loving people"}

I see a lot of problems to do with this industry. Three weeks ago, a relative of ours had an incident, they came and chopped him up, put him in a bag and left him at his house. This is not the first time, this has happened a few times. We Tolai people are peace loving people, you know Lorena, if something happens here, we have policemen, the court system, and all of our people around. But down there is none of that, and see things like these: three weeks ago, one of our relatives from here was the one that they chopped up, later a small child was found dead in the palm oil plantation.

So that is another side of the migration for my people, they migrate to have money, before they leave they are told only some of the positive sides of the palm oil industry, but they don't tell them about the bad. 
"Tolai people are peace loving I agree Talatala ToMorton Amos, I have felt always so safe in this land with your people".

Ok, yes, we have problems here but not as big, we have people that shout out and make noise, but in comparison to other places, these other people - they mean business. They will never leave you alone until you are dead.

One of the ideas of putting people together in the palm oil plantations in West New Britain is to teach them to live together as Papua New Guineans, but they do not realise, that even though you go down there, you are still a Sepik, you are still a highlander, and not a 'Papua New Guinean'. So, the 'Papua New Guinean dream' is not being realised, because I will still live as a Tolai, or as a Sepik, I will confine myself to my cultural group and ways.

"That's true Talatala ToMorton Amos, because the country lines that were drawn on maps by the colonial powers did not take into considerations your cultural groups and your cultural ways of relating to each other".

Boundaries!

"Yes, boundaries Talatala ToMorton Amos, we see what is happening in West Papua thanks to those lines drawn on maps: a slow-motion genocide, the destruction of land and peoples by extractive industries like palm oil, mining, forestry".

Lorena, it is about respect. Sometimes specially here in Gelegele, we are closely related, but you only see us together at church, and 
community meetings, we tend to mind our own business. When something happens to my relative, ok, you will see us come together and show that we still maintain our relationship. We don't often see it but it is there, when something happens, you will see us coming together and sharing whatever we have.

"It is always that respect, I have learnt this with my time living here: everyone minds their own business, but everyone looks after each other at the same time".

In our custom, the way we call someone is important, you see when I mention Iva, I will never mention her name without a special edition to it. A token of respect, because we are siblings. I don't just call her Iva, no... it's always with another, what do you call it, title perhaps? My nephews yes, I call them by their names, but my sisters or cousins, especially on the mother's side, we call her name and then there is a little bit more..$^{70}$

To show them respect! (Talatala ToMorton Amos and I say this in unison, followed by some great belly laughs)

In our custom is like that, for example I don't mention my daughters' husbands' names, I only call him my in-law, my tambu, but not his real name because it's tabu. It's very strange that some people from other places in the region, even though we follow the

70 Talatala ToMorton Amos here refers to the Gunantuna/Tolai custom of adding the prefix Ia (for female) or To (for male) before mentioning someone's name to show respect to that person and situate yourself within the relationship. 
same custom, those people don't show respect to their sons-in-law and call them by their name. This is strange to me.

\section{"Counting coconuts is different from counting eggs"}

Just like with our names Lorena, one thing I admire about my society, is what you might call "technical terms", especially in counting. Counting coconuts is different from counting eggs, eggs have a certain name for 2, 4, 6, 8 but we have different names for 2, 4, 6, 8, 10 coconuts. But you never use the same numbers for eggs, as you do for coconuts, no.

"I' $m$ bit by bit learning what a very rich language Kuanua is Talatala ToMorton Amos".

And for tabu, our shell money too, we have certain names for different lengths of tabu. For one fathom, 10 fathoms, 100 fathoms, 1000 fathoms, they all have their own names for counting. So, for counting eggs, we use a term starting from 4 eggs, you say 'kevat'. If you say: "I will go and buy kevat", it means: "I will go and buy 4 eggs". For coconut, a evult means 2, nirait means 4; so, you don't go and get 'kevat coconut' no, kevat is only used for eggs. Even bananas, we have a certain way of counting bananas. So, 8 eggs is 'a urua kevat', that is 2 sets of 4 . It might sound like this: 12 is 'a utula kevat, that is 3 sets of 4; 20 I think that's a different type, I have forgotten it, hmm, I think it will fade away some day. Matupit people, because they live in the place where megapode eggs are breeding, they know it very well but the people from other areas don't, not like our grandfathers, they know very well. 
Bananas too, many people just call them bananas, but we Tolais, we differentiate between the different types of bananas. We have different types of banana for this or for that. You don't bring the wrong type of banana for this occasion, people will make jokes of you (Talatala ToMorton Amos laughs). We ask what is that banana? You can't eat it.

"Tolai have such strong cultural ways".

\section{Storying about identity}

This Sunday at lotu the pastor was talking about identity you remember Lorena? There I thought we should also touch on cultural identity.

"Yes Talatala ToMorton Amos I remember he talked about identity, and I agree that your identity is also made of the way you count bananas, the way you count eggs and coconuts, and the way that you know what to bring to which occasion, what to say in which occasion, where to sit when your tambu is around, how to refer to a person's name and how to behave in each occasion".

All people in the world have certain identities Lorena. I was walking in the streets of Kimbe and I came across these people, I didn't actually see them, but I heard them speaking our dialect, so I thought these are my wantoks, it bust me up, and I thought I have wantoks here! Specially our dialects ah, they are also our identity, when we speak this dialect, especially us Tolais - we can easily identify 'who' you are from. Through your dialect we know you are North Coast, Kokopo, Toma... 
"I know when we are waiting for the bus to come, mum IaIva is always listening to the dialect, if she hears it, she says, ok, we are going home".

Just because of our identity.

"I agree with you Talatala ToMorton Amos that education is the door and that as you said, it has to be holistic. It is not only about, one plus one is two, but knowing that one plus one, plus two, plus four, can be different in language, in tok ples (Talatala ToMorton Amos laughs approvingly). You know it's not only about knowing how to say: 'one plus one equals two', but knowing how many coconuts are in a set, and how to call that set. That's a kind of education that goes beyond the maths exercise workbook".

How many eggs I want to buy, and you don't say 4 eggs, no, we have technical terms for them".

\section{"When you think about us all, it's about our relationships"}

When you think about us all, it's about our relationships ah. How we relate to each other, the way we have certain names to call each other; especially with Iva, ok Iva is from this side and I am related because of our fathers, so that's a special term I use there ah. There are certain brothers, and sisters who are form the mother's side also. We call it turanakava, it means 'we came out of one set of brothers'. Maduk's children all call her mother, because you don't only have one mother. My wife, she has four other sisters, so our children don't differentiate between them, they call all of them mothers, mother, not aunty. The only way we can tell that they are talking about the eldest is because they will call her big mummy, 
another one is called mother Morobe, because she is married to a Morobean, but nothing will separate that real sense of 'mother' of 'motherhood' ah. We treat them as the same, with the same respect, this is very unique and very good.

\footnotetext{
"Very unique in the word I agree Talatala ToMorton Amos. If we had something like all around the world, I wonder how different things will be if we had something like this everywhere in the world"
}

Life is all about strengthening, everything we do is for strengthening our relationships. Ok, so I call him son, my younger brother or older brother's son, I call him my son, just like with my real son or daughter. An they consider me their father, they call me dad, they call my wife, mum. The same respect they give to their mother and father, they give to me and my wife, because there is no difference. It's very interesting specially when I go to Moresby, sometimes when I'm in town I will hear someone saying: yes dad, and then some will also call me grandpa, but I ... (Talatala ToMorton Amos laughs, with a confused look in his face).

But my wife is very good at recognising our people, and she will say: "these are from that cousins' side", she is very good; even those that she hasn't met before, she can identify them and she knows: this one is from this person's side or that person's side. So sometimes I am lucky when I go with my wife, because if somebody calls me dad, I talk the person and then ask my wife, she says: "aye don't you know that's your relative?" (Talatala ToMorton Amos laughs), she's very good at identifying those people. 
"An amazing woman she is Marama. I realise that one of the reasons I belief this is one of the wealthiest places in the world is because you have a cultural structure where you look after each other so much, so that you make sure that no one is hungry, or homeless, or sick. You respect each other and mind your own business, yes, but when something happens as you mentioned before, you are all there to help, you are always there. One night here in Gelegele I thought to myself: 'hey I never hear babies crying', in all the different villages and places I've lived in, you don't really hear little babies crying, they always have someone looking after them, they have all their mothers. They grow up not feeling alone but having a sense of belonging".

\section{"Thank you for collecting our degree on our behalf"}

I think in our society we have concerns with belonging. Ok, so if you are my relative, when you graduate with a master's degree we will see that as our achievement, not yours alone. We looked after you. The same happens when you buy a car, that is our car, even if we didn't pay a toia for it. I still claim that that is my car (we both nod and laugh out loud).

"And that's so good".

And your success is everybody's success!

"You don't measure individual success, who you are is because of the people who made you who you are". 
But I think that there is also a danger there, especially when you are running a business, if you think this is mine, then you go and get that tin fish (Talatala ToMorton Amos laughs).

"And a couple of lollies, and an ice block" (we both laugh).

I think that doesn't happen everywhere, they still pay for it.

"I think in the case of higher education Talatala ToMorton Amos, it is true, that it is important that that knowledge, that achievement is shared with those that looked after us".

\section{'The sacred is not for sale}

So, after you stay here, where will you go?

"Back to Aotearoa New Zealand for a bit, I'll go but then come back after finishing studies. Because we need to continue the work with mum, you know we just had the launching for the curriculum that we were working towards with the teachers, leaders and people from here. It was great hearing a few of the leaders during the launching talking about education. Saying that education should be about culture, about making sure that everything that is coming here is not going to exploit the people and the environment. That education should be about taking pride on being Gunantuna/Tolai, on being Taulil, Pomio, Duke of York, Butam, Sulka, Quiakit. That education is about values. Hearing leaders encouraging educators and students to see how proud and strong Tolai people are". 
When we talk about this culture, I see the government dancing sometimes, and dancing alone, is not culture. Nowadays the government is promoting 'culture', but in my personal opinion, culture is being sold. They are paying us this much, so that we will perform; if you don't pay us, we won't perform, - that is wrong, that is very wrong. But that is what is happening today, Tolai people are being paid to perform.

"Transforming your culture into something you can sell and buy".

In occasions when culture is sold I see especially how our dukduk are being abused. Originally in our society when they perform, they wouldn't do it for people who come to see it as a form of entertainment. Dukduks don't perform to entertain somebody, NO! They have certain roles and responsibilities in our society, they are not to perform for tourists that come to spend their money. But now they don't care about the fact that this is very wrong. I wonder if our elders realise this?

Before, they would appear only when a person dies, or when a person is a new dukduk ah. They will come and introduce it and then we dance to escort the new duduk at the sea for the first time. But not to perform for us, for the sake of performing. Those that do this have been blinded by money, and they have abused the role of the dukduk in our society.

"I agree Talatala ToMorton Amos, I saw in a few occasions this happening, but I turned around and left or hid behind something, because as a woman I don't want to see this. It's tabu ah. I see the 
tourists and the female ones wanting photos close to the dukduk, this makes me sad".

You know some of the males don't like me, because I speak against it.

"Yes, I could imagine, but I know also some good males like our deputy governor and MP for Education, Mr Cosmas Bauk, when he spoke at the curriculum launching he said: "we cannot allow our culture to be sold for a few dollars, yes tourism is coming here and yes we want people to come and visit, but that doesn't mean that we have to sell ourselves".

That is very true.

Our cultural and sacred practices are not for sale, they are more than a performance, they are there for a reason. For example, our Tumbuan oversaw our systems of family planning to prevent overpopulation, and they are responsible for the law and order in our society. Our cultural practices have all to do with our land and they ensured we maintained values like good hygiene and trust as vital for our society. We were a wealthy society, we were an egalitarian society. I remember the women in the market will leave the spots where they sell their produce unattended, and those that bought something will just leave the shell money in a heap as payment in the place where there once were bananas, coconuts, kaukau. We trusted each other, we were wealthy.

"Your cultural values and practices are your wealth" 
"The sun is getting you Talatala ToMorton Amos".

Ok, it's very good Lorena, very good you are coming here.

"Ngalana boina tuna Talatala ToMorton Amos for sharing your time and wisdom with me, I'm very lucky, I feel very blessed, I will get some water for you".

Mum IaIva is bringing water for us, we have spent quite a long time storying, when Talatala ToMorton Amos says to me:

I woke up in the morning, that man has died, and some people were telling me that I should go with them to the origin, yesterday there was a meeting. I said: "I'm sorry I won't be going today", so today I was getting ready to meet with you and I'm not feeling so well also, so my wife went, Marama went. I thought I have a commitment today, I will go and visit Lorena. Preparing to go, and tambu said Lorena is preparing to go, I was about to leave, and I saw you coming up. 


\section{Tok stori with ToHenry Tavul}

I have said this to you and this is from my heart: our Melanesian

societies do not have room for poverty.

Poverty was something that was brought in. Melanesian societies

historically, we were people that took care of ourselves, of our

relatives, and fellow travelling men.

There is always somebody, you were not to be begging on the

streets, you are supposed to be looked after by your relatives.

They are always there, there is land.

(Storying with ToHenry Tavul, 2016)

I treasure the giving of time by ToHenry Tavul to every story shared throughout the years, and honour the knowledge shared, from the public to the private domains of knowledge. I regard every interaction sacred, because as a young woman from the other side of the Pacific Ocean, sitting next to a Gunantuna/Tolai elder, leader and visionary man such as ToHenry Tavul, listening to his stories, is a sacred space of learning. I honour the stories that occupy that secret and sacred relational knowledge space and thus they will remain private, nestled safely within the nurturing womb of our aware and dutiful silences.

Below is an insight into the storying that took place one day with ToHenry Tavul, who kindly shared of his time and knowledge to support the deepening of our discussions and understandings of topics such as education, development and mobility. 


\section{"A healthy, wealthy and wise people"}

I work with the Department of East New Britain, with the

Provincial Administration as the Advisor of the Division of

Commerce and Industry. Today I am happy to be talking to you

Lorena about how best our people can organise towards achieving

our targets. For me as the person in charge of a very important

sector, we are changing the mindset of our people, showing them

that we can, and we are achieving a lot more than just waiting. So,

this is our target, and alongside the government, we are revisiting

our strategic development plan from 2011. The strategy

development plan for ENB government is that by year 2021 this

province should produce people that will be 'healthy, wealthy and

wise'. People that will be living in one peaceful community, no

matter if you are from a different province; as long as we are

writing and living the same language, appreciating the East New

Britaners 'as we call ourselves'; and enjoying and following the

directives and principles that the ENB government has developed

for its people.

In this plan we are also talking about education, and we are

revisiting issues such as: Is our education curriculum or extra-

curriculum or community-based curriculum achieving the goals

that will achieve the 2021 strategy plan? That is one of the biggest

challenges in our division, we also have the need of creating

employment, we need to be creating small and medium enterprises,

we need to be contributing to the gross-domestic-product (GDP).

How do we do it? We are talking to the PNG National

Government now that ENB is the national tourism hub, but we do 
not want to be greedy about this status. The challenge is: what can we do to link up our fellow regions? West New Britain, New Ireland, Autonomous Region of Bougainville and Manus. How can they come in and be part of the opportunities that are available?

ToHenry Tavul it is fantastic to see throughout these years how the strategy plan has come down to three specific and holistic targets: 'a healthy, wealthy, wise people'. Do you think that education will have the capacity to help the province working towards those goals?

\section{The so-called 'poverty syndrome'}

Absolutely Lorena! In order for us to create this wisdom, this wise knowledge, and to be getting people out of the syndrome, the socalled 'poverty syndrome', we have to be looking into how else we can be helping our people. The best part of this is how, we the people of ENB should be driving this, so that we don't continue to rely on others to do it, to make it happen for us.

Yes ToHenry Tavul, because I see that the wealth is here, the wisdom is here

It is here Lorena! I think a lot of people in the Pacific Region, including ENB, are pushing for autonomy, for autonomous powers, but you can never be truly autonomous is you can't make this happen, if you cannot stand on your own two feet. We want our people to have the wisdom, to think right. We want them to be healthy, because we need a healthy workforce, and then when these 
two are working hand in hand, you will develop a lot of wealthy people that will not have to go to the extent of begging.

ToHenry Tavul, I agree entirely with you when you refer to the so called 'poverty syndrome', because is not, it should not be a reality among such healthy region and people.

It shouldn't be! Lorena, I have said this, and this is from my heart: the Melanesian society does not have room for poverty. That was something that was brought in, I don't know, to attract the funding. You see it come in and quickly gone. But it is only promoting people to rely on others to feed them, Melanesian society historically, we were people that took care of ourselves, so we had no room for parasites.

ToHenry Tavul, I think these are some of wisest and most educational remarks I've heard about Melanesian society: 'there is no room for poverty here'.

No, there is no room Lorena, because we took care of ourselves, we are supposed to be taking care of ourselves, of our relatives and fellow travelling men. There's always somebody, you are not to be begging on the streets, you are supposed to be looked after by your relatives. They are always there, there is land.

ToHenry Tavul, throughout these years I have come to learn that Melanesian people are some of the only people that still have land, I mean land not simply as a commodity, but in the way of customary rights to land. Land as 'ples', as home and family, as a sense of belonging. 
We talk about land Lorena; Melanesian societies had the best! But when 'development' came into being, we started to have strong influences, they told us: "you are poor, you need to accept this programme to come in". I don't understand why we believe this, there is so much land here, people worked the land to the best profitability. So here is where the wisdom must come in, the wisdom is now in educating ourselves and our people to leave those beliefs behind. There is no need for us to believe that we are poor, that we need programmes to come in from the outside. For them to come and tell me: 'Henry you are poor', I can tell them to go and jump. And here is when education comes in, for teachers are supposed to be the influencers, the agents of change. They tell us what we want to produce for our people.

\section{"We have all the chocolates you want" - ToHenry Tavul on 'development'}

ToHenry Tavul throughout these years I have been honoured to be able to learn from someone like yourself, a highly respected member of the community and now the head the Division of Commerce and Industry for the province. For me, it is a gift to be able to sit down today with a respected Gunantuna/Tolai man and leader and hear these words: "development has tried telling us that we are poor", then what do you see development to be? What are the objectives of development here, in your ples?

Lorena, I think it depends, because development partners come in a package, and they will come, and they will tell you: 'we have all the chocolates that you would like to have' (ToHenry Tavul laughs) 
They will not tell you though, that in the chocolate box, they also have some ginger. By the time you've realised that there is ginger and chilli and whatever else they want to put inside - they will be gone! This is what has happened since independence in 1974 and to some of us that have been around, we have gone through some of those experiences.

Yes, I relate to this ToHenry, it is literally like they bring the chocolate that they think you so want to have, and we don't realise that they used our own cocoa to make the chocolate. This is also what happens in Ecuador, you know, where I was born.

Thank you, there you are Lorena! I mean, we were told the same thing, we were even told: 'you can't plant rice, you can't sell bananas' (ToHenry Tavul laughs). Look what is happening now, we have export potential. For ENB, cocoa and copra have been our life line, ever since colonisation came into being, from the German administration to the Japanese invasion, to then, you know the rest... But we have been able to build this place based on these two commodities. We don't have the gold, we don't have the mines, but yes, we have cocoa and copra. And the best part of this, is that we are lucky to also have the wisdom, the power to make decisions based on changing situations, we look at realities, and we talk realities rather than... (ToHenry Tavul looks at me and we laugh together)

ToHenry what I've learned living and working here among Gunantuna/Tolai people is that, you look at those 'boxes of chocolates' that development and aid programmes come packaged 
in, and you say: 'ok, I like this flavour, but you know what, you can take all of these other flavours back'. And that is a very powerful way of engagement.

I think in the past Lorena, [during colonial times] our people weren't yet educated to see this clearly, maybe they had to do it out of... So, they gave way into our land for plantation 'development'. But now we are saying ok, we can develop our own!

Nowadays, maybe we can partner with some of those development partners, to make things happen the way we want them to happen. Then it comes down to the education. Yes, there are approaches to make it universal education, standard based, outcome-based education or whatever, but the bottom line is: are the people really benefiting from it? This is the biggest challenge that we have regarding education and development.

\section{"This is who we are, this is ENB"}

ToHenry this brings me to think about how mobility is affected by all of this, as you said, there is a big push to bring people out of poverty, or what they call "poverty", and one of the things that I have seen around the world is this drift from the rural to the urban areas to access employment and education opportunities. During my time working in education here in ENB I see how our young ones feel and think that going back to the village after their education is somehow a sign of failure. I remember telling stories with you a while ago, and you told me how important it is to have people in the village to bring us back; so that when anything happens, you have them there, supporting you. 
Lately Lorena, there has been a lot of discussion about migration, and we are thinking that because of the way ENB has been developing, we seem to be attracting a lot of migration from other provinces. When they migrate here, they bring in their different ideologies. They come and ask us: 'goodness, what kind of people are in here? Too neat, we thought we were in New Zealand or something!' (ToHenry Tavul laughs). We tell them: 'no it's something that is happening right up here and coming out of here'.

And when its coming from here, no matter how many copies you will take from whatever document, it belongs to your locality. Because you need to have that combination: 'the mind and the heart'.

This is something that I can say, that we in ENB, we can tell you, we accept it: 'this is who we are, this is $E N B$, where there are things that brings us up this way'.

This is why a lot of our people that make it through to higher learning institutions, they feel comfortable going back and working in the land.

\section{Education and mobility}

So, Lorena, when we are talking about education, we know that it is about coming back and showing up; also, about developing the right curriculum with the right principles. Because when we continue to migrate to other places, we are not going to make it, the change happens for us here. It's taking ownership of the situation and saying: 'you are on'. 
Yes, ToHenry I have heard of many stories of people from here that have done that. They have gone out, and even those that found carers or jobs outside, they always end up coming back.

Yes! For our province that is right Lorena and you've seen it. I mean I worked for almost thirteen years outside of the province, before I came back. I was a freelancer in so many fields: trainer, educating people from TVET high schools, developing educational programmes such as Start Your Business (SYB) and Know About Business (KAB). I went all the way to Indonesia, Italy and even to Germany to bring back what we have seen. We cannot replicate exactly what is there, but the challenge is: how can we make it happen on the local context, and based on the local environment?

We don't have to be like others, for example we cannot say: 'we need to be like Germany', no, Germany went through a lot and we have seen what it leads to. Learning this I think, is a big plus for our own people, the people of ENB. This is why Lorena, when I left the public service I decided to have exposure to a different world. If we do not have this exposure, it is like imprisoning your thinking and imprisoning your capabilities, the sky is the limit! Attack the sky! I mean go to Mars, go to the end of the universe! And when we are talking about education, we have policies, directives and principles that are established in the name of 'development', but a lot of times they imprison us, they catch us, so that people don't become enterprising, about how they, how we should see life! Get out there, enjoy it, and see what we can get out of the world. You will never appreciate the world and what you have if you don't get 
out there! Every individual in this world is different, I cannot be you, we can't all be Lorena (ToHenry Tavul laughs out loud).

Well, ToHenry, all you need is to have a really weird accent and very very long hair, that's all, em tasol (by now we are both in tears of laughter).

I always have this image in my mind ToHenry: I have seen Gunantuna/Tolai people taking their baskets everywhere they go, around PNG and even in other countries; as if they were carrying their village and their lives in that basket, as if it was a constant reminder that they will return to lie that basket down in their ples again.

Yes Lorena, for us in the province, when you go to another province and you see them holding that basket you know what it means: 'I am my origins!' 'I'll be here for a while, but I need to go back to where this basket came from, literally speaking, we are not saying it out directly, but seemly, a basket on a hand is saying: 'I am from ENB and I want to go back to ENB'. As the story goes, there is no better place than home! I mean what else can we say? Where are you going from here? Of course, I am going to Kokopo or Rabaul, there is no better place than Radaz ${ }^{71}$ ! (ToHenry Tavul proudly smiles).

\footnotetext{
71 'Radaz' is the name given to Rabaul town following the Tavurvur volcanic eruptions in 1994, and it refers to the presence of dust or ' $d a z$ ' (pidgin) that originates from the subsequent constant volcanic activity that produces volcanic ash and descends upon the neighbouring villages and town.
} 


\section{"Can education help to fulfil that basket?"}

It is supposed to Lorena! I mean, if we look deeper into the values, the statues of education, it is supposed to be the tool that you use to make that happen. Education should be the most appropriate, it has to be right, because sometimes we can be teaching the wrong topics and the wrong subjects, or we can be teaching with generic materials that have no relevance to the local environment. We can be wasting so much, we can be travelling at a thousand miles but what for? If you can get there travelling at fifty miles an hour and enjoying it! In the case of ENB, I was engaged in almost 15 years of education institutions and two programmes. But I saw that a lot of curriculums and handbooks are developed from generic materials here in the province. We need to supervise this, as we cannot use African materials here per se. We need to make education, a Papua New Guinean education. So, for us in ENB we need to start speaking in this way. This is what ENB would like to see happening.

\section{Economic development and education}

ToHenry, you used to work developing some of those programmes alongside mum IaIva Magaga. You, the visionary people in education and development have together carried that thinking for decades. You collectively asked: why do we need to copy something from Africa or Australia? from anywhere? If this is us.

We had forgotten how long we've been storying by now, so food (aibica and avudu) was being kindly offered to us inside our friend's home. 
Yes Lorena, and this should be a challenge for any good thinking Papua New Guinean. We have the national PNG vision for 2050, we are talking about broader issues here. And of course, we have the SDGs targets, and the ENB provincial targets which are set up to be achieved before 2030. For my division, we are working to ensure we are part and parcel of facing these challenges and achieving these targets. We are connecting people to financial institutions, so I came up with the idea of creating the microfinance institution of Kokopo, of which I have been chairman for over 10 years. I wrote that particular document, using my experience in education and finance. We started with PGK 250,000 and today we are talking about almost 13 million kina, serving up to 30,000 members. Not only from ENB, but from New Ireland, Bougainville, and we have automatic tailing machines. If the big players can make it happen, there is no reason why the smaller players can't. We can make it happen for us, this is the message that I want to put forward, to challenge development: 'Whatever the elephant can do, the ants can make it happen better!'

Now my sector and division have developed a provincial planapart from the national small and medium enterprise (SME) policy-, we are waiting provincial endorsement for our own SME policy. We don't have to wait for the national side to tell us what to do, we are making it happen here!

Those are great news ToHenry, because worldwide, one of the biggest issues with achieving global and national goals in anything from education, to economic development: is that they are so generic and not specific or relevant to certain localities. 
Yes Lorena, a lot of times they don't apply to the local

environment, because of development partners that come and tell us: "you need to do it this way, exactly this way". It takes away the enterprising ability. It's like caging me, like throwing me into a cage with a monkey, and telling me: "you belong in there and you don't belong outside in here.

So those are the challenges we are facing and if we are serious about education, this is an educational problem. Let's talk about financial literacy. Let's ask ourselves for example: how we make hospitality and tourism contribute to the livelihood and the survival of the simple person here? We can make it happen, why should we wait for people to come and tell us how to do it? We are challenging our creative thought, we forgot our thinking caps, we need to do something that we value.

Sharing stories with a Gunantuna/Tolai leader reminds me always of who holds the wisdom and the future in this land, in this ples. Boina tuna, ngalana boina tuna.

It is a pleasure Lorena, all the best on your work, on your thesis too, you will become an even better person for education.

Let's go eat! Let's go eat! 


\section{Tok stori with ToGideon Turpat}

"This is our home ground, education is our land, our land is our education.

If you've no land that you can cultivate, but you have lots of this (ToGideon Turpat points at his head), then you are lucky, you can earn your life.

From the beginning I told the people this story: 'push your kids to school, encourage them to have as much education as possible, that's your living, if you don't have land, education is your future'.

If you've got no land, your education is your land".

I had the honour of meeting ToGideon Turpat on a Sunday, at lotu. I was living with mum IaIva Magaga in Gelegele-Matalau village when she said to me: "you must meet ToGideon, he knows so much about education, he is a very important elder here, with decades of experience in education, he will have many stories to share with you". So, that Sunday after lotu, mum introduced us, and so we started telling stories about education. These are some of the stories shared with ToGideon Turpat one day at his home in Gelegele-Matalau. We storied together about the meaning of land and education, about the complex and sophisticated Indigenous systems of learning, family planning, governance and law and order that were in place before colonisation in his ples, about his vision of the future of his people's well-being and education. 


\section{ToGideon Turpat: early memories of education}

My name is Gideon Turpat, my father's name is Polly, my mother's name is Emma. Big boss [father] died one day in 1943, and mother died in 1950. They left me as an orphan boy.

I tried my best to go to my early education, I went to primary school in 1947 in Matalau, I went to high school in 1952 in Kerevat and stay there for 3 or 4 years.

Because the education department needed somebody to be a teacher, they asked in the classroom who wanted to go, so I went to do my training in 1957, in a college around here. A year later I had my first job as a teacher. Since 1875, there was a little education classroom at home in Matalau with missionaries, they were the first ones to teach here in Papua New Guinea. In 1932 they built a big classroom, this is a long time ago isn't Lorena?

I remember the old people, they went to the school at home in the origin, in Matalau. That school that started in 1932, was the first school in PNG, it was here in my home. My uncle went to that school, a teacher Mr Waterhouse taught him everything, it cost nothing, no money. I told Morse code to the young ones last week, my uncle taught me, he knew it and used it in the war. Once upon a time, when we were sitting at home and somebody was working busy in telecommunications, he was beating a box of matches, his friend was replying to him, he also knows Morse code. Everybody was surprise about what they were doing, how they were communicating. 
That school formed a lot of very good people, one became a police officer, another was in telecommunications, there were teachers also. My uncle was the second in the list of local teachers in the whole of PNG, the first one was from Kavieng. There was no teacher college, but they both were trained by Mr Waterhouse, at home, with a few expatriates who worked to educate these people. They were living in the hill, all coming together to teach, lots of people from other places around the area will come to Matalau to get their education here, they came from Matupit, from Rabui.

A year after the school started in 1933, when I was a little boy, my uncle was the appointed class monitor. He slept near the school, with his wife, they had no children. His wife went and got me from my mum, sometimes, during school times, I still remember sitting with them, they gave me lollies (ToGideon laughs).

When I started my primary education in 1947, I remember with the other kids, we had no much concentration, we didn't know much about education, we felt that education was not good for us. So, our parents used to force us to go to school. I was pressured to learn English in those times, if I speak my own language then I got to be punished, the education department mandated for us to speak English. Way back on the day. 


\section{Indigenous systems of learning and governance}

ToGideon, this is something I have only asked mum IaIva before: what was education before the Europeans came?

There was no education.

Hmm, education back then, was a classroom with a house (taraiu), a classroom while talking, you have the diary in your head, what I say you write it down in your head. That's what they used to do, telling stories, sitting here with people saying something. You know, instead of writing it down, you put it in the mind, that's what they used to do.

Everything is done in a secret place, everything taught to the men happens there, the old men will teach the young boys. They guide the young men through initiation, they celebrate them when they get married, in the secret place, not at home. Everything was done out there in a secret place in the bush, until the Europeans came here. It was hard for our old people to control this, they didn't realise that things will change: the education of what is right and what is wrong, the law and order that came with Tumbuan - they were changed.

But even in those times when the missionaries were here, the law and order was administrated through the secret place, through the Tumbuan. People have to obey the Tumbuan, for they are law and order. Tumbuan says: "don't rape, don't get married to two women, don't steal, don't fight your kid". If you disobey these laws, this will be dealt within the secret place, and you have got to be punished by way of compensation with tabu, shell money. Tabu 
is valuable, and in those days, there was little of that around. So, if you have 4 or 5 fathoms, you are rich! In those days you could buy a wife, you have enough to pay for her bride price with 50 fathoms.

Tumbuan, they are the judge, the magistrate. You got to be very careful, no matter who you are, if you are getting into trouble, if the Tumbuan hear something about you, then you will be caught and taken to the secret place, to be judged. The trial happens in the bush and the Tumbuan must be obeyed, it must be followed. You must be killed sometimes, if you disobey. It was very strict.

This happened until 1875 when Dr George Brown ${ }^{72}$ got to ENB. I don't know about other provinces.

But the Tumbuan has still lots of power now, the Tumbuan say: "men mustn't fight or belt his wife, or his children, or have some quarrelling at home, because some sort of judgement will come on you. Payment must be now, not tomorrow, because something will happen to you". This is immediate justice and definite.

\section{"The more you give, the more life you get"}
"I wonder how I am like this?" (ToGideon Turpat says
watching his bubu ${ }^{73}$ sleeping next to us).

I'm 83 years old now, you live longer when you do good things for other people. So, I have lived longer than many other men who passed away because they didn't look after their wives or share much with our people. This is something for me to boast about. The

\footnotetext{
${ }^{72}$ George Brown: British born Methodist Church missionary throughout Polynesia and Melanesia.

${ }^{73} \mathrm{Bubu}$ : (Pidgin) grandchild and grandparent.
} 
more you give, the more life you get. And life in the jungle was better than living in the town, you get the food from the ground not from the store, everything is free.

"Yes ToGideon, I see many of the elders here, you are strong mentally and physically. How do you teach the young ones now, in this time of fast technological change? How do you teach them what is right and what is wrong? How are they going to be strong like you are, like the elders are?"

Well you see, it is not about trying to stop them from using mobiles, because this is hard. I tell my bubus, go get a book, sit under a tree to read it, instead of pressing a mobile: 'it is a bad start, with a bad end'.

I think to myself: 'what about we invest with the government on getting books for them? Instead of saying to our young ones: "stop using your phone"', we need to provide them with options, something like a library right here in Gelegele. What I think about is the future of my bubus, they will appreciate this, the options that I can offer them, the education I can give them.

"ToGideon, how did this, your long life of devotion to education begin?"

In a high school, that was only a grade 9. This was my first teaching place: in my home land Matalau for one year, then the inspectors sent me back to Vunamame. I taught in Vunamame Farmers Training Centre, later wanted to go and teach somewhere else than my home, so I wrote an application to the education 
department and they accepted me to go to Manus Island. I stayed there for 4 years. I worked with an ex-patriate there, it was very good.

Then I went back to Rabaul in 1963, where I had some postings around some schools. After 4 years, the education department sent me to a teachers' college for 5 months where I piloted a science syllabus for 5 months, with some other ex-patriates, Catholic brother ones. Thirty teachers from all over PNG were piloting this science syllabus in 1968.

My last posting was in the 1970s, it was quite remote and inland. The school I was teaching at was far from the beach to the mountain. I had no week off, you have to work and work, it was a hard life. I got very sick, no sanitation or way to properly clean, there was very little.

So, in those days, I lived on herbs, my olds fathers taught me how to squeeze the leaves and drink it, that's what they used to do in the olden days, there was no clinic or hospital anywhere, they use only herbs.

So, I finished from the Education Department in 1981, I resigned and stayed at home. Some people asked me to be their administrator, so I went, and I did that out in Rabaul, and after 4 years I resigned again. Later I worked under the education department for one year until 1994 when the eruption happened. Then and there, I finished with the education department and stayed with my people, I helped them in the community, I built a church, a house, I restarted the school again at home by myself, 
there were no other people helping me, only me. (ToGideon looks across the room as if those memories were being projected on the wall in front of us, he humbly smiles at every scene played).

"I didn't mind them", he continues.

When I feel hungry, when I had no lunch for me, I will have what was there: bananas and coconuts. That's what I saw from my old parents, they worked for nothing. (A loud knock on the ground with his walking stick stops the projection on the wall and brings us both back to ToGideon's home).

"I see this in a lot of the elders I have the honour of knowing here, and just like you ToGideon, you all work for nothing, and you all work hard."

We give with no complaints. I don't like complaining (he firmly says).

\section{Education in the aftermath of Mt Tavurvur volcanic eruptions}

"I remember ToGideon, when we started telling stories after lotu about your experience when the eruption happened, and you remembered how everybody ran away"

"Yes, Lorena, everybody, big people, small people, everyone!"

I asked somebody to help me bringing the disabled people to the boat. So, we got them to the banana boat and then brought them up to another ship, there were big sea currents, some of the boys swam, they took hold of one side of the banana boat and swam. So, after 
helping all the disabled people to get onto the boat, I told them: "ok, now that everybody is in the boat, I won't be going with you. I will stay here for some days and I will come out after". They strongly asked me to go with them, "you come with us" they said, "you helped us, you come with us". But, I stayed for another three days, Monday, Tuesday and on Wednesday, I came to Kokopo.

The eruption went on, and when I arrived to Kokopo I carried the old women from the boat to the bridge. It was a sorrowful day for all my brothers, some went to Kokopo High School, where is now the BSP Bank, that was a show ground before the eruption.

"Is it there where they put all the tents up?"

The government gave us some tents, not enough for all of us. I slept in my own tent, everyone slept in their small semi house, but I slept in my tent until we came up here to Gelegele in 1996. The missions gave us rations, some rice and meat. I coordinated its distribution, I had a book, I was talking through the loud speaker, saying: "you don't take that, you do this, you do that... put up a little tent here or there".

"What happened with education at that time with no schools running ToGideon?"

I strongly decided to bring the kids to an education, to a school. So, I went to the big people in the government and asked them to spare us a little place where we can have some teachers working with us. So that we can continue teaching the little kids, that was a hard time for them and for us. We had no proper places to teach. 
I was the chairman at a community school at home in the origin Matalau, so we came up here to the relocation place in GelegeleMatalau in 1996, I went to Kokopo and I asked those big names to provide us with a truck, so I went home to Matalau where our own school was before the eruptions and took the desks, the books, everything. I started teaching the kids up here in Gelegele-Matalau. Everyone was wondering what to do, because the department didn't think about us, didn't help us. All those years after my retirement, I went back to be a teacher because I love the kids. (The sound of ToGideon's walking stick against the concrete floor presses the play button again, and that wall in front of us becomes alive once more with memories, he continues...)

A father from Vunapope, the Catholic Archdiocese of Rabaul came and helped me. So, I started the school here and looked after it for 20 years, when I decided to resign. I thought, I better resign and let somebody come in and take my place.

That's my life... (The strong, conclusive and proud knocks of ToGideon's walking stick make every memory projected on the wall remain still, yet numinous)... you love people and then leave it for other people that have a fresh mind to take over from you, to help evolve the education for the kids.

\section{Bringing education back}

"Mum IaIva told me stories about you ToGideon bringing back the school to the origin Matalau"

I started the school back in the origin Matalau in 2004. I built up two classrooms and one teacher's house with the help of our MP Dr 
ToAllan Marat. I told our member: "I want my school to reopen next year" and so, he helped me. I wrote the invitation to big people here to attend the reopening of my school. We thought grades 3, 4, 5 and 6. The school had only two teachers and a headmistress. I found accommodation for a lady teacher, and the other two used to walk all the way to Kokopo and back to school. So, I told the lady: "I don't mind if you come late, I understand the situation".

Before the school was built again, the children out there in the origin Matalau, used to walk a long way to town for their education, from the origin, to Rabaul there are about 26 kilometres, I'm afraid for them. So, I talked to government representatives at the time and told them that I was afraid for their safety, specially of our girls and women and said to them: "what about a school? Can you build a school for us?" They didn't say anything. So, I built the school from the ground up, I got a carpenter, I told him: "come, you will be paid, I will go to the district office and tell people to pay you to build away". I thought to myself: "I am not going to write a letter, I'm going to write a letter with my mouth". So, I did, and we built the school.

I did write a letter though, it was to one of the INGOs, the Rotary Club, asking them to help me with more desks, so they provided those to us. They were very nice desks, better than the primary school ones. I told the children: "these are your desks, you don't have to write on them, you don't have to drag them on the floor, if you want to move them, lift them, and move them, don't drag them". So, they did. 


\section{"They thought the sea was a river"}

"ToGideon, do you think good education in the origin Matalau, will help people that want to go back to the origin? Because I can see here in Gelegele, soon there's not going to be enough land for everyone"

No, is about more than education alone. It seems the government mustn't have seen our situation. We are building up big buildings here in Gelegele-Matalau. What is the government going to do to us now? Because when the relocation happened the government told us that this was a transit place. They said we will be here for only 5 years, it's not 5 years, it's more than 20 years now, you can see it Lorena. The environment here is not suiting us, that is why there are so many people losing their lives here, you see: 'we are people from the beach, we are not from the land'. Now there are people that are starting to move one by one back home to the origin Matalau and they are planting cacao.

So, talking to many of the people here in the relocation place I told them: "let's ask the government what it is going to do with our properties here in Gelegele-Matalau?"

We can go home back to the origin Matalau, we've got land at home, we can go. But we have two places that are our home and are responsible for both. I tell you this: I had my house back home in the origin Matalau, a big building, but when I came to help start the school in Gelegele-Matalau some people broke into my house, they looted everything, pulled the timber and took it, my home is so damaged by it. I had my house there. 
"Sorry ToGideon, this feels as a double loss, first it was what the volcano took away and the rest was taken by others".

Yes, it was a big loss. It should take time for people to rebuild themselves. Well it is of course about money nowadays, money is the problem for people. Our crops were destroyed by the volcano. I lived back home in the origin Matalau for 6 years after the volcano eruptions in 1994. I went back home, I built the school, I lived there for 6 years. While I was there I started to plant new coconuts, they were coming up to bearing fruits by 2004-2005, but then in 2006, when the second volcano eruption happened, we moved back here to Gelegele-Matalau.

I'm ready to go back but I've got no house back home, I've got no house. So, I'm not going back now. I told my kids to build a small house in Matalau for me, so I can stay there for a week and come back here to Gelegele-Matalau.

"ToGideon I have heard stories from some elders about copra and cocoa, they told me that when you were young, you tutana ${ }^{74}$ worked on the land then when they were ready go and collect them and it'll bring some income to you".

I am one of the land owners, I've got a big mass of land, the land of my clan, I am the leader of the clan. It starts from the beach up to Mt Kambiu. So, I told my little ones: "go back home, money is there, you plant cocoa and coconuts and sell the coconuts for their

\footnotetext{
74 Tutana: (Kuanau) man
} 
meat by the volcano. There are in our land, go and collect your coconuts and sell them for your pocket money".

"The young ones that were born here inland ToGideon, they are used to living in the relocation land, by the town. I hear that some of the young ones here don't know how to swim, going back to the origin by the beach might be hard for them".

Let me tell you a funny story Lorena, we brought some little ones to our home in the origin Matalau, and we went down to the beach, we walked along the beach and found some coconut shells. They sat on the shore and they started taking water with the coconut shells and pouring the water on their heads. They thought it was fresh water, they thought the sea was a river or what? So, we began laughing. What you describe is quite true Lorena, many of them do not know how to swim anymore.

"ToGideon, I hear people telling stories about how land is becoming more and more scarce to accommodate the population growth here in Gelegele-Matalau. What is going to happen to the next generations?" There is land by the beach back in the origin Matalau, but they don't know how to swim"

We would like the government to give us a lease on this land in Gelegele-Matalau. We can do things thinking of the future; we start slowly to move back to the origin, stay there for a week or two weeks, and then come back here. Because if anything happens again with the volcanoes, this time at least we have a hiding place. 
I told the people: "don't try to all move back, if we move away from this place, new people, new faces will come in and take over from you; and you will have no place, some of you might have no ground at home, no land. You will be only a migrant from Matalau". If you have got your plate, your cup, your spoon in here, then the government will not take this land away from us, because we have our land, our second home in here.

"Living here with mum IaIva, I was thinking about this relocation land, how they gave this land to the villages affected by the eruption. But ToGideon was there are a plan for this land to have a place for schools, or for sacred places?"

The government promised to give us that space, but we have been waiting too long now. Our member is working hard to help us, Dr ToAllan Marat is trying his best to find a land and buy it for us, so we can grow our crops.

\section{"If you've got no land, your education is your land"}

"Graun em laip (land is life), I see these words everywhere here in East New Britain, but what will happen to some young ones

ToGideon, to those that do not have land?"

Well, one way is encouraging our kids to have an education.

Lorena, this is our home ground, 'education is our land', do you see this? If you've got no land that you can cultivate, but you have lots of this (ToGideon points at his head), you are lucky, you can earn your life. From the beginning I told the people this story: "push your kids to school, encourage them to have as much education as possible". So now, many of us are going to university. 
That's your living, that's your future, education is your future: 'If you've got no land, your education is your land'. There are a few people with no ground, they've got no land, the only thing they've got is this (ToGideon Turpat points at his head again).

Storying about land, ples and their importance to the wellbeing of our people, I find myself sharing my own stories in front of this respected and wise elder. ToGideon Turpat encourages me to story about the places that have seen me growing up, so I share precious and sacred stories from Ecuador, and some from Aotearoa, these stories belong to our private relational space. Yet there are some other stories that can be written today.

I feel interest Lorena; how do you compare us to New Zealand?

"You have your land, you have so much ToGideon, you have your land".

I have heard that governments take lands from their people, does that happen in New Zealand too?

"Yes ToGideon, as you know the Indigenous people of Aotearoa New Zealand are the Māori people. I have been honoured to learn a bit about their history from a few Māori leaders and educators in the many years of my life becoming a woman in their land. I learnt that through the expansion of the British colonisation on Māori land, which started over 200 years ago, - and even though a treaty called Te Tiriti o Waitangi was signed around 1840 between the British Crown and some Māori chiefs -, only 30 years later the new 'government' had taken 95\% of Māori land by force. Many perished trying to protect their land on wars across Aotearoa. That was followed by policies that attempted at breaking down the 
connections between their tribes, their clans and their family groupings. When this government installed their system of education on Māori land, they used to punish Māori children if they spoke their own language, both physically and psychologically. They dispossessed Māori people of their sacred lands, their cemeteries, so many of their sacred places in the bush, their big sacred trees were burned down and turned into farming lands for British settlers".

Yes, it was the same here, in high school, if I speak my own language I am to be punished. They will make me take a stem of a big tree, until I take out every root, I'll do that for a long time. For speaking my language or Pidgin.

"Yes ToGideon, similar punishments were given to Indigenous people in Ecuador for many centuries".

"Yet in Aotearoa and in Ecuador, these last few hundred years have also seen Indigenous resistance and protection of people and land.

"When you ask me to compare places and peoples ToGideon, I can't, there's no comparison, there are different experiences and stories, collective and individual ones. But I can say one thing, and this is with all my heart, that in my eyes you are some of the wealthiest people in the world, because true wealth for me is in community, true wealth is land and you still have your land and strong kinship connections. ToGideon, I lived in Kabaira for a while, you know, by the coast; every morning I could see from our beach across to the Bainings, all that bush, hills and land, the little 
towers of white smoke from the village fires, but slowly they started disappearing in front of my eyes, that deep greenish-blue of the bush, its cloak of smoke and fire became dull. So, when I see that in these last few years here in East New Britain, that there are more and more big companies coming from all over the world to 'buy' or 'lease' customary land, is very scary, because of the experiences we have in Ecuador; these companies have destroyed our land. I hear from some mummas, men and elders that the companies that are here and want land for oil or mining, forestry or palm oil plantations are promising them to pay school fees for their children; but often the children are not going to school, they end up working for the plantations, filling up the little bags with soil for the new sprouts. They tell me that these companies come and clear out their land, even the blocks that were supposed to be for village gardens, men and women working for nothing in their own land, and later when the land is depleted, the companies leave behind the people and the land impoverished and sick".

Lorena, we are lucky here, because we have tribes, we have land, and each tribe has land. My land starts from the beach up to the mountains, Mt Kambiu, and it belongs to my clan, not to everybody, not to the sub clans. The sub clan does not possess the ground, my ancestors were the first people coming to this land from New Ireland. We are the first people to come here, this is big land, and this is our land.

My wife has a clan and they own massive grounds, from Matalau to Rabaul. The government bought a bit of it and exchanged it with some ground in Gelegele. My wife, as a woman, has her own land 
and that land belongs to her, not to me. Everybody is like this here; the women have their own land. For Tolai, we have our land, this is our ground.

So, it is hard for those that intermarry, because some of them will have no land in Matalau. It's hard for them, when they try to go back to their home ground. It is also hard, now that our Tolai population is growing up fast and the new families need land.

\section{Family planning is not a new concept here}

"ToGideon, when I talk to the elders they tell me that the population here is growing too fast, not like in the old days. Then, I see many people from the outside coming here and trying to teach in the villages about 'family planning', but talking to mum IaIva, to some of the women I work and live with and other elders, they say that there were Gunantuna/Tolai practices to keep the population in balance before colonisation".

The men must stay in the taraiu, in the haus boi, the house for the men. When the wife is pregnant the father must stay out in the secret place in the bush, when I say the secret place I mean with the Tumbuan. They will stay there for a month or two months. In our tradition, our men need to stay away, so that it prevents population growth, and because the man needs to stay away from the wife, they will have two or three children, not like these days, they have too many children. It's hard to control family planning nowadays. 
The sisters tell the women not to be close to their husbands, but

things have changed. I believe the population now is growing too fast.

\section{"The village is your teacher"}

So, what is going to happen with so many young people soon becoming adults here? Where are they going to go? How is the land going to suffice?

There is a lot of confusion about this Lorena. It is hard for a father to control his children; so, the mother has to take the children to her home ground. For example, I married this woman, and I had to go to her home ground and work there, instead of working in my own home ground, because I have so many behind me, I have a clan. So, I have to go to her ground and work for my children. We tell the young people: "go to your mother's ground and work there for your kids, instead of just letting your kids look after you".

But it's hard to force them to work in the land Lorena. You know with modern technology, they rather be on their phones than working on the land, they can plant cocoa, coconuts, something, but they don't want to do this. Also, the parents are expecting the kids to just find a job when they leave school, instead of teaching them to also work in the land, this is bad. It doesn't matter if she or he has got a good mind, they need to know how to work in the land. We used to tell them: "to go back to the ground and work, planting things, so if the education doesn't give you jobs, you can go back home". 
A vocation is here in the village, not over there, the village is your teacher. The basic skills of mechanics or carpentry, how to repair a lawn mower or a grass cutter, we need to teach the young ones these skills. Because nowadays everything costs money, even education, so with a vocation they know how to work in the land, how to fix their own machinery, how to build their own houses.

\section{The current state of education}

I remember how until 1951, we got free books, free pencil, free rubber, free education. That was free education, no what the government says nowadays to be free education, it is not, it is money-education. Instead of saying it is 'free-education', it should say 'project-fee-education'. Everybody, across the board has to pay project fees, from PGK100 up to PGK1,000 for grade 11 or 12. My bubu is in grade 12 now. It is so much for all of us. What free education? In colonial times everything was free, nowadays is PNG time, everything needs money.

"What about before the colonial times ToGideon? When there was no money, when you had tabu/shell money instead.

That is true Lorena, there was no money, everything was truly free.

\section{The future of education in East New Britain}

"ToGideon, when I came here to East New Britain I learnt about the big changes that came with the tuition free fee policy the government implemented in schools across Papua New Guinea. I was working with a few teachers in a vocational centre for girls and living out in the North Coast. The teachers told me how 
things changed and one of the biggest changes was the number of students in one classroom. These teachers were exhausted and spent most of their time working inside and outside the classroom to support their students".

I used to teach up to 24 students in a class. It's a lot more helpful when we as teachers can be with them all. But now, if one drops out you don't even know, the ration in the class is too big. With more than forty students, you can't go to the individual to help, I can't go to you, cause I'm running to the time, I am teaching according to the time. I can't stay back with students to help them, I have to go and teach another subject. Our teachers are always running behind, our students are dropping out. The numbers are too high.

But Lorena, listen: kids are alright, children are alright, the system of education is dropping our kids. To me, I look at it this way: "you as a teacher change the system of education to suit the rhythm of the slowest learners".

"ToGideon, you have seen so many changes in your land throughout your life: this land under colonial rule, the independence of the country, the new governments that came and went, the destruction and rebuilding after the eruptions, and all along you dedicated yourself to education. What can be done now ToGideon for those kids, for the future of education here, now?"

People have to think about education and the future of their children, try and put their views together, so that they can bring it up to the education department. Parents, our communities share a 
lot of good ideas while we sit together and share stories, they always raise very good points. For example, nowadays parents are concerned about teaching in vernacular and about when it is right for English to be introduced to the children in elementary school. They are concerned because they see that without good English, their children cannot find jobs. So, the government says: "teach the vernacular in elementary school", but parents are concerned that they are not learning also English at the same time. They see their children dropping out and finding no jobs after their education. So many of them think: 'ok, then stop the vernacular and teach them only in English because you cannot apply for a job with a vernacular'. We have so many children dropping out of grade 10 and 12 and they cannot find jobs. I think, we can get together and train them to be teachers in the village, they can teach the little ones in elementary for example.

A lot of people in Port Moresby can't speak their vernacular, and that's why the department of education is trying to bring it back. I think we must keep our vernacular alongside English, they must go together. Here in the villages, you hear the little ones speaking Pidgin instead of speaking their own language, their own tok ples, this is bad, a bad foundation for our children. We just started talking Pidgin when we came up here to Gelegele, at home in Matalau we don't speak Pidgin because there are no plantations near us. The government is worried about us losing our vernacular, so they introduced the vernacular into elementary schools from the beginning, the missions also did this. But it would be good if by the age of 4 or 5 years old they can also learn in the foreign language. 
"Yes, ToGideon, mum IaIva told me stories of the time she was away for studies at university in Goroka, and other times here when she would be waiting for the PMV at the side of the road when it would start to get dark. She said: "my Matalau dialect keeps me safe, I can always find my people, I don't need to see them, I only need to listen, and I know that night I will be home safe. My dialect, the Matalau dialect gives me a sense of identity, of belonging to place, of safety, as long as I can hear it I know who I $a m^{\prime \prime}$.

At that moment ToGideon Turpat's bubu is woken up by a loud and enthusiastic dog that interrupted our stories and announced mum's arrival. Mum IaIva Magaga comes into the house followed by her niece, the bubu's mother; a piglet circles around their legs smelling the fresh kulau brought for us all to share together. ToGideon Turpat looks at me and says:

"It's all about the bubus Lorena, and he is catching up". 


\section{A homegrown curriculum for East New Britain - a story}

The 'East New Britain provincial curriculum development project' story is a narrative story about the collective action and relationalities involved in the making of the first-of-its-kind Indigenous-conceptualised, -created, -led and -implemented vocational curriculum and teaching resources in ENB province.

The ENB Provincial Division of Education (DoE) came together with educators from across the province to tok tok stori, to share stories, about what was happening in their own schools and vocational centres. School principals and managers supported teachers in becoming curriculum writers, and alongside civil society members and communities, together contributed with their own experiences and vision to the future of education and vocational training in ENB and Oceania.

\section{Creating a curriculum for East New Britain}

\section{Background}

'What we need is an education with a focus on survival, on thriving, not on simply getting jobs'

(Tok Stori with mum IaIva Magaga)

When I started working alongside the DoE we discussed the many stories, the visions and concerns we heard from teachers across ENB. What they needed in classrooms across ENB was a vocational training curriculum model capable of linking the educational and cultural requirements of local communities and local industries. Mr Pius Gawi, big pela bos at the DoE alongside Mr Cosmas Bauk, Education Chairman in the ENBPA, have been committed to supporting a vocational education model that is capable of successfully satisfying the objectives of the ENB Province Education Plan, as well as responding to the national government's 2050 Vision which aims to see a 'healthy, wealthy and wise' Papua New Guinea by the year 2050.

With over 800 languages and over a thousand proudly different tribal groupings, Papua New Guinea's diversity of land and peoples has no match throughout the 
world. The idea of delivering a completely uniform vocational curriculum across the country ignores the cultural and geographical diversity present in this land.

Previous vocational curriculum materials have proven to be largely out of context and culturally irrelevant to the local communities and educational institutions of this province. For many years previous curriculum materials have not been able to cater to the learning requirements of trainees from grades $8-12$, as well as RPL ${ }^{75}$ and nonschool leavers. Educational materials that teachers have had access to are disproportionally populated with foreign content, generally from a Western source. Educators see the importance of students engaging with this type of information. However, there is an imperative to first introduce students to a vocational curriculum model that was local, accessible, relevant and respectful to the cultural norms and values of their own people. Learning first about their own Indigenous cultures, their own values, their land and their own systems of knowledge, are the best foundations for students to later engage with any learning paths within the wider formal education system. We need to first cultivate strong roots before we can grow big branches.

Our elder in charge IaIva Magaga, told us again and again that what the province needs is a kind of education that will see people thriving, an education with a focus on survival, not simply on getting jobs. In order to contribute towards a kind of vocational education in ENB that will see students and their communities thriving, it was collectively agreed that this curriculum could not focus solely on Westernsanctioned technical skills and industry-based requirements. All of us involved, did however ensure excellence at collating locally-relevant skill requirements, by thoroughly engaging and forming partnerships with many knowledgeable and generous provincial industry representatives, whose expertise and requirements became part of this curriculum.

${ }^{75}$ RPL: requirement of prior learning, completion of Grade 6 - 8 (Primary Personal Development). 
Importantly, the collective research led by our elder and educators, and the stories shared by local communities, leaders, educators, their relations and elders: revealed millennia-old Indigenous knowledge, which became the foundation of how those skills are articulated and presented in every lesson written. The aim is to contribute to a kind of vocational education that respects and upholds the sacredness of land and that of relationships, as well as the strong cultural roots, identity and sense of belonging of ENB people. Vocational education and training, as well as employment that do not promote these culturally enhancing values and focus solely on the generation of profit, provide very little to the wellbeing of individuals and communities.

Through tok stori with curriculum writers and with our elder IaIva Magaga, we shared together experiences of the changes we have seen in our different lands and oceans around the world. It is clear to us all that in a time when the world is going through the existential threat of climate change and the imminent disruption to livelihoods and environment across Oceania, people in this province currently are, and will continue to, face the consequences of the actions of those motivated by profit. So, here in this powerful island of the Pacific, and after hours, nights, months and years of stories shared, we thought, why not? Why not making a local vocational education curriculum into a source of wellbeing and hope for this land? Why not providing the people involved in teaching and learning with knowledge and information that support local and regional efforts towards improving the health and wellbeing of people, and the protection of Indigenous land and the environment? And why not doing so by placing Indigenous knowledge, values and leadership at the centre of the entire process? Curriculum writers thus focused on topics that contribute to the protection of the natural environment and social structures of the different Indigenous groupings in the province. They have made sure that these curriculum materials respectfully represent the different ethnic groups, cultures and peoples of ENB. 
Every lesson created by curriculum writers have sought to transform what could have been a recycled version of a curriculum on 'Tourism and Hospitality' into a source of transformative change for a system of education that provides this industry with most of its workforce. Educators, students, leaders and elders in this province no longer want vocational education that replicate and perpetuate colonial legacies present in the formal education system. They do not agree to their young serving within a tourism and hospitality industry that has historically disregarded their Indigenous customary land, peoples, cultures and values. Mr Cosmas Bauk's words captured this during the launching of the first set of teaching materials held at Kabaleo Vocational Centre in April 2017:

"...we cannot allow our culture to be sold for a few dollars, yes tourism is coming here, and yes we want people to come and visit, but that doesn't mean that we have to sell ourselves, we cannot have our people begging for a few tourists' dollars. And, the right kind of education can help making sure that this does not happen in our province".

The teachers involved in the creation of this curriculum understand the realities of education and job scarcity in the province, and so they envision this educational resource helping trainees in many ways:

"It helps them to go find work and it also benefits them back at home, maybe to start a business for themselves, or just to help them back in the house, on how to clean, how to cook, to improve their daily living".

(Tok stori with Jeddah Violet Gigi, ENB Curriculum Writer, 2016)

\section{A curriculum made of relationships - Politics of relationality}

Throughout the years working alongside the DoE, our elder IaIva Magaga and I came together to share countless stories with educators, leaders and our elders in ENB. We came together in meetings with managerial staff at schools and vocational centres, and also with industry and civil society representatives. We sat under trees, or by the seashore, in offices or classrooms, or in air-conditioned rooms that were too cold and would make a few of us feel a bit uncomfortable and drowsy. We told stories, good ones and hard ones, stories of hope and stories of loss; and we ate, we 
always shared food. In those times IaIva Magaga guided me through the reading of educational policies and industry guidelines for PNG and ENB. Every time I looked up, our elder was there, calm and ready to walk me through any burning questions, keeping an eye on me and making sure I ate. I also read through books about education curricula in Oceania, and there was one in particular I could not put down, 'Re-thinking education curricula in the Pacific: challenges and prospects' (2005) was that book. Its editors include two revolutionary thinkers and educators, Kabini Sanga and Konai Thelu Thaman, whose work and writings on education and development have for a long time inspired and guided my own work. I noted down a quote by Bakalevu I found in a book in one of my own notebooks, it said that 'the choice of a curriculum is a political one' (2009).

I believe this to be true, because the many people, families, clans, public and private institutions, community and political leaders, churches and elders that came together to try and make this dream into a reality, meant that there were millions of political decisions and negotiations made on every step and at every encounter. The continued sharing of stories and food, space and tok tok with all of those that became the stakeholders of this curriculum at that initial stage of the project generated a sense of committed and constant support by all. The process then became one of continued sharing of knowledge, vision, concerns and requirements by all the relevant stakeholders of the curriculum. Each of them has become an important part of the process. For the purpose of the project and reporting we call all those involved: 'relevant stakeholder', yet this term could never encapsulate the enduring relationships, the human element, the values shared, and the reciprocity and care between everyone involved.

\section{What kind of vocational education?}

The vocational education that those involved in this curriculum initiative are aiming to contribute toward is one that is built upon Indigenous values and principles, one that respects Indigenous knowledge and Indigenous land, one that is weaved 
through storytelling, and one that requires of everyone's hands and work for the weaving to take place. A kind of vocational education that is made of, and honours relationships between people, between institutions, between sectors, between communities and most importantly between the genealogy of people, land and knowledge. The aim is to inspire cultural pride and a sense of belonging and empowerment in education for Indigenous people in ENB. To contribute to a kind of education that supports Indigenous youth in the protection of their customary land and their ancestral knowledge and practices. A kind of education that is geographically and culturally appropriate and relevant. The aim is

"to create and write a curriculum $[\ldots]$ that would be simple, local, relevant and
respectful to the cultural norms and values of the people of East New Britain" (ENB Curriculum Development Writers, 2016, p. 8).

The vision is to support a kind of vocational education that is grassroots in its process, content and approach. One that can find a home within formal education institutions and can lead and contribute towards geographically and culturally relevant primary and secondary education provision. Importantly, the vision is in a kind a vocational education that includes education provision for village people of all learning requirements and ages. A kind of vocational education that does not focus only on creating a workforce for an industry, but that it is driven by a core aim to become a source of support to peoples' wellbeing at the village level.

\section{'The weavers of stories' - The curriculum writers}

When educators from across the province shared stories about their experience teaching at different schools and vocational centres, a common concern was the difficulty of not having access to locally and culturally relevant curricula or teaching resources for vocational training. Most teachers at schools and vocational centres have heavy teaching schedules, therefore, having to put together lesson plans for their students without access to a simple, local and relevant source of teaching 
materials takes a large proportion of their day. This in addition to pastoral care teachers provide, especially if they teach at a boarding institution. Yet, teachers' daily duties do not stop at the school gates. They also are responsible for their homes, families and customary obligations. Teachers here have very little time left to recharge and rest. Yet, these teachers manage to tend to all of their professional and community responsibilities remarkably. Seeing them in action is nothing short of awe inspiring, even when they are overloaded and tired.

Sharing stories together about teaching and learning, revealed that being a teacher provides an opportunity to be whoever we want to be in that classroom. We can be performers, storytellers, story weavers, aunties, old people, children, nature, land, river, mountain, tree, we can be the sea. Yet all of us humans with our human relations -past, present and future-, and our relations in land and sea, also need time to stop and reflect, we all need silence and stillness. Likewise, teachers need that time and space before walking into the classroom to again become storytellers, weavers of knowledge, the voice of all our relations. Teachers need time to be them, to be mothers, fathers, sisters, aunties, uncles, and to be with mountain, tree and sea. Yet most of the time when they could be sitting by the fire telling stories with those they love, they spend it trying to find any information they can to put together lessons for the days ahead. Between preparing materials to give daily lessons, endless cycles of marking assessments, school duties, any extra curricula activities they are involved in, and their family and community responsibilities: teachers sacrifice sleep, rest and time for quiet reflection. I saw how so many teachers got sick during exam times because of the heavy workload preparing students and marking their assessments.

Teachers' dedication to their students' wellbeing is also a relational matter. Many teachers create strong, reciprocal and respectful relationships with students. This provides students with sense of belonging, making them feel safe and loved, they feel at home. Many teachers and students come from the same clans or villages, 
these relationships create a network of care and support that go beyond the formal schooling format of interaction: schools can become a village, and education a relational matter, made of values of reciprocity and trust. When I see and experience this in ENB, I think of the opposite forces I observe in education: the one that derives from the colonial legacy of the formal educational format which oftentimes separates the human and relational core of those involved in the learning process; and the other is the force that comes from a people that are part of strong and tightly knitted kinship networks past to infinity. These forces are negotiated on the daily basis by both teachers and students in ENB, who fight every day to hear and express their Indigenous voices within the heavy pressures of formal education.

After much tok tok stori about what teachers needed to simultaneously support their work in the classroom and improve their lives, families and villages, some of them joined this curriculum initiative becaming curriculum writers and later facilitators of the project. They are the weavers of the stories contained in every book written and every lesson planned. They come from every corner of the province, bringing with them a diversity and magnitude of knowledge and enthusiasm that inundated the rooms where we gathered to run a myriad of tok stori sessions together. They are from different Indigenous ethnic groups, some are young and some of them elders, some teach at secondary schools and some at vocational centres, they attend different churches, combined they speak dozens of different languages and dialects, they all love education and are some of the best storytellers and story weavers I have ever had the privilege to sit down with.

Yet these teachers do not stand alone when telling and weaving stories. Because in order for them to share their knowledge, their time and their labour during the process of producing a new curriculum for ENB, many of their relations took on their responsibilities back in their villages and homes. Their families, mothers, fathers, aunties, uncles, sisters, brothers, cousins and specially their spouses and children supported them, encouraged them, and patiently and lovingly waited for 
our teachers whilst they worked in Kokopo during the development of this curriculum. Their school principals, managers and teacher colleagues were also crucially supportive, as they looked after the classrooms that this curriculum writers could not teach during this time. All of those involved share an endless gratitude to the teachers, principals and managers that relieved these curriculum writers throughout those months.

Guided by IaIva Magaga's wisdom and dedication to caring for our teachers' personal wellbeing, together we planned and facilitated months of intensive professional development and upskilling for this curriculum writers delivered through what we called tok tok stori tasol. Before this curriculum writers began weaving stories together into the courses they created, we explored together areas of teaching and learning methods, assessment, computer literacy, facilitation, research and curriculum development. The result is the outstanding and unprecedented creation of six well-researched, content rich and culturally relevant courses contained in five teacher guides, which are based on their own vocational educational experience and above all in their Indigenous knowledge.

Together we witnessed the uniqueness of the creation of a network of support and reciprocity around a province-wide educational initiative by every single family member, every school, every person in public and private communities and every leader involved. The creative process of this project was conducted with strong Indigenous values, kinship networks became its very fabric, and it now depends entirely on relationships. The relational core of this project was replicated in every space of the process. The strong friendships developed between this curriculum writers are essential part of the weaving of stories contained in the curriculum. They supported each other through enormous workloads. What many might miss when reading every lesson written by our teachers is the rich background of collective support and encouragement contained, of hours and hours of shared knowledge, of stories told, revised, discussed and agreed upon, of laughter and tears, of sleepless 
nights thinking and reflecting on the writing ahead, of missing loved ones. Teachers worked tirelessly and lovingly, and they made each other, their loved ones and their elders and leaders proud.

Here are our weavers of stories, the minds, hands and soul behind this one-of-a-kind curriculum by Indigenous people and for the Indigenous people of ENB province: Sussie Bray, Jeddah Violet Gigi, Carrie-Anne Karella, Marcela Vovovon, Janet Kamara Magaga, Doreen Newton Darius, Cornelia Lote, Georgina Komen, Tania Paivu, Ruby Peni, Diana Pakar, Sheila Vinia Walia, Enisal Guria Boas, Ester Sigere Painuk, Dorothy Puipui, Alice $V u e^{76}$. These remarkable educators received technical support and were encouraged and fed on the daily basis at OLSH by IaEleonora Vigil, Mrs Dorcas Guta, Mrs Juliana Babate, Mr Boniface Kompage, Mr Tonga and a Japanese volunteer Mr Shimada.

Stories are not only spoken or written, they are also shared in the form of art. These are the local artists that fill every page of this curriculum with colours, with greens and blues that belong only to these lands, islands and ocean: Rodney Simai, George Vavana, Chris Tangot, David Wama, Paul Wama and Luis Toring.

Every single weaver of stories present here, is made of all her and his relations, past, present and future. And the stories told and woven together are their legacy and their way of giving back to their people. It truly takes a province-wide village to set and later maintain a project of this kind in motion. It takes strong and enduring relationships, it takes trust and respect for each other, it takes oceans of love. It takes putting Indigenous values of love, respect, trust, obedience and Indigenous concepts of time before any results or achievements. It is taking all of us to do exactly that every day.

\footnotetext{
${ }^{76}$ They are supported at their institutions by other educators such as: Rosvita Torot, Matthew Tuga, Sister Goretti Tajik, Bianca Lowon, Alberta Karai, Constance Kanau, Janet Ikiane, Robbie Baibuni, Albert Aloist, Agnes Tikot, and more.
} 


\section{Educational institutions and their leaders}

The secondary schools and vocational centres involved in creating this curriculum became the veins of the project. Principals and managers engaged with us for months on several tok stori sessions and meetings during the formative part of the project. They welcomed us and shared their institutional knowledge, concerns and hopes for the project. Later, they relieved their teachers and supported them to become curriculum writers. These school leaders worked throughout the development phases of the curriculum, by also being part of the trialling process of the resources back in their own schools. They were pivotal to ensuring the usefulness and relevance of these resources, by providing feedback and suggestions on ways to improve lessons and their delivery.

Six vocational centres and four secondary schools were directly involved with the project. Yet those numbers cannot contain the many relationships between institutions, between their leaders and between their educators. For instance, I realised early on, that a number of leaders and educators involved were taught by or studied alongside IaIva Magaga. These long-held relationships were built on values of trust, respect and love. Strong relationships and shared values were thus the starting point of interactions among these institutions.

The leaders at these institutions are: Mrs IaEleonora Varmari Vigil, principal of Our Lady of the Sacred Heart Secondary School, who provided a home to this project and educators. IaEleonora Vigil was preceded by a kind and committed educator $\mathrm{Mr}$ Ben Berom who honouring her legacy, continued the institutional support for the curriculum project. Mrs Rose Monalua is the kind, devoted and visionary manageress that transformed Milmila Vocational Training Centre in the Duke of York Islands (DOY). Mrs Lilac Baining, principal of Malabunga Secondary School, whose strong leadership and years of hard work made this school nestled in the Baining Ranges into an exemplary institution in the education sector in the province. Mrs Baining provided continued support to teachers that became curriculum writers 
and was very engaged during the trialling stage of the curriculum, providing us with invaluable feedback that resulted in a complete re-structuring of the order of the content in the books created. Mr Oliver Pereu, and Woolnough Vocational Training Centre the institution he manages, have been a calm and safe shore to moor for those involved in this project. Mrs Cathy Tasman the manageress of Kabaleo Vocational Training Centre has supported teachers and facilitators among her demanding schedule running this institution. Mrs Tasman alongside her husband Mr Dau Tasman from the DoE, took on the enormous task of putting together an unforgettable launching of the first set of curriculum materials at her institution in April 2017. These leaders' tireless work alongside vocational and academic staff from across the province, as well as DoE personnel to launch this provincial curriculum is one of the collective milestones of this project.

There were other great education leaders that walked alongside us during the project. It was inspirational to see these leaders from vocational and academic institutions coming together for a common purpose. They went beyond any individual agendas and put separate institutional interests to the side in order to work towards the collective goal of supporting the creation of a curriculum for their province, by their people. Those involved are endlessly grateful for the selfless and continuous support by: Mr Donald Kolita manager of Vunamame Farmers' Training Centre and his predecessor Mr Herman Pious; Mr Hosea Lulupa principal of Malaguna Technical Secondary School and his successor Mr Mathais Maibi; Maryanne Lingling manageress of Kabaira Vocational Training Centre and her successor Ms Marcella Vovovon; Mr Paul Raia principal of Kokopo Secondary School; Mr Dominic Mim manager of Uvol Vocational Training Centre; and the late Nick Nagas manager of Karlai Vocational Training Centre. This collective action was also supported by managerial, academic and vocational teaching staff from Kokopo Business College: John Karis, principal and Celestine Ponau, academic deputy principal, alongside tourism and hospitality lecturers Mr Mondo, Shona Meckle and 
Rachel Alu, spent many days with us sharing their stories and their institutional wisdom, as well as participating in advisory sessions to support curriculum writers.

\section{Relationships between public and private sectors}

The process of transforming the dream of this curriculum into a reality, formed unprecedented relationships between people in the public and private sectors of the province.

First, we formed a strong relationship between the provincial education sector leadership and the leading facilitators of the project. This relationship was nurtured by the vision and encouragement of our Deputy Governor and Chairman for Education Mr Cosmas Bauk and the care of our Provincial Advisor for Commerce and Industry Mr Henry Tavul. This initiative have been supported by many people and bodies from the public sector, such as the then Governor Hon. Ereman Tobaining Jr; the ENB Provincial Administration led by Provincial Administrator Mr Wilson Matava, Deputy Provincial Administrator Mr Levi Manu; as well as Members of the National Parliament -past and present-, Dr Allan Marat for Rabaul and Mr Jelta Wong for Gazelle; Kokopo Mayor and Tourism Chairman Mr Diuvia Kopman; and the East New Britain Tourism Authority. Representatives from the National Department of Education and the National TVET Curriculum Development Wing have also shared their support and institutional wisdom with us along the way, some of them are: Rosa Apelis, Stellina Sergius, Beatrice Aurora, Ruben Aue, Agatha Simango, Violet Geraga. In our provincial DoE we had much assistance from Mr Dau Tasman, Mr Andrews Aru and Mrs Ruth Kula. Representatives from the ENB Tourism Promotion Authority such as Leith Issac and Ezekiel Lulu shared their views and were also a sounding board for us involved in the process.

Working together with the public sector we then started to strengthen relationships with civil society bodies and the private sector. We have shared stories and learned from the ENB Council of Women and its director Mrs Alice Pawa, as well as from 
the remarkable women and men behind the ENB Women and Youth in Agriculture. Our relationships stretched and reached many other civil society groups, we forged together fruitful relationships with local NGOs at a time when our curriculum started to have a strong focus on environmental conservation and sustainable livelihoods for local communities. Here we encountered Wide Bay Conservation Association (WBCA) Director Elizabeth Tongue, an internationally acclaimed leader in conservation, and her son Rodney Simai, who is also one of our curriculum artists. We learned from the work of Toimtop Bio Cultural Conservation \& Development (TBCCD), and received immensely valuable information, posters, artwork and multimedia on biodiversity and forest regeneration by Kokopo-based Forest Management \& Product Certification Service (FORCERT).

Archbishop Francesco Panfilo supported this project through sharing his wisdom distilled from decades of educational leadership throughout the world. Alongside him were Father Francis Meli and Mrs Flavia Luringan, whose generosity of time and expertise helped us immensely. Throughout the years Archbishop Panfilo and I sat down and told many stories, on one occasion he said:

"What we are talking about is not education or health as services, but as part of integral formation, of integral development. Integral development means holistic education, it means body and soul. Humans are made of body and soul, we cannot say: 'tis is the body, and this is the soul'. So, for example in the hospitals run by the church, our nurses are not just there to give medicines, people in the hospital need love and affection. Similarly, with the many churches we have here, we have to work together for education, to build this community".

(Tok stori with Archbishop Francesco Panfilo in Vunapope, 2016) 
At the initial stages of the project, we were supported on the ground by Howard Iseli, the then in-country programme manager for VSA Aotearoa New Zealand, and by his wife Jacqui Iseli, a highly trained educator. Nevertheless, the relationship that I will always be inspired by is that between Howard and Rela Wawaneya. Rela, originally for Goodenough Island in Milne Bay Province, was the local in-country programme officer for VSA, they worked together to create sustainable partnerships in ENB. Rela storied with me about this relationship:

"We had a mutual relationship. It's two different cultures coming into contact [...] but we blended well because we had developed a greater understanding of each other's personalities. [Howard] involved me in all meetings, and always encouraged me have a say, even if it's with dignitaries. He just made me feel that I was on the same level as him. It's not like: 'you are the programme officer, one level below me, no'. He would say: "you are by my side, and if I am not there, you represent me". This is the true representation of the organisation, from the CEO right down to the country level. And if a manager can do that, then there's no barriers. When I saw that, I knew that there were no limits, you know. As a female, there's no limits".

Together Rela and Howard went above and beyond to support this project. Rela provided us with transport for our curriculum writers, took many administrative requirements off our hands, she personally ensured that my fridge always had food. Rela is a fiercely intelligent woman whose friendship, loyalty and dedication to all volunteers and to this project became one of the major reasons why we continued on: 
"We [Howard and Rela] had to look at the bigger picture on how a project like this could impact the 2020 goals and objectives of the National Education Department. So, when I could really see that, it is when I gave my support on the ground. Even though there were a lot of struggles along the way, we both put our prayers and support to this because we know it will lift up and will support education at the national level. We can be satisfied that it has captured the bigger vision as set by the parliament and the education department.

The impact is truly that it supports life and the things on the ground. But it has to be right, there has to be passion and love for something to get it off the ground. And yes, it needs input and support from everybody".

(Tok stori with Rela Wawaneya, 2017)

We also formed strong and invaluable relationships with volunteers such as Alison Holmes, who supported us with her extensive education expertise and kindness. Other great former staff at VSA supported the initial stages of the project, sadly most of them including Howard and Rela finished their work with the organisation. Shortly after I also finished my work with this organisation. VSO LSP volunteers, who at the time were working with educators and leaders from across the country creating programmes on academic subjects, kindly invited us to spend time with them and learn from their experiences bringing educators together to create curricula.

Relationships are the fabric of this curriculum. There are two people from the local ENB wider community that stand out and who were crucial to every stage, every development and every step I took as co-facilitator of this project. Dana Iselin and 
Jason Seeto's support and friendship, care, hospitality and genuine love to us all facilitators and teachers were the encouragement during the good days, and the medicine during the challenging ones. Other members of the wider community such as Mel and Jelta Wong, Joyce and Oliver Bluett, Wande, and Sabine Hess and Martin Maden also contributed immensely to the project by simply being there for us, sharing their time, hospitality and friendship.

The support we received from many industry representatives was also a product of building strong personal and professional relationships. From the beginning these representatives made themselves available to share their industrial knowledge with us. They also provided space, time, resources and training for our curriculum writers and facilitators. One of them is Sevi Kaue the manager of Kokopo Village Resort (KVR), a tourism business that is proudly locally run and owned by the Pidi family and directed by Douglas Pidi, a visionary and generous Gunantuna/Tolai man. Sevi Kaue is a man whose values have always inspired me. During a tok stori session he shared with me how proud and honoured he feels working in a nationally owned and managed company:

\footnotetext{
"Something that I always continue to talk to my staff about, is that

this is a Papua New Guinean company, so I tell them that we should be serving them with passion. Over the years, I have worked for different companies, but to actually work for a Papua New

Guinean company, it's a real honour".
}

(Tok stori with Sevi Kaue, 2016)

Sevi Kaue gave selflessly of his time and industrial knowledge during many encounters with different stakeholders and speaking during the project's launching. He joined us in classrooms and during tok stori sessions, supporting our curriculum writers by sharing the unique knowledge of a man who represents the pride of doing tourism and hospitality the Papua New Guinean way. Seeing him working 
alongside other Papua New Guineans at KVR was awe-inspiring, he treated all staff and elders working at the company with the utmost respect, understanding the customary order of things. When there is a funeral, a bride price, or any customary responsibilities KVR staff must attend to, they are supported and encouraged, for these are not regarded as an impediment to their work. By upholding the values of this land and its people, it is obvious how this company has flourished.

Another supportive industry representative is Mario Pangalos ${ }^{\mathrm{t}}$ the former general manager for Gazelle International Hotel in Kokopo (GI). Mario's willingness to listen to stories had an impact on the industry and later in vocational education. Mario shared also his concerns and his vision for the industry in ENB and around the country:

"Lorena, I know how long and how much it takes for my staff to get to work every day. Some live so far away, yet somehow, they make it to work on time. They have so much to do in their own homes; they are mothers, fathers, part of families with huge responsibilities. So, when they arrive here, I want to know that they feel welcomed, cared for, by providing them with food, a decent place for them to rest and a place to clean up if they need to. And if they have customary responsibilities back home, well, that is a priority too".

(Personal communication with Mario Pangalos)

Alongside him for many decades was Luis Gomes, who is currently the general manager of GI, and all other staff who have continued supporting this project, our writers and facilitators in researching for curriculum writing. Jackson Pinia, GI's tour guiding coordinator, storytelling ability and knowledge of the stories of this land have been a source of invaluable guidance while writing various modules on tour guiding. 
There were days when writing was hard and we all felt overwhelmed by the share amount of daily research, storying, negotiations and decisions to be made. Storying with tongue and pen is hard labour. Sophie Marshall was there by our side during some of the most crucial moments. She is the Director of The Relax Corp, a successful international massage therapy business that she built on her own for many years. She supported this project from its very inception and developed a good friendship with IaIva Magaga, all of our curriculum writers, and I. Sophie offered again and again free massage therapy for our writers. Sophie is a remarkably aware educator herself. Following a long time of training at Kokopo Business College (KBC), Sophie joined our curriculum training sessions and shared some industrial knowledge. Sophie's goal to encourage and train Papua New Guinean women to work in therapeutic massage was strengthened by her cultural awareness. Thus, she first ensured she went and studied in a local institution in order to understand teaching and learning methods that are appropriate and relevant to the local population. She went onto successfully train and work alongside three local women:

"I'm passionate about massage, its healing capabilities physically and emotionally, and I wanted to train up a couple of Papua New Guinean women, support them with new skills.

But, well there's a theoretical side, and a practical side to this. So, I used that passion as a catalyst to enrol to study at the local business college in Kokopo. It happened when I met Alison. I needed to obtain a certificate, the old trainer-trainer stuff, you know. This certificate was the catalyst to get my act together and work out how I was going to present the whole course, lessons, and the material that I needed. For over 30 years I had been gathering 
all the notes, the pictures of the anatomy, the physiology, doing questionnaires. The course I put together really helped me consolidate it, which I then implemented, and tried it out on the girls. It was good!"

"So, Sophie, you found ways to educate yourself in terms of how to educate in Papua New Guinea", I said.

"Yep! And survived all the academic jargon, thanks to Alison!" (Sophie laughs).

(semi-structured interview with Sophie Marshall, 2016)

There were also those that housed and fed writers during the many months of training and writing of this curriculum. Evelyn Foo, Simon Foo and Fiona Tanner from Kokopo Beach Bungalow (KBB) supported immensely by offering discounts on accommodation and food at Taklam Lodge. Their staff looked after and fed us all after long days of work. The many dinners shared with our teachers at Taklam are most treasured memories. Many other industry representatives have been of inspiration and support to this project: Irene Leggett from Kulau Lodge; Lyn, Bert, their daughter Hannah Woolcott and their son Stephen ${ }^{\ddagger}$ alongside his wife Marsha Woolcott and their staff at Kabaira Beach Hideaway and Kabaira Dive and Tours; Maira Home Stay in Mioko Island is a community owned and run business headed by a local man Simon, brings a sustainable number of visitors into the island and focuses on the protection of the cultural heritage and environment of the land and its people. We have learned a lot from and were inspired by the resilience of these small businesses and those running them while writing our curriculum. Local tourism and ecotourism operators, and guided tour providers such as Ellis Waragat from Kokopo Tours, Douglas Pidi from Rabaul Discovery and Ecotourism, Melly Paivu from Paivu Tours, William Vomne from Toimtop Bio Cultural Conservation \& 
Development Incorporated, and Jackson Pinia, are but a few of those that constitute the heartbeat of the local tourism industry. The exceptional work done by these local operators is a constant source of inspiration and pride for our curriculum writers. They have reminded us that 'hospitality' is an innate practice and value in these localities, that their ancestors have been visiting other places and have had visitors from across Oceania for millennia. They proudly do it their own way, with their own local values, procedures and towards their own outcomes.

\section{The process of developing a curriculum - a tabu making stori}

The process of creating a curriculum that is based on relationships and done through tok stori is unique to the place and the people involved: it is the result of what happens within that relational space. To tell the story of this process as simply four stages of curriculum development (training, writing, trialling and editing), will not honour the vastness of knowledge contained and the weaving of relationships required. The process of developing this curriculum occurs in a storying space which is held by relationships between people, place and their genealogies of kin, connections and knowledge. Our elder IaIva Magaga always reminds us that 'learning is a sacred pursuit, a relational matter'. Thus, with her guidance we began the process of creating something for education that saw learning as a sacred pursuit and something that belonged to and was made of relationships. Gradually, day after day, the different stages of creating this curriculum became to feel part of a process that sought to honour relationships and the wisdom and values of all those involved.

So, allow me reader to tell you about this part of the story through the metaphor of the process of making tabu (Gunantuna/Tolai shell money or shell wealth).

But first let's remember that within this story, and as a strongly held personal belief, tabu is much more than a mere object of exchange or a representation of social facts or happenings. Dr Jacob Simet (1991) a highly respected Gunantuna/Tolai leader and academic reminds us through his work of the sacredness of tabu, of the 
inherent and temporary forces attached to it, which will determine its use and guard it from misuse, abuse or misappropriation. To clarify, I am not stating that the product of the curriculum development process is an any way similar to the final representation of $t a b u$. The metaphor relates to the process of tabu creation, rather than the tabu itself. So, in this story, I do not refer to tabu in its infinite faculties, properties and power, because it is something sacred of which I only have the knowledge that I have been granted by elders, people of the land and my own involvement through ritual and ceremony. Tabu is therefore something that I dutifully respect. In this story I refer to the making and to the social mapping capabilities of tabu in the form of metaphor only, rather than attempting to portray or speak to the properties of tabu itself. This metaphor emphasises the relational core of the processes of knowledge generation and collective action required to create this curriculum. It is based on the many stories and writings of Dr Simet on the process of making tabu, and the parts of the stories told to me by IaIva Magaga, by elders, and other Gunantuna/Tolai women and men, which I am able to share in writing: Under the sea in the middle of the night, a symphony of shiny white and light brown tiny nassa shells leaves the sand in search for food. They crawl and settle on little heaps of coconut flesh, banana skins and vegetables that mysteriously appear on the sea floor from time to time. The music stops with the sunrise when they feel the pull from above. They cling to the heaps that gave them food, hoping it would also give them protection. They will next be buried without their food and away from the sea. The next time they return to the solwara will be to be washed and rid of what has waned after days under the ground. They leave this bath of salt and water after the sun and moon have been reflected on the water's surface, twice. The second time they feel this pull from above, it will be the day they become pala tabu also known as palakanoara: tabu shells.

When they were not found around Gunantuna/Tolai territory, countless pala tabu of shiny white lips and light brown whorls, made their way to Rabaul in the returning 
canoes of Tolai men. There are a few places where these men collect pala tabu, yet its main source required them to travel to other places around New Britain; or as far as the Solomon Islands in more recent times. Traditionally Tolai men from the coastal areas of the Gazelle Peninsula would choose certain times of the year to embark on journeys to collect shells. Before heading west towards the Nakanai area in West New Britain where the most numerous and best quality shells were found, they would load their canoes with goods that they would then trade for pala tabu. In these lands away from the Tolai domain, the customary owners of the beach and sea perform the tasks of collection of shells in the water, while Tolai men wait on the beach for trading.

Once pala tabu from near and afar reach Rabaul, they will again undergo a process of transformation, now into tabu. First in the process comes Binabar, which is the step of breaking of the light-brown whorl on the back of the pala tabu; anyone even children can join in doing this. Second is Niuk where pala tabu is strung onto strips of rattan. The third step is Rurua, where the new pieces of tabu are joined into longer pieces. Customarily, niuk and rurua would only be done by those with expertise and elders, but now with the influx of shells, experts and elders are no longer able to cater for all the demand of tabu production. So, many people including young people, are now also helping in the process of transforming pala tabu into tabu; some are even paid for these jobs. To become tabu, shells undergo a process of physical transformation. Yet the process of transforming something physical into a powerful source able to communicate more than words can and one that signifies so much to a people: is a process layered with negotiations, wisdom, storying, collective work and relationships. This process is at every stage a relational process, one that depends heavily on relationships. This is a sacred pursuit that ultimately makes tabu not into a mere object of exchange, but a powerful way of communicating between people and mapping their genealogy of relationships and knowledge, across generations and space. 
The process of developing this homegrown curriculum for ENB required also of a kind of collective action that is transformational for education. The different stages of the process brought together many people from all walks of life who engaged in the labour of tok stori, and who shared and negotiated their knowledge and their different values and needs within a safe and relational space. 


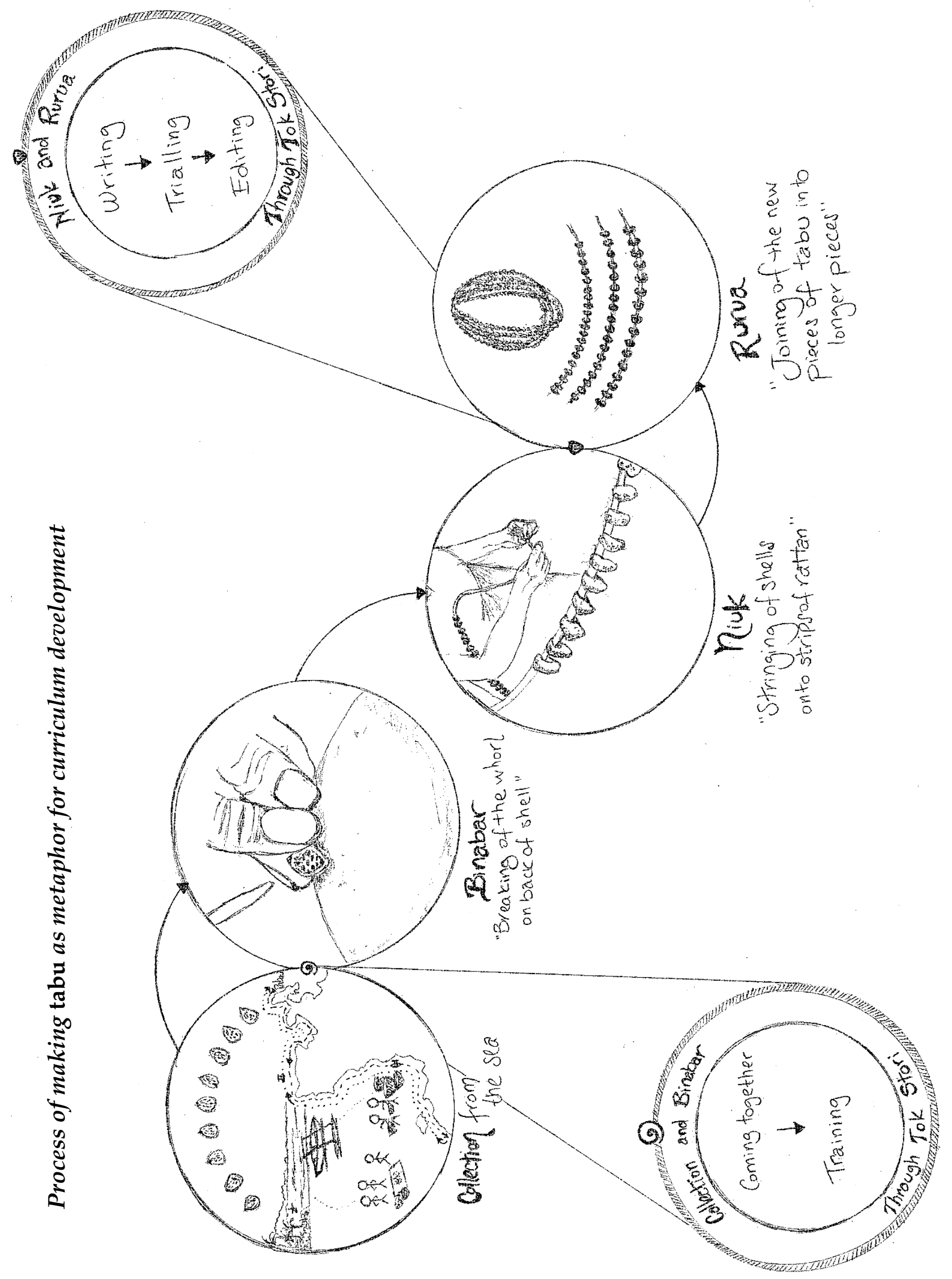




\section{The process of developing a curriculum - a tabu-making stori metaphor}

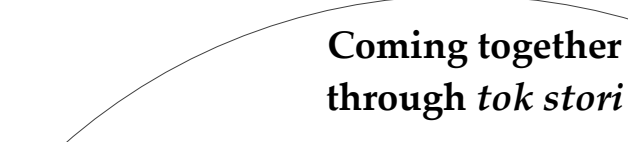

Relevant people, educators and public and private sector bodies come together to tok stori and share food

A safe relational space is created by leaders and facilitators and guided by elder in charge

Relationships are formed and strengthened

Negotiations of knowledge, requirements, interests, values and vision

Different requirements and visions are gathered

$$
\stackrel{\downarrow}{\downarrow} \text { Writers are appointed }
$$

Logistical matters to cater for writers are organised by facilitators with the support of relevant people.

leaders and bodies involved

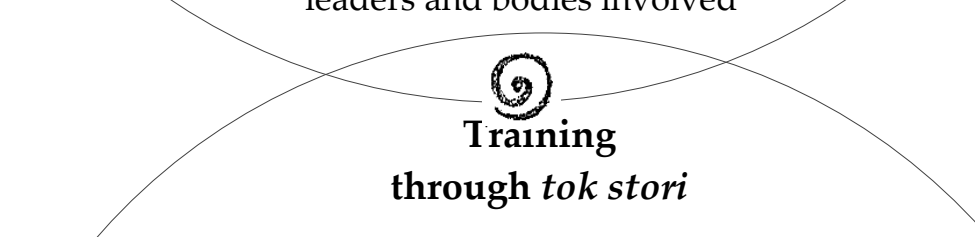

Elder in charge, facilitators and writers engage in tok stori sessions

Creation of group's vision mission, values and rationale for curriculum in general and a draft title for each course

$\downarrow$
Breaking preconceived divides between vocational and academic Breaking preconceived divides between vocational and academic
knowledge through group activities, tok stori sessions and in-service knowledge through group activities, tok stori sessions and in-services
Breaking divides between education sector, communities and civil society through advisory and tok stori sessions with education sector community and civil society representatives relevant to each course (experts, leaders, elders, community members, storytellers, artists)

The process for writing each course is decided together

Upskilling lessons for writers on computer literacy, IT requirements and Teaching \& Learning strategies are conducted

Facilitators put together structure and format for course writing and present it to writers and elder in charge for feedback and final decision

\section{Writing}

through tok stor

Facilitators and writers revise and agree on course rationale

Tok stori sessions to decide on course's general content and module titles conducted first by facilitators and later by writers

Storying and defining together: topics, final wording, Learning Outcomes (LO) and Assessment Criteria $(A C)$ of all modules for the course to be written in the agreed format

Collectively decide the allocation of modules to each writer Assisted by facilitators, writers research content for each module (engaging with advisory people and bodies as required)

Writing of module content and each lesson based on $\mathrm{LO}$ and $\mathrm{AC}$ - Write background and supplementary information for each lesson - Write Assessment Tasks (T\&L activities) using collectively created and agreed Teaching \& Learning (T\&L) strategies

$$
\text { each, with }
$$$$
80 \text { minutes tenching time for each lesso }
$$

Writers share module draft with facilitators

and other writers

Editing

\section{through tok stori}

Writers incorporate feedback from trials into the lessons they wrote

STaN: Swap, Teach and Note

essons they want to finalise for final trialling and editing at host school)

Swap: Writers pair up and swap their lessons with another writer Teach: Writers prepare and teach partner's lessons to 10-25 students and note any changes that need to be made to improve tht by part After the lesson is taught by pater, writes hold an evaluation (a) tok stori session with the students, and note their feedback to improve their lesson

Writers do final editing of lessons using feedback from trials and STAN evaluations

Writers share their final draft with facilitators
Graphics and Art content

Local artists and graphic designers work alongside writers on every module to weate the graphic content of each lesson

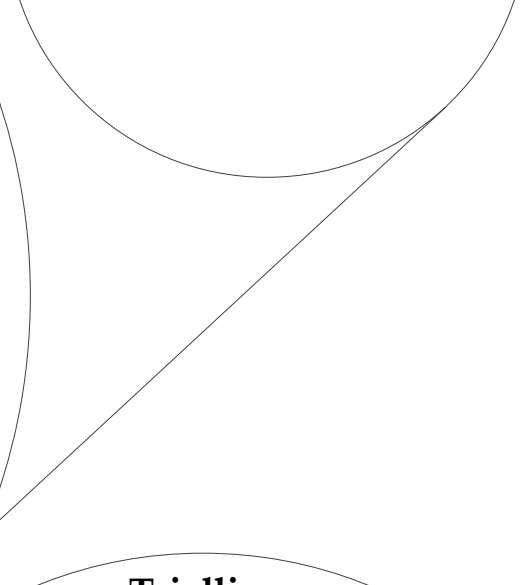

through tokstori through tok stori

Writers trial their own newly created lessons with students at host school and when possible at their own secondary schools and vocational centres Facilitators gather feedback from other teachers an students at trials in host school through tok stori sessions to ensure trialling process is appropriate

Writers gather feedback from colleagues principals, managers and students after lesson trials at their own secondary school and ocational centres

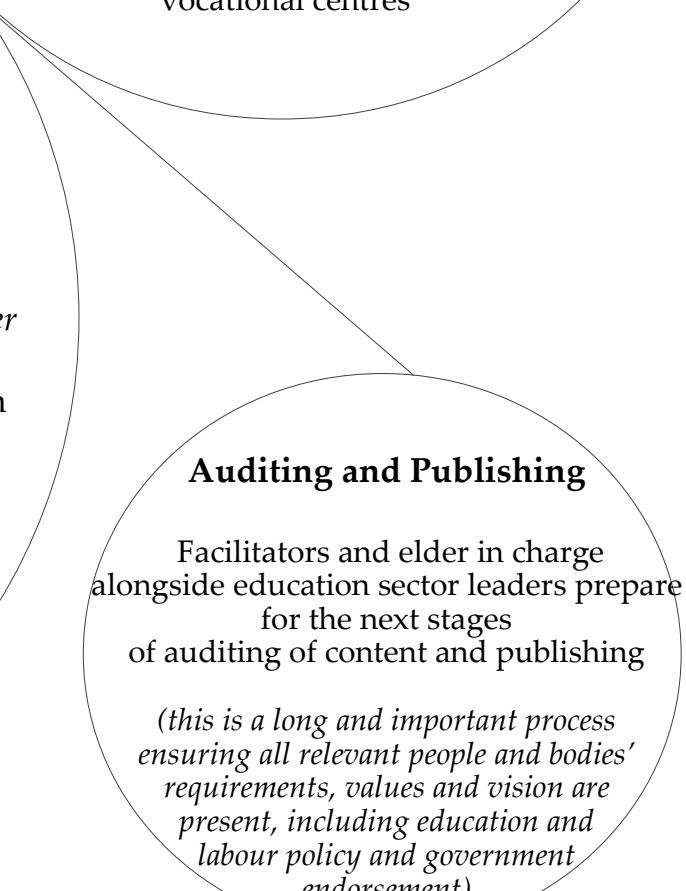
including education and
policy and government
endorsement) 


\section{The process of developing a curriculum - a tabu-making stori metaphor}

The steps involved in tabu-making provide a great metaphor for the process of this curriculum development through tok stori. The process of creating this curriculum through tok stori methodologies meant that we shared the understanding of a world that is "dialogic, relational and processual" (Sanga \& Reynolds, 2019):

\section{'Collection of shells from the sea' step and 'Coming together through tok stori' stage}

In the process of making tabu the initial step of 'Collection of shells from the sea' requires of people coming together to collectively perform tasks to gather shells (logistics), of forming and maintaining relationships (near and afar), of negotiations (including trade), and of respecting relevant peoples' land, ples, practices, values and knowledge. Similarly, in the process of developing this curriculum the initial stage of 'Coming together through tok stori' brought all relevant people, educators and public and private sector bodies together to tok stori. Through the guidance of our elder in charge IaIva Magaga, we worked alongside DoE leaders to create safe relational spaces for all those involved to tok stori. This required very essential components: deep listening, and sharing of food and time together. In these safe relational spaces, we formed strong relationships with everyone involved. The process was strengthened by pre-existing relationships like the one between IaIva Magaga and IaEleonora Vigil which resulted in us finding a home for writers and facilitators to conduct the activities required to develop this homegrown curriculum.

A relational space, however, is also inhabited by the negotiations of knowledge, requirements, interests, values and vision of all those community members, educators and the public and private sector leaders and representatives involved. Alongside IaIva Magaga, it was part of my responsibilities to dutifully gather and record all different requirements and visions, as they were to become the core content, the heart of this curriculum. Engaging everyone through tok stori also gave 
us an idea on how each person and organisation could contribute to the development process of this curriculum.

And so, we started organising all related logistical matters alongside different relevant people, leaders, experts and organisations from across the province. We coordinated all financial matters with our DoE Provincial Advisor Mr Gawi and our Deputy Governor and Education Chairman Mr Bauk, who supported by Mr Warpit and Mrs Boni Nelson, secured local funding for the developmental phase of the project. We agreed on advisory relationships with representatives from the National Department of Education, from the National TVET Curriculum Development Wing, and relevant local lecturers at Kokopo Business College; as well as with our Provincial Advisor for Commerce and Primary Industries and respected elder Mr ToHenry Tavul. IaEleonora Vigil the principal of OLSH secondary school provided this project with a home, space and resources at her institution. Writers were appointed with the support of Mr Warpit from the DoE together with principals and managers, to ensure that this would not put too much pressure on their secondary schools and vocational centres.

IaIva Magaga and I continue engaging on tok stori sessions and meetings with principals, managers and importantly with the educators from across the province that were to become curriculum writers. Meanwhile, I also engaged on advisory sessions with VSO LSP volunteers, to gain an insight into existing education programmes that work alongside local educators and leaders. With IaEleonora Vigil's support we found computer literacy trainers and IT support for curriculum writers; as well as food catering for facilitators, advisory guests and writers at OLSH. We were able to hire a small bus at a very discounted rate through Rela Wawaneya (ex-VSA Local Project Officer) to transport our teachers from their accommodation to the curriculum development working sessions at OLSH. We agreed on continued industrial expertise advise for our writers by a substantial list of local industry representatives, who also provided practical support offering training sessions and 
discounted rates for appropriate accommodation and food for our writers for the months they were in Kokopo writing with us. Together we all agreed to a continued advisory relationship with, and logistical support by, all relevant community members, elders, as well as public and public sector experts and leaders.

\section{'Binabar' step and 'Training through tok stori' stage}

'Binabar', is the step of breaking of the light-brown whorl on the back of pala tabu (the shells collected that are to become tabu). It invites people, including children, to join in this step of collectively transforming those shells, and one by one preparing them for the next step of the process. Similarly, in the process of developing this homegrown curriculum, the stage of 'Training through tok stori' requires of everyone that is involved, invested and interested in the process, to come together and through tok stori begin the work of breaking any preconceived divides between them. It requires these people to help each other, to support our elder in charge, our facilitators and our writers in preparing and securing all resources, logistical assistance as well as professional, emotional, mental and spiritual support for those involved in the next stage of writing.

During the training stage our elder in charge IaIva Magaga, us facilitators and the curriculum writers engaged in tok stori sessions to story and define our collective vision, mission and values. At the centre of the process were the values of trust (nurnur), obedience (tinarom) and love (waramari). One day through storying, curriculum writers: Sussie Bray, Jeddah Violet Gigi, Carrie-Anne Karella, Marcela Vovovon, Janet Magaga, Doreen Newton Darius,

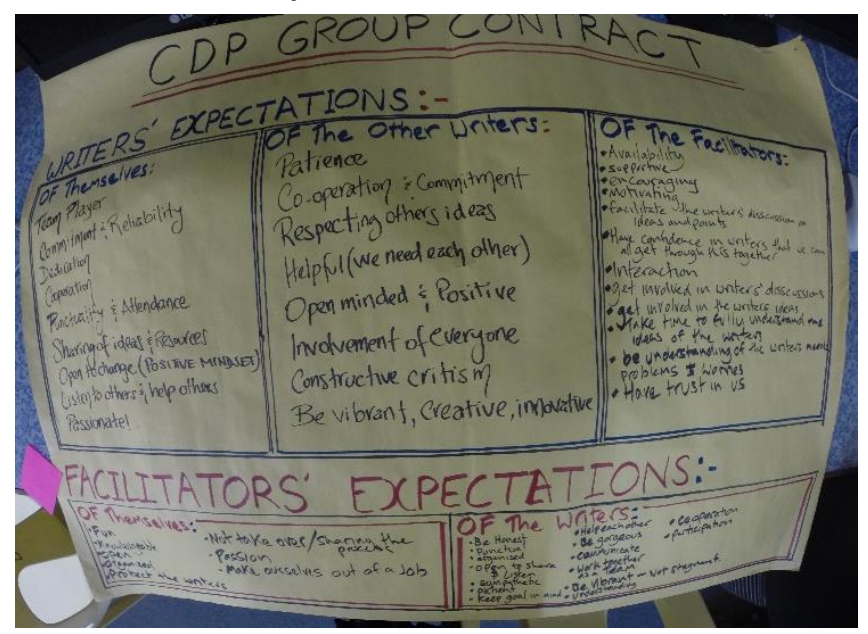

CDP Group Contract by CDP Writers Collective Cornelia Lote, Georgina Komen, Tania Paivu, Ruby Peni, Diana Pakar, Sheila Vinia Walia , Enisal Guria Boas, Ester Sigere Painuk, Dorothy Puipui, Alice Vue an assistant facilitator 
Joe Dawson, our elder Mrs Iva Magaga and myself Lorena de la Torre, created together a group contract that defined the writers' expectations of themselves, of other writers and of the facilitators; it also defined the facilitators' expectations of ourselves and of the writers.

Following this, we created together a rationale for this curriculum that defined its purposes, principles and aims. After touching on the relational foundation to this project, together reiterated that the teaching materials being created here were to be geared to community-based training on tourism \& hospitality practices. These teaching materials were to be focused on building cultural pride on trainees and encouraging the development of skills that are helpful not only for those looking for employment, but also for those returning to the village.

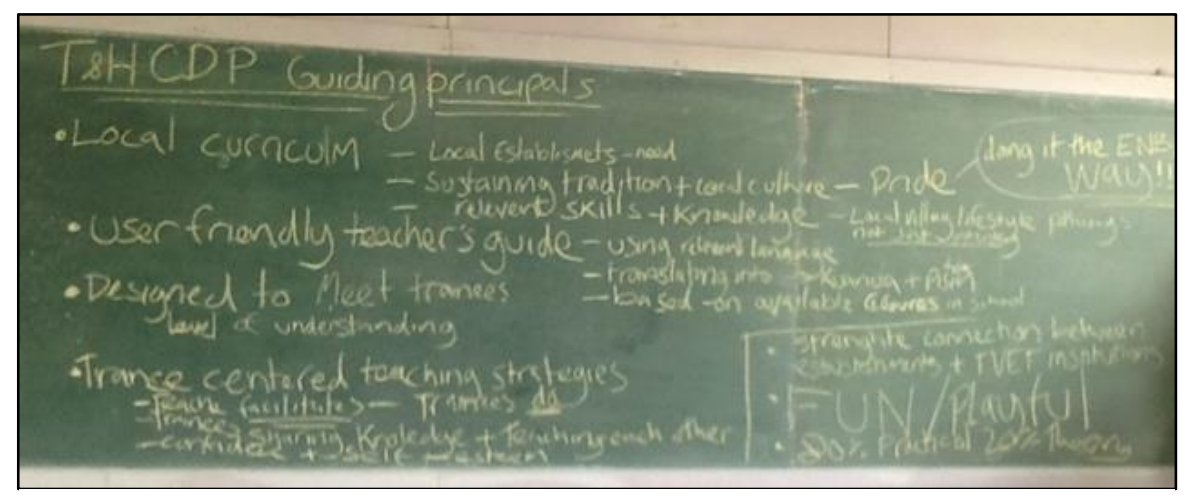

THCDP collectively agreed guiding principles by CDP Writers Collective

The purpose, principles and aim of these course materials are thus: to introduce relevant and transferrable skills into the community; to equip trainees with life skills and knowledge, through teaching and practical demonstrations; to raise the standards of living all the trainers and trainees and their communities; to encourage community wellbeing; to support trainers and trainees to continue valuing their culture, to respect and uphold the cultural norms and practices of their peoples and their land; to equip trainees with industry relevant skills endorsed by the ENB industry (provincial) and the National Apprenticeship \& Training Testing Board NATTB (nationally) and; to equip the ENB tourism \& hospitality industry with highly qualified, skilled and confident people. 
As explained by a curriculum writer and facilitator:

"We really wanted something for East New Britain, so that we could teach something that is uniform and something that is relevant, both in the industry and back at home. So, I think we had to use some of the knowledge that we had at home and we had to conduct research with the industry so that all our lessons would merge the two, the industry and the lifestyle back at home".

(Tok stori with Jeddah Violet Gigi, 2016)

Following this, we drafted the titles for each course through tok stori sessions that focused on the wider picture and the overall content that writers wanted to see in these courses. These sessions also focused on revising all other relevant peoples and organisations' requirements of, and visions for, this curriculum. Together six course titles were decided upon which brought together and satisfied all of the above.

The process of facilitators and all writers sitting together to tok stori with our elder, had the ability of breaking preconceived divides between teachers that came from either vocational centres or secondary schools. The false perception of a hierarchical divide between vocational and academic knowledge and learning, was gradually dissipated among curriculum writers through a series of group activities led by an assistant facilitator, as well as the continuous training sessions, tok stori spaces and in-services put together, where IaIva Magaga and I worked together to delve deep in and demonstrate the complementarity of the writers' diverse knowledge systems, skills and worldviews.

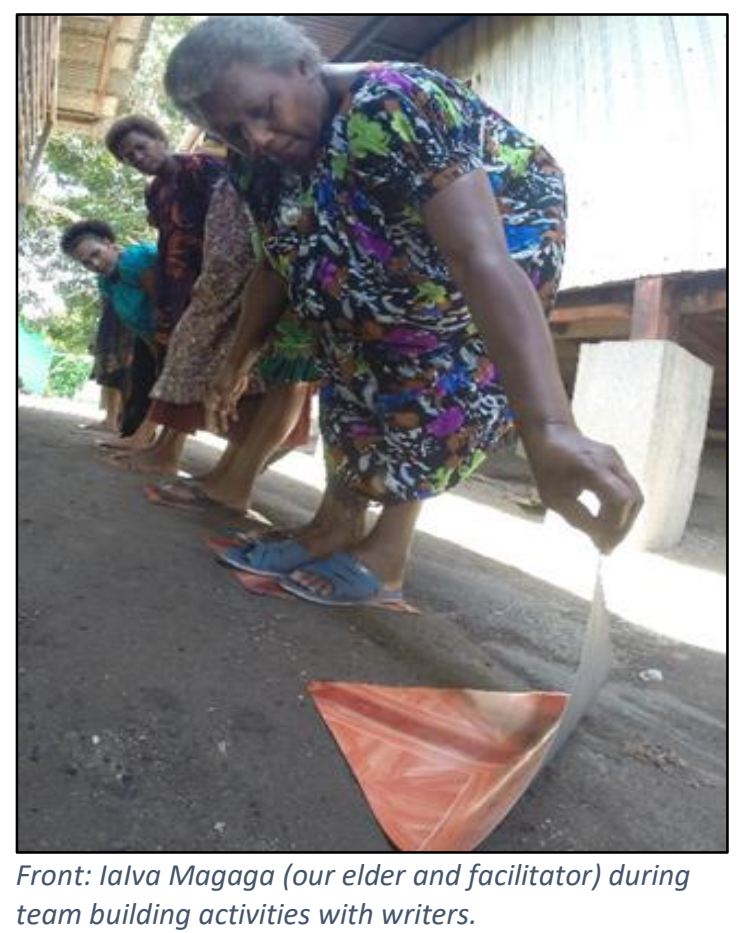


Together, we also continued breaking the divides between the education sector and civil society, through inviting advisory and tok stori sessions with experts, leaders, elders, community members, storytellers and artists from across the public and private sectors.

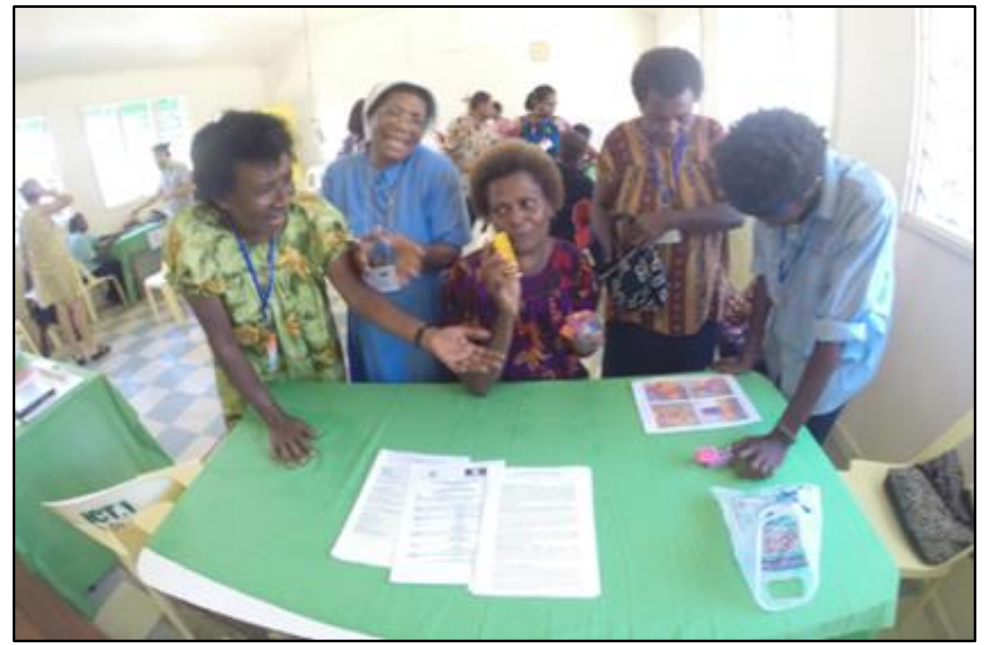

Curriculum writers engaged in tok stori sessions and group activities on: curriculum local ownership and cross sector cooperation. From left to right: Georgina Komen, Sister Goretti, Cornelia Lote, Dorothy Puipui, Albert Alois.

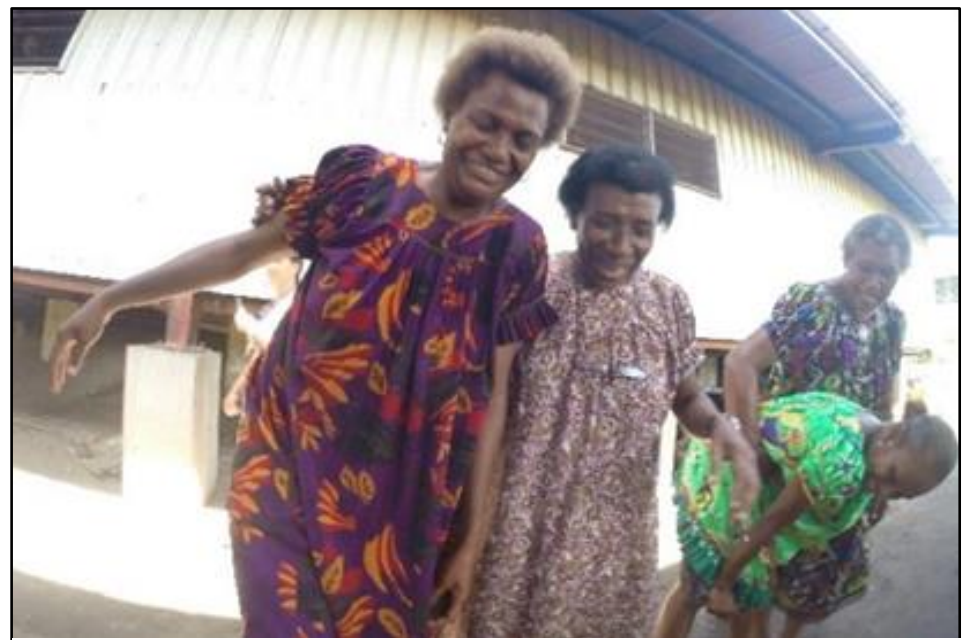

CDP Writers Collective team building activities during Training Stage. From left to right: Cornelia, Georgina, Sheila and Ialva Magaga

In preparation for training, alongside IaIva Magaga, I worked closely with the DoE and our provincial government staff to understand all relevant policy requirements. We later engaged on the research of all relevant technical information, people's and organisation's requirements. We engaged experts advisory and found guidance in 
the wisdom of community leaders and elders through various tok stori sessions. These steps provided us with a soft timeframe for the process of putting together these teaching materials. However, a tok stori, a relational practice meant that the final decision for the way each course was to be written, and what it was to contain was made and constructed together with facilitators and writers during the training stage of the process. Here I remember sitting down with educators from across the province and some of our writers hearing stories about some teachers that had previously been taken to Port Moresby for four or five days and told to write a curriculum. I listened to the stories of teachers who had been presented with foreign content (Australian teaching content in particular) and told to practically copy and paste it into the new curriculum. They were given close to no allowance to include any local or culturally relevant content.

A curriculum writer reflected on previous sources of materials used for teaching and the sense of professional and cultural pride generated by being part of the creation of this homegrown curriculum:

"What we usually teach to the trainees are just collections of information from the internet, or wherever we could get the information from. But this is one of a kind, it is made especially for East New Britain, by the East New Britain women.

I feel very proud of myself and my group, to see our names on those books because of the work we have done. So, in five-or ten-years' time, when someone is opening the books and teaching, I will come past the classroom and say: "Yeah, I wrote that" (Jeddah laughs).

Students, the little ones in the family will be sitting in the classroom doing all those activities and when they come home and 
tell us: "oh we did this today", then I will be smiling and say:

"Yup, that was me"".

(Tok stori with Jeddah Violet Gigi, 2016)

Rela Wawaneya, also shared her experience as the child of a teacher:

"From my own background, I saw my mum who was a primary

school teacher, discussing a lot about how the curricula are not well

fitting in communities where teachers get to teach. This is because

they are taken from elsewhere, from another curriculum, and then

adopted into the local education system. It's quite a big struggle

trying to get the grasp of the curriculum for teachers, and then try

to get the students to do the same".

(Tok stori with Rela Wawaneya, 2017)

So, we continued to tok stori, each moment coming closer to a collective

understanding that the only way for a homegrown curriculum development process to work, is when the holders of knowledge (our local educators) are to be supported and encouraged to write content that is culturally and geographically appropriate: a curriculum that reflects them, sounds like them, and speaks about and to them.

Throughout this process I shared with our writers and our elder IaIva Magaga, a personal certainty that my function was only to facilitate various relationships as well as logistical and technical support for our writers, I am not here to write the content of these courses. This is because despite my time in this land, my professional involvement in the education sector and the strong relationships I have formed which have also led to my adoption into a Gunantuna/Tolai family: I was not born here, I am not a local teacher or student. My knowledge about the actual content needed to effectively support the teaching and learning space of our teachers and students in this province is bound to be limited, but above all, is my personal 
belief that a homegrown curriculum writer's space is not my place to occupy. Rela Wawaneya who supported us through the project shared with me her impressions of the project during a storying session:

"You cannot begin to understand what you are actually doing if you come as an outsider and say: "I've got this brilliant idea, I can do this". But if you don't really really grasp the reasons of the people around you, the way of living, the culture, their languageeverything about them - it's a waste of your time coming into a different ethnicity and trying to implement something.

For the project that you have taken on board, you've given the place and credit to the write up of that to the locals: 'that will make it completed'. If anyone comes and asks: "how come you've finished that within the time frame, is this real?" It is because you have given the place and credit to the people to do it themselves. And that's how you get support, by giving the ownership to the people, the local people, to take up something that is theirs. When you do that, as a person that is supporting them always, you see from every end, that everybody will come in to support you, to take this up. Because they know that, man, this is ours, we're going to do it for our country.

It's a lot about how you relate to people, and how you've taken it on board: that you can see people still thinking of and anticipating seeing the actual reality of it. And now the drive that you have coming in as a researcher to continue doing it, to not give up. Because we've seen other volunteers come and gone and the projects end up just like that. But you've come back, no longer as a 
volunteer, but to lift that collective spirit, to say we've done this, you guys have done this, and I'm here to carry this on with you.

East New Britain is the most ideal place where you would make any project work in Papua New Guinea. But here is something important: 'it takes agencies to really really really understand and communicate well'. When they are working together and communicating well with local people on a daily basis, then that relationship that will take you really really far in getting any projects uplifted. Without the relationship, you will get nowhere, you will really struggle.

It is about relationships Lorena, you know this well".

(Tok stori with Rela Wawaneya, 2017)

So, while our educators embarked on the journey of occupying and claiming their rightful space as curriculum writers, IaIva Magaga and I secured various upskilling lessons for our writers on computer literacy, IT requirements, Teaching \& Learning strategies, as well as technical skills and sessions with local storytellers. While they were taking part of these upskilling lessons, I collated our writers' feedback and knowledge generated from tok stori sessions, and drafted a structure for course writing to be later presented to our writers and elder in charge for feedback and final decision.

\section{'Niuk', 'Rurua' steps and 'Writing', 'Trialling' and 'Editing' through tok stori stages}

In tabu-making process, the step of 'Niuk' where pala tabu (or palakanoara/individual tabu shells) are strung onto strips of rattan, requires of a level of knowledge and expertise by those involved in said process. This used to be traditionally done only by experts and elders and although more and more people are involved in making 
tabu due to the influx of tabu shells and the demand for them, the process still requires them to engage in learning the steps of that process.

Similarly, in this curriculum development process the "Writing through tok stori" stage requires of knowledge holders, in this case our writers, to come, share and string together that knowledge through the writing of the content of each course.

\section{'Writing through tok stori'}

Throughout this stage of the process, we the facilitators alongside writers first revised and agreed on the rationale and aims of each course, one course at a time. Later we engaged on tok stori sessions to decide on the course's general content and with that start creating course modules titles. This was first conducted by facilitators and later by our writers who themselves became facilitators at different stages of the curriculum development process.
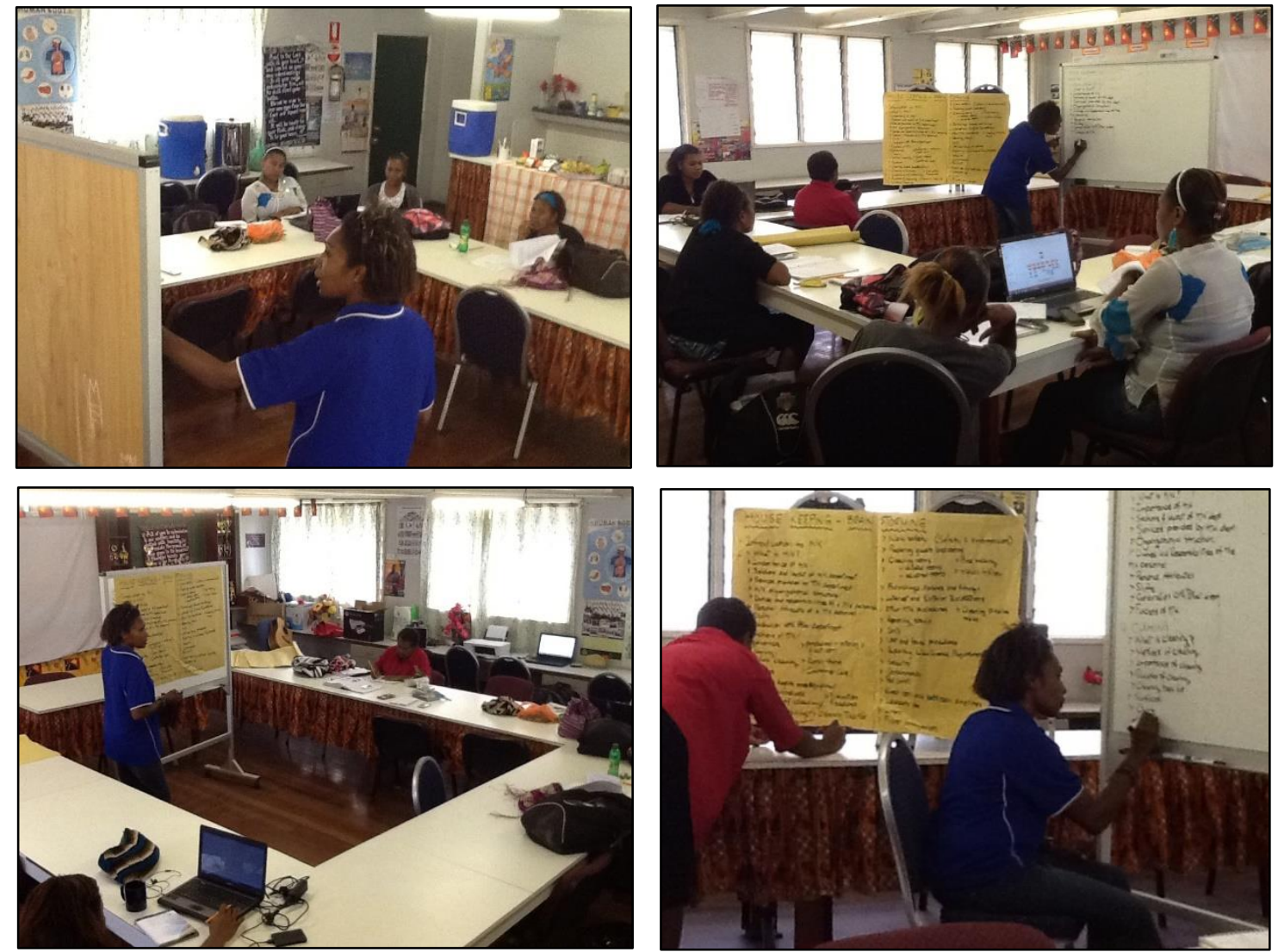

Writers storying and developing Modules, Learning Outcomes (LO) and Assessment Criteria (AC) for courses. Facilitator and writer in this session: Carrie-Anne Karela. Writers in these photos: Doreen Newton Darius, Diana Pakar, Sheila Vinia Walia, Marcella Vovovon, Jeddah Gigi.

Other writers present at tok stori sessions: Sussie Bray, Janet Magaga, Cornelia Lote, Georgina Komen, Tania Paivu, Ruby Peni, Enisal Guria Boas, Ester Sigere Painuk, Dorothy Puipui, Alice Vue. 
Through storying together, we were able to define: the topics, final wording, Learning Outcomes (LO) and Assessment Criteria (AC) of all modules for the course to be written in the agreed format. The allocation of modules to each writer depending on their familiarity with the topics, expertise and willingness, were decided collectively.

Later, and assisted by the facilitators, curriculum writers researched the content for each module. OLSH made its library (one of the best libraries in ENB) available to our writers, IaIva Magaga supplied us with a number of her own relevant resources and we facilitated writers' access to internet sources. Our writers also brought along their own resources and teaching plans that they had created throughout their teaching careers. When our writers required engagement with advisory people and bodies to support and inform their writing, the facilitators made possible access to them through guest appearances at writing sessions. These included: education sector officials who helped ensuring that the wording, formatting and content of our modules also complied to national TVET Module Standards, CBT\&A77 and accreditation process; the visit by Jackson Pinia a local storyteller; industry representatives such as Sevi Kaue from KVR and Sophie Marshall from the Relax Corp; local conservation NGOs and; Michael Crane an

Environmental Economist and Ecotourism advocate from the United Nations Development Programme. We coordinated visits to different industry establishments such as GI where Luis Gomes and his staff showed our writers around their establishment and shared their

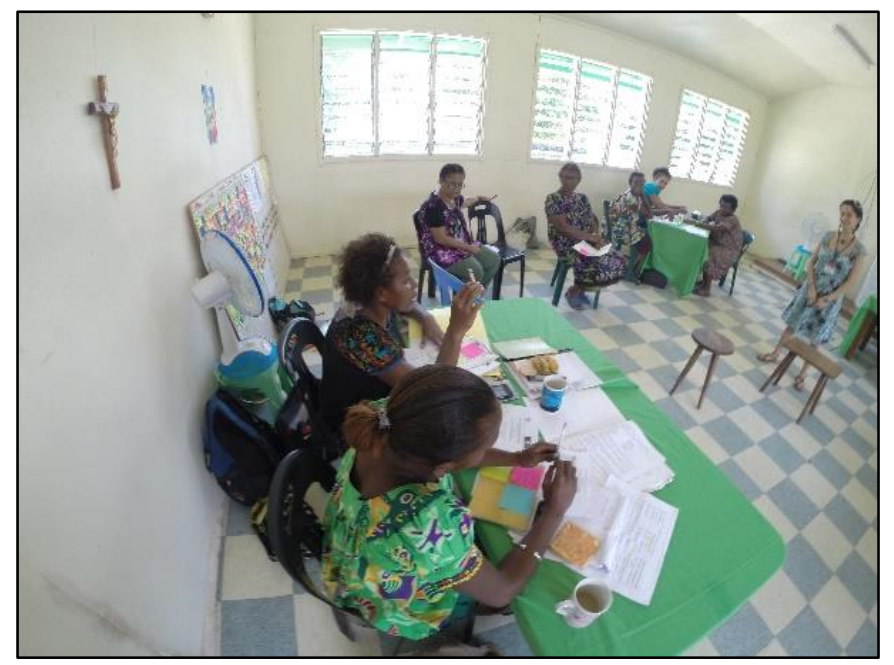

Advisory Session with our National TVET Representatives: Stellina Sergius, Beatrice Aurora.

${ }_{77}$ CBT\&A: Competency Based Training and Assessment 
industrial wisdom. Phone connection was also made available to our writers when they needed to communicate with community members, elders and family that could share the knowledge they needed with them.
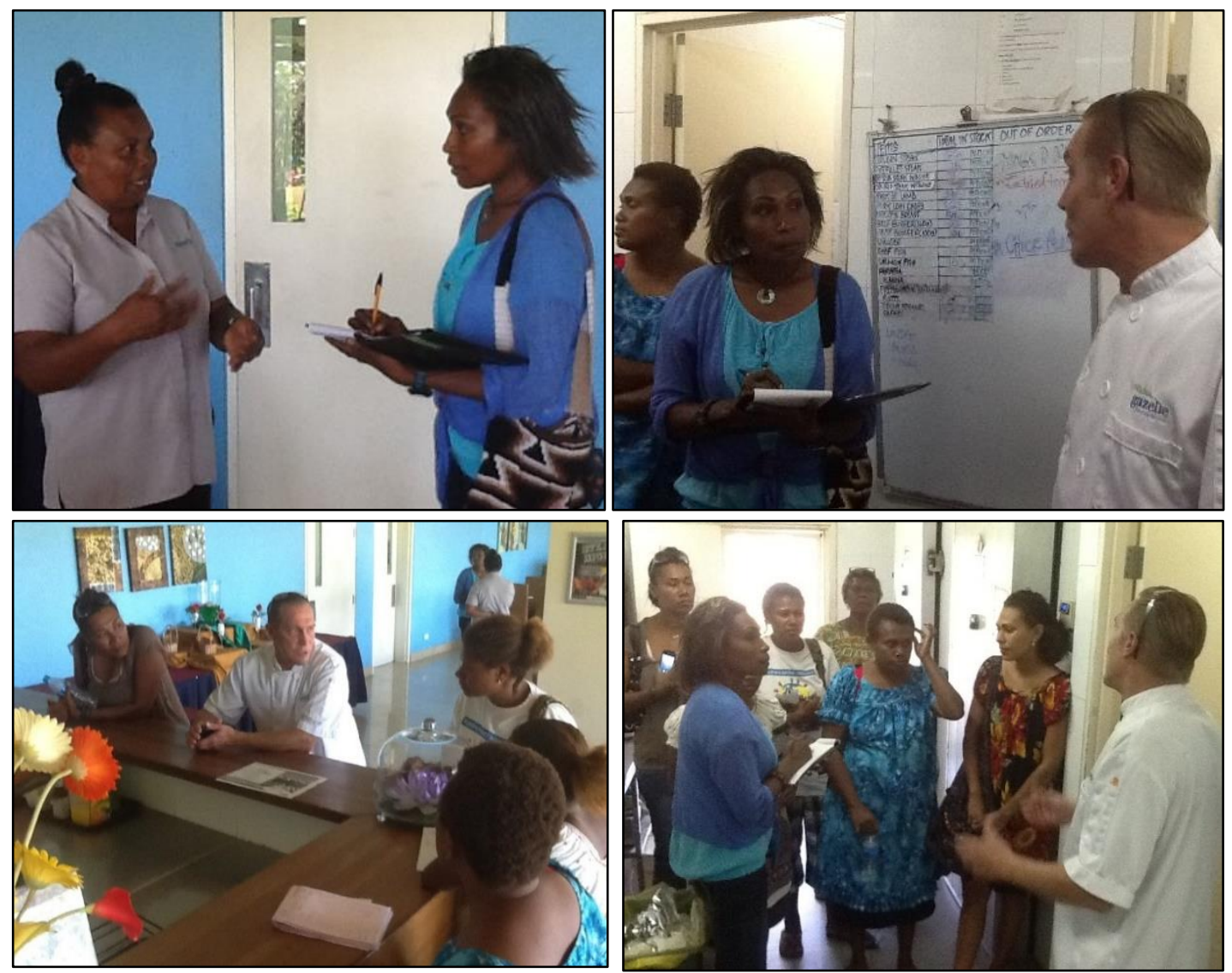

Tourism \& Hospitality Industry training and consultation - a constant part of the curriculum development and research process for curriculum writers. This industrial consultation visit was held at Gazelle International Hotel, where we were hosted by Luis Gomes, General Manager and his staff.

Importantly, through IaIva Magaga's guidance, as facilitators, we encouraged writers to share the 'public' domains of their own Indigenous knowledge, those that they were comfortable sharing in order to uphold Indigenous people's knowledge through a homegrown curriculum by and, for Indigenous people. Tok stori sessions shared the importance of upholding and enacting the East New Britain way, the local way, "our own ways" throughout this homegrown curriculum. It was also important to all of us involved, to see the protection of 'secret' and 'sacred' domains of Indigenous knowledge through this curriculum. Curriculum writers were masterful in creating modules and lessons that explored the topics of Indigenous 
values, practices and land, and the importance of protecting their sacredness in the face of increasing industrial pressures, the imposition of foreign values in education and their communities, and rapid technological changes. It was their deep held Indigenous knowledge combined with their professional teaching expertise, that filled the writing with rich, well-researched, comprehensive and culturally and geographically relevant module content and lessons.

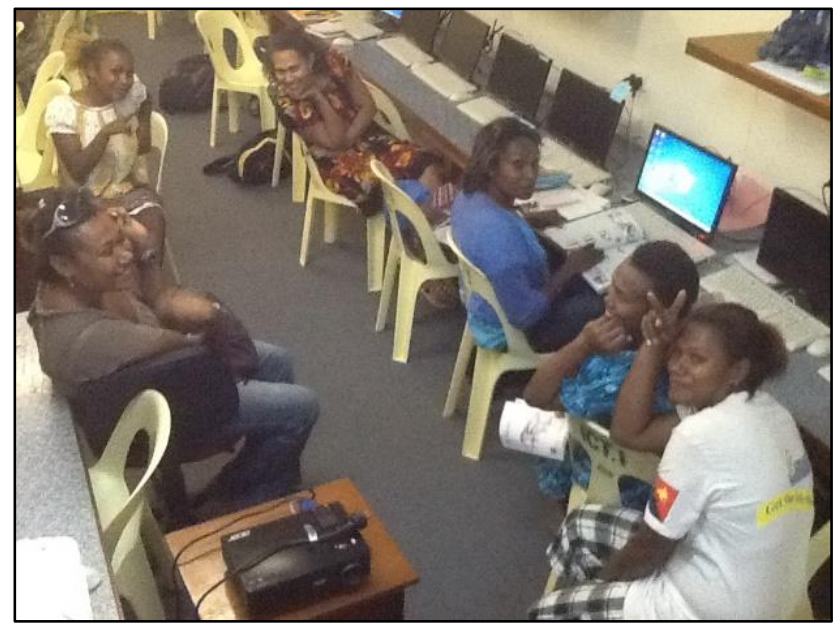

Writing at OLSH Secondary School. Clockwise: Jeddah, Sheila, Sussie, Carrie-Anne, Marcella, Diana.

In a writing laboratory provided by OLSH and with the IT support by Mr Kompage and $\mathrm{Mr}$ Tonga, curriculum writers then effectively wrote the content of over 50 teaching modules. Each module with its own lessons which were based on the Learning Outcomes (LO) and Assessment Criteria (AC) that were previously developed together with facilitators and other writers. Curriculum writers first wrote the background and supplementary information for each lesson, which serves as 'Notes for the teacher/trainer'. Before every lesson, teachers using this course resource are directed to the page number containing these 'notes' which are the background and supplementary information that they will be required to revise and know before delivering that lesson. Next, curriculum writers wrote the Assessment Tasks which are a series of Teaching \& Learning activities using collectively created and agreed Teaching \& Learning (T\&L) strategies. This was certainly a heavy workload for our writers, as a module can have up to 10 lessons with a minimum of 
3-4 T\&L activities each, with 80 minutes teaching time for each lesson. Once writers finalised their first module drafts, they shared them with the facilitators and the other writers.

During these writing sessions, the relationships between our writers became
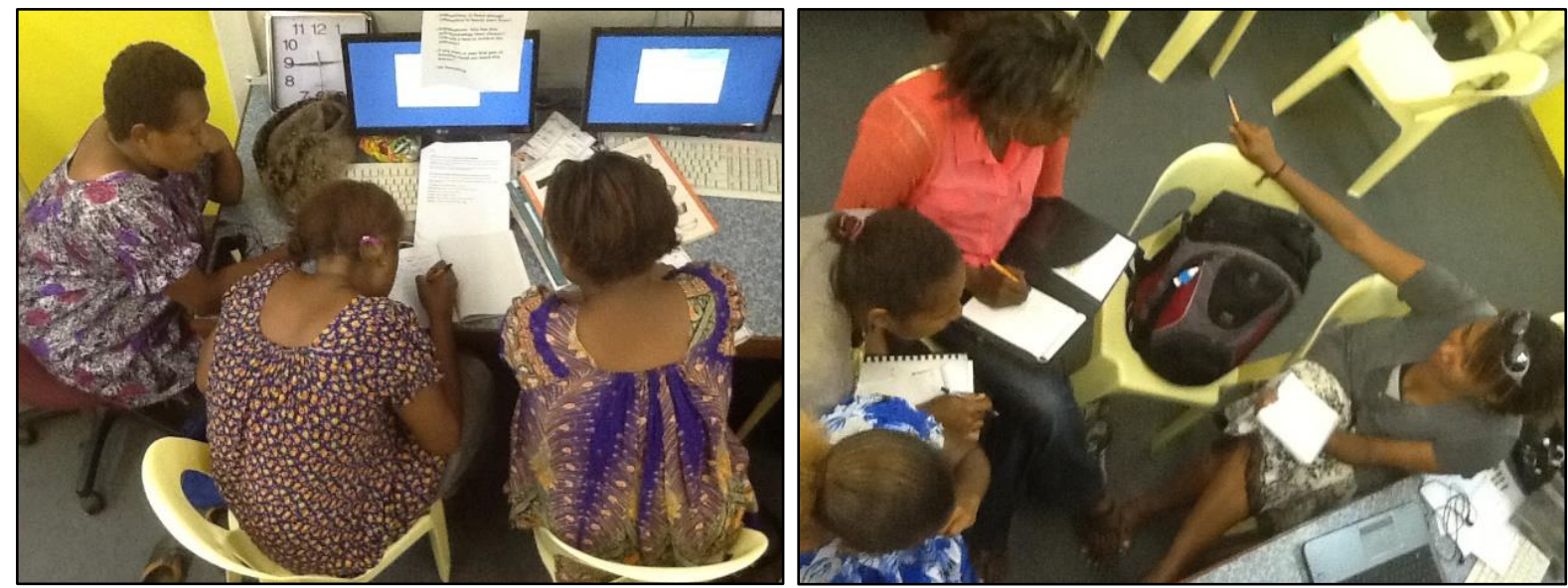

Writers working together during Writing Stage.

stronger and more enduring, as tehy supported each other through enormous workloads, offering their own talents and expertise to look after one another. For example, there was one of our writers who was older than other writers and who had limited command of computer literacy, but who was a well of knowledge on a specific module. So, another younger writer after finishing her own module, sat down and typed every single lesson for her. Our writers worked closely together, asking each other questions, checking others' lessons and activities, and making sure everyone felt supported, look after and an important part of what became the curriculum development project writers' collective. My responsibility was making sure everyone ate well and had all the resources they required. IaIva Magaga our elder looked after us all facilitators and writers ensuring our mental, emotional, and spiritual wellbeing was upheld day after day, week after week, month after month. She never left our side, she listened to every single one of our stories, our worries, our jokes and our dreams. And her love and wisdom guided us and healed us. We became a family. 


\section{A curriculum writer reflected on those times:}

"Actually, I've never taken writing or anything like that, it was something new to me. But then getting feedback like: "that is so amazing", "people cannot just write 6 books and 6 months", but oh yes, we did just that!

A lot of teachers here in East New Britain are not computer literate, so I think that was quite something, a little bit of professional development for us as teachers.

This experience I think strengthened the bond between us as teachers as well. So, we keep in touch all the time now, even just to say: "good morning", that's all.

This helped when we were sharing knowledge. We are strong thinkers and remained open-minded to any kind of possibility, because we did have a few arguments. But arguments stay inside the discussion and when we are outside, we're friends again. We've learned some things, some very important things, like being openminded and respectful during discussions.

Also, it's because most of ladies that were doing the write-up were colleagues from the different schools, and so we were all good friends in those schools. So, when we got together to do this it was okay. Unlike some of those ladies who we did not teach with in those same schools, they were holding back at the beginning. But then they eventually started coming out of their shells. So, yes, I think the openness and how we treated each other like sisters it's 
what gave us the courage to be open and later to take charge in facilitating.

For me, I think it was because I was comfortable in the group that I was in. I think I was comfortable enough to share, to open up to the group. And I think that's what happened to other ladies in the group as well, because in time everyone started being open to each other. It's the comfort that we felt in that group that made us be open".

\section{Graphics and Art content}

Our writers also worked alongside local artist and designers who created outstanding artwork and graphic designs for each lesson. It was nothing short of amazing to see them working side by side and observing lessons coming to life through a kind of art that was filled with colours that belong only to this land and to its people. George Vavana for example created the beautiful and rich front cover for our first course book, as well as other great art works. Rodney Simai also created many wonderful graphic designs for

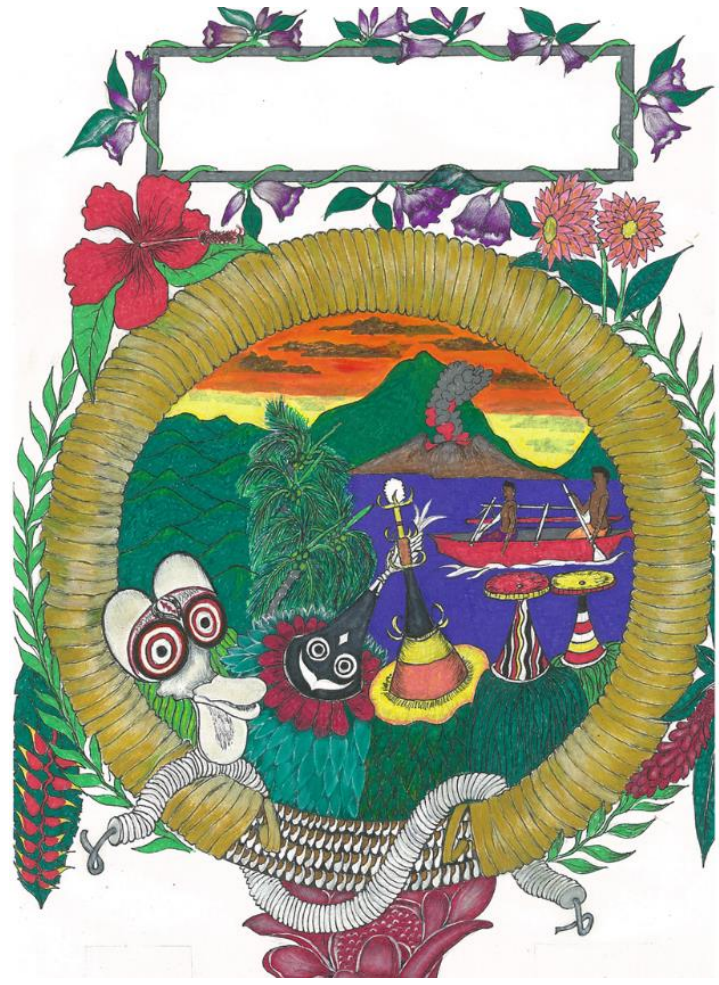
Book 1 Front cover art by George Vavana, local many lessons across the curriculum.

\section{'Trialing through tok stori'}

Once we had strung each shell to the strips of rattan, we needed to make sure that they were strong, properly spaced out and they were ready for the next step in the process. So next in our process of curriculum development was the trialing stage. 
Here our writers trialled their own newly created lessons with students at OLSH (our host school) and when possible at their own secondary schools and vocational centres. With the support and guidance of IaEleonora Vigil and OLSH staff, we the facilitators gathered feedback from other teachers and students at the trials conducted at the host school through tok stori sessions to ensure the trialling process was appropriately carried. Curriculum writers also gathered feedback from their colleagues, principals, managers and students after conducting lesson trials at their own secondary school and vocational centres.
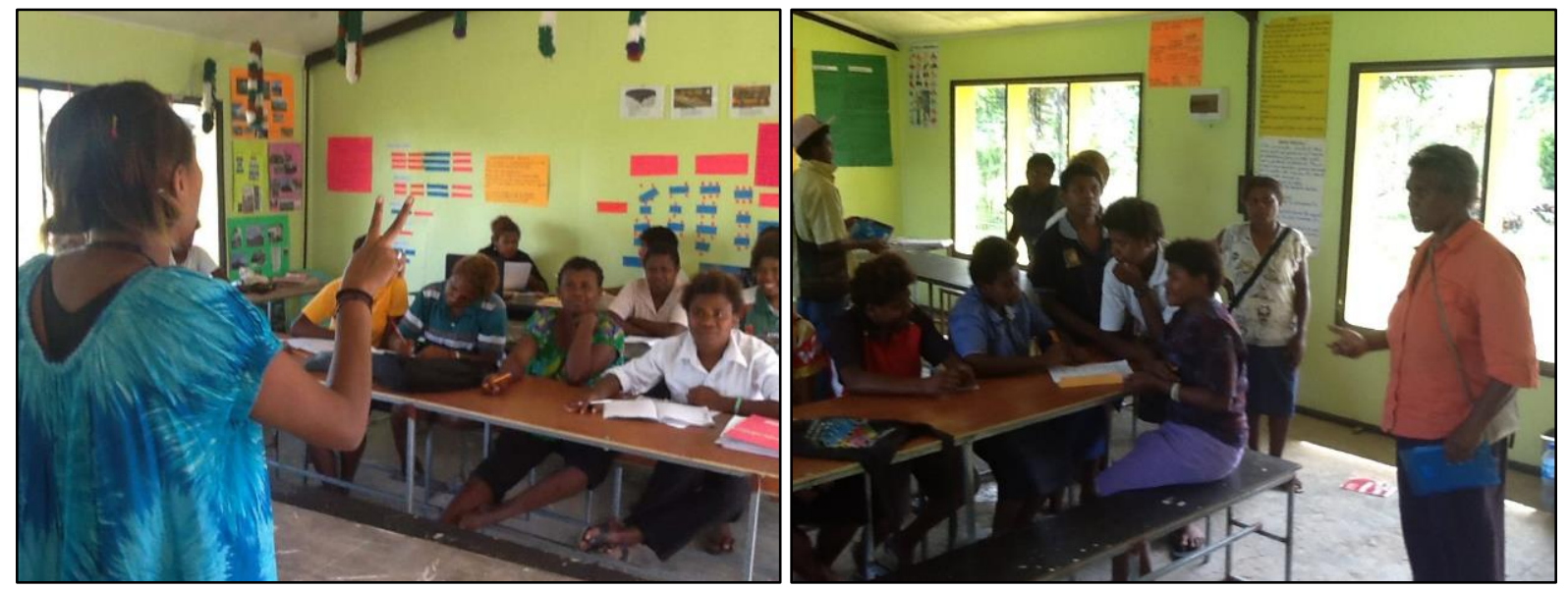

Writers during trials at OLSH Secondary School. Left: Jeddah Gigi. Right: lalva Magaga observing trials.
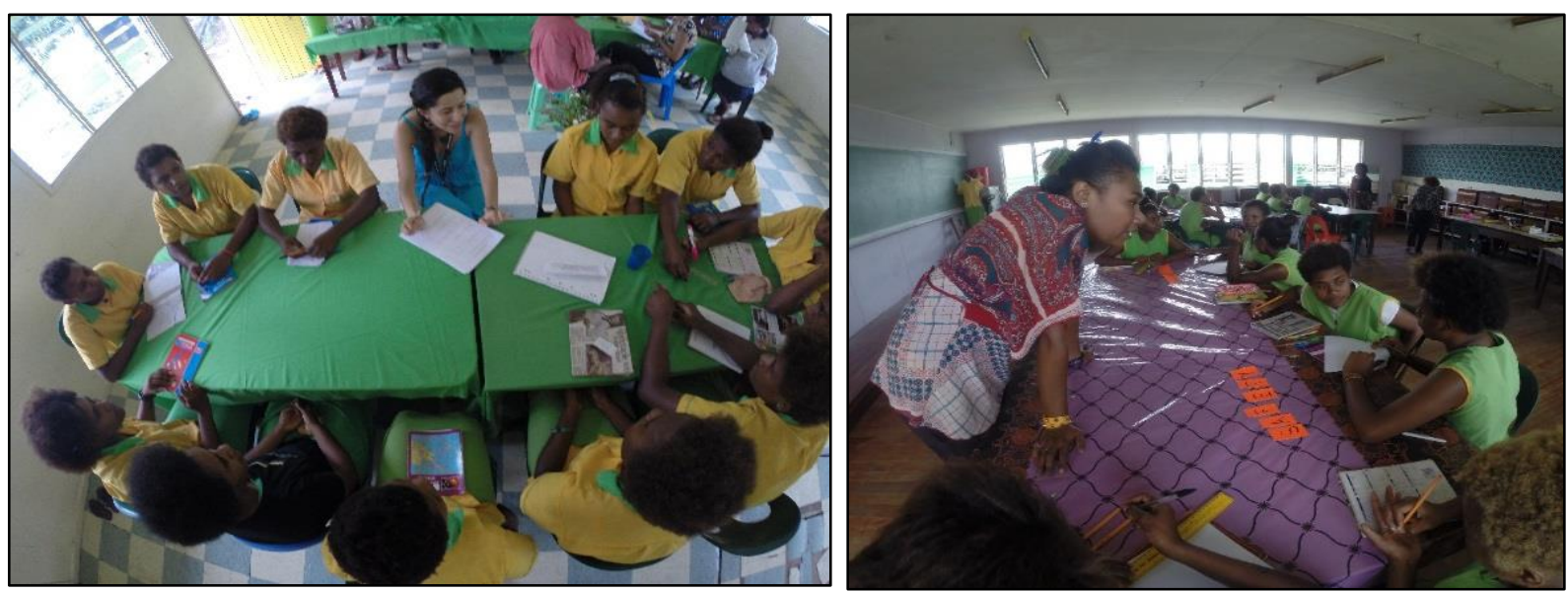

Facilitators and writers engaging on feedback sessions with students. Left: Lorena. Right: Jeddah. Both with students at host school. 


\section{'Editing through tok stori'}

During tabu-making in the step called 'Rurua', the new pieces of tabu are joined into longer pieces. Similarly, in the process of curriculum development once writers have finalised writing and trialling their modules and lessons, they incorporated the feedback from trials into the lessons they wrote. During this process, writers choose lessons they want to finalise before final editing, and trial them again at our host school through a method called STaN: Swap, Teach and Note. The facilitators support writers coordinating a process where they:

Swap: Writers pair up and swap their lessons with another writer

Teach: Writers prepare and teach partner's lessons to 10-25 students

Note: Writers observe and evaluate their lesson being taught by partner and note any changes that need to be made to improve their lesson
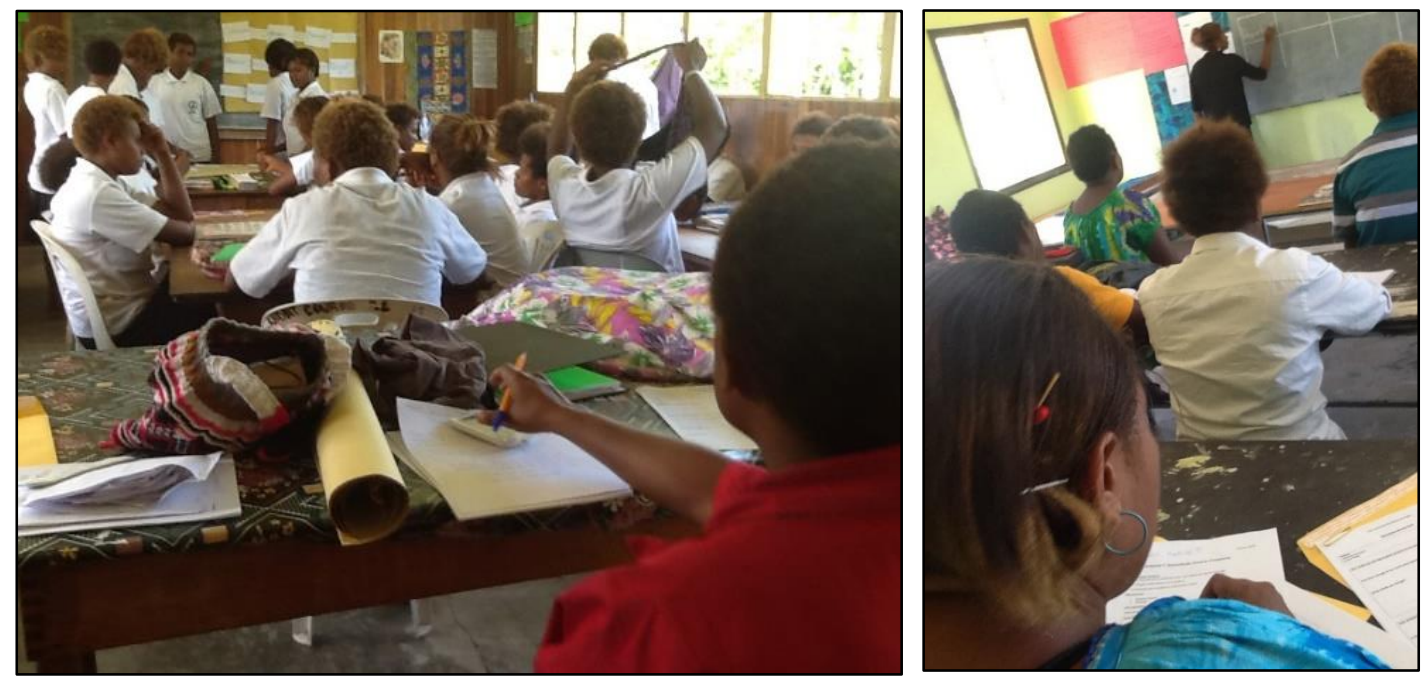

Writers during STaN sessions. Left: Marcella Vovovon. Right: Diana Pakar and Jeddah Gigi.

After the lesson is taught by their partner, writers hold an evaluation tok stori session with the students and note their feedback to improve their lesson. For example, following a trail lesson at Malabunga Secondary School one of our writers Ester Sigere brought back the feedback from her principal Mrs Lilac Baining, which helped us restructuring the whole positioning of the 'Notes for the teacher/trainer' 
within the books in order to become easier and clearer to teachers using these resources.

Writers do the final editing of their lessons by incorporating (joining) the feedback from trials and STAN evaluations. Once this 'joining' of feedback was completed, writers shared their final draft with facilitators.

\section{'Auditing and Publishing'}

Once curriculum writers had finalised their course writing we, the facilitators and our elder IaIva Magaga alongside education sector leaders engage in preparations for the next stages of auditing of content and publishing. This is a particularly long and important process which focuses on ensuring that all relevant people and bodies' requirements, values and vision are present in the curriculum. We are also engaging in auditing that each module complies to national TVET Module Standards, CBT\&A guidelines for subsequent accreditation process. Most importantly, that each lesson is living up to its purpose and aim of contributing to raising the standards of living of all the teachers, students and their communities; that each lesson is encouraging community wellbeing and helping teachers and students to value and protect their culture and land, by respecting and upholding the cultural norms and practices of the people and the sacredness of relationships and that of ples.

To become tabu, shells have undergone a process of physical transformation making it into a powerful source able to communicate more than words can and one that signifies so much to a people. So, in relation to this curriculum, the stages of 'auditing' and 'publishing' are crucial and delicate parts of the process of ensuring that this homegrown curriculum which carries so much of the knowledge, hard work, love and dedication of our writers, communities and leaders, becomes a powerful source able to communicate the myriad of negotiations, wisdom, storying, collective work and relationships contained. This will ensure that every lesson that gets to print is also providing our teachers and students with a source of cultural pride, 
identity, and confidence. We are working to ensure this Indigenous led and enacted vocational education initiative, can become a powerful way of communicating between people, which (carrying on with our tabu-making metaphor) could have the ability to map the genealogy of their relationships and knowledge, across generations and space.

During an encounter with educators and all relevant people, Mr Bauk reminded us that these teaching materials are recording and documenting culturally important information about the people and cultures of East New Britain in relation to the history of their traditional practices and cultural values in regard to hospitality, mobility patterns, environmental conservation, entrepreneurship, health, community wellbeing and so much more. Nationally, this is a unique, comprehensive and culturally appropriate curriculum for vocational training. And one that can support the teaching of tourism and hospitality not simply as a trade and a way to secure a job, but one that first and foremost focuses on honouring this land, peoples, their values, practices and relationships through vocational education.

\section{Topics}

"I think it is about bringing back the history, not what you see on the internet about us, but what the local people know".

(Tok stori with Jeddah Violet Gigi, 2016)

Storying topics for a curriculum into existence with writers was filled with excitement, negotiations and the coming together of different knowledge systems, that found a home within shared stories that became the titles to those topics. Every course and module carried within invaluable knowledge (including ancestral knowledge) regarding Indigenous governance, Indigenous values, Indigenous concepts of relationality, tourism, hospitality, mobility, as well as Indigenous wisdom on land conservation. This combined knowledge aims to contribute to the peaceful conservation and development of the natural and cultural heritage of their 
people. The values of trust (nurnur), obedience (tinarom) and love (warmari) are at the centre of the process of choosing topics, becoming also an important part of the content within the books, alongside important koko ('do nots' - related to rules, laws and regulations in Gunantuna/Tolai societies). The content of specific modules, lessons, posters, other teaching aids and teacher notes presented in these resources, were built with a strong focus on ways of preserving the natural environment and social structures of the different Indigenous groupings in the province and include some information about PNG and the Pacific Region.

These are the only vocational educational materials in existence that are fully developed, researched and carried out by local educators and people in ENB. They contain a unique recollection of Indigenous knowledge, underpinned with strong Indigenous values and under the guidance of Indigenous elders and leaders. They constitute a rich and powerful brake from previously foreign-introduced educational resources, which have not provided a source of local ownership of education objectives and outcomes in the province. The skills development within the tourism and hospitality sectors facilitated by these resources, aim at the dignified and culturally respectful economic development of people in ENB. These resources position community and environmental well-being, village health, gender equality and Indigenous values as the basis and prerequisite for peaceful economic development. These resources are focused at meeting the wider need of the community from vocational education on tourism and hospitality, which is far broader than 'simply getting jobs'. They aim to support the improvement of health, living standards and quality of life through a strong focus on nutrition, food security, and HIV/AIDS education. They furthermore provide youth with skills that can produce income generation alternatives at the village level.

These resources are rich in language and content that supports local and especially Indigenous ways of governance. They thereby support peaceful paths towards selfsustainability, by ensuring that the dignity and continuity of land and people (which 
are regarded as one and the same) are upheld within the use of any resources and in the interaction between peoples and communities. They promote the sustainable management of natural resources, encouraging thus conservation of unique habitats and ecosystems, they however, go further and advocate for an Indigenous understanding of the relationality of humans and the natural world, where natural resources are no seen as resources, but rather considered in relational terms. A large number of modules are dedicated to familiarising teachers and students with representative, endangered or threatened species. These lessons are full of local artwork, photographs and descriptions of flora and fauna; one of them, for instance, focuses on Indigenous knowledge on medicinal plants and their health benefits. They were informed by local community members and local environmental conservation NGOs. They aim to build capacity in local communities, especially among the young population for the development of Indigenous ecological knowledge.

The conservation and restoration of local sites of natural, cultural and historic significance are also at the heart of these resources. They provide education on land deforestation and mining, water pollution, coastal and reef degradation, plastic pollution and off-shore oil drilling, and their impacts on livelihoods and on the natural and social fabric of the province and its peoples. These resources are fully focused on raising awareness of, and improving access to, local historic, environmental and cultural heritage through education. The importance of protecting the sacredness of Indigenous knowledge, ancestral systems of governance and social structures permeates throughout all of these resources. This has been achieved through the guidance and support of our elders and leaders whose vision is to improve the future of their descendants and communities, by encouraging Indigenous cultural pride, identity, self-sufficiency, and security, as well as the improvement of communication and cooperation between the different Indigenous groupings in the province and all their respective cultures and peoples. 


\section{The making and launching of first set of teaching materials}

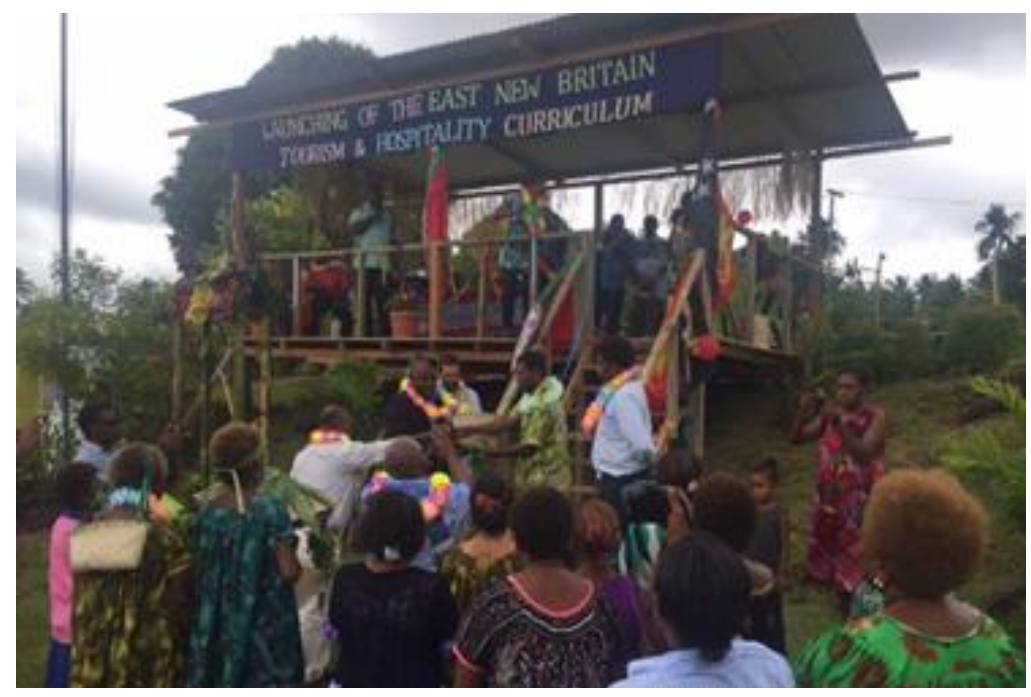

Launching of the East New Britain Tourism \& Hospitality Curriculum

At the end of 2016 IaIva Magaga travelled to Aotearoa New Zealand to work together through the process of editing, auditing and publishing the first set of materials of the curriculum. These were months of relentless work, in which our relationship grew and my respect and love for IaIva Magaga overflew. Together we gave of our time, resources and skills to finalising what became the first set of materials of the first of its kind homegrown curriculum for ENB province. Cup of tea, after cup of tea was placed in front of me, while IaIva Magaga tok stori and checked page after page of these teaching resources. It is her wisdom and spirit that became the guide and strength throughout the many weeks of arduous work of mind, body and spirit that this process demands. Once we were ready to go back to ENB, we had to leave behind much of our belongings in Aotearoa in order to fit over a hundred books in our luggage. We were left with a few singlets and meri blouses to share, and with sore backs from carrying the books in and out of airports, but overjoyed when in February 2017 all of the books made it to Port Moresby with us. IaIva Magaga then paid for the transfer of all those books to ENB; both of us arrived and rested, waiting for the launch of our first book to take place. 
In April 2017 and with the guidance and support of Mr Hubert Wangun our current Provincial Education Advisor, we launched the first set of the newly developed curriculum resources titled 'Teacher Guide: Introduction to Tourism and Hospitality'. Mr Tasman, Mr Warpit and Ms Boni Nelson from the DoE oversaw the event that took place in Kabaleo Vocational Training Centre in Kokopo. Mrs Cathy Tasman the manageress of this centre mobilised her staff and worked diligently alongside all other secondary schools and vocational training centres in the province to provide for the day. Together, they built a stage using carpentry skills from one of the centres, as well as cooking and catering skills, art, music and performance skills, decorations, leis, banners, and so much more, from each and single one of the educational institutions involved. That day they showcased what hospitality looks, sounds and feels like in ENB province.
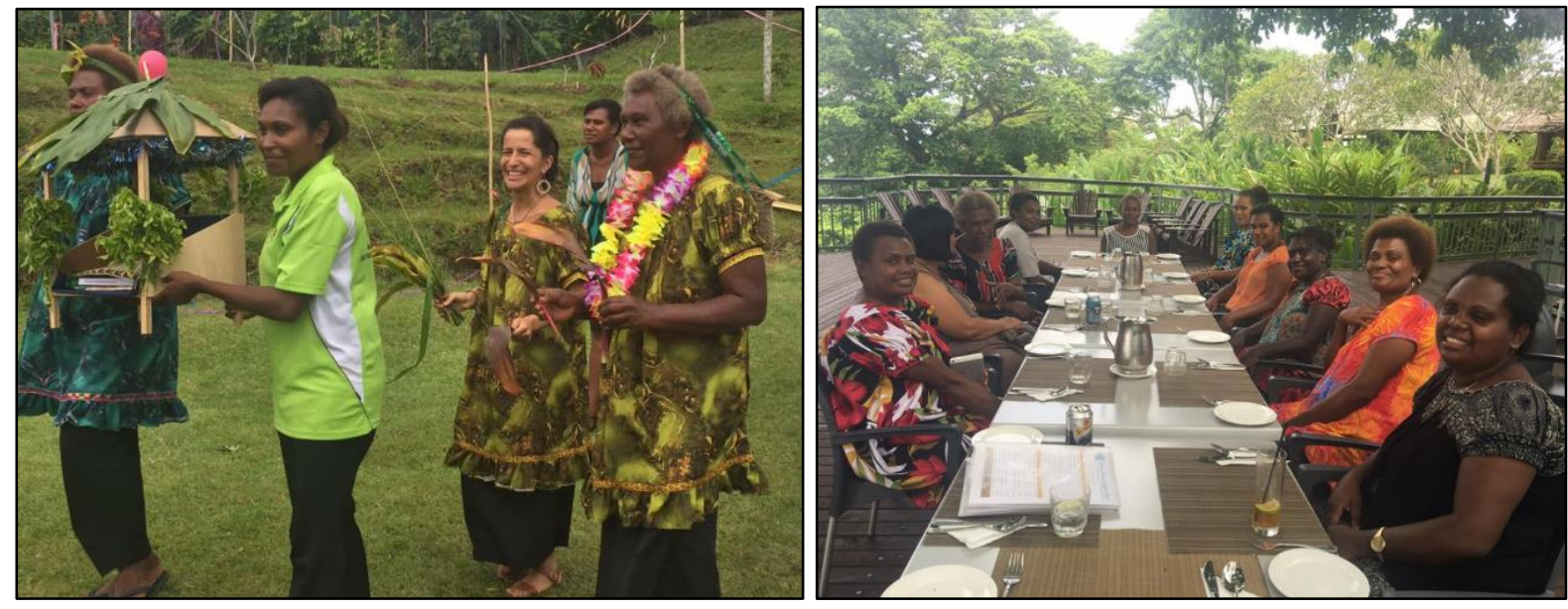

Left: Carrying our Book 1 during Launching Day. Right: Celebrating with our writers at KBB after launch.

Present during the launching were all the provincial leaders that had supported us throughout the years. Public and private sector representatives and our wider community members came together and shared on the celebrations with stories, food and ceremony. We celebrated a province that has a rich history of leading in the education sphere. We celebrated leaders whose focus is on the protection of their land and the wellbeing of their people. We celebrated collective action in education that is made of relationships. The weaving of those relationships pulled us strongly together that day, and we also honoured those whose words and colours fill every 
page in this book: our writers and our artists. We celebrated and showed our gratitude to their families, their spouses and their children for their sacrifice, support and patience. On that day, our leaders spoke and reminded us that education should not only promise jobs, but it should also provide a means to survival. That education should provide a way for surviving and thriving. They said: "our teachers are on the front lines of tourism and hospitality in this province", trusting the development of this industry in the hands of local educators and local communities, will see the protection of minds, futures and land that are currently facing a rapidly changing technological, economic and environmental world, and will contribute to dealing with the outside pressures of exploitative extractive industries.

On that day our leaders and elders placed tabu in front of IaIva Magaga and me.

\section{Implementation through tok stori methodologies and potential implications}

Tabu moves between people, between generations and across the land, mapping a genealogy of reciprocal relations, holding within the history of a people and communicating more than words could ever say. The knowledge contained within this curriculum which is made of relationships and of strong collective values, mobilised and brought together countless people and resources. It mobilised our educators and their supporters into sharing stories that can guide and protect who and what is precious to their people and ples. As tabu moves with people and across time and space, so does the collective action, love and knowledge that are contained in this curriculum.

Ahead of us is the province-wide implementation of these resources through tok stori methodologies. In the forefront of the implementation process will be our writers, who already carry with them their shared relational knowledge built upon tok stori methodologies. Supporting an education system where educators have the ability of teaching and learning with resources that look like, feel like, and sound like them 
and their students: has potentially transformative implications. It has the potential to reshape, and construct new realities for education, a kind of education that advocates for powerful pedagogies that focus on collaboration and cooperative activity and action through talk (Sanga, Reynolds, Paulsen, Spratt, \& Maneipuri, 2018). Powerful, culturally and geographically relevant pedagogies that focus not on simply promising jobs, but on supporting the survival and thriving of ples and people.

\section{Wise, culturally grounded and ethical leadership}

The momentum created by the stories shared by teachers, students, communities, school principals, and vocational centres managers was seized by a wise group of provincial leaders. The kind of leaders that see and act beyond individual agendas. Leaders with deep cultural roots and undivided loyalty to the collective good of their people. Leaders that are a moral compass to many and an inspiration to us all that work with and for them. These leaders became the pillars upon which we were able to build this dream; the bridges between policy, education and community; and the wisdom behind the collective action that started to take place in the technical and vocational sector of the education system in ENB. Some of these leaders are Gunantuna/Tolai elders, whose wisdom and guidance ensured that we kept on paddling our canoe in the right direction. They read the stars, listened to the winds, felt the currents, and showed us the path ahead. This enabled us to keep on paddling and concentrating on working hard for them. Our aim ultimately is to make them proud.

From the public to the private sectors: political, education, spiritual and community leaders, as well as business representatives, all came together to offer their support and expertise to the idea of a project in formation. 


\section{Weaving relationships across the ocean and throughout time}

Transformational action certainly does not come without its difficulties, yet through many struggles we have carried on. Here, I am always reminded of the words by Rela Wawaneya, who later became my sister by adoption:

"Understanding and working with people it's like a coin; a coin has two sides. If you let it flip and fall flat, you will only see one side. But when you stand it up, you are reminded that it is two-sided. Then it is when you know the true value of that coin.

You do not put it down, you let it stand to see the whole coin. So, it's about looking at the bigger picture, always looking at the real value. It's a holistic view.

And what this project has done here is taking a hold of that coin and saying: "it's a whole coin". No one side, or the other. Not them, not us.

Remember, if you put it on one side, you forgot the other side. That side may be the one that has already made a major impact, you can't just put it down. So, when we sit down and see this work, and the potential impact for our community, then it takes true Papua New Guineas that don't come along because of money matters, but to really really look at supporting the people who are lifting these projects off the ground.

(Tok stori with Rela Wawaneya, 2017)

Our strong and enduring relationships in Aotearoa New Zealand have supported me after I had to unexpectedly leave ENB, and later when IaIva Magaga joined me in Aotearoa during the editing and publishing stages of our first curriculum materials. 
Suddenly and unwantedly being away from ENB, from IaIva Magaga, from the writers and the wider community, was a challenging time which stretched the weaving of our relationships, but then they pulled us back together.

It is here that I kept on remembering the importance of understanding time not as a linear concept, but moving in a circular motion, always returning to those we love, always weaving us closer together. We kept our relationships and our work going from afar, spending all we had on internet data for Skype, and all our patience on cursing the internet providers in PNG for making that data disappear like dry leaves in a gust of wind. Curriculum writers, who throughout this precious relational process of creation became like sisters to me, took on the physical facilitation space I occupied, and they carried on writing, creating and communicating with me as much as needed.

It was during this time of uncertainty that I started my studies back at university, being fortunate enough to receive a full scholarship which came accompanied by two minds and hearts in academia that I respect and admire to no end, my two supervisors: John Overton and Warwick Murray. John's capacity to sit down, story with, and to understand the mind and spirit of a mestiza woman will always floor me and firmly secure me in the path of following that mind and that spirit.

Knowing that my spirit is firmly planted in ENB alongside IaIva Magaga, I continue working with her in this curriculum caringly, compassionately and gently finding ways to finalise auditing and publishing the remaining teaching resources. At the same time, I am engaged in this PhD writing stories of this land, those that I am allowed and encouraged to share by my relationships in ENB and by my elder and my mother through adoption, my dear mum IaIva Magaga. 


\section{Conclusion}

The Indigenous conceptualised, led and enacted alternatives in education represented by these tok stori texts, share "a rich language replete with specific terms and understandings of exchange, reciprocity, in kind payment and interconnectedness [that] describe complex practices of reciprocal labour exchange and voluntary gifting of labour" (Gibson-Graham, 2005, p. 13). They are able to see the positive socio-political, economic and spiritual relevance and influence of Indigenous imagined and led education alternatives in their localities. They are "alternatives that are contained in the horizon of concrete possibilities" (De Sousa Santos, 2004, p. 241), and in the case of East New Britain in 'the horizon of concrete realities'. These initiatives bring together individuals and groups that stori, imagine, enact and are concerned with, collective development, that responsibility that connects Indigenous peoples within their own groups and throughout the world: "it connects us, the responsibility to the collective, because the individual purpose is futile" (Doherty, 2017; Magaga, 2016). 


\section{Tok stori bibliography}

Bauk, C. (April 2017). Deputy Governor and Education Chairman's Speech during ENB Tourism and Hospitality Curriculum Launch Day [Unpublished Speech].

De Sousa Santos, B. (2004). The WSF: Toward a counter-hegemonic globalization. In J. Sen, A. Anand, A. Escobar \& P. Waterman (Eds.), World Social Forum: Challenging Empires (pp.235-245). New Dehli: Viveka Foundation.

Doherty, W. (2017). Ngāa-here: Exploring the Landscape of Pūrākau. Paper presented at the Kimihia te mea ngaro: Pūrākau and Indigenous Storywork Research Symposium, Waikato-Tainui College for Research and Development, Hopuhopu, Ngāruawāhia.

ENB Curriculum Development Project Collective, C. (2015). Curriculum Development Project Reports. L. d. 1. Torre \& I. Magaga (Eds.) [Unpublished Division of Education (PNG) Project Reports].

ENB Curriculum Development Writers. (2016). East New Britain Division of Education Vocational Programme: Introduction to Tourism and Hospitality: Teacher Guide (L. d. 1. Torre Ed.) (1 ${ }^{\text {st }}$ ed). Wellington: Kokopo.

Gibson-Graham, J. K. (2008). Diverse economies: performative practices for 'other worlds'. Progress in Human Geography lecture, 32, 613-632.

Gibson-Graham, J. K. (2005). Surplus Possibilities: Postdevelopment and Community Economies. Singapore Journal of Tropical Geography, 26(1), 4-26.

Gigi, J. (2016). [Unpublished Tok stori with Jeddah Violet Gigi, ENB Curriculum Writer].

Kaue, S. (2016). [Unpublished Tok stori and Interview with Sevi Kaue from Kokopo Village Resort].

Magaga, I. (2016). [Unpublished Tok Stori with a Gunantuna/Tolai elder, education leader and my adoptive mother: IaIva Peteva Magaga].

Magaga, I. (2018). [Unpublished Tok Stori with a Gunantuna/Tolai elder, education leader and my adoptive mother IaIva Peteva Magaga].

Marshall, S. (2016). [Unpublished Interview with Sophie Marshall, ENB Civil Society Sector]. 
Panfilo, A. F. (2016). [Unpublished Interview with Archbishop Francesco Panfilo in Vunapope].

Pangalos, M.(nd). [personal communication with Mario Pangalos from Gazelle International Hotel Kokopo].

Papua New Guinea Government. (1983). The Education Act of Papua New Guinea. Waigani: Government Printer

Sanga, K. (2016). Split-worlds, side-questions and weaving: Storying the politics of Pacific Learning. Paper presented at the The Politics of Learning Noku ano te Takapau Wharanui, Victoria University of Wellington.

Sanga, K., \& Reynolds, M. (2019). Melanesian tok stori in leadership development: Ontological and relational implications for donor-funded programmes in the Western Pacific. International Education Journal: Comparative Perspectives, 17(4), 1126.

Sanga, K., Reynolds, M., Paulsen, I., Spratt, R., \& Maneipuri, J. (2018). A tok stori about tok stori: Melanesian relationality in action as research, leadership and scholarship. Global Comparative Education: Journal of the WCCES, 2, 3-19.

Sanga, K., \& Thaman, K. H. (2009). Re-thinking education curricula in the Pacific: challenges and prospects. Wellington: He Parekereke.

Simet, J. (1991). Tabu: Analysis of a Tolai Ritual Object. (Doctoral Thesis, Australian National University). Canberra. Retrieved from https://openresearch-repository.anu.edu.au/handle/1885/110381?mode=full

ToHenry Tavul (2016). [Unpublished Tok stori with a Gunantuna/Tolai elder and leader: ToHenry Tavul].

Wawaneya, R. (2017). [Unpublished Tok stori with Rela Wawaneya]. 